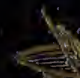

S.

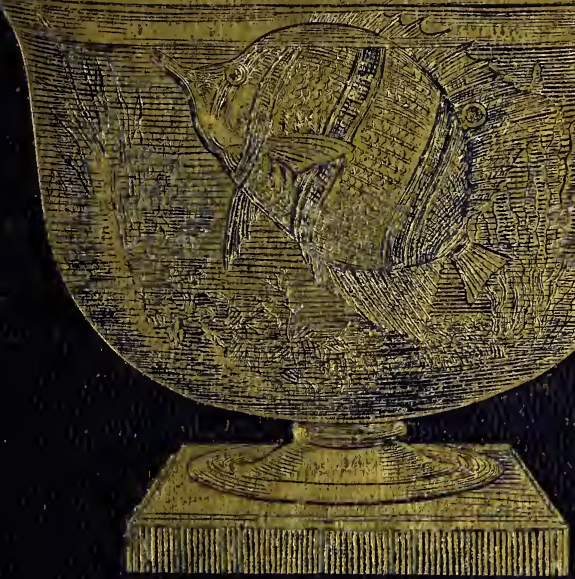




\section{9}

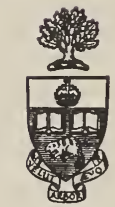

\section{Library}

$$
\text { of the }
$$

University of Toronto 
lst ed.

p. 220 numbled 201.

p25 not misnmwhind :

$$
2|10|=
$$





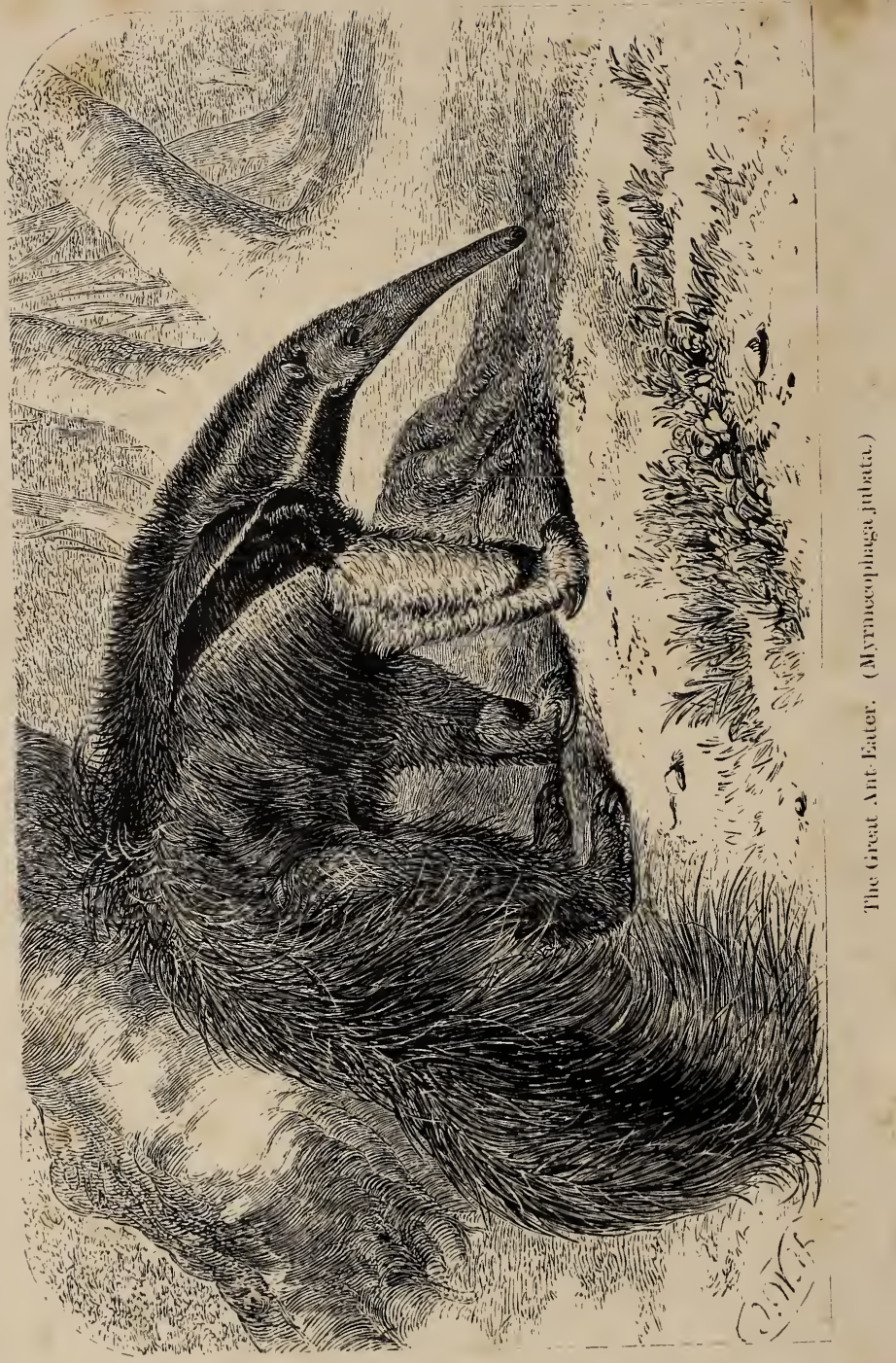




\section{LIFE}

IN

\section{ITS LOWER, INTERMEDIATE,}

AND HIGHER FORMS:

OR,

MANIFESTATIONS OF THE DIVINE WISDOM IN

THE NATURAL HISTORY OF ANIMALS.

BY

PHILIP HENRY GOSSE, F.R.S.

LONDON :

JAMES NISBET AND CO. 21 BERNERS STREET. 



\section{PRE EACE.}

THE greatest part of the following Work was originally published in the form of successive papers in "Excelsior." Several entire chapters have, however, been added, to make the survey of the animate creation more complete, and the whole has been carefully revised. The design of the author has been to present to general readers, who have not the time or inclination for the study of works more elaborately technical, a glance at the more interesting phenomena of animal life; and, in particular, the diversities of structure that the physiologist recognises as he travels up the complex scale, and the wondrous adaptation which exists between these and the various functions, habits, and instincts of living beings. And, finally, he has endeavoured, unobtrusively, to lead the mind of the reader to God, and to link the perfections of creation with His glorious and immutable attributes. 



\section{CONTENTS.}

PAG椠

INTRODUCTION, . . . . . . . . 1

\section{PAR'T I.}

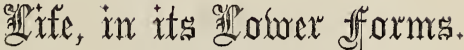

CHAPTER I.

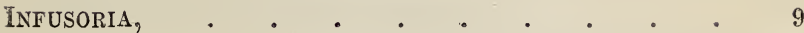

CHAPTER II.

INFUSORIA-Continued, . . . . . . . 17

CHAPTER III.

Porifera (Sponges), _ . . . . . . . 25

CHAPTER IV.

Porifera (Sponges)-Continued, . . . . 39

CHAPTER V.

POLYPIFERA (Polypes), • . . . . . . . . 49

CHAPTER VI.

Polypifera (Polypes)-Continued, . . . . 58 
CHAPTER VII.

Polypifera (Polypes)-Continued,

CHAPTER VIII.

ACALEPHE (Sea-blubbers),

CHAPTER IX.

ACALEPHE (Sea-blubbers)-Continued, ${ }^{\circ}$. . . . . 83

CHAPTER X.

ECHinodermata (Star-fishes),

CHAPTER XI.

EChinodermata (Star-fishes)-Continued, . . . 99

CHAPTER XII.

Echinodermata (Star-fishes)-Continued, . . . 108

CHAPTER XIII.

Helminthia (Intestinal Worms), • . • . . 116

PART II.

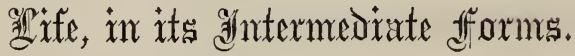

CHAPTER XIV.

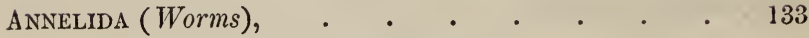

CHAPTER XV.

Myriapuda (Centipedes) 
CHAPTER XVI.

INSECTA (Insects),

CHAPTER XVII.

INSECTA (Insects)-Continued, $\cdot \cdot$
CHAPTER XVIII.

INSECTA (Insects)-Continued,

CHAPTER XIX.

INSECTA (Insects)-Continued,

CHAPTER XX.

Arachnida (Spiders, Scorpions, and Mites),

CHAPTER XXI.

ROTIFERA (Wheel-bearers)

CHAPTER XXII.

Crustacea (Crabs and Shrimps), . . . . . 204

CHAPTER XXIII.

Crustacea (Crabs and Shrimps)-Continued, . . 213

CHAPTER XXIV.

Cirripedia (Barnacles), $\cdot \cdot \cdot$
CHAPTER XXV.

Polyzoa and Tunicata,

CHAPTER XXVI.

CONCHIFERA AND GASTrOPODA, (Shell-fish), • . 239 


\section{PART III.}

apite, in its gifrolyer forms.

CHAPTER XXVII.

Pisces (Fishes)

CHAPTER XXVIII.

PIsces (Fishes)-Continued, $\cdot \cdot \cdot \cdot$
CHAPTER XXIX.

AMphibia (Frogs and Toads),

CHAPTER XXX.

Reptilia (Reptiles),

CHAPTER XXXI.

Reptilia (Reptiles)-Continued,

CHAPTER XXXII.

Aves (Birds),

\section{CHAPTER XXXIII.}

Aves (Birds)-Continued, $\cdot \cdot \cdot \cdot$
CHAPTER XXXIV.

Mammalia (Quadrupeds), · · ·
CHAPTER XXXV.

Mammalia (Quadrupeds)-Continued, .

CHAPTER XXXVI.

Mammalia (Quadrupeds)_Continued, . . . . 346

INDEX, 


\section{LIFE.}

\section{INTRODUCTION.}

"THe works of the Lord are great;" but we must not estimate this greatness by their actual dimensions; ; else $a_{0}$ man would be of less importance than a hippopotamus, and the Bass Rock would be immensely more valuable than either. It is a greatness not measurable by rule and line; not to be determined by bulk and weight; it is to be estimated by far other qualities,-by the relative importance which the objects bear to each other, by the variety and complexity of their parts, by the elaborateness with which they are constructed, by their fitness for the purposes which they are destined to subserve, and especially by the degree in which they shew forth the power, wisdom, skill, and goodness of Him who made them for His own glory. Many of the animals of which we are about to speak are so minute that the unassisted eye takes no cognisance of their presence; yet most of these,-perhaps all, if we were able to investigate them,-are so curiously fashioned, 
LIFE,

so elaborately constructed, as to deserve to be included in the category of those works which the adoring Psalmist says are GREAT.

We propose in this volume to describe the various phases of animal life, commencing at the foot of the scale, where we catch the first glimmering of the vital spark, and tracing it step by step upwards through its various developments and changes, its forms and functions. But what is LIFE? There is a mystery couched under that little word which all the research of philosophers has not been able to solve. Science, with the experience of ages, with all the appliances of art, and with all the persevering ingenuity and skill that could be brought to bear upon it, has ardently laboured to lift the veil; but philosophy, and science, and art, stand abashed before the problem, and confess it a mystery still. The phenomena, the properties of life, are readily observable. We take a bird in our hands; a few moments ago it was full of energy and animation; it shook its little wings as it hopped from perch to perch ; its eyes glanced brightly, and its throat quivered as it poured out the thrilling song which delighted us. Now the voice has ceased, the eye is dim, the limbs are stiffening, and we know that it will move no more. Chemical changes have already begun to operate upon its organs; decomposition is doing its work, and soon the beautiful little bird will be a heap of dust. We say that its life has gone; but what is it that has gone? If we put the body in the most delicate balance, it weighs not a grain less than when it was alive; if we measure it, its dimensions are precisely the same; the scalpel of the anatomist finds all the constituent parts that made the 
living being; and what that mighty principle is, the loss of which has wrought such a change, alike eludes research and baffles conjecture. We are compelled here to recognise the Great First Cause, and to say, "In Him we live, and move, and have our being."

The researches of modern science, however, aided by the inventions which it has brought into requisition, though they have been unable to throw a single ray of light on the nature of Life itself, have yet done much to make us familiar with its phenomena. The microscope, in particular, has opened to our inquiry what we may call a world of life, under phases and forms as strange and surprising as they were before unknown. It has enabled us also to separate and analyse the various substances or tissues of which the highest forms of animate being are composed, and to resolve them into their first elements. Numerous and diverse as are these substances-bone, cartilage, sinew, nerve, muscle, hair, the teeth, the nails of the hand, the transparent lens of the eye,-all are reducible to one kind of structure. This structure is a cell. All organic substances are made up of cells. The primary organic cell is a minute, pellucid, globule, invisible to the naked eye, and containing within it a smaller cell, called the nucleus, which again contains a still more $\mathrm{mi}$ nute granule, called the nucleolus, or little nucleus. Even the highest animals, in the early development of the embryo, are composed entirely of nucleated cells, which afterwards assume the forms peculiar to the various tissues. In the lowest classes of animals, their more simple bodies consist almost entirely of cells of this kind. If we take a minute portion of the gelatinous flesh of a medusa or a zoophyie, 
and crush it between two plates of glass beneath the microscope, the substance is presently resolved into a multitude of oval pellucid granules, each of which for a short time maintains a spontaneous motion, sometimes rotating upon itself, but more commonly jerking or quivering irregularly. These are the primary cells, and their motion is, doubtless, to be attributed to the presence of certain hairs, called cilia; for we canuot believe that it is at all connected with currents in the fluid that surrounds them, to which it has sometimes been referred.

Cilia play an important part in the economy of all animals. Even in the highest forms, many of the internal surfaces are furnished with them, and nearly all the motions which do not depend upon muscular contraction are produced by them. In the lower tribes, especially those which are aquatic, the office of these organs becomes more important and more apparent, until in the very lowest we find all movement originating with them.

The form of these essential organs is that of slender, tapering hairs, commonly arranged in rows, resembling the eyelashes, whence their name. The base of each hair is attached to the surface of the body to which it belongs, its whole length besides being free.* During life each cilium maintains an uniform motion of a waving or lashing kind, bending down in one direction and then straightening itself again. This movement is not performed by all the cilia together or in unison, but in rapid succession : for example, the instant after one has begun to bend, the next begins, then the next, and so on ; so that before the first has re-

* Perhaps it would be most correct to consider a cilium as formed by the wall of a cell drawn out to a fine point. 
sumed its erect condition, perhaps half a dozen of its successors are in different degrees of flexure. This sort of motion will probably be better understood by referring to that beautiful and familiar spectacle, the waves produced by the breeze upon a field of standing corn. The motion is exactly the same in both cases. The wind, as it sweeps along, bends each stalk in turn, and each in turn reassumes its erect posture; thus the wave runs steadily on, though the stalks of corn never remove from their place. The appearance of the ciliary wave, when viewed under favourable circumstances with a good microscope, is so exquisitely charming, that even those who have been long familiar with it can scarcely ever behold it without admiration. 



\section{PART I.}

\section{LIFE, IN ITS LOWER FORMS.}






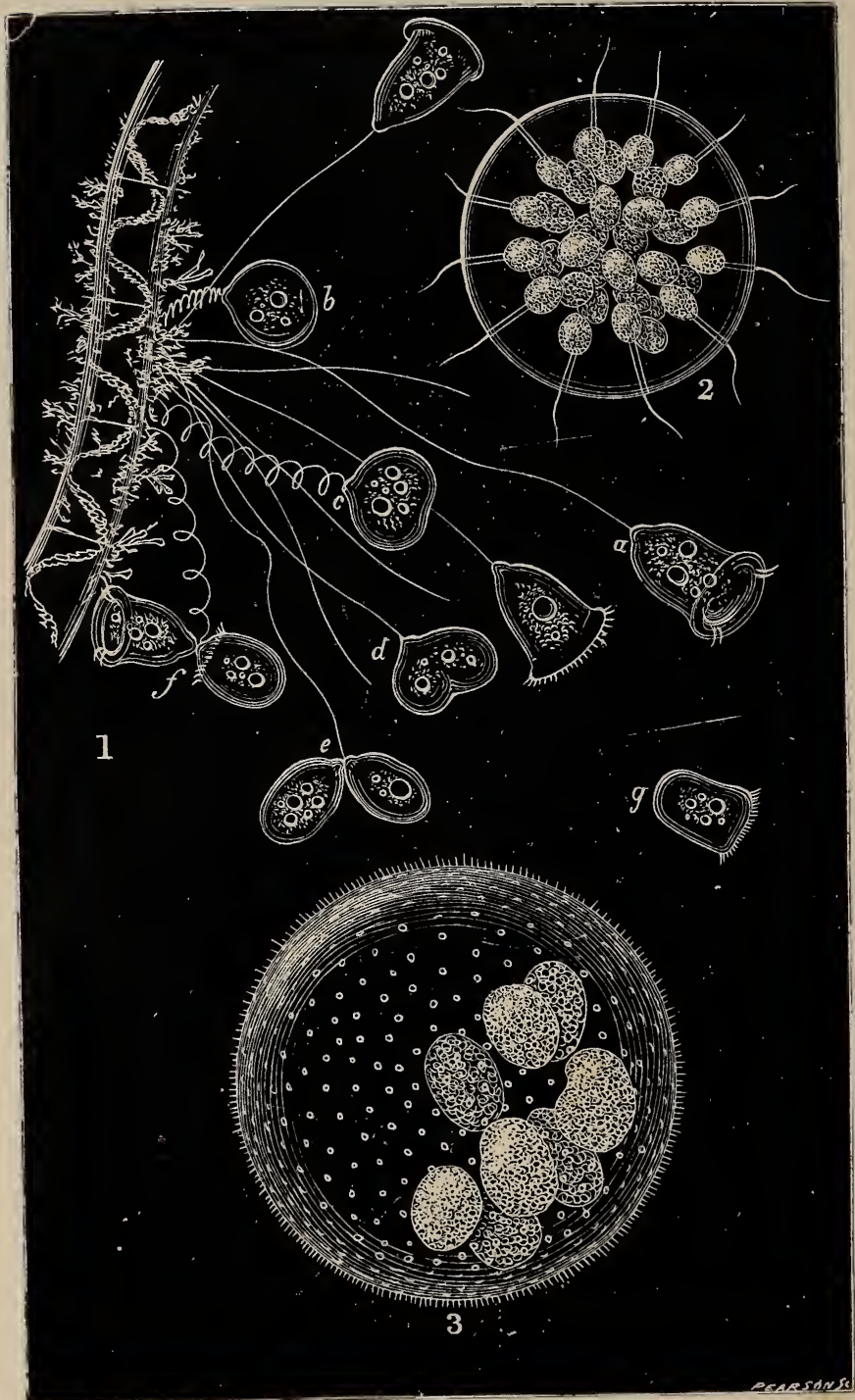




\section{CHAPTER I.}

\section{INFUSORIA.}

THE most minute and the most simple of all living beings, so far as the powers of the best microscopes have yet reached, closely resembles such a ciliated cell as we have been describing. It has been called the Twilight Monad (Monas crepusculum); so named because it is considered to be, as it were, the unit of existence-the point where the glimmering spark of life first emerges out of the darkness of nonentity. It consists of a tiny speck of pellucid matter, rounded in form, and supposed, from its movements and from analogy, to be furnished with a single cilium, by the lashing action of which it rows itself through the water. No words can convey an adequate idea of the size of an animal so minute as this; but the imagination may be assisted by supposing a number of them to be arranged side by side in contact with each other, like the beads of a necklace, when twelve thousand of them would go comfortably within the length of a single inch.* Eight

* An esteemed lecturer is reported to have lately said that the cheese-mite is an animal of middling size in existence; in other words, that there are creatures as much smaller than it as there are larger. This is not strictly correct. The largest animal known is the Rorqual (Balcenoptera boö $\rho$ ), which 
hundred thousand millions would be contained in a cubic inch; and as they are found swarming in water to such a degree as that each is separated from its neighbours by a space not greater than its own diameter, a single drop of such water has been estimated to contain a thousand millions of living active beings. If we take a bunch of leaves, of the common sage, for example, or a few twigs of hay, and, tying them into a bundle, suspend them in a jar of water, allowing the contents to remain untouched, but exposed to the air, some interesting results will follow. If we examine it on the second day, we shall find a sort of scum covering the surface, and the whole fluid becoming turbid, and slightly tinged with green. If now we take, with the point of a quill or a pin, a minute drop of the liquid, and examine it with a good microscope under a magnifying power of about two hundred diameters, we discover the water to be swarming with animal life. Immense multitudes of minute round or oval atoms are present, which move rapidly with a gliding action. These are animals of the genus Monas just described. Among them we shall probably see other bodies still more minute, resembling short lines, most of which are seen to be composed of more or fewer bead-like bodies, united into a chain. These occasionally bend themselves, wriggle nimbly, and effect a rather rapid progression in this manner. The scum, or transparent pellicle, is found to be composed of countless millions of these latter, congregated about as

is about 100 feet in length. The smallest is the Twilight Monad above mentioned, whose dimensions are $\frac{1}{12000}$ th of an inch. It is evident that the middle term between these extremes is $\frac{1}{3} \mathrm{~d}$ of an inch, which is about the length of the common house-fly, which may be therefore considered as an animal of medium size in creation. 
thickly as they can lie, into patches. They constitute the genus Vibrio. Several may be seen among them briskly wriggling along, which resemble a little coil of spiral wire. Such forms bear the generic appellation of Spirillum.*

As all infusions of vegetable or animal substances are found to be speedily filled with animals resembling these, in great variety, though not always of the same species, the circumstance has been seized by naturalists to afford a name by which this class of beings should be distinguished. They have been therefore called Infusoria, or infusory animalcules; a very extensive group, and one which, in a more advanced state of our knowledge, it may be found desirable to divide, since it includes animals of very different grades of organisation. Those of which we have spoken are among the simplest of these forms : we shall now describe others of a higher place in the scale, and more attractive in their appearance and in their habits. Every day during which the infusion is allowed to stand, it will display fresh forms, and generally those which appeared most abundantly in the earlier stages will be found successively to die out, and be replaced by other species. The more highly organised kinds will usually be discovered at the later periods.

But there is a very beautiful form, and one which cannot fail to possess great interest for the young microscopical student, which commonly occurs pretty early. Perhaps we shall see some of the stalks of the macerated hay, or floating portions of the semi-decomposed leaves, clothed. with what appears to the naked eye to be a very delicate

* Recent researches, however, render it probable that these are the earliest stages of Intestinal Worms. 
white mucor, or mouldiness. Such a fragment placed in the "live-box" of the microscope will not fail to present many groups of one of the most attractive of all the Infusoria, the lovely genus Vorticella. (See Plate I. Fig. 1.) A little bell of glassy transparency is affixed by a sort of nipple to a slender filament or stem, eight or ten times its own length. The bell has a broad and thick rim or lip, within which, on the two opposite sides, are apparently two pairs of cilia,* which are sometimes withdrawn, sometimes protruded, and are vibrated with a rapid snatching motion (a). The result of this is very curious, for when any atom in the water is drawn near the bell-mouth, it is not driven away or drawn in, but is whirled round in a continuous circle above either pair. This gyration may be frequently seen, even when the cilia are so far withdrawn as to be invisible.

Within the glassy bell are seen many pellucid bodies, which have been supposed to be numerous stomachs; these are continually changing their sizes, forms, and relative positions ; since they are not defined vesicles, but simply excavations of the common mass of gelatinous flesh, produced by the escape of the food from the open extremity of the gullet. Besides these globules, there are scattered granules, a contractile bladder, and a band-like dark organ, which is called the nucleus, and which appear's to possess the reproductive function.

In general, the animal floats loosely through the water, the thread fully extended, but rarely so straight as not

* The cilia are really placed in a complete circle around the bell-mouth; and the appearance above mentioned is merely an optical illusion, dependent on the relation of these parts of the circle to the eye, as viewed in perspective. 
to shew slight undulations; the basal extremity of the stem is affixed to the support; and the bell slowly roams about, with the length of its tether for a radius, now turning its open mouth, now its sides, and now its foot, to the eye.

On any shock, such as a tap with the nail on the stage or "live-box,"-instantly, with the quickness of thought, so that the eye can scarcely trace the motion, the long stem is contracted into a beautiful spiral (b), suddenly bringing the bell close to the point of adhesion, when it immediately, but gradually $(c)$, uncoils to its full length. It does not seem alarmed by tapping, except when fully extended; for it we tap the box all the time it is unfolding, it does not shrink again, until it has reached its full extension, but then it does instantly. It frequently, however, springs back again, when partially uncoiled, of its own accord, several times in succession. Hence we may presume that the spiral contraction is the result of alarm; but that though alarm may be felt from the bell's contact with substances in the water, or from currents, \&c., at any time, a shock or tap produces this effect only when the stem is tense, and capable of vibration. The whole of the actions of this little animal are very sprightly and elegant.

The ordinary increase of the animals of this class is by self-division. In the Vorticella it takes place in the following manner :-One of the full-grown bells begins to alter its form, becoming first globular $(b)$, then a flattened sphere (c), presently a slight notch or depression is observed in the upper part of the outline, and it soon becomes apparent that this depression is a constriction extending all round, which gradually becomes deeper and more 
marked $(d)$. As the two divisions become more separate, each assumes an oval form, united at length to its fellow only at the base (e). At this time the motion of the cilia is plainly visible, forming a circle in each within the body, near the summit. As the process goes on, the connexion between the two is reduced to a mere point, and they become capable of separate motion, so far as to diverge and look in opposite directions; the point of union being the common stem $(f)$. At this stage we may observe that the bell which is destined to remain is open at the top, within which the ciliary waves are chasing each other in continuous wheels, the other bell being closed at the summit.

But on the latter, which is ultimately to be thrown off, a new and highly interesting phenomenon appears. The cilia, which before the division had played around the mouth, have become obliterated, probably by absorption; the orifice at that extremity has closed up permanently, for this is to be the base of the new animal; and a new bell-mouth and a new wheel of cilia, are to be formed at the opposite end, which at present remains attached to the common stem. The first indication we can detect of this new formation is a very slight motion in the water, a little quivering around what we must as yet call the basal part. Presently there appear waved hairs, which seem very flexible, and the motion of which resembles that of a fringe of loose silk moved through water, an action very different from the regular waves of perfect cilia. These waving hairs increase rapidly in length, and in the vigour and rapidity of their undulations, which gradually become decidedly rotatory, producing at length strong currents in 
INFUSORIA.

the surrounding water, and imparting a tremulous motion to the whole bell.

It is evident now that the separation is imminent, for the minute point of connexion cannot long withstand the rushing current of these rotatory paddles. At length the bell suddenly shoots away $(g)$, gliding with great swiftness through the water, borne by its numerous paddles, and whirls about for a while in a headlong, giddy manner. At length it chooses a place of rest, becomes stationary, fixes itself by that end which had formerly been the mouth, but is now closed up, and presently begins to rise by the development of a slender stalk, which, though minute at first, quickly increases in length, until it attains the original dimensions.

But another mode of increase, yet more singular, has been found to prevail in these creatures. At certain periods the Vorticella closes its ciliated mouth, and passes into a sort of chrysalis state, taking a globular or bladderlike form, with a distinct double wall. After remaining a while in this encysted condition, pencils of slender fibres shoot out from two or more points, each fibre terminated by a minute globule. This form has been often detected by the older observers, without a suspicion that it was but a stage in the metamorphoses of Vorticella. By Ehrenberg it was constituted a distinct genus, under the name of Acineta.

According to Dr Stein, who first made known the true nature and relations of these forms, the Acinetce "have no mouth ; it is, indeed, difficult, from the toughness of their tunic, to effect a rupture; no food or stomach sacs, likewise, can be found in them, their substance being homogeneous, granular, soft, and containing, besides its very 
fine granules, some larger globules, probably of oil (fat), a contractile sac anteriorly, and an elliptic discoid granular nucleus, often accompanied by another smaller, finely granular, discoid globule, well defined.

"The larger nucleus is the one destined to undergo the first change; this it does by the development of fine cilia around its periphery, which actively vibrate, and so cause its rotation. Whilst this goes on, it increases in size, advances towards the anterior of the Acineta, which takes on active contractions, and thereby ultimately ruptures its integument, allowing the embyro (ciliated nucleus) to escape. On its emergence, the embyro swims away rapidly by means of its cilia; what further changes it undergoes are yet to be discovered.

"However, the part the Acineta body has to perform is not completed by the production of the one embryo; but the same process has to be repeated again and again, until its formative granular mass is used up, when the Acineta becomes a contracted, shrivelled, empty sac, seated upon the persistent stalk.

"After an emission of an embryo, the Acineta body contracts strongly; some of its diverging fibres shorten, whilst others are entirely withdrawn. This contracted condition, after lasting for a time, relaxes; the Acineta resumes its usual movements; the fibres spread out anew, moving about as usual in various directions; and it finally regains its original characters, save that it is smaller, and, instead of a smooth, even surface, it has its tunic thrown into folds or undulations. The spot from whence the embyro escaped soon becomes imperceptible."*

* Condensed from Stein, in Pritchard's Hist. of Infus. Animalc., p. 537. (Ed. 1852.) 
INFUSORIA.

\section{CHAPTER II.}

\section{INFUSORIA.}

Continued.

THIs brief sketch of the history of the Vorticella will serve to illustrate that of the whole class of Infusoria; as the facts, at least the earlier ones, with slight modifications, are common to all. The round bodies resembling beads, which we mentioned as scattered in the interior of the bell, are characteristic of the whole of these animals. Professor Ehrenberg considers them to be so many stomachs, connected either with the common mouth, or with an intestinal canal which runs through the body. To this conclusion he came by prosecuting a series of curious and ingenious experiments. By mixing coloured substances, such as carmine or indigo, with the water in which the animalcules were living, he found that they readily imbibed them, and that the colouring matter was presently accumulated in these internal vesicles, which then appeared crimson or blue, according to the pigment employed. Hence he applied the name Polygastrica to the class, a term which would be as appropriate as it is significant were it quite certain that his conclusions legitimately follow from his premises. But later naturalists have doubted that these vesicles are 
stomachs at all, nor have they been able to discover any such common tube as the learned professor describes. The true explanation of the phenomena appears to be, that the gullet terminates by an open extremity in the midst of the gelatinous flesh that occupies the general cavity of the body; and that the food, as swallowed, passes in pellets, enveloped in mucus, into this flesh, having assumed globular forms from the rotation produced by the lining cilia of the gullet. These pellets are partly absorbed, and partly expelled by a proper orifice.

There is another curious organ found in a large number of these animals, the office of which is even more puzzling. It is commonly known as the contractile bladder. If we are watching one of these animalcules, a Paramecium, for example, we see in a particular part of the body a circular space perfectly clear and colourless, which gradually enlarges until it takes the appearance of a distended globose bladder. When arrived at its utmost dimensions it suddenly contracts to a point, and presently begins to enlarge, until it reaches its former size and appearance, when it again contracts as before. This alternation of distensions and contractions goes on continuously; the latter taking: place at regularly measured intervals, perhaps of about a minute. We feel assured, from numerous observations, that the bladder is filled by some fluid which gradually percolates into it, and that this is discharged by the periodic contraction; but what is the nature of this fluid, and what relation the process sustains to the general economy, we are ignorant. Our own opinion is, that the organ, with its accessories, is the first rudimentary form of the urinary system of higher animals. 
The external organs of these animals are few and simple. In all, except the lowest forms, the mouth is surrounded by rows of strong cilia, by the vigorous vibrations of which currents are perpetually formed in the water, which bring to the entrance of the stomach whatever particles of matter suitable for food there may be floating about. Besides these, the whole surface of the body is, in many species, clothed with delicate cilia, which act as paddles to row the animal rapidly along. A few of the more highly organised genera are furnished with bristles, styles, or hooks, which appear to be merely cilia more than usually developed and deprived of vibratile power. They serve as instruments of locomotion, for crawling, or climbing about aquatic plants. In many species we see a red speck, which is probably an organ of sight in a very rudimental condition; perhaps possessing a sensibility to the presence of light without distinct vision.

Some of the members of the class are protected by a shell formed of silex, or the substance of flint. These shells may be considered as indestructible, and they are found in a fossil state, the memorials of Infusoria which existed in former ages in multitudes that defy calculation, and almost exceed belief. There is in Bohemia a mountain composed of a substance which, from its use in the arts, has long been known by the name of polishing slate. Professor Ehrenberg has found this substance to be entirely composed of the shells of fossil Infusoria, the genera and species of which can even yet be distinguished. Of these, he computes that $41,000,000,000$ are contained in every cubic inch of a stratum fourteen feet thick. On the shores of certain lakes in Sweden a fine powder is 
found in large quantities resembling flour in appearance. The natives of these districts have long been in the habit of collecting this, and of using it, under the name of bergmehl, or mountain-meal, as an article of food. This, also, the microscope reveals to be composed of the remains of incalculable millions of shelled Infusoria.

Some interesting examples of a protecting case of different structure are found in the family Tintinnidce. They are animals allied to the Vorticella, but inhabiting a transparent tube, open at the top, of a gelatinous or membranous texture., This case is affixed to the stems of water-plants, sometimes by its base, when it is erect, at others prostrate, adhering by its side, and occasionally placed at the tip of a footstalk, like a tiny handbell turned upside down. The animalcule protrudes to a considerable distance from the margin of its glassy cell, unfolding a ciliated mouth like that described in the preceding chapter; but on the least disturbance it shrinks, a little shapeless ball, down to the very bottom of its tube. Sometimes two animals dwell in the same tube, and their amicable movements are viewed with ease through the transparent walls of their miniature crystal palace.

Those who have never looked through a microscope can scarcely form an idea of the beauty of these little animals. Engravings of many of them, and technical descriptions, are, indeed, to be found in published works ; but of their brilliant transparency, their high refractive power, resembling that of flint-glass, their sudden and sprightly motions, their general elegance and delicacy, and the appearance of intelligence which they display, neither books nor engravings will give any adequate conception. 
On the surface of stagnant ponds may often be seen, especially in spring, a stratum of what looks like a bright green powder. If a small quantity of this be taken up and examined, many curious and beautiful forms will be discovered. A large portion of the substance will probably consist of different species of the genus Euglena -little active creatures, somewhat resembling fishes in shape, of a rich green hue, with a large red eye. Among them we may find what is sometimes called the High-priest's Breastplate (Gonium pectorale), consisting of sixteen oval green masses, disposed regularly in a transparent shell of square form, like emeralds set in a plate of the purest glass. Another brilliant casket of gems is the Pandorina morum (Plate I. fig. 2), a species which we have taken in the neighbourhood of London. It is a crystal globe enclosing about thirty globose animals of a rich green hue, from each of which proceeds a long, whip-like proboscis, about as long as the radius of the globe. By means of these filaments it proceeds rather quickly, rolling over in an irregular manner as it goes. Its appearance is very rich and beautiful, particularly when the light is transmitted, as it sometimes is, through the interstices of the animalcules, and gleams through their dark-green bodies. The newly-invented paper-weights, consisting of balls of solid glass, in which are imbedded some beautiful coloured objects, will give an idea of this creature.

Many kinds are interesting from the close resemblance in form which they display to other well-known objects, animate or inanimate. The Volvox (fig. 3) rolls majestically through the water, revolving regularly on its axis like an artificial globe ; and as it is of greatly superior 
dimensions to most others of the class, we may compare it to the planet Jupiter surrounded by a host of moons.* The Stentors, also, are of comparatively large size, being distinctly visible to the naked eye ; these resemble trumpets in form. One beautiful species, hence named Trachelocerca olor, charms the eye by its close resemblance to a swan. It has a plump, rounded body, a slenderpointed tail, and a very long and graceful neck, the motions of which, thrown into arching curves, and protruded in every direction, give the most lively representation of the elegant waterfowl after which it is named. Indeed, in one species of this genus, $T$. biceps, we may see the living representative of the celebrated bird usually considered to be as scarce as the lost Dodo itself-the swan with two necks.

The genus Amœba has long been celebrated among microscopists, from its power of constantly changing its form, whence it is sometimes called the "Proteus." It consists of a mass of clear, jelly-like matter, with a few granules, two or three of the supposed stomachs, and a contractile bladder. But its peculiarity is that which we have just mentioned. It is ever altering its outline; and to so great a degree, that not only are no two ever found alike, but the same specimen does not retain the same shape for two successive minutes. Here a point projects and gradually pushes out more and more, while a sinuosity

* Many of the organisms which, principally on account of their spontaneous movements, were considered as animals, when Professor Ehrenberg published his elaborate work, "Die Infusions-thierchen," are now generally admitted to be plants. And there are not a few who contend that the beautiful Gonium and Volvox must be removed from the domain of the zoologist also. As this position is not, however, quite established, their elegance pleads for them to remain for the present where we have put them. 
is forming in some other part; one portion is contracting, another enlarging; so that the only idea that can be given of its shape, is by comparing it to the figure of a country upon a map, which is perpetually transformed into that of some other country.

These are but a few examples of the variety of form which this curious class of animals presents to us : it remains now only to give, to those who may be desirous of examining them for themselves, a few instructions to aid their researches. A good microscope is, of course, indispensable ; if the study is intended to be pursued scientifically, a compound achromatic, with magnifying powers ranging from fifty to five hundred diameters, must be employed; but very much entertainment, and a good idea of many of the forms, may be obtained with an ordinary simple microscope of three powers. The penetrating and defining properties of a microscope are of more importance than mere enlargement.

If we were asked where specimens are to be obtained, we might reply, almost everywhere, provided water be present: but even in the air they have been lately detected by the eminent Prussian professor. In ditches and ponds, in the trenches of meadows, in the ruts of highroads, in marshes, in lakes and rivers, in estuaries, and even in the sea, various species may at almost all times be found. Stagnant waters, especially such as are covered with a thick scum, contain some species in immense abundance, but these are generally of the simplest structure : little hollows in boggy ground, especially where a red sediment betokens the presence of oxide of iron, frequently contain species of great rarity and beauty; but 
clear standing water, in which the more delicate aquatic plants grow, and particularly when covered with duckweed, will be found the most productive resource both for number and variety.

The mode of collecting them is very simple. The water must be dipped up in a phial, which may be tied to the end of a walking-stick; a moment's examination of its contents with a pocket-lens will determine whether the water is worth carrying home. If no moving particles are seen, another dip may be taken elsewhere; should this likewise prove valueless, another locality should be sought.

When brought home, a small drop may be taken at random, and placed in what microscopical observers call an aquatic box or live-box; a small fragment of duckweed-root, or the stem of some slender water-plant, put in also, will aid the search : this should then be examined with a low power at first, the observer proceeding to the use of higher powers for the closer examination of particular specimens.

Should any of our readers who may possess a microscope, or access to one, be disposed to investigate these minims of existence, we shall be disappointed if they do not find objects which will not only please their fancy and inform their understanding, but also give them fresh and unexpected ideas of the ways of Him whose glory is no less displayed in the construction of an animalcule than in the creation of a solar system. 



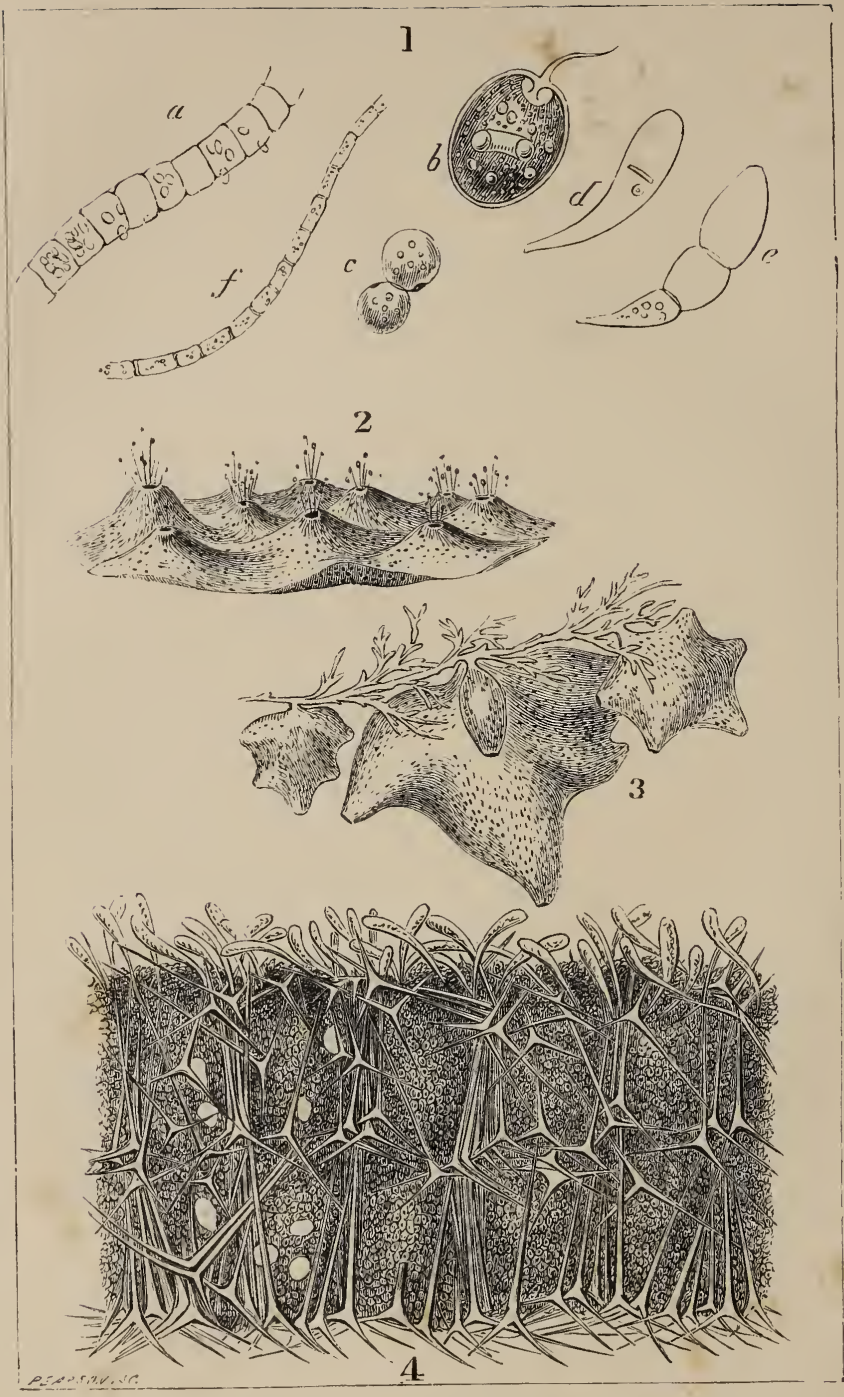

Porifora. (Sponges.) 
SPONGES.

\section{C.HAPTER III.}

\section{Porifera (Sponges).}

What is an animal? Nothing seems easier than to answer this question. Our thoughts in a moment recall the image of the stately horse shaking his neck of thunder, and projecting columns of vapour through his translucent nostrils; or the painted tiger crouching in the jungle, awaiting in lithe readiness the approach of some unconscious antelope to make his mortal spring; or the trembling antelope itself, as it pants, and struggles, and groans beneath the fangs of its merciless foe. Nothing appears simpler than to define an animal. A being with head, and body, and limbs ; full of energy and vigour ; possessed of various instincts; master of many ingenious contrivances all helpful to its peculiar economy; executing various movements ; manifesting intelligence in different degrees, and. governed by a wayward will.

True, such a creature as this is an animal; but are there no animals but such as possess these characteristics? Let us enumerate a few familiar instances. Look at the ferocious crocodile. Is this an animal ? "Without doubt," you answer. The serpent, the frog, the mackerel? 
"Without doubt," you still reply. The worm, the caterpillar, the snail, the oyster ? "Yes," you say still, perhaps hesitating a little upon the last, as its energy and vivacity are confessedly not great. Still, probably, you have been accustomed to consider an oyster as an animal, though one in which the animal life is in about its lowest condition; and you think you have got through your catechism without any great difficulty. Stay: we must ask you to descend with us a step or two lower than the oyster. You have, perhaps, seen on the sandy shore in summer the flat cakes of motionless, colourless jelly, commonly called sea-blubber : are these animals? If you have seen them in the sea, possibly you will consider the spasmodic contraction of the circular disk at regular periods as an indication of life, though you begin to see that in such a mass of clear jelly as this, without limbs, without organs, without senses, without intelligence, without a power of governing its movements, we have departed somewhat considerably from such a standard of animal nature as the horse or the tiger presented.

But let us look further yet. The brilliant-hued Sea Anemone that adheres to the rock, and expands its lovely fringed disk like the blossom of a flower,-what is this? People call it an animal-flower; but what is it, animal or flower? Probably you are at last puzzled; you are inclined to think it a sort of marine flower, though its fleshy substance, and its shrinking when touched, produce some misgivings in your decision. Well, try again. In the baskets of dried sea-weed which are exposed for sale in watering-places, you have often seen the papery leaves of pale-brown hue, or feathery plumes of pure white, mingled 
with the crimson and green specimens. You have never doubted that these are all sea-weeds, that is plants, alike. And yet if you saw these growing on their native rocks, plant-like as they are in form, you might discern, on careful examination with a pocket lens, that from various points of their surface tiny star-like circles of radiating points were protruding, that possessed spontaneous motions, and exhibited a shrinking sensitiveness to danger, and a power of seizing and swallowing food; and you would suspend, if not alter, your judgment.

If now, we ask, What is an animal? you will confess that the answer is not so easy as it appeared at first; still there remain some characters common to all the beings that we have glanced at, and these we may perhaps conclude to be inseparable from, and distinctive of, animal existence. Of these characters, the most constant and the best defined are the power of spontaneous motion, and the possession of a stomach, or at least an enclosed cavity, in which other substances are converted into nutriment.

With regard to the former of these characters, what shall we say to the Sensitive plants of the tropics, the pinnate leaflets of which fold together, and the jointed leaf-ribs fall, on the rude touch of a foreign body? What to the plant called Venus' Fly-trap (Dioncea muscipula), found in the marshes of North America, whose broad two-lobed leaves, armed with strong teeth standing up from the surface, ordinarily lie widely expanded; but when an insect touches their hairy centres, instantly fly up like a rat-gin, the teeth cross each other, and the offending fly is pierced, and held a prisoner until it dies? What to the Gorachand of Bengal (Hedysarum gyrans), whose 
actions, still more unaccountable than those just noticed, are thus described by the younger Linnæus? "No sooner had the plants raised from seed acquired their ternate leaves, than they began to be in motion in every direction: this movement did not cease during the whole course of their vegetation, nor were they observant of any time, order, or direction : one leaflet frequently revolved, while the other on the same petiole was quiescent; sometimes a few leaflets only were in motion, then almost all of them would be in movement at once; the whole plant was very seldom agitated, and that only during the first year." These motions, which are little dancings or startings to and fro, are much more lively in the native country of the plant than in our best stoves. What is curious is, that if the leaflets be held between the fingers for a short time, and thus prevented from moving, immediately on their release they dance with renewed rapidity, as if to make up for the lost time.

All these, however, are examples of motions in the organs of plants ; but there are not wanting instances of spontaneous locomotion. The Oscillatorice, a tribe of minute plants among the Conferves, derive their name from the spontaneous movements which they display. They oscillate to the right and left, and shift their position with considerable rapidity, often travelling ten times their own length in a few hours, and that when every precaution has been taken to prevent agitation of the water in which they grow, and to exclude the influence of external agents. The motion of these vegetable tubes has a writhing, twisting, undulating, creeping character ; almost identical with that of animal movement. 
The necessity of a stomachal cavity to an animal is a more precise distinction, and appears to be the only one. Yet even this is not without obscurity. The Hydra, when turned inside out, like a glove, absorbs its nutriment as well as before, though the surface which is its stomach now was before external, and vice versâ. And Dr Lindley remarks, in speaking of vegetable organisms, "that it is impossible to say that the whole interior of a living independent cell is not a stomach." *

It will now be readily admitted that the limits between the animal and vegetable kingdoms are exceedingly indistinct and subtile, and that these two grand divisions of organised being merge into each other by shadowy and almost imperceptible gradations. In fact, it is more than doubtful whether there are any boundaries at all.

In a former chapter we described beings of excessive minuteness, but of energetic motions, most of which have been universally allowed to be animals; yet a considerable number of those which were included by the illustrious Ehrenberg in the same class, are now pretty generally

* "As is well known, all the older criteria by which animals were separated from plants have long since been regarded invalid; and some of those which in late years have been regarded among the most constant, have, quite recently, been declared as equally unsound. Cellulose has been shewn to be a component of animal as well as of vegetable structures, and Kölliker has insisted that some forms which have neither mouth nor stomach, but consist of a homogeneous mass, are true animals. If these premises are correct, nothing will remain, as I conceive, for a distinctive characteristic, but voluntary motion. This when positive, is indubitable evidence of any given form being of an animal character ; and it must remain for each indiviaual observer to determine what is, and what is not, voluntary action, in each particular case. Moreover, even should Kölliker's view of a stomachless animal prove correct, the inverse condition of a true stomachal cavity being present must, I think, be regarded as positive evidence of the animal nature of the form in question; for this must always be a distinctive characteristic of the two kingdoms when present." $-(D r$ Burnett, in Siebold's "Comparative Anatomy," p. 18.) 
considered to be plants, in spite of their movements, and constitute the order Diatomacece. But what is stranger still is, that there are some forms which are animals at one period of their lives and plants at another! The Green Microglene (Microglena monadina), a beautiful oval monad not uncommon in our ditches, is declared by Kützing to be produced from a threadlike plant, which he names Ulothrix gonata. From the cells of which the thread is made up, the minute vegeto-animals are discharged in numbers (See Plate II. fig. 1 a), and assume the form of an oval green monad, with a red eye-speck, a transparent colourless mouth, and a delicate proboscis or cilium (b). They swim energetically, with a vibratory rotation on the long axis ; increase by self-division $(c)$; and at length, by transverse constriction and elongation $(d)$, grow into jointed vegetable threads $(e)$, the lowest joint still retaining the eye-speck.

This interesting phenomenon, the reality of which has been ascertained by Kützing beyondall possibility of doubt, dissipates the idea of any supposed line of demarcation between the organic kingdoms of nature; and proves that the disputes which have been so pertinaciously maintained between zoologists and botanists on their boundary question, have been concerning words rather than things.

Among the organisms the position of which has been most debated, are some very familiar to us, from our habitual employment of some of the species for domestic purposes. They constitute the extensive and widelydistributed class Porifera, or the Sponges, the history of which forms the subject of this chapter. We shall not enumerate the names or record the opinions of the contro- 
versialists who have contended for scientific dominion over these bodies; naturalists of the highest eminence have been arrayed on each side. We shall content ourselves with giving the judgment of Dr Johnston, the learned historian of British Sponges, and one well worthy of being listened to with respect; and we quote him the rather because his decisions, while they tersely exhibit the real merits of the case, have so yielded to accumulated evidence as to shift from the side first advocated to the opposite.

When the "History of the British Zoophytes" was published, the author omitted the Sponges, and gave the following summary of his reasons for so doing :- "If they are not the productions of Polypes, the zoologist who retains them in his province must contend that they are, individually, animals; an opinion to which I cannot assent, seeing that they have no animal structure or individual organs, and exhibit no one function usually supposed to be characteristic of the animal kingdom. Like vegetables, they are permanently fixed ; like vegetables, they are nonirritable; their movements, like those of vegetables, are extrinsical and involuntary ; their nutriment is elaborated in no appropriated digestive sac ; and, like cryptogamous vegetables, or algæ, they usually grow and ramify in forms determined by local circumstances; and if they present some peculiarities in the mode of the imbibition of their food and in their secretions, yet even in these they evince a nearer affinity to plants than any animal whatever." *

A few years later, however, the learned writer published his "History of British Sponges," in the introduction to

* Brit. Zooph., p. 29. 
which he elaborately examines the whole question, concluding with the following verdict :- "Few, on examining the green Spongilla, would hesitate to pronounce it a vegetable, a conclusion which the exacter examination of the naturalist seems to have proved to be correct ; and when we pass on from it to an examination of the calcareous and siliceous marine genera, the impression is not so much weakened but that we can still say with Professor Owen, 'that if a line could be drawn between the animal and vegetable kingdoms, the Sponges should be placed upon the vegetable side of that line.' We shall possibly, however, arrive at an opposite conclusion if, proceeding in our inquiry, we follow the siliceous species, insensibly gliding, on the one hand, into the fibro-corneous Sponge, filled with its mucilaginous fishy slime, and, on the other, into the fleshy Tethya, in whose oscula the first signs of an obscure irritability shew themselves. Sponges, therefore, appear to be true zoophytes; and it imparts additional interest to their study to consider them, as they probably are, the first matrix and cradle of organic life, and exhibiting before us the lowest organisations compatible with its existence." *

Many of our readers are probably cognisant of only one kind of Sponge,-the soft, plump, woolly, pale-brown article, so indispensable in our dressing-rooms; or, at the most, two, if they chance to have noticed the large-pored, coarser sort with which grooms wash carriages. It may surprise such persons to be informed that the streams and shores of the British Isles produce sixty or seventy distinct species of Sponge ; and that every coast, especially in the

${ }^{*}$ Brit. Sponges, p. 68. 
tropical seas, where they are very numerous and varied, has species peculiar to itself.

A Sponge, as it is used in domestic economy, is merely a skeleton : it is the solid frame-work which in life supported the softer flesh. This skeleton is composed of one or two of the following substances,-flint, lime, and a peculiar horny matter. The first two are crystallised, and take the appearance of spicular needles either simple or compound, varying greatly as to their length, thickness, shape, and curvature, but constant in form in the same species. The horny matter, of which the common domestic Sponge affords an example, is arranged in slender, elastic, translucent, tough, solid fibres, united to each other irregularly at various points, and in every direction, and thus forming an open netted mass commensurate with the size of the whole sponge. The horny Sponges are almost confined to the warmer seas, but the siliceous and calcareous kinds are common with us, especially the former.

The solid parts are, during life, invested with a glairy transparent slime, so fluid in most species as to run off when the Sponge is taken out of its native element; yet this clear slime is the flesh of the animal.

The spicula, whether of flint or lime, or the horny fibres, are so arranged as to form numberless pores, with which the whole animal is perforated; it is to these that our common Sponge owes its most valuable property of imbibing and retaining water, as we shall presently see when we investigate the history of this species in detail. In life the surrounding water is made to flow through these pores by a continual current (interrupted, however, at the will of the animal) from without into the interior of the 
body. But whither goes this current? The pores lead into large channels, which also run through the body, like the drains from individual houses, which run into the main sewers ; and these open on the exterior of the body by more or less conspicuous orifices called oscula, or mouths. From these latter the effete water is poured in forcible streams, and thus a circulating current is maintained.

It was Dr Grant who first established the fact of this current from personal observation. His account of the discovery is full of interest. "I put a small branch," he observes, "of the Spongia coalita, with some sea-water, into a watch-glass, under the microscope, and, on moving the watch-glass so as to bring one of the apertures on the side of the Sponge fully into view, I beheld, for the first time, the splendid spectacle of this living fountain vomiting forth from a circular cavity an impetuous torrent of liquid matter, and hurling along, in rapid succession, opaque masses, which it strewed everywhere around. The beauty and novelty of such a scene in the animal kingdom long arrested my attention; but after twentyfive minutes of constant observation, I was obliged to withdraw my eye from fatigue, without having seen the torrent for one instant change its direction, or diminish in the slightest degree the rapidity of its course. I continued to watch the same orifice, at short intervals, for five hours -sometimes observing it for a quarter of an hour at a time,-but still the stream rolled on with a constant and equal velocity." The vehemence of the current then began to diminish, and in about an hour ceased.*

No one can have looked with any attention at the rocks

* Edin. Phil. Journ. xiii. 102. 
on any part of our shores that are left exposed by the sea at low spring-tide, without noticing irregular masses of yellow fleshy substance incrusting them, which rise into little conical hillocks perforated at the extremity, like the crater-cones of tiny volcanoes. This is the Crumb-of-bread Sponge (Halichondria panicea), one of our most common species; and it is peculiarly suitable for displaying the currents of which we have been speaking (Plate II. fig. 2). Dr Grant remarks, that it presents the strongest current which he had seen. "Two entire round portions of this Sponge," he says, "were placed together in a glass of seawater, with their orifices opposite to each other at the distance of two inches; they appeared to the naked eye like two living batteries, and soon covered each other with feculent matter. I placed one of them in a shallow vessel, and just covered its surface and highest orifice with water. On strewing some powdered chalk on the surface of the water, the currents were visible at a great distance; and on placing some small pieces of cork or of dry paper over the apertures, I could perceive them moving by the force of the current, at the distance of ten feet from the table on which the specimen rested.*

The publication of these facts convinced naturalists that the gelatinous flesh of the Sponge exerted some vigorous action by which the currents were maintained, and cilia were suspected to be the organs. But the closest scrutiny failed to detect them, until first Dr Dobie, and then $\mathrm{Mr}$ Bowerbank, succeeded in seeing them in action in a living native Sponge. In similar situations to those where the Crumb-of-bread Sponge occurs, may be found, but much 
more rarely, the elegant Sack Sponge (Grantia compressa). It takes the form of a little flattened bag of angular outline, and of a whitish hue, with an orifice at each angle. The bags, which are frequently clustered, hang by a slender base from the stalks of sea-weeds, or from the naked rocks (Pl. II. fig. 3). When examined they are found to be hollow, with thin walls ; and if a small portion be torn off and placed beneath a microscope, it will exhibit well the structure of a spicular Sponge. The substance will appear crowded with, and almost composed of, calcareous crystals, most of which are stars of three radiating points, but some are linear needles, and on the exterior are many which are pointed at one end, and terminate in a bent, club-like knob at the other.

It was this species which, under Mr Bowerbank's experienced eye and delicate manipulation, revealed the moving cilia. By tearing specimens in pieces (for the use of the keenest cutting instruments so crushed the texture as to destroy the parts), and examining the separated edges with high powers, he found that the sides are composed of a number of hexagonal cells, defined by the peculiar arrangement of the triradiate spicula, and having their walls formed by a multitude of nucleated granules (fig. 4). These angular cells are laid at right angles to the long axis of the Sponge, extending from the outer surface to the inner; and they are crossed, near the middle, by a thin partition, perforated in the centre. In this perforation, several long, whip-like cilia were seen lashing with energy, and the same organs were afterwards found to be connected with the granules of which the cell-walls were composed. By means of the wavings of these cilia, then, 
the water is made to flow through the cells from without, being discharged into the interior of the sack, and poured out in streams from the orifices (oscula) which terminate the angles of the Sponge.*

This beautiful and interesting discovery leaves no doubt of the animal nature of the Sponges, which is still further confirmed by some interesting observations we had lately an opportunity of making on the irritability of Halichondria sanguinea.

"When carefully watched under a power of 70 diameters, this brilliant species exhibits the following appearances :-At first we discern an uneven surface with little eminences here and there, like hills in an undulating country. A great number of very slender glassy rods project at various angles from the surface, perfectly straight, equal in thickness in every part, with blunt tips. Webs of the investing membrane cling around the bases of these rods (spicula), and are a little elevated with them.

"Presently from one and another of the hillocks, a round bladder is seen pushing out, which gradually lengthens, until it becomes elliptical. It is composed of a clear gelatinous membrane, excessively subtile, with a yellowish granular film spread irregularly over its surface. Orifices are now perceived in the rounded tip of the bladder, the formation and increase of which are so very gradual, as to defy detection, except by the result. . . . These orifices slowly alter, increasing or diminishing; sometimes a minute one appears at the margin of a large one, augmenting at the expense of the latter, until the dividing film stretches across, - a narrow straight isthmus between

* Trans. Micr. Soc. iii. 137. 
two lakes of equal dimensions. Sometimes the whole bladder wrinkles and partially collapses into a rugose column, and then slowly distends again, when the openings are seen as they were before. . . . .

"The efferent stream pours out at each of these orifices, carrying with it fœcal matters from the interior, and any light-floating atoms that may be in the vicinity, as I saw with beautiful distinctness, by making the surrounding water slightly turbid.

" On my touching the bladder with the point of a needle, it at once shrank up into a wrinkled column, but did not retract, and presently distended again. Thus the specimen exhibited very distinctly those characteristics of animal life - sensibility to touch, and spontaneous movements." *

$$
\text { * Tenby, } 320 \text {. }
$$


SPONGES.

\section{CHAPTER IV.}

\section{Porifera (Sponges).}

\section{Continued.}

THоUGH the horny or keratose Sponges are distinguished from those which have calcareous or siliceous spicula in them, this distinction must not be understood to imply that the former are totally destitute of these bodies, but only that they possess them in an excessively minute proportion. Mr Bowerbank, in his elaborate and valuable investigations " On the Keratose Sponges of Commerce," has found spicula of very minute dimensions imbedded in the substance of the horny fibres of various species.* Still the immense preponderance of the corneous structure fully warrants their isolation as a natural group.

The horny fibres, as we have already said, form an irregularly netted mass, uniting to and separating from each other at various angles and distances, without the least order. They are not tubular, as has been supposed, but solid and of unequal thickness in different parts. Sometimes they are rigid and coarse, as we have seen in a large tubular Sponge on the shores of Jamaica, almost

* Trans. Micr. Soc. i., p. 32. 
emulating the entangled twigs of a thorny bush in their inelastic stiffness. But more commonly the slenderness and arrangement of the fibres impart to the Sponge that elasticity which is one of its most valuable qualities.

In order to apprehend truly the character of any Sponge, it should be examined alive if possible ; but if this be impracticable, at least specimens should be selected which have been dried as they came from the sea, without having been subjected to any processes of washing, pressing, or cleansing. In specimens of Turkey Sponge in this condition, Mr Bowerbank finds the horny fibres surrounded by a beautiful tissue of branching vessels in great abundance, enclosed in an external membrane or sheath. This tissue Mr Busk has succeeded in injecting with coloured fluid.

The fibres are also covered with a web of darker colour than their substance, composed of minute granules, which are conjectured to be incipient gemmules; for nucleated gemmules were found on the fibres of other specimens, in which the granulose texture was wanting. The maceration in fresh water, however, and the immersions in diluted acid to which the commercial Sponges are subjected, remove the whole of the gelatinous flesh, and render this structure inapparent in specimens sold in the shops.

In commerce two kinds of Sponge are known-the Turkey and the West Indian. But of the former Mr Bowerbank makes two species, undistinguishable indeed by any marks that the naked eye can appreciate, but recognised in an instant on microscopical examination, by the presence or absence of the investing vascular tissue above men- 
tioned. Both of these species grow abundantly in the eastern parts of the Mediterranean, especially around the numberless islets of the Grecian Archipelago. Smyrna is the great market for the Sponge trade, and the exportation of this article forms no inconsiderable source of its prosperity.

Great Britain imports annually about 60,000 lbs. of Sponge, paying duty of $6 \mathrm{~d}$. per lb., with five per cent. addition. The greater portion comes from the Levant, but Barbadoes and the Bahamas supply a coarser sort, chiefly used for washing carriages. Its pores are large, and it has projecting lobes; the fibres possess little cohesion, and hence it is commonly called "rotten."

The Grecian Sponges grow in moderately deep water, usually assuming a more or less manifest cup-form. Those which reside in the deeper recesses of the sea are said to be of larger dimensions, as well as of finer texture, than such as are more exposed to the action of the waves. Aristotle, who enjoyed peculiar facilities for the study of these organisms, and who has speculated on their nature, says that in a living state they are black, except as covered with the light earthy sediment of the sea :-a circumstance which, notwithstanding his high authority, we venture to doubt. He may possibly have supposed specimens to be alive which were dead, and blackened with sulphuretter hydrogen.

In many of the Greek islands, the diving for Sponge forms a considerable part of the occupation of the inhabitants, as it has done from the most remote antiquity. Hasselquist says :- "Himia is a little, and almost unknown island directly opposite Rhodes. It is worth notice, on 
account of the singular method the Greeks, inhabitants of the island, have to get their living. In the bottom of the sea the common Sponge is found in abundance, and more than in any other place in the Mediterranean. The inhabitants make it a trade to fish up this Sponge, by which they get a living far from contemptible, as their goods are always wanted by the Turks, who use an incredible number of Sponges at their bathings and washings. A girl in this island is not permitted by her relations to marry before she has brought up a certain quantity of Sponges, and before she can give a proof of her agility by taking them from a certain depth." * In other islands the same custom prevails, but with reversed application, as in Nicarus, where the father of a marriageable daughter bestows her on the best diver among her suitors,- " "He that can stay longest in the water, and gather the most Sponges, marries the maid." +

In fact, the employment seems to be common to both sexes and all ages. Savary, describing a little insular dependence of Rhodes, named Syme, observes as follows :"The Sponges which grow around this isle are the only resource of the inhabitants. Men, women, and children, all learn to dive. All must seek beneath the waters the only patrimony which nature has left them. The men excel all in this dangerous art. They precipitate themselves into the sea, and descend to an enormous depth. Often they do violence to themselves in retaining their breath too long, and on emerging vomit a mouthful of blood. At other times they run the risk of being devoured 
by sea-monsters, against which the knife which they carry is but a poor defence. They distinguish with clearness distant objects through the crystal element, and as soon as they perceive voracious fishes, they shake rapidly the foot of the rope, and in an instant are drawn up to their boat. I learned these particulars from a diver of the country, who complained sadly of his hard lot and of his small profits." *

The uses of Sponge have been appreciated from very ancient times. We learn from Aristotle that it was used to line the brazen armour which his countrymen wore in battle. "The kind called Achilleum, fine in texture, and very thick and strong, they put under helmets and greaves, viz., between the armour and the skin, whereby blows are rendered less stunning." The same kind was employed, as with us, for cleansing purposes. Thus Homer says :-

"Then with a sponge he drest

His face all over, necke and hands, and all his hairie breast." $\dagger$

And in the Odyssey, the seats and tables after the slaughter of the suitors are cleansed by "well-soaked sponges." + Martial also informs us, $\S$ that the tables after meals were carefully scoured with wet sponges; for the Greeks and Romans knew not the comfort of table-cloths, which the Nineveh marbles shew to have been familiar to the Asiatics. Another use was that of conveying liquids to the mouths of persons incapable, from exhaustion or other causes, of drinking; and the Christian remembers with interest that the last office rendered to the Lord Jesus in his humiliation, was the moistening of his lips by means of a sponge. $\|$

* Lettres sur la Grèce, 96.

+ Iliad, lib. xviii.

† Odyssey, lib. xxii.

$\S$ Apophor. n. cxliv.

|| Matt. xxvii. 48. 
Pliny alludes to the Sponge as one of the articles used by painters of his day : it has been conjectured from this that water-colours were employed in ancient art, and the Sponge probably performed a similar office to that which it holds in the hands of a modern artist-washing out lights, \&c.

In modern surgery, the use of the Sponge is great. The flowing blood in operations is absorbed by it; acrid discharges from wounds and ulcers are thus imbibed; and dangerous hemorrhages are checked and sometimes arrested by its application. The sponge-tent, formerly much used for dilating sinuses and small openings, was made by dipping the sponge into melted wax, and then compressing it until it became cool, between iron plates.*

The quality of bibacity in which the value of Sponge chiefly consists, is owing to the multitude of minute channels with which its whole substance is perforated, and is dependent on the law of capillary attraction. By this law fluids ascend, in tubes of small diameter, to a height which increases in proportion to their tenuity, as any one may observe who will plunge the end of a fine glass tube into water. It is not requisite that the tubular form should be perfect or uninterrupted; the interspace between two closely approximated fibres will serve as a capillary tube; and thus the sponge-fibres present a series of canals, through which any fluid, with which a portion of the surface is in contact, will continue to flow until the whole are filled.

A very different process is this spontaneous imbibition of water by capillary attraction from that already de- 
scribed, by which a constant stream enters at the pores, and passes out at the oscula. The one is a mechanical, the other a vital operation. The latter is performed only during life and health, and contributes to the nourishment of the animal; the former goes on after death, and is of no benefit to the Sponge, though very useful to its possessor. The one may be compared to that indiscriminate devouring of books, which we sometimes see in great readers-a voracity insatiable indeed, but which leaves the mind as empty as it was before; the other to that guarded selective reading which ever watches to extract mental food, separating and rejecting by a secret, but potent alchemy, the useless and the bad. Or we may compare the one to a soul dead in trespasses and sins, incapable (because destitute of spiritual perceptions) of distinguishing truth from error, and therefore carried about by every wind of doctrine of those who lie in wait to deceive,-the tools of Satan and his agents, whose purposes they are unconsciously serving. The other may be likened to a living soul, who brings everything to the touchstone of the Word, proving all things, and holding fast only that which is good, by which he is nourished and edified, his spiritual life is developed, and he grows in knowledge, in service, and in grace.

Perhaps we may carry this parallel further. The eclectic process in the Sponges is not so simple a thing as might be supposed. From the common water, which bathes all alike, various and dissimilar substances are separated, selected, and appropriated by different species. "For example, it is very common to find growing on the same rock, or seaweed, a siliceous, a calcareous, and a horny 
sponge; they have all the same exposure, and are all recipients of the same nutriment, yet does each act upon this differently. One extracts from the fluid silica, which it causes to assume a solid crystalline form; another selects in the same manner the calcareous particles, which, obedient to the laws of life, assume figures novel to them in their mineral state; and again, another rejects both the lime and the flint as injurious to its constitution." *

So, when the minister of the Word, " a Scribe instructed unto the kingdom of heaven, bringeth forth out of his treasury things new and old," souls of varying powers, circumstances, and necessities, receive the same truths; and the Spirit of life in their heart, ministering to every one severally as $\mathrm{He}$ will, admonishes one, stimulates another, guides a third, comforts a fourth; and thus the Word is found "profitable for doctrine, for reproof, for correction, and for instruction in righteousness."

The manner in which the Sponges increase their race is highly curious, and affords a beautiful example of the care which the All-wise God has exercised over His lowest creatures. According to Professor Grant, there are found at certain seasons of the year, within the channels of a living Sponge, innumerable yellow granules, imbedded in the gelatinous flesh. These gradually increase in size, and project more and more into the channels, until at length one by one becomes freed, and is immediately hurried along to the nearest outlet by the constant ex-current. On examination, it is now seen to be a little oval gemmule,

* Johnston : Brit. Sponges, 16.

$\dagger$ Edin. Phil. Journal, xiii. 
which one might call an egg, but that it possesses the faculty of spontaneous motion. The larger extremity is covered with excessively minute cilia, by the waving motion of which, as by innumerable oars, it is rowed along through the water, exactly like one of those Infusoria which we described in a former chapter, and for which it might readily be mistaken. It does not, therefore, fall to the bottom of the sea as soon as the ejective impulse of the parental current is exhausted, but continues to shoot along, until, exerting apparently a power of choice, it meets with a suitable locality for its settlement. Here it lodges, spreads out an adhesive film of gelatinous matter, absorbs its now useless cilia, becomes stationary, grows by increase of its circumference, and soon develops all the structure, and exercises the functions, that characterised its parent.

"It is curious," observes Professor Jones, "to observe the remarkable exception which Sponges exhibit to the usual phenomena witnessed in the reproduction of animals, the object of which is evident, as the result is admirable. The parent Sponge, deprived of all power of movement, would obviously be incapable of dispersing to a distance the numerous progeny which it furnishes. They must inevitably have accumulated in the immediate vicinity of their place of birth, without the possibility of their distribution to other localities. The seeds of vegetables, sometimes winged and plumed for the purpose, are blown about by the winds, or transported by various agencies to distant places; but in the present instance, the still waters in which Sponges grow would not have served to transport their progeny elsewhere ; and germs, so soft and 
delicate, could hardly be removed by other creatures. Instead, therefore, of being helpless at their birth, the young Sponges can, by means of their cilia, row themselves about at pleasure, and enjoy for a period powers of locomotion denied to their adult state." *

* Outline of Anim. Kingd. 17. 


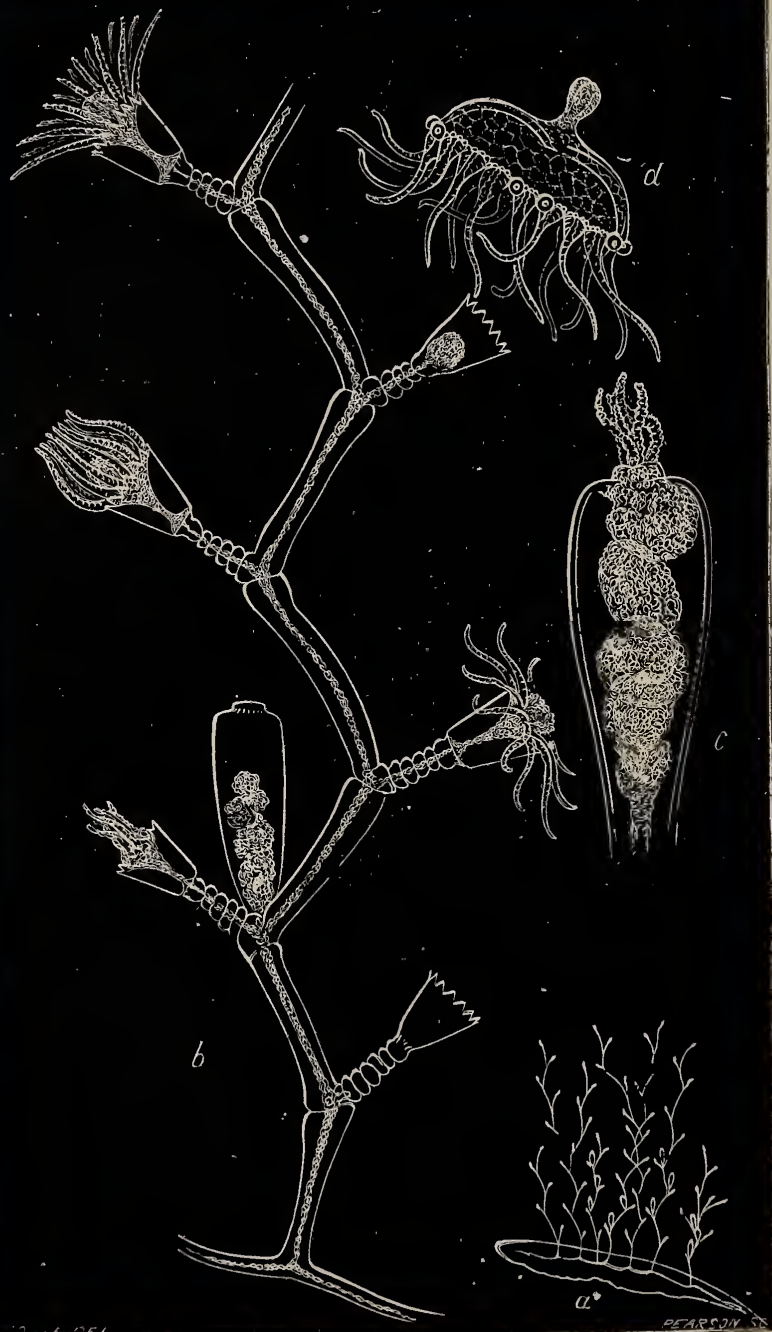

Polypifera. 
POLYPES.

\section{CHAP'TER V. \\ Polypifera (Polypes).}

\section{Continued.}

If any of our wonder-loving readers will put a small phial into his pocket, and stroll through some hedge-rowed lane or quiet field at the sweetest season of the year, he may find food for meditation in the results of his walk. Let him direct his steps to the side of the first ditch or pool in which the water is not fetid, where the surface is already mantled over with the verdant duck-weed, and where many aquatic plants, springing from the bottom, wave their leaves in the limpid element. Stooping down on the brink, let him lift with his fingers a little of the coating of duck-weed, disturbing the water as slightly as possible, and then, peeping through the opening he has made, examine slowly and carefully the bottom thus revealed. On the mud he will probably see a good many round knobs of jelly, from the size of a turnip-seed to that of a pea, of a transparent green hue, and others of the same kind adhering to the stalks and under surfaces of the leaves of the aquatic plants :-let him select a few of 
these, place them, with some clear water and a fragment of some plant, in his phial, and hasten home. He will have obtained a creature which, about a century ago, electrified the scientific world, and opered up a new and most marvellous chapter in the history of Life. It is the Fresh-water Polype (Hydra viridis).

The invention of the microscope had given an immense

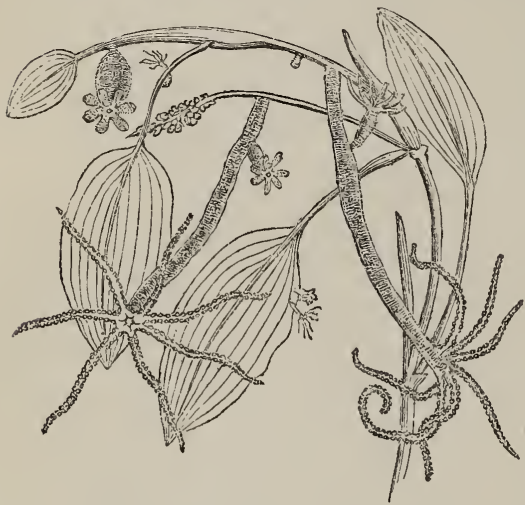

Hydra viridis-(nat. size magnified.) impetus to natural science; and a galaxy of illustrious men had by its means been announcing wondrous facts, the records of which fill the pages of the Philosophical Transactions of our own Royal Society, as well as many works of great merit specially devoted to microscopy. But yet, when, in 1744, Abraham Trembley of Geneva declared what he had seen of this little fresh-water animal, this living ball of green jelly, it was regarded as a thing incredible, and even impossible. The facts "were so contrary to all former experience, and so repugnant to every established notion of animal life, that the scientific world were amazed; and while the more cautious among naturalists set themselves to verify what it was difficult to believe, there were many who looked upon the alleged facts as impossible fancies. The discoveries of Trembley were, however, speedily con- 
firmed; and we are now so familiar with the outlines of the history of the fresh-water polype, and its marvellous reproductive powers, that we can scarcely appreciate the vividness of the sensation felt when it was all novel and strange: when the leading men of our learned societies were daily experimenting on these poor worms, and transmitting them to one another from distant countries, by careful posts, and as most precious gifts ; and when even ambassadors interested themselves in sending early intelligence of the engrossing theme to their respective courts." *

Let us try to see what Trembley saw. Put the phial in a window, and allow it to remain untouched a while. The balls of jelly have all attached themselves, some to the glass sides, some to the plant, but they are balls no longer. Each is a thread of some half-inch in length, and about as thick as small twine, adhering by one extremity; while from the other radiate, like a star, six slender threads, which are waved irregularly through the water, thrown into spiral coils or various contortions, elongated, contracted, elongated again, slowly or suddenly, and in different degrees. Two or three minute water-insects are swimming giddily about; one of them, as he shoots unconsciously by, just touches one of these slender threads. In an instant the playful course is arrested; the little thing strives to pursue his way, drags the flexible cord that holds him hither and thither; redoubles his efforts, pulls away and stretches it till we think it must break and free him. No! like a skilful angler, the Jelly is but wearying his victim : suddenly the thread is thrown into corkscrew coils, 
and the helpless insect is dragged in; another thread is brought to bear upon it, and another. Poor thing! "actum de eo est," it is all up with him! He is dragged helplessly to the base of the radiating threads, and there, in the midst of their circle, an aperture is gaping, which stretches wider and wider, while the prey is slowly sucked in, until it is quite engulphed within the gelatinous body. But, for some time before this, the prey had become quite motionless ; its struggles, though violent at first, had soon entirely ceased, and it was evident that a fatal effect had been produced by the mere contact of those slender threads.

What is the nature of this subtle venom that resides in a creature apparently so low in the scale of being, so simple in structure, and almost homogeneous in substance? Worms, and the larvæ of insects, that may be wounded, and even chopped into pieces, and yet survive for hours, die suddenly from a touch of these gelatinous threads! "I have sometimes," says Baker, "forced a worm from a polype the instant it has been seized, at the expense of breaking off the polype's arms, and have always observed it to die very soon afterwards, without one single instance of recovery." On the other hand, the tiny water-fleas, and other minute Crustacea, frequently escape with impunity even from the very mouth of the polype ; for they are enclosed in a horny shell, which evidently protects their vital parts from the morbific touch.

The microscope throws light on the question, and reveals a most elaborate system of offensive weapons with which these soft and sluggish creatures are provided.

* History of the Polype, 33. 
According to Corda, each tentacle forms a slender membranaceous tube, filled with an albuminous substance nearly fluid, mingled with some oily particles. This substance, at certain definite points, swells out into tubercles or dense warts, which run round the tentacle in a spiral line. Each wart is furnished with several spinebearing vesicles, which are organs of touch, and with an organ of highly curious structure, which is the weapon of offence.

The organ of touch consists of a fine sac, enclosing another with thicker walls, within which there is a small cavity. From the upper extremity, where the inner and the outer sacs are in contact, there projects a long cilium, or fine pointed bristle, which is not retractile, and appears to be immoveable.

The weapon of offence is placed in the midst of these spines, in the centre of each wart. It consists of an oval transparent sac, imbedded in the substance of the wart, with its perforated extremity exactly at the surface. At the bottom of the interior of the sac there is a body, in shape resembling a saucer, in the centre of which stands a small oval, solid body, bearing on its summit a calcareous dart, pointed at its extremity, and bifid, or sagittate, at its base. This dart can be projected at the will of the animal, and again withdrawn into the sac. When the prehensile instinct is exerted, the darts are thrust out with force, and, entering the tissues of the prey, retain it: while at the same time, in all probability, a subtle but potent poison is injected, the effects of which we have already alluded to.

But this is a modern discovery. The circumstance in 
the economy of these animals which appeared so anomalous, was the mode in which they were both naturally and artificially multiplied. They were manifestly animals, yet it was found that they could be propagated by slips or cuttings, like plants! In the warm weather of summer each polype is observed to shoot forth, from various parts of its body, little warts, or knobs, which increase rapidly, until in a few days they assume the form of the parent animal, each one being furnished with a circle of tentacles, though still attached at its lower end. The young one, which up to this period had received its nutriment from the parent's stomach, from which a channel had communicated with its own, now catches prey with its own tentacles, the duct closes, the connexion of the base with the mother becomes more slender, and at length the little animal falls off, and commences independent life. Such is the ordinary mode of increase-generation by gemmation.

In autumn, the Hydra propagates by means of eggs, which are deposited around the parent; the basal portion of her body being spread over them, and becoming a horny protecting skin. She immediately dies, and the eggs are hatched in the ensuing spring.*

But these strange animals may be artificially increased at pleasure, and that by means which, to higher animals, would inevitably destroy, instead of multiplying life. If the head of a polype, with all its tentacles, be cut off from the trunk with scissors, it will presently develop a new trunk and base, while the headless trunk begins to shoot out new tentacles; and thus, in a little time, two perfect

* Laurent, L'Institut, No. $\leq 65$. 
animals are formed. If one of these be cut into three, four, or half-a-dozen pieces, each piece supplies the wanting parts, and so many animals are made, all as perfect and active, and endowed with the same functions, as the first. Nor does it signify in what direction the mutilation is made; a longitudinal, a diagonal, or a transverse division is equally successful ; nay, even a small portion of the skin soon grows into a polype.

It was from this power of perpetual reproduction, that this singular animal received the name of Hydra, by which it is known among naturalists; as if it realised the ancient monster of fabulous story, whose heads sprouted anew as fast as they were cut off by Hercules.

Most curious monstrosities were produced by the experiments of philosophers on these animals, especially by partial separations. If a polype be slit from the summit to the middle, one will be formed having two heads, each of which will capture and swallow food. If these again be slit half-a-dozen times, as many heads will be formed surmounting the same body. If now all these be cut off, as many new ones will spring up in their place, while each of the severed heads becomes a new polype, capable of being, in its turn, varied and multiplied ad infinitum;so that in every respect our little reality exceeds its fabulous namesake.

The polypes may be grafted together. If cut-off pieces be placed in contact, and pushed together with a gentle force, they will unite and form a single one. The head of one may be thus planted on the trunk of another.

Another method of uniting them, perhaps still more wonderful, is by introducing one within the other; the 
operator forced the body of the one into the mouth of the other, pushing it down so that the heads were brought together. After forcibly keeping it for some time in this state, the two individuals at length united, and a polype was formed, distinguishable only by having twice the usuai number of tentacles.

There is one species which can actually be turned inside out like a glove, and yet perform all the functions of life as before, though that which was the coat of the stomach is now the skin of the body, and vice versâ. If it should chance that a polype so turned had young in the act of budding, these are, of course, now within the stomach. If they have arrived at a certain degree of maturity, they extend themselves towards the mouth of the parent, that they may thus escape when separated. But those which are less advanced turn themselves spontaneously inside out, and thus place themselves again on the exterior of the parent.

A multitude of other viriations, combinations, and monstrosities, have been, as it were, created by the ingenvity of philosophers; but these are sufficient to give a notion of the extraordinary nature of these animals, and to account for the wonder with which they were regarded.

The Hydra was, until lately, considered as an animal of very simple structure, being composed of mere gianules of jelly, set in a glairy, enveloping fluid. But the further we push our researches, the more are we disposed to hesitate in pronouncing on the comparative simplicity or complexity of any organism. We have already seen the elaborate array of weapons in the tentacles. M. 
Gervais has shewn that the component granules of the body are of diverse forms, and, in all probability, sustain different relations to the general economy. The whole body consists of a sac, with thin dilatable walls, enclosing a capacious cavity, which forms the stomach : the granules which border this cavity are conical papillæ projecting into the stomach, and are supposed to have a digestive function; the exterior series are lengthened, and constitute an integument, while some of the intermediate ones are arranged in bands, which are, with little doubt, presumed to be muscular. The muscular bands in the tentacles are still more distinct, running in four series, which pass diagonally to and fro from side to side, forming lozenge-shaped spaces by mutual intersection. 


\section{CHAPTER VI. \\ Polypitera (Polypes). \\ Continued.}

LET us suppose that the buds continually put forth from the sides of the Hydra, instead of falling off to commence a new and isolated existence, remained permanently attached to the parent stock, giving forth in their turn buds, becoming permanent branches. We should then have the essential form of a Compound Polype; such, for example, as that of the great marine family, Sertulariadce. Here we find the germ first developing a single Hydra-like polype, consisting of a slender stem or body of granular flesh, enclosing a stomachal cavity, the orifice of which is surrounded by a circle of sensitive tentacles. Soon, however, a lateral bud projects, which shoots upward and develops a similar head of tentacles, while, from the side of this, another shoot still carries up the rising stem, which assumes a plant-like condition of branching stalks, with many lateral tentacled buds. It is true that in these marine species we commonly find an additional structure, of which'no trace appears in the fresh-water Hydra. The whole compound animal is enclosed in a tube of transparent substance, somewhat flexible though firm, resem. 
bling horn, an exudation from the gelatinous integument; and this tube, at every bud, takes the form of an open cell or cup (varying much in shape according to the species), into the cavity of which each individual polypehead can withdraw itself on alarm, and from the orifice of which it protrudes and expands when seeking prey.

In the accompanying Plate, the figure $a$ represents one of the most regular of these species; and, therefore, one whose construction is peculiarly intelligible. It is a group of the Polype named Laomedea geniculata, very commonly found springing from the broad leathery leaves of the fingered tangle, Laminaria digitata, that great olivebrown sea-weed that waves its huge fronds to and fro just below the level of the lowest spring-tides. The first appearance of the Polype is a slender horny thread that creeps along the surface of the leaf, adhering firmly to its surface. Presently such a tiny budding stem as we have just described springs up from the root-thread, which continues to creep on its way over the leaf, now and then bending its course at an abrupt angle, and sending up fresh stalks at regulir intervals, which at length become a miniature forest. A few such stalks are represented at $a$, of the natural size; and, at fig. $b$, one of these, or at least a portion of one, is shewn as it appears considerably magnified. The horny tube is seen, with its cup-like cells: the body of the Polype, a thread of gelatinous flesh, permeates the stem and the branches, maintaining a common life : at intervals, the polype-heads project in the manner of buds, each occupying its transparent cell, and displaying its crown of tentacles which radiate on every side. The lower cells are commonly empty, the polype-heads having 
died out, successively, as young ones continually shoot forth at the extremities of the branches.

At certain seasons of the year peculiar vesicles appear, which are special organs of reproduction. The analogy to a plant is maintained here also; we have already seen the development of a stem with buds, growing into twigs and branches; here we have the fruit-capsules bearing the germs of another generation.

Sometimes we find these organs few in number, seated here and there in the angle formed by the branches, or by the buds with the stalk. At other times they are very numerous, crowded together on the stalk, projecting in regular succession in the same plane, which forms a right angle to the arrangement of the cells. Each of the capsules or vesicles is a tall, vase-like, transparent body, considerably larger than a cell, but closely resembling it, except that its summit is abruptly narrowed to a short rim like a pitcher. One of these organs is represented in fig. $b$.

The common nutrient flesh permeates the capsule as it does a cell, and develops therein a very peculiar embryo. When somewhat matured, the permeating tube is seen swollen out into separate ovate sacs, ten or more in number, each of which contains several embryos. Those nearest the mouth of the vesicle are first developed, and escape successively by slowly emerging from the pitcherlike rim. Fig. $c$ represents a vesicle much magnified, with its included embryos in various degrees of maturity, and one in the act of escaping. The appearance of the tiny creature when it finds itself at liberty is most surprising and interesting, especially when, from a crowded forest of 
Polypes, the embryos are escaping by thousands. Mr Peach, who first observed them, thus describes the scene he saw. Having, on the 19th of February, placed a specimen of Laomedea dichotoma in a large glass of sea-water, he found, a day or two after, that the water appeared muddy, an appearancecaused by myriads of moving objects, that resembled umbrellas without handles, or very wide and short hand-bells. "I took," says this agreeable observer, "a small quantity of the water, and placed it under the microscope, when thousands of the objects were sporting about in all directions, moving at a rapid rate by the ciliary appendages on their rim. All at once they would withdraw their cilia, and the handle-like appendage on the back, and become a mere speck; and after resting a short time they would again throw out their cilia and appendage, and round they went waltzing with each other. It was perfectly astonishing in this crowded assembly to find that they very seldom came into collision; and if so, how soon matters were again accommodated. They continued active up to the $2 \mathrm{~d}$ of March, when I lost them as if by magic. I fancied they might have been the young of worms; therefore, I took the Laomedea, washed it, took fresh seawater and filtered it through three or four folds of fine linen, and placed the specimen in this : the next morning I had a still more innumerable host of these delightful things. They assume various positions, and when in the water they remind me of thousands of parachutes thrown from a balloon, descending in various states of expansion."

The author of these pages has had an opportunity of confirming and extending the observations of $\mathrm{Mr}$ Peach. It is easy to find the minute, sylph-like creatures, for all 
that is needful is to place in a vessel of sea-water a frond of sea-weed studded with the zoophyte, and in a few hours scores or hundreds will be seen, even with the naked eye, playing and dancing about in the most amusing manner. Fig. $d$ represents the embryo, very highly magnified.

In structure the tiny animal, which, though just born of a stationary zoophyte, is now swimming at will in a sprightly manner through the free water, is evidently a Medusa ; in all essential particulars being the very counterpart of one of those exquisitely delicate animals which Professor Forbes has so beautifully described and portrayed in his "Monograph of the British Naked-eyed Medusæ." It consists of an umbrella-shaped disk of translucent jelly, the diameter of which is about $\frac{1}{60}$ th of an inch. Four vessels cross the disk at right angles, and from the centre of union there springs a fleshy peduncle, with a sort of neck, capable of many varied motions and many alterations of form. The margin of the disk carries twenty-four slender tentacles, exactly corresponding to those of the parent Polype, and essentially to those of the Hydra, being studded with warts, which analogy pronounces to be aggregations of barb-bearing capsules, instruments for arresting and killing prey. At the bases of the tentacles, arranged at certain definite points on the margin of the disk, are placed eight beautiful organs, which are doubtless the seats of a special sense. Each of these organs consists of a transparent globe, not enveloped in the substance of the disk, but so free as to appear barely in contact with it. In its interior is borne a smaller globule or lens, of high refractive power, placed a little towards the outer side. Almost every one, on first beholding these organs, would unhesi- 
tatingly pronounce them eyes, and so they are considered by some eminent physiologists. Others, however, consider them to bear a closer analogy to our organs of hearing, the crystalline globule (or otolithe) being, as it is stated, capable of vibration within its vesicle. Whatever they be, the same organs are found, in the same form, in that class of animals just alluded to, the Jelly-fishes or Medusæ.

The disk is endowed with an energetic power of contraction, by which the margin is diminished, exactly like that of a Medusa in swimming; and the tentacles have also the power of individual motion, though in general this is languid, their rapid flapping being the effect of the contraction and expansion of the disk just mentioned, producing a quick involution and evolution of the margin, and carrying the tentacles with it. Occasionally, however, all the tentacles are strongly brought together at their tips, with a twitching, grasping action, like that of fingers, which is certainly independent of the disk.

The phenomena, of which an example has been given in this paper, have almost as greatly startled the philosophers of our age, as those connected with the reproduction of the Hydra astonished our ancestors a century ago. As in the former case, they were disbelieved, denied, ridiculed, confirmed, believed, wondered at, and at length have found a place among the recognised laws of organic life, as the Law of the Alternation of Generations. When we come to speak of the Medusæ as a class, we shall have occasion to revert to the topic again; for the present we may state, that the order described is found to prevail among many species and genera of the marine Polypes. 
That order is briefly as follows:-The Polype, a fixed and rooted animal, increases its own individual life for a while by putting forth a succession of budding heads, but at a certain period gives birth to a number of beings that bear no resemblance to itself in form or habit, but are, to all ntents and purposes, free swimming Medusæ. Each of these, after pursuing its giddy course for a time, produces a number of eggs, which change into active animals having the closest resemblance to Infusoria. Each of these latter presently becomes stationary, and affixed to some foreign body, along which it creeps, as a root-thread, shooting up tubular and celled Polypes, as described in the early part of this chapter.

It is evident that this is a very different thing from the metamorphosis which takes place in Insects and Crustacea, where it is but one individual passing through a succession of forms, by casting off a succession of garments that concealed, and, as it were, masked the ultimate form. The butterfly is actually contained within the caterpillar, and can be demonstrated there by a skilful anatomist. In this case, however, there are distinct births, producing in a definite order beings of two forms, the one never producing its image directly, but only with the interposition of a generation widely diverse from it. Hence, to use the striking though homely illustration of one of the first propounders of this law, any one individual is not at all like its mother or its daughter, but exactly resembles its grandmother or its granddaughter. 
POLYPES.

\section{CHAPTER VII.}

\section{Polypifera (Polypes).}

\section{Continued.}

WHо is there, among the thousands that throng from our cities and towns to breathe the air of the coast and to gaze out on the boundless sea, that is not familiar with the Sea-Anemones? And who is not eloquent in their praise? Who has not admired the starry flowers, all instinct with life and sensation, that spread their beauteous petals beneath the crystal water?-the Anthea, with its snaky locks of satiny green, tipped with pink; the Thick-horned Bunodes in the dark tide-pool, sheltered beneath overarching tufts of crimson and purple weeds, as if, like the modest violet, it would hide its charms, those pellucid ccnes of crimson and white, set in gorgeous array, of which it needs not to be ashamed; the Daisy Sagartia, expanding its broad and flat circular disk, soberly hued and margined with an elegant fringe, over the edges of some narrow fissure in the leprous rock? Who has not felt somewhat of a naturalist's enthusiasm at seeing the sea-worn stones studded with the plump, glossy, fruit-like, Smooth Anemones (Actinia), their array of tentacles carefully packed away within the body, waiting the return of 
the tide which has left them dry, and each one contracted into a hemispherical button of tremulous flesh, varying exceedingly in colour,-brown, chocolate, dark red, purple, crimson, pink, flesh-colour, green, olive, and not unfrequently, especially in the overgrown specimens, specked all over with light green on a dark red ground? Yes; our readers are doubtless familiar with these attractive creatures, and are prepared to hear with interest some of the details of their curious structure and economy.

In order to understand the subject more perfectly, it would be desirable to study the Sea-Anemones at home and at leisure. Nothing is more easily accomplished. Carry down to the rocky margin of the sea, at low tide, a wide-mouthed phial, and select your specimen. It adheres firmly to the stone by a broad fleshy base, but the attachment is one of adhesion merely; there is no organic connexion between the animal and its support. You will find no difficulty in detaching it, if you proceed gently and with care, working the back of your finger-nail, or (if you like it better) a thin slip of wond, under the circumference of the fleshy base, and gradually proceeding onward. When you have succeeded in getting it off, drop it into your phial, which you may partly fill with sea-water, and carry home.

A nice little aquarium may now be improvised for its accommodation. A washing-basin, or a soup-tureen, will answer admirably; or a delft foot-bath, or a milk-dish, or a brown earthen pan. Whatever vessel you choose, put a few pieces of rock on the bottom, half-fill it with clear sea-water, and place in it a few (only a few) living seaweeds. If you mean to establish an aquarium of consider- 
able duration, your sea-weeds must be procured with their root-bases uninjured, the fragments of rock on which they grow being knocked off by the help of a hammer and chisel; but for a shorter period-a week or two, for example-it will suffice to pluck up the living sea-weed with the fingers, securing as much of the base as possible. The bright-green weeds are the best.

In a wash-basin of moderate size, a dozen Sea-Anemones may be accommodated comfortably, and will flourish and display their beauties and their instincts for an indefinite period, without any further care, if the vessel be so placed that the sun's light may every day fall on it, yet not so exposed as to become tepid. The water, maintaining its purity and its clearness, will not need to be changed ; and a scene of charming interest will be constantly presented.

The animals will soon begin to re-attach themselves by their broad basal disks to the pieces of rock, or to the sides of the vessel, and after a few hours will have made themselves at home in their new habitation. Some of them will be contented to abide week after week where they first chanced to settle; others, more restless, will manifest a travelling propensity, shifting their position from one part of the stone to another, or from rock to rock, or crawling slowly along the sides of their prison. It is true the motion is not appreciable to the eye, being about as tardy as that of the hour-hand of a watch; still it is not uncommon for an Actinia to accomplish a march of three or four inches in the course of a night. It is effected by a gliding of the muscular base along the surface, much like the crawling of a snail.

A Sea-Anemone, or Actinia, is essentially a Hydra, 
being a cylindrical column of flesh, with the free or upper extremity truncate, and surrounded by one or more circular series of tentacles. The interior is hollowed to form a stomach, which is closed inferiorly, and opens superiorly by a slit in the disk. This orifice is margined by two muscular lips, excessively extensile, dilatable, and variable in form. The space between the stomach and the outer walls of the body is occupied by a number of perpendicular septa, or partitions of membrane, which are set in a radiating manner, dividing the whole into chambers. In these chambers are situated the ovaries, in the form of frilled bands, much convoluted and covered with cilia, the germs of which are developed in the interseptal chambers, and find their way out through a duct which opens at one of the angles of the mouth. It is a pleasing sight, and one by no means uncommon, to see five, ten, or twenty young, of various sizes, but perfect in form, expelled from the duct, and dispersed around, where they soon attach themselves and constitute a colony around their parent.

While in the body of their mother, they occasionally find their way into the tentacles, as these organs are hollow, and communicate with the interseptal chambers. Sir John Dalyell, who had paid great attention to these animals, thought that this was their normal position. "The embryos," he says, "appear first in the tentacula, from whence they can be withdrawn and transmitted to others by the parent, and are at last produced by the mouth. In the course of six years a specimen preserved by the author produced above two hundred and seventysix young; some pale and like mere specks, with only 
eight tentacula; others florid, and with twenty. They are frequently disgorged along with the half-digested food, thirty-eight appearing thus at a single litter. An embryo extracted artificially from the amputated tip of a tentaculum began to breed in fourteen months, and survived nearly five years. Monstrosities by excess are not uncommon among the young, one produced naturally consisting of two perfect bodies; and their parts, sustained by a single base, exhibited embryos in the tentacula at ten months, bred in twelve, and lived above five years. While one body was gorged with food, the other continued ravenous." *

It is interesting to see the Actinice fed; and as they are very voracious, they are rarely unwilling to gratify their benefactors with a display of their swallowing powers. Their natural prey consists of the smaller Mollusca, Annelida, Star-fishes, Crustacea, and, in short, of any animals which they are able to seize and to retain. The tentacles have the same prehensile power as those of the Hydra,-a power which depends on the presence of projectile barbed weapons, ordinarly coiled in elastic cells. These organs are found in inconceivable multitudes imbedded in the tissues of the tentacles, of the lips, of the stomach, of the frilled ovarian bands, and especially, in some species, in long threads which are protruded from pores in the integument of the body.

The structure of these weapons is as follows :-Each consists of an oval or elliptical sac of transparent membrane, within which is seen a thread coiled up, and in some instances an oblong or lozenge-shaped chamber. At the

* Rep. Br. Assoc. 1834; and Edin. New Phil. Journ. xvii. 
pleasure of the animal, or under the stimulus of pressure, the thread is shot forth from one end of the cell with great force, until it extends to a length from twice to fifty times that of the cell. When fully extended, it is seen that the thread is but a continuation of the cell itself ; that when it was dormant, it was turned in ; and that in the process of expulsion, every part of its length has actually been turned inside out, like the finger of a glove. Sometimes the thread appears simple, but in those cases in which a chamber appeared within the cell, it is furnished with an armature of barbed threads, which after expulsion project from the sides of the thread in various directions. The propulsion of the thread is sufficiently forcible to enable it to enter the tissues of other animals, and the barbed structure enables the weapon to retain its hold in the flesh, which facts warrant the presumption that a highly poisonous fluid is at the same time injected, capable of arresting and destroying animal life. Some of the forms of these organs are represented in the accompanying figures.

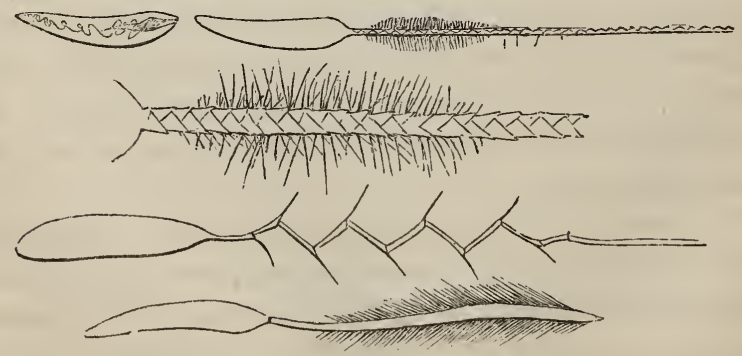

In captivity, the process of taking food may be witnessed 
by presenting to the Sea-Anemone any small shellfish or an atom of raw meat. When a tentacle comes into contact with it, it contracts forcibly, and the prey is thus dragged upon the oral disk, the surrounding tentacles arching over it. The lips instantly begin to protrude, stretching out towards the morsel, which they presently embrace, and gradually enclose, extending their volume, until they close over it, sucking it in as it were, and forcing it to disappear within the body. Digestion now takes place; and in the course of the next twenty-four hours the remains, such as the shell of the mollusk, or the hard parts of a little crab, are disgorged through the mouth, enveloped in a tenacious, slimy mucus.

Though commonly the prey of the Actiniæ is small, it is not always so; the voracious creature occasionally mastering and swallowing a victim even much larger than itself, strange as such a proposition may sound. Dr Johnston has recorded from his own experience an example of this. "I had once brought me," he observes, "a specimen of Actinia crassicornis, that might have been originally two inches in diameter, and that had somehow contrived to swallow a valve of the great scallop (Pecten maximus), of the size of an ordinary saucer. The shell, fixed within the stomach, was so placed as to divide it completely into two halves, so that the body, stretched tensely over, had become thin and flattened like a pancake. All communication between the inferior portion of the stomach and the mouth was of course prevented, yet, instead of emaciating and dying of an atrophy, the animal had availed itself of what undoubtedly had been a very untoward accident, to increase its enjoyments and its 
chance of double fare. A new mouth, furnished with two rows of numerous tentacula, was opened up on what had been the base, and led to the under stomach : the individual had, indeed, become a sort of Siamese twin, but with greater intimacy and extent in its unions!"*

What may be the duration of life in these low forms of existence we know not, but recorded facts seem to warrant the belief that it is considerable. Sir John Dalyell stated in 1845 , that one was then in vigorous health which had lived in his possession for a period of seventeen years.t They appear subject to few vicissitudes, and to enjoy a more than usual immunity from the attacks of other animals.

The reproductive energy is no less vigorous in these animals than in the Hydra; and similar experiments to those already described have been instituted on these with similar results. They have been variously maimed and cut into pieces, the fragments reproducing the parts lacking, and rapidly assuming a complete and normal condition.

We have at least fifty species of Sea-Anemones, including the allied genera, on the British coasts ; and it is probable that they are even much more numerous than this, as new discoveries are constantly rewarding the close examination of any particular locality. Among them are two or three representatives of a form which is far more abundant in the tropical seas, where they have acquired renown above their fellows as "master-builders." The

* Brit. Zoophytes, i. 235.

+ We were informed, but a few days ago, that this notable individual still (September 1856) survives. From its appearance Sir John Dalyell considered that it was about seven years old when he procured it; it must now, therefore, have attained the age of thirty-five years. 
structures of the Coral-worms very far excel the mightiest edifices of man. What was the impious project of Babel, what are the Pyramids of Egypt, compared with the coral reef of Australia-a barrier which extends almost without an interruption for a thousand miles !

The notion that the coral-rock was commenced in the fathomless depths of the ocean, and gradually reared to the surface, has been exploded by the discovery of Darwin, that the Coral-polypes cannot exist at a greater depth than some twenty or thirty fathoms. Our limited space will not permit us to do more than allude to his beautiful and ingenious theory, by which all the phenomena of coral formations are explained. It seems certain that every such structure must have been commenced on the inorganic rock; and the slow subsidence of these in many instances has produced the various forms of atolls, or ringislets enclosing lagoons, of barriers, and of fringing reefs.

Most intelligent persons are acquainted with the more comrnon forms of Madrepores or Corals. Whether existing in massive, ramified, or laminated structures, they commonly consist of a light porous stone, studded with shallow pits, in which are seen thin perpendicular plates radiating towards a centre. Sometimes instead of pits and a radiating arrangement, the plates are set in rows in an involved and sinuated pattern. Now, during life, from amidst these plates rises up a gelatinous tissue bearing a mouth with protrusile lips, and an array of sensitive tentacles, all of which on alarm are cortracted so as to disappear completely in the stony recesses, leaving nothing apparent but the white and apparently naked plates. Really, however, they are not naked, but are still invested with a 
film of gelatinous flesh, so tightly stretched as to be reduced to an invisible tenuity.

In these massive or arborescent Corals, each single pit must be considered as the babitation of a single animal ; and the whole body bears the same relation to the little simple Madrepores of the European seas, as the compound Laomedea, with its numerous branches and cells, bears to the solitary Hydra. The elegant Coral that studs the rocks of Devonshire and Cornwall (Cyathina Smithii) is an instructive example of the simple species. It consists of a stony cylinder or inverted cone, the summit of which, hollowed into a shallow cup, is formed by the edges of thin plates that radiate towards the centre. While in its native element, a pellucid gelatinous flesh emerges from between the plates, sometimes rising to the leight of an inch above their level; exquisitely formed and coloured tentacles fringe the sides of the cup-shaped cavity, across which stretches the oral disk, marked with a star of some rich and brilliant colour surrounding the central mouth, -a slit with white crenated lips, like the orifice of one of those elegant cowry-shells that we put upon our mantelpieces.

In this condition the affinity between a Madrepore and an Actinia is seen to be very close. Indeed, if we imagine calcareous particles to be deposited on the surfaces of the radiating membranous partitions of the latter, we should have the stony plates, and the Actinia would be in every essential point turned into a Coral. The habits and economy of the two forms coincide exactly, except that the Madrepore is permanently attached to the rock by the adhesion of its stony skeleton, while the attach- 
ment of the Actinia, as we have already observed, is voluntary.

What a storehouse of life is the vast ocean! what a prodigious Alma Mater! What varied forms of being are borne in her prolific womb, and nourished on her expansive bosom! "This great and wide sea! wherein are things creeping innumerable, both small and great beasts." -(Ps. civ. 25.) 


\section{CHAPTER VIII.}

\section{ACALEPHA (Sea-blubbers).}

Is walking through the crowded thoroughfares of London on a clear winter's evening, we have often admired the beauty of the lamps that illuminate the shops and cast such a flood of radiance on the thronged streets. The elegant forms of the glass shades, the beauty of the material of which they are composed, and the various degrees of translucency which they are made to assume by the roughness or polish of their surface, in particular, have often attracted our attention; and we have been interested by tracing their very obvious resemblance to certain living creatures that swim in the vast deep,-creatures which the poet describes as

"Figured by hand Divine; there's not a gem

Wrought by man's art to be compared to them;

Soft, brilliant, tender, through the wave they glow,

And make the moonbeam brighter where they flow." *

We refer of course to the Medusce. The forms given to our lamp-shades,_spherical, hemispherical, umbrellalike, saucer-like, spheroids either oblate or prolate, and 
others which no single or compound term can express, are the very counterparts of those of the sea-blubbers, They, too, look as if they were blown in glass ; the perfect transparency of some, and the dimly pellucid, and as it were granulated, texture of others, accurately represents the polished or ground condition of that substance; while in some species (as in the genus Aquorea, for example) we find both conditions, arranged in alternate longitudinal bands, exactly as we have seen stripes of clear and ground glass in some lamps at the west end. And further, as we occasionally see these shades made of stained glass, and arrayed in colours whose brilliancy is heightened by the translucency of the material; so, while most of the animals of which we speak are devoid of positive colour, there are a few which add a gay hue to a hyaline clearness.

Among the forms which find their true affinities among the Sea-Anemones, there is a genus named Lucernaria, which departs very considerably from the ordinary appearance of its fellows. It is a gelatinous animal, of the shape of a vase, cup, or trumpet, affixed to the stems of sea-weeds by a narrow foot, but so slightly as to be detached on the least disturbance. The margin of the cup bears at certain symmetrical points clusters of slender tentacles, and a little mobile protrusile proboscis stands up in the bottom of the vase-like cavity. All these particulars indicate this delicate animal as the connecting link between the Actiniæe and the Medusæ.

The most ordinary form assumed by a Medusa is that of au umbrella or a mushroom, of greater or less thickness, composed of a tender jelly of so little consistence that 
almost the whole may be resolved into simple water, or a fluid which no chemical analysis has been able to distinguish from sea-water. A large sea-blubber weighing fifty ounces is cast upon the beach, and after lying exposed to a day's hot sun, all that remains is a subtile and impalpable film spread over the sand where it lay, which, if carefully collected, will not weigh five grains. The texture appears to be a collection of cells formed of the most attenuated membrane and filled with seawater.

Yet out of these simple elements, according to the researches of Professor Agassiz, the muscular, the vascular, the nervous, and other tissues are composed; various organs, some of them sufficiently complex, are formed; and different functions are originated. By a periodical succession of alternate expansions and contractions, the apparently helpless animal contrives to pump itself along through the waves with force and precision; by the elastic threads which lie coiled up in innumerable capsules, ready to be darted into the flesh of its intended prey, it can instantly arrest, benumb, and paralyse the lithe worm and the arrowy fish; by the contractility of its fimbriated membranes it can drag the prey to its protrusile mouth, in which it is speedily engulphed, and almost as speedily digested. Feeble and inert as they appear, some of these animals are truly to be dreaded for their power of stinging, whence the whole class have derived their appellation of Acalephce, or nettles. "Among them," says Professor Edward Forbes, "Cyancea capillata of our seas is a most formidable creature, and the terror of tender-skinned bathers. With its broad, tawny, fes- 
tooned, and scalloped disk, often a full foot or even more across, it flaps its way through the yielding waters, and drags after it a long train of riband-like arms and seemingly interminable tails, marking its course when the body is far away from us. Once tangled in its trailing ' hair,' the unfortunate who has recklessly ventured across the graceful monster's path, too soon writhes in prickly torture. Every struggle but binds the poisonous threads more firmly round his body, and then there is no escape; for when the winder of the fatal net finds his course impeded by the terrified human wrestling in its coils, he, seeking no combat with the mightier biped, casts loose his envenomed arms and swims away. The amputated weapons, severed from their parent body, vent vengeance on the cause of their destruction, and sting as fiercely as if their original proprietor itself gave the word of attack." *

This remarkable property, there can be no doubt, resides in the barbed threads, which are projected with amazing force from elastic capsules, and which are, in all probability, connected with a reservoir of the most subtile poison. They are accumulated in vast numbers in the tentacles, in the fimbriated furbelows, and in the edges of the lips, and probably in other parts. It is an astonishing sight to witness the propulsion of myriads of these javelins, crossing and recrossing their mutual courses, and rapidly turning themselves inside out, for, as we have before stated, the projection of each thread is an actual evolution of its whole length.

Another property common to the Sea-blubbers, though not constant in all the species, is that of emitting phos-

* Brit. Naked-eyed Medusæ, p. 10. 
phorescent light. Thaumantias pilosella, occasionally so abundant on our western shores, is a hemisphere of

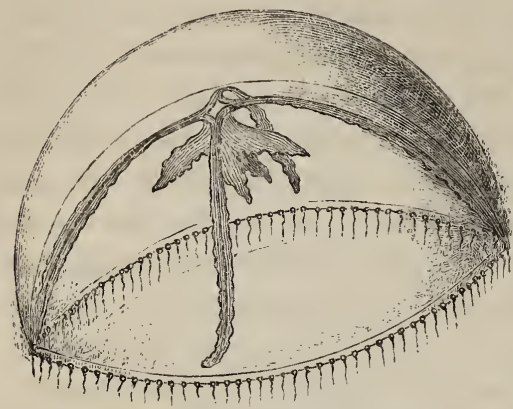

Thaumantias pilosella-(magnified.) hyaline jelly, as large as a shilling, the edge of which is studded with black or rather dark purple eyespecks. If we irritate one of these creatures in the dark, by touching it with a stick, for instance, instantly a circle of bright tiny lamps is lighted up, every eye-speck becoming a spark, like a coronet of glittering diamonds, or like a circular figure of gas-jets, lighted at a public illumination, and seen from a distance; more especially as some of the constituent sparks appear to go out and revive again, just as do the gas-flames if the night be windy. And the beautiful Equorea Forbesiana, a flat species resembling in form and size a cake or bun, on being disturbed gives out its light in a marginal ring, which suddenly becomes vividly luminous, like those circles of glory with which the Italian painters delight to crown their saints and sacred personages.

But these examples yield to some of those that swim at large in the boundless ocean; where the mariner, in his lonely watch, occasionally sees, far below the keel of his ship, what look like swimming globes of fire, or cannonballs heated to incandescence : these are believed to be some globose species of Medusæ of large dimensions. 
In size, the tribe before us extends through a wide range, from that lovely little gem, the Turris neglecia, that looks like a bead of red coral no larger than a hemp-seed, to the massive Rhizostoma, which frequently finds its way into our southern harbours, the disk of which resembles in dimensions a lady's parasol. In general, the smaller kinds belong to the Naked-eyed division, the larger to that characterised by Covered eyes. These terms are convenient formulæ to express distinctions, which, while they include, the organs of vision, do not rest wholly on them, the characters in question being found associated with others which unitedly indicate the latter as a higher grade of organisation than the former. In the one, the margin of the disk bears wart-like eyes, which are protected by complex folds or veils of membrane; and this circumstance is associated with another of great importance, the presence of a much ramified and anastomosing series of vessels. In the other division, the eyes, when present, are of simpler structure, quite naked; and the vessels are simple canals, usually unbranched, and never anastomosing. To the former group, the Covered-eyed Medusæ, no more than about ten species are assigned as natives of the British seas ; and these have as yet found no special historian. Of the latter, Professor Forbes, in his beautiful "Monograph of the British Naked-eyed Medusæ," has enumerated forty-three species, arranged in eighteen genera, and several more have been added since the publication of that work. We shall take the liberty of quoting from it a few practical directions for procuring these lovely creatures, and the more willingly because we have, by personal experience, proved their efficacy :- 
"They are to be sought for in summer and autumn when the weather is warm and dry, and the sea calm and clear. They abound within reach, mostly in the afternoon and toward nightfall,-probably, also, during the night, though not then so near the surface of the water. A small bag of fine muslin, attached to a metal ring, is the best instrument by which to take them, and may be used either as a land-net fixed to the end of a stick or pole, or as a tow-net suspended over the stern of a vessel, when at anchor, or making very gentle way through the water.

"When the tow-net is taken out of the sea it is to be carefully reversed, and its contents gently emptied into a basin or glass jar, filled with clear salt-water. It is best to plunge the net beneath the surface when being emptied, as thus the Medusæ are enabled to detach themselves from the threads and swim away without injury. When the net is out of the water they appear like little, adhering, shapeless, masses of clear jelly, and exhibit no traces of their elegant form and ornaments. When in the jar or basin they are often, on account of their extreme transparency, very difficult to distinguish; but by placing the vessel in the sun or beside a strong artificial light, we see their shadows floating over the sides and bottom of the basin, like the shadows of flitting clouds on a landscape. These soon guide us to the creatures themselves, and before long we distinguish their ocelli and coloured reproductive organs;"*-when they may be lifted into other vessels,the larger by means of a spoon, the smaller with thumbtubes, for more close examination.

$$
\text { *Op. cit., p. } 89 \text {. }
$$


Acalephes (Sea-blubbers).

Continued.

We propose now to speak of the reproduction of the Medusæ, at least of the Discophora, or umbrelliform families, for of the other orders we know little, except their forms. Some of the phenomena of Alternate Generation have been described in a previous paper, a compound hydroid Polype giving birth to tiny Medusæ, which afterwards produce a generation of Polypes. We have now to contemplate the counterpart of this wonderful process, free swimming Medusa producing gemmules, or motive eggs, each of which becomes a stationary Polype, and ultimately throws off a number of Medusæ.

The ovaries in these animals are ordinarily placed in contact with the walls of the central stomach, or with the digestive canals that radiate from it across the disk. At the season of development they consist of numerous ribands of membrane, much folded and convoluted, and fringed with free pendent filaments, covered with vibratory cilia. The ova are globose, gelatinous germs, existing in immense multitudes, which on extrusion are strongly ciliated, and bear a close resemblance to Infusorial Animalcules. They 
are endowed with the power of spontaneous motion, and apparently of choice as to locality, and have a definite form, which is commonly pear-shaped, though the outline is very flexible and variable.

As the time of oviposition approaches, the umbrella becomes gradually reverted, or turned inside out, the ovaries swelling and protruding more and more, until they occupy the principal portion of the animal. We believe this to be general in the discoid Medusæ, having observed it in species that belong both to the Covered and Nakedeyed divisions-namely, in the genera Chrysaora, Pelagia, and Turris.

In the case of the lovely little Coral-bead Medusa (Turris neglecta), already alluded to, the phenomena are well seen, the ovaries being orange or pale scarlet, studded with proportionally large ova, of a rich purple hue. The latter appear to escape from the walls of the ovaries, working their way out at the sides. They drop down on the bottom of the vessel, where they move about slowly for a while, but to no great extent, by means of their vibratile cilia. By watching them we ascertain the following facts. The gemmule, having adhered to some foreign substance, grows out into a lengthened form, variously knobbed and swollen, and frequently dividing into two branches, the whole adhering closely to its support. After a day or two's growth in this manner, a perpendicular stem begins to shoot from some point of this creeping root, and soon separates into four straight, slender, slightly divergent tentacles, which shoot to a considerable length. The whole is of a crimson hue, with the exception of the growing extremities of the creeping root, which are pellucid white. 
The little creature is now a polype of four tentacles. We have not been able to trace the development further in this species, but the deficiency has been supplied by the observations of others upon the larger genera.

The most common-or, at least, the best known-Medusa in the British seas is the Aurelia aurita, that Seablubber, with four imperfect rings of pink in the disk, which is so often seen floating in our harbours, or washed ashore on our beaches. In this species the whole progress of development, from the first appearance of the ova to the formation of perfect Medusæ, has been traced by several observers, and the following is an epitome of the highly curious facts.

The pink semi-rings are the ovaries, in which the ova are first developed. At a certain early stage they are transferred to four pouches beneath the arms, where they increase in size, become granular in texture, and at length assume the figure and manners of an oblong Infusorium. As each one quits the maternal pouch, it swims freely away by the aid of its investing cilia, with its larger end foremost. Soon, however, it selects a place of rest, to which it adheres by its smaller extremity, and quits the roving for the stationary life.

A depression now forms in the thicker end, which deepens and becomes a digestive cavity ; while the margin expands and buds out into four processes, which are strongly ciliated. Up to this time it had been yellowish and opaque ; it now becomes colourless and transparent. Four other processes are now formed in the interspaces of the former four ; so that the little animal now closely resembles a Hydra with eight tentacles, especially as these 
organs, together with the whole body, are exceedingly extensile and contractile. It is voracious, and cannibal in its appetite, swallowing even its fellows which are in the incipient erratic condition.

Meanwhile the number of tentacles increases by the successive growth of new ones in the interspaces, until they amount to thirty-two; the Polype augments in size, and even produces buds, as the Hydra does, which become Polypes like itself, with the power of changing ultimately into Medusæ; and at length it becomes marked with a series of constrictions, which, growing more and more deeply cut, divide the whole body into a number of distinct portions, which resemble so many tiny tea-cups piled one within another.

The changes thus described occupy the autumn and winter months; on the return of spring the little cups, whose margins are cut into eight cleft processes, successively detach themselves from the body, turn themselves over, and swim away,-minute, but veritable Medusæ,needing only the development which abundant nutriment soon supplies to become in all respects like their parents of the preceding season.

Such is the brief outline of some of the wonderful phenomena displayed in the generation of the Sea-blubbers, which are cast up by thousands on the shingle, to dissolve berieath a summer's sun. Such is one of the works of Him "whose way is in the sea, and whose path is in the great waters, and whose footsteps are not known." (Ps. lxxvii. 19.)

But all the Medusæ are not comprised in the umbrellaformed Discophora. There are other orders, which we 
shall briefly exemplify. The seas around our coasts swarm in summer with hosts of a little creature which resembles an oval ball of the purest glass, varying from the size of a pea to that of a hazel-nut, though there is a larger species on the Scottish coast, as big as a lemon. The one we speak of is named Cydippe pileus. If we take one from the muslin bag of a towing-net, and shake it off into a tumbler of clear sea-water, we shall have a most interesting object before us. Indeed, so perfectly hyaline is its consistence, that we must keep a sharp watch on it, or it will escape our sight, and we may not easily find it again. From pole to pole of this crystal globe run eight bands, like meridians of longitude, across each of which are fixed a great number of flat plates, which move up and down symmetrically and rapidly, rowing the little ball along like so many paddles. By the vigorous action of these organs, which, decomposing the rays, play in the sun's light with the most brilliant prismatic colours, the Cydippe performs at pleasure the most varied movements, with inimitable ease, rapidity, and grace. It shoots with force through the water, catching its prey with open mouth; nor is this always of the most helpless sort; small shrimps of various species form its ordinary food, and these are swallowed and digested with surprising facility.

At times the little Cydippe wishes to arrest its motion; and for this purpose it is furnished with two cords of great length, which, whatever other ends they may serve, certainly answer the purpose of mooring-cables. At the sides of the body there are two oblong cavities, into which these threads may be entirely coiled up in an instant, or 
at the good pleasure of the creature projected, and unfolded to a length ten or twelve times that of the body. Each thread is set with a single row of short filaments, at regular distances, which are ordinarily carried in spiral curves, capable of elongation or contraction like the cables themselves.

The crystalline Cydippe represents the Ciliograde order of Acalephe, or that whose motion is performed by means of ciliary paddles. Another order is the Physograde, where the apparatus for swimming consists of one or many bladders inflated with air, probably generated by the animal. An example of this tribe is well-known to those who navigate the warmer regions of the ocean as the Portuguese man-of-war (Physalia pelagica), where we have seen it in myriads studding the calm surface of the glittering deep. Nor is it wholly a stranger to more northern climes, for fleets of these adventurous craft are sometimes driven by the force of Atlantic currents far out of their reckoning, and stranded upon our western shores.

This singular animal consists of an oblong bladder of clear membrane, surmounted by a thin crest, which runs along its upper edge, and is capable of being contracted, so as to be almost invisible, or of being elevated into a tense and lofty sail. When in the latter condition, the whole forms a beautiful object; the glossy, colourless bladder reflecting the sun's rays, while the upper half of the sail is tinged with a delicate rose-colour, and the bottom of the bladder with a rich azure. As the little thing tosses and floats upon the waves it bears a striking resemblance to a child's toy-ship ; and even those most familiar with its appearance gaze upon it with pleasure. We 
wonder that it never capsizes, but, on looking more closely at it, we see depending from its bottom a great bunch of wrinkled strings, some of which are blue and others crimson ; these help to keep it steady. These pendent organs, which differ considerably among themselves in form and appearance, have, doubtless, diverse functions ; but some of them are known to be endowed with a most terrific power of stinging, and are, therefore, concluded to be prehensile tentacles, whose use is to arrest, benumb, and hold the fleeting prey.

In another tropical genus we find a new form and a new principle of motion. A number of delicate threads, called cirri, hang from the under surface, which are considered as the swimming organs, and the animals constitute the order Cirrigrada. We are not sure, however, whether these ought not rather to be grouped with the last mentioned, the cirri being probably analogous, both in structure and function, to the pendent tentacles of Physalia. These, too, are dauntless mariners-oceansailors of an antiquity long prior to the period when he of the "robur et ces triplex" acquired poetic fame. We once met with a few specimens of the "Sallee-man"* (Velella) on the shore of Portland; but we will use the elegant language of Professor Jones to describe it :-

"Its body is a flattened disk, which floats upon the bosom of the sea; and as it swims we see depending from its under surface a great number of small suckers, wherewith to suck up food as it moves slowly onward. Pro-

* The popular names given to those oceanic Medusæ point to a time when the maritime power of Portugal and Morocco was more formidable than it is now. 
jecting from the upper surface is the broad, flat sail-a soft, transparent membrane, but still strong enough for the light boat that bears it.

"But if a sail be given to beings such as these, whose bodies are almost of the same density as the salt water in which they live, and at the same time so soft in their consistency, some provision must be made to float the tiny - ship, and keep it buoyant. A mast is likewise needful, and, moreover, ballast must be furnished to secure its steady course, and keep it from capsizing. All these are furnished, and by means as simple as they are efficient. Unlike the other Acalephs, whose body is entirely soft, these species form in the substance of their backs a shelly plate, so thin as scarcely to be visible, and yet so porous that, being filled with air, it is extremely light, so much so as to constitute a float, by means of which the creature swims. Placed vertically on the top of this stands up another lamina of shell, still thinner than the former, planted in the substance of the sail ; this forms the mast, and gives sufficient strength and stiffness to enable the thin, filmy sail to stand erect against the wind, which otherwise would be impossible. The ballast is obtained from other sources; small shells and stones are seized by the appendages upon the lower surface of the body, which, from their weight, may serve to trim the little vessel as it scuds along, climbing the billows as they rise and fall, or slowly sailing on the tranquil deep." *

$$
\text { * “Nat. Hist. of Animals," i. } 189 .
$$




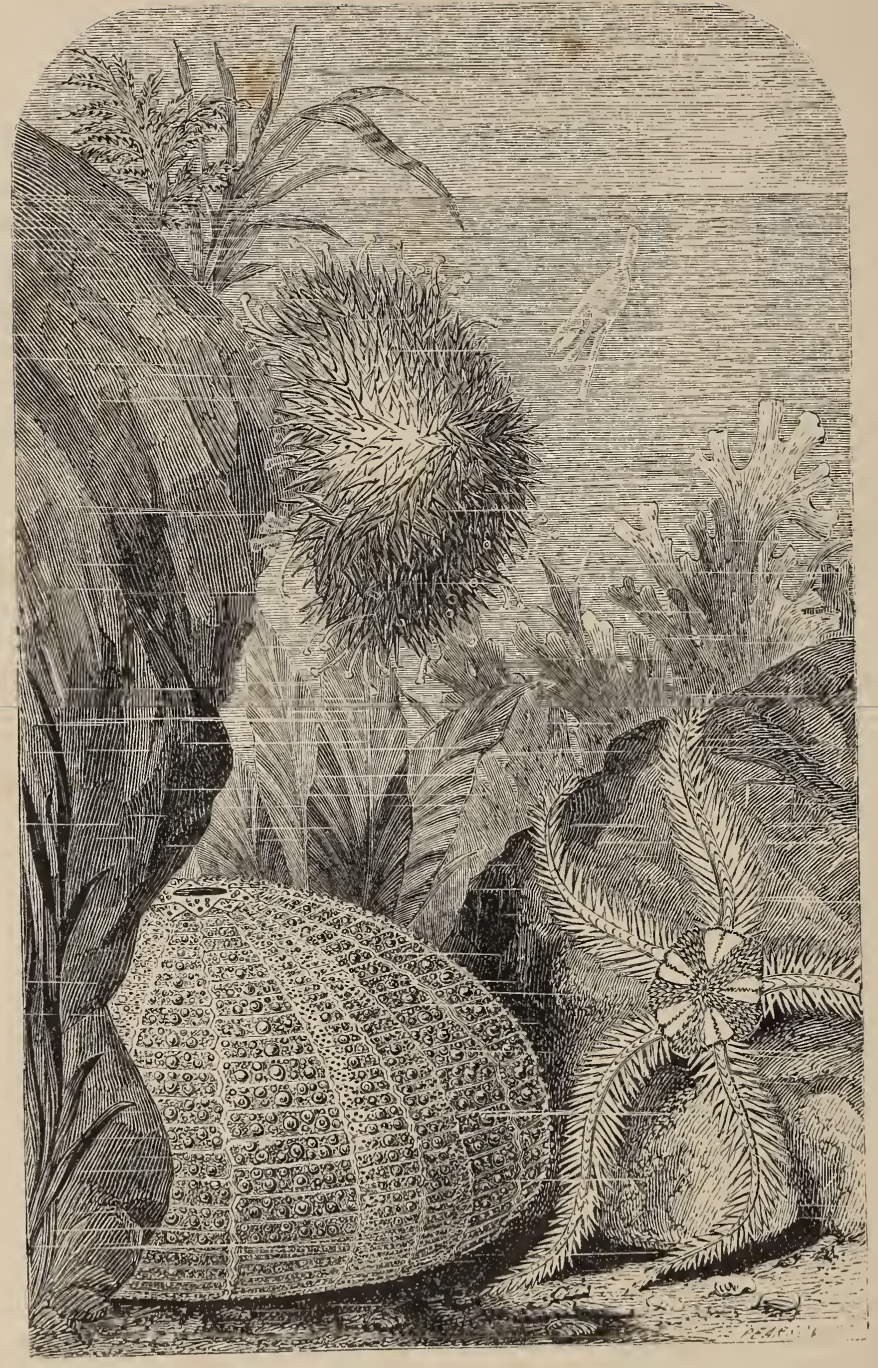

Echinodermata. (Star-fishes.) 
STAR-FISHES.

\section{CHAPTER X.}

\section{Echinodermata (Star-fishes).}

Or many a shingly beach where the limestone formation occurs there may be found small perforated pebbles, which, rounded and polished by the action of the waves, resemble beads of stone. In the days of Popish superstition, these were supposed to be fashioned by an imaginary "Saint Cuthbert" for the rosaries with which prayers and invocations were meted out by tale. One of the rocky islets that speckle the tempestuous sea of Northumberland, was assigned to the special manufacture of these useful articles :-

"___ On a rock by Lindisfarn

Saint Cuthbert sits, and toils to frame

The sea-born beads that bear his name."-Marmion.

In the same districts where these occur, the wondering peasantry have often admired what they call Lily-stones, a class of fossils to which modern geologists apply the equivalent term Encrinites; the stony stem, and a crown of rays bending in sigmoid curves, resembling the stalk and elegant bell-shaped blossom of a liliaceous flower. 
Now the "beads" are nothing more than the joints of which the stem of the Encrinite is composed, and the Encrinite itself is the fossil skeleton of an ancient Starfish. The abundance of these animals in the primeval seas may be inferred from the profusion of their remains; vast strata of marble, extending over large regions in the northern parts of both hemispheres, being made up of these "lily-stones," as absolutely, to use the graphic simile of the late Professor Buckland, "as a corn-rick is composed of straws.".

The form, however, is as rare now as it was anciently common. Some years ago a fine specimen in a living state was brought up by the dredge in the Caribbean Sea; and as the stem was violently torn asunder, the basal portion being wanting, it is inferred that the base is immoveably fixed to the rock like a sea-weed. With the exception of a few fragments found on divers occasions, and carefully treasured in national museums, this is the only recent specimen of any considerable size which has been seen. But a minute kind has been ascertained to inhabit our own seas, a tiny Encrinite about three-quarters of an inch in length. It is described as bearing "five pairs of beautifully pinnated arms, and as of a deep rose-colour, dotted over with brown spots, which are regarded as the ovaries. It is dredged up," observes Mr Patterson, "on many parts of the Irish coast, and is occasionally found upon the strand. The first specimen we ever possessed was taken on the beach about six miles from Belfast, and was brought to that town alive. Anxious to secure so attractive a specimen for the cabinet, we placed it in a shallow vessel of fresh water, and found, to our surprise, 
that it emitted a fluid which imparted to the water a roseate tinge." *

But the discovery of this little animal, interesting as it was for its own sake, was rendered more interesting by a subsequent discovery. The Encrinite proved to be only the youthful condition of a well-known elegant Star-fish, called from its colour and its plumose crimson rays arrayed in five pairs, the Rosy Feather-star. But this is a freeroving species, swimming at will through the sea, by the periodical contraction and expansion of its incurved rays, in the manner of a Medusa.

The metamorphosis of the little Encrinite to the Comatula, as the Feather-star is technically named, was at first but a matter of probable conjecture. It has, however, been verified by actual observation. "When dredging;" observes Professor Forbes, the learned historian of British Star-fishes, "in Dublin Bay, in August 1840, with my friend Mr R. Ball and Mr W. Thomson, we found numbers of the Phytocrinus, or polype state of the Feather-star, more advanced than they had ever been seen before; so advanced that we saw the creature drop from its stem and swim about, a true Comatula ; nor could we find any difference between it and the perfect animal, when examining it under the microscope." +

And thus was completed what the same zoologist designates as "one of the little romances in which natural history abounds; one of those narrations which, while believing, we almost doubt, and yet while doubting, must believe." 
A full-grown Feather-star is about four inches in expanse ; it consists of a central disk, which is a little cup of shelly substance containing the viscera in its concavity, and furnished on its margin with ten long, slender, jointed shelly rays. Strictly speaking, they are but five ; but they bifurcate so close to their origin as to appear like ten. The joints of the rays are composed of calcareous substance ; are perforated, so that each ray is tubular; are rough on the outside, and bear on two opposite sides rows of flattened leaf-like appendages (pinna), which are themselves jointed, and margined with tentacular filaments. Besides these complex organs, the convex (which is the inferior) side of the body is furnished with about thirty jointed filaments, which are shorter, and not pinnated.

A very elegant object is the Feather-star when in health and activity in its native element. Its ordinary hues are crimson and yellow, disposed in irregular patches. On ore occasion we had an opportunity of personal observation of its manners. We have alluded to its mode of swimming: when it reposes, it sits on the frond of a sea-weed, or on the projecting point of some angular rock, which it grasps with its dorsal filaments, and that so firmly, that it is difficult to tear it from its hold. If violence be used, it will catch hold of its support or of any other object within reach, with the tips of its rays, which it hooks down for the purpose, and with its pinna; so that it seems furnished with so many claws, the hard stony nature of which, as well as the muscular force with which they are applied, is revealed by the creaking, scratching noise which they make when they are forced from any hold, as if they were made of glass. 
By this beautiful animal we enter into the Echinodermata, a class of beings much more highly organised than any which we have yet considered. Their most prominent characteristic is, that their softer parts are enclosed in what may be called an external skeleton, a case of calcareous substance, sometimes leathery in texture by the predominance of animal matter in the combination, but more frequently resembling in its hardness, rigidity, and brittleness, the texture of shell or stone.

If this skeleton, however, were made in one unbroken piece, it is manifest that there would be no possibility of the growth of the animal. As the soft glandular parts are all within the shell, every particle of calcareous matter deposited would, by being added to the interior surface, diminish the capacity of the box, and leave less room for the vital organs. This emergency is met by a most admirable contrivance. If we take a common sea-urchin (Echinus) into our hands, and rub off a few of the spines which cluster over its surface, we shall see that its solid exterior is a box made up of a vast multitude of tiny pieces of regular shape, fitting together at their edges, and soldered, as it were, into one, with the most exquisite precision.

Yet, close as these pieces appear to be to each other, and firm as is their adhesion, reason assures us that there exists between them a living vascular tissue, of excessive tenuity indeed, yet capable of secreting and of depositing the materials of growth, in the form of calcareous particles, continually added to the edges of the polyhedral plates, thus enlarging the capacity of the whole box by the slow, even, and imperceptible growth of the thousands of constituent pieces. 
But between the Feather-star and the Sea-urchin there is so great a diversity in form and appearance, that our readers may be reluctant to admit them into the same category; the gulf that separates them seems to be too wide. Let us see however, if we cannot bridge it over.

If you have ever thrown a dredge overboard in any of our quiet bays a mile or two from shore, and examined the host of curious and strange things which it has brought up from the floor of the sea, you know what a Brittle-star is. But if not, we will try to describe it for you. We select the commonest species,-Ophiocoma rosula, the Rosette. Imagine a central disk about as large as a silver fourpenny-piece, of a form between a circle and a pentagon, composed of five pairs of triangular plates pointing towards the centre, and separated by bands of leathery skin studded with minute spines. In the centre of the under surface of the disk is the mouth, an aperture into which project five complex plates, and from whose margin spring five long slender rays diverging on every side, and looking much like the tails of so many scaly lizards.

Now these rays are of exquisite workmanship. They appear to be nearly solid columns, with narrow tubular canals running through them; but they are penetrated by various organs, with muscles for motion, with glands for secretion, with nerves for sensation, and so forth. Externally they are seen to be built up of plates, which fit and partly overlap one another, so as to allow great freedom of motion. Those on the upper side are triangular, with blunt points; those beneath are square, with the corners cut off. These two series are connected by lateral 
ridges, bearing long, slender diverging spines, some seven or eight in each perpendicular series on each side.

These spines, when examined with a microscope of high power, present very beautiful objects. We have this instant been charmed by the appearance of several of them magnified about two hundred diameters. When the rays of sunlight are reflected from them, they resemble the most elegant taper columns or obelisks, roughened with projecting points shooting perpendicularly upwards, and arranged in parallel rows throughout the whole length; and, as the whole is composed of a substance of brilliant transparency and exquisite polish, the points sparkle in the light as if the whole column were sculptured in crystal. Professor Edward Forbes truly remarks of a spine of this Brittle-star highly magnified, that it exhibits " a structure, the lightness and beauty of which might serve as a model for the spire of a cathedral."

The internal structure of the spines is no less admirable than their external beauty. The calcareous substance of which they are composed,-a carbonate of lime, mixed with a minute proportion of the phosphate, according to Professor Grant,-which, as we have already observed, resembles in appearance crystal or flint-glass, is not solid, but is excavated by a multitude of apparently empty cells, having no connexion with each other, but set in rows and series more or less exact. We notice this because it is the plan upon which all the calcareous parts of the animals of this class are modelled; the plates of the globular case of the Sea-urchin, those of the Brittle-star, the spines of both, the tubercles of the Cross-fish, the stems and skeletons of the singular Pedicellarice, which we shall presently have 
occasion to notice,-all present the same structure, which is thus eminently characteristic of the class, - a transparent, hard, brittle, crystalline deposit, hollowed into numberless isolated cells. These cells are sometimes so numerous that the solid matter is reduced to a series of slender bridges and attenuated pillars, when, though the beauty is much enhanced, the fragility is in proportion.

It is interesting also to observe the flexibility which is imparted to the long rays of the Brittle-star. Though composed of rigid and fragile plates, a wonderful flexibility is afforded to it by their number and arrangement; and whoever has watched, either by its native sea-shore, or in the tiny mimic ocean which the marine aquarium furnishes, one of these animals twining over the shells and stones that lie on the bottom, as it pursues its rapid but devious course, must have been struck with the precision and ease with which these plaited organs, all bristling over with points and spines, catch hold of projections, and drag the body along, in much the same manner as a man would do if reduced to a prone position, and if all his limbs were arms.

Perhaps our readers think we have made small progress in our travels from the Feather-star to the Sea-urchin; still there is an advance; and in our next chapter we hope to shew that the journey is not so long as might be supposed. 


\section{CHAPTER XI. \\ Echinodermata (Star-fishes).}

\section{Continued.}

THE English name of Brittle-star refers to a peculiarity very characteristic of the stellar forms of this class of animals, - an unhappy tendency to suicide. The eager naturalist, in dredging for these interesting creatures, is often annoyed and disappointed by seeing some fine specimen that comes up from the depths, crumble into fragments by a spontaneous movement, the instant he endeavours to lay hands upon it. Professor Forbes has described his experience of this habit in the case of Luidia fragilissima, the Lingthorn, a seven-armed species, some two feet in expanse. The passage has been often quoted, but it is so graphic, so descriptive, so full of humour, that we must beg permission to enliven our pages with it :-

"The first time I ever took one of these creatures, I succeeded in getting it into the boat entire. Never having seen one before, and quite uncouscious of its suicidal powers, I spread it out on a rowing-bench, the better to admire its form and colours. On attempting to remove it for preservation, to my horror and disappointment I found only an assemblage of rejected members. My con- 
servative endeavours were all neutralised by its destructive exertions, and it is now badly represented in my cabinet by an armless disk and a diskless arm. Next time I went to dredge on the same spot, determined not to be cheated out of a specimen in such a way a second time, I brought with me a bucket of cold fresh water, to which article Starfishes have a great antipathy. As I expected, a Luidia came up in the dredge, a most gorgeous specimen. As it does not generally break up before it is raised above the surface of the sea, cautiously and anxiously I sunk my bucket to a level with the dredge's mouth, and proceeded in the most gentle manner to introduce Luidia to the purer element. Whether the cold air was too much for him, or the sight of the bucket too terrific, I know not, but in a moment he proceeded to dissolve his corporation. and at every mesh of the dredge his fragments were seen escaping. In despair I grasped at the largest, and brought up the extremity of an arm with its terminating eye, the spinous eyelid of which opened and closed with something exceedingly like a wink of derision." *

The Lingthorn, by the length and slenderness of its rays, and by the comparative minuteness of its disk, as well as by the fragility just mentioned, bears evidences of close relationship with the Brittle-stars; yet it truly belongs to another order of the class, the Star-fishes distinctively so called. The surface is not here formed of angular imbricate plates, but of a tough leathery or cartilaginous skin, strengthened by calcareous plates imbedded in its substance, and more or less studded with spines or tubercles. The Cross-fish, or Five-finger (Uraster rubens), that

* Forbes” “ Brit. Star-fishes," 138. 
commonest of objects on every shore, is an excellent example of this order.

Now here we have a very evident tendency to centralisation. There are five distinct radiating arms, as in the Brittle-star ; but they are massive, thick, short, and comparatively inflexible, while the disk or central undivided portion bears a much greater proportion to the whole expanse.

But a change much more remarkable has been effected in the manner of progression. In the Feather-star, as we have seen, the motion is truly natatory, performed by the alternate contraction and expansion of its inflated arms, aided, perhaps, by the lateral pinnæ, with which these are furnished. In the Sand-stars and Brittle-stars the swimming faculty is lost; the animal drags itself over the stones and even up perpendicular surfaces by its flexible arms, the spines of which catch hold of every projection and roughness. In the Star-fishes a new set of organs is developed, highly curious in their nature, and, like all other of the works of God, well qualified for their office.

Let us go to the first Five-finger we see lying on the shingle, and turn it over. We now see that each of the five rays has a deep furrow running along its under surface, proceeding from the mouth in the centre of the disk, even to the tip of the arm. This furrow has been fancifully named the ambulacrum, or avenue.

Now let us, in the plentitude of our compassion, take the poor wretch from the stones where he lies broiling in the burning sun, and, bearing him home, gently place him in a glass vessel of cool sea-water. Our virtue will be its 
own reward. From each of the avenues hundreds of filmy tubes are seen protruding, which twist and twine in all directions, as if seeking some object to lay hold of. Nor do they seek in vain. We are supposing that the Star-fish has been laid upon his back. Well, the extremity of one of his rays presently bends itself over, so that the pellucid tubes can reach the bottom;--they catch hold; the arm bends still more; other tubes reach the ground, and, in a minute or two, over turns the Star-fish bodily, and is " as right as a trivet."

See how gently and equably he is crawling over the bottom, gliding uniformly along like a snail! But how does he do it? What is the nature of his locomotion? Stay! we shall see; for he has reached the edge of his prison-bottom, and is beginning to mount up the glassy side. Watch him now, through the transparent medium, and you will understand the seuret.

The flexible tubes, which look like so many caterpillars, are seen to have dilated extremities, which, when brought into contact with the glass, are made to adhere, just on the same principle as a truant schoolboy makes his sucker of wetted leather stick fast to the parement. The tubes are thrust out and drawn in at pleasure; as the Star-fish advances, new sucker-feet are pushed onward as far as possible, where they adhere, and drag up the body after them; and by a succession of such apparently feeble efforts progression is effected.

The mechanism of these sucker-feet is very simple. At the bottom of the furrow or avenue in each ray are four rows of minute pores, through which the suckers are protruded. The base of each sucker is expanded into a little 
globular vesicle, which lies above the pore in the interior of the ray. The walls of this vesicle are muscular, and therefore contractile; and it is filled with a fluid. When, therefore, the animal wishes to protrude and extend any given sucker, it contracts the vesicle at its base by an effort of the will ; the fluid is thus forced into the tubular stem, which is, therefore, compelled to elongate; on the removal of the contractile force the fluid returns to the bladder, either by the elasticity of the tube, or rather probably by its muscular action, and the sucker is gradually withdrawn. The adhesion of the terminal disk is another process. This is, doubtless, effected by the pressure of its edges to the surface, and the simultaneous retractation of its centre, producing a vacuum, on which the surrounding medium presses by the law of gravity.

It is beautiful to trace the workings of the Divine Mind in contriving, and the Divine Hand in executing, such problems in mechanics as these, and all for the comfort and benefit of a creature that man tramples under his feet when he meets with it, as not merely worthless, but an encumbrance, whose existence is not to be tolerated! The meanest "thing that creepeth upon the earth" has occupied the infinite wisdom of God from all eternity; and when His creative energy was put forth at the appointed time to call it into being, it was the object of His infinite complacency. "And God saw every thing that He had made, and behold it was verY GOOD." It is permitted to us, in examining the same works, and discerning a little of their perfection and fitness, to share in our humble measure the Divine complacency.

If we inquire into the gastronomy of the Star-fish, we 
shall find it no less unique than its locomotion. The whole tribe are the scavengers of the sea, searching out and greedily devouring the fragments of carrion that otherwise might infect the ocean and render it poisonous to living animals. But besides this indiscriminate appetite, the Star-fish has long been suspected of a dainty epicurism in the matter of shell-fish; and old Admiralty laws inflicted a heavy penalty on any one who, finding a Fivefinger on the shore, did not crush it under his heel, or throw it up beyond the reach of the tide. Difficulties, to be sure, presented themselves in the way of a Star-fish inclining to oyster-suppers, and a theory was, as usual, invented to meet them. It was reported that the Starfish, insidiously lying in wait till the blind oyster gaped, dexterously inserted a ray between the valves, which being thus prevented from closing, the delicate morsel was extracted at leisure. This would have been surprising enough ; but truth is stranger than fiction. Observation seems to have established the following facts: The mouth of the Uraster is destitute of teeth ; but the whole œsophagus, and, in fact, the stomach, are capable of being turned inside out in the form of great vesicular lobes, and of insinuating themselves into minute orifices. When the animal, then, wishes to feed on a bivalve mollusk, it clasps it, valves and all, with its embracing rays, holding fast its prey though the waves may roll it about like a ball. Meanwhile the stomach is pouted out, and finding access into the interior at the points where the valves slightly gape, it manages to dilate itself within, and extract the nutritive juices of the victim; the process being aided, as is supposed, by the injection of a poison- 
ous fluid, secreted and poured out from the lobes of the stomach.

The order which includes the Star-fish is very extensive, comprising many species, and even many genera. In a series of these genera, such as any well-stocked museum affords, the naturalist sees a gradual deterioration and obliteration of the rays, and a commensurate development of the disk or body. This double change proceeds by the filling up of the angles between the arms, until the outline, instead of being five-rayed, is five-sided. A beautiful British species, the Bird's-foot Star (Palmipes), affords an example of this pentagonal form.

From this condition it is easy to imagine the disappear. ance in other species of the very angles themselves; the sides become progressively convex in their outline, and at length a figure nearly orbicular is attained. Such, in short, is the aspect of one of the rarest of British Echinodermata, the Cake-urchin (Scutella).

The integument by this time has changed as well as the form, having become shelly, presenting a hollow box, built up of many thin and nearly flat pieces of definite geometrical figures, some pentagonal, others hexagonal. And thus we have made our way to the curious flattened spheres which are characteristic of the Sea-urchins. Many of the links which perfect the chain are, it is true, exotic species : but even in British forms it is not difficult to trace the connected progress from type to type-one of the most beautiful gradations in the whole circle of Zoology.

The shelly case of an Echinus is indeed an exquisite structure. It is mado up of twenty rows of plates, of which five pairs are ambulacral, pierced with minute pores 
for the protrusion of the sucker-feet, and five pairs alternating with the former are inter-ambulacral.* Both kinds are studded on their exterior surface with tubercles or strong warts, each of which is crowned with a little globular highly-polished bead. On every one of these beads played during life a spine with a hollow at its base, forming with its supporting spherule a ball-and-socket joint of perfect construction, the spine being kept in its place, and yet allowed great extent and freedom of motion, by means of muscles that bound its dilated pedestal to the surrounding integuments.

Professor Forbes informs us that in a moderate-sized Urchin there are sixty-two rows of pores in each of the ten avenues, and as there are three pairs of pores in each row, the total number of pores is 3720 ; but as each sucker occupies a pair of pores, the number of suckers is 1860 . He says, also, that there are above three hundred plates of one kind, and nearly as many of another, all dovetailing together with the greatest nicety and regularity, bearing on their surfaces above 4000 spines, each spine perfect in itself, and of a complicated structure, and having a free movement in its socket. "Truly," he adds, "the skill of the Great Architect of Nature is not less displayed in

* The author of "Tanks and their Inhabitants," having done us the honour of quoting the above description, says :- "We do not attempt to explain these terms, for they appear to be arbitrary, and certainly have nothing to do with walking, as the word would seem to imply." The word ambulacrum means not a walling urgan, but a walking-place, a walk or alley in a garden. The plates which carry the tubercles are comparable to the flower-beds of the garden, and the narrow spaces, pierced with pores, are the walks between. It is true, the walking organs, the suckers, are protruded from these spaces, and from thence only, but we believe the name ambulacra was given long before it was known that these organs were connected with locomotion. 
the construction of a Sea-urchin than in the building up of a world !"*

Time and space would not permit us to dwell on all the marvels of creative power displayed in these animals; in the elaborate system of muscular bands and loops and capsules ; the singularly complex array of arched teeth constituting what is called "Aristotle's lantern :" the apparatus of water-ducts that resemble the mains and pipes of our great metropolis; the forest of chased and fluted and sculptured spines that bristle and nod upon the surface! But there are some points of further interest which we must not pass over, though we will defer their consideration to a future chapter.

$$
\text { * Op. cit., } 152 .
$$




\section{CHAPTER XII.}

Echinodermata (Star-fishes).

\section{Continued.}

WE have already, in the course of these pages, brought before the reader some singular phases and conditions of LIFE; and have shewn that its forms and conditions are not at all confined to those limits which circumscribe it in the nobler creatures. One of the most remarkable of such curiosities of vitality now comes before our notice in the existence of certain organs, so unique in their forms and functions, so apparently independent of the animal's will in their movements, that it was long a matter of dispute whether they were truly organic appendages or merely parasitic intruders. We refer to the Pedicellarice of the Urchins and Star-fishes.

If we look at a Sea-urchin disporting himself in his clear element, we shall presently see among the spines and suckers, even with the naked eye, objects that are distinct from either. We had better apply a lens to them, however, when we shall discover their appearance and actions distinctly. They are very numerous, crowded irregularly on most parts of the skin, but especially around the mouth. There are several forms; but in general they 
may be described as a thick head, cleft into three divisions, and set on a long, slender, flexible stalk. Through a portion only of the stalk passes an inflexible shelly support like a bone, but there is left a considerable part which is perfectly soft, flexible, and highly contractile; and by the motions of this part, the massive head is thrown about in all directions with great vivacity.

Now let us look at the heads of these strange nodding creatures. The largest sort has a head shaped something like a sugar-loaf, split from the apex to the base into three lobes, which gape widely and close together with most ferocious snappings. These openings and shuttings of the threefold jaws are constantly going on, fitfully and without any regularity or agreement; and most curious it is to watch them, and to endeavour (though without success) to discover what possible end is accomplished by the procedure.

If we examine these bodies with high microscopic powers, little light is afforded on the question of their special functions, though they are thus determined to be organic appendages of the Echinus. But new admiration is excited at their elaborate structure and finish. The head consists principally of calcareous substance, which, as well as the supporting column of the stalk, is penetrated with isolated cells throughout. The bases of the three-lobed head are articulated in the most remarkable manner ; and the lobes themselves, which are sometimes attenuated to three slender pins, are cut along their meeting edges into minute teeth, which fit and lock into each other with exquisite precision. The whole body and head are invested with a gelatinous flesh, in which are imbedded 
minute red glands, that are common to the integument of the whole class, and this is covered with a series of vibratile cilia.

Conjecture has been busy upon the use of these very curious organs in the economy of the animal; but abso. lutely nothing is yet certainly known on the subject. Their prehensile power is obvious; but whether this is exercised in the way of defensive weapons, or as hands to catch food and hand it to the mouth, is among the things that we have yet to learn.

The Sea-urchin may be considered as the type or model of the radiate structure, to which we have traced the gradual approach from the polype-form, through the Featherstar, which, in its pentacrine condition, retains the aspect of a true Polype. But in nature there is a constant progression : and we must now briefly glance at the transition from this perfection of radiism to another sort of symmetry -bilateralism, in which there are parts which we can distinguish as right and left, dorsal and ventral, head and tail. This symmetry now begins to appear, and henceforward is found to characterise the whole range of animate existence.

On turning over stones at the lowest verge exposed by the retiring tide, - a means of acquaintance with strange creatures which no marine naturalist neglects whenever he has the opportunity,-we occasionally find adhering to them cylindrical, or rather pentagonal leathery animals, very much resembling small cucumbers. They are the representatives of an extensive family of this class, called Holothuriadce.

If we place one of these in water we shall see the fol- 
lowing particulars :-It protrudes from its fore extremity a circle of plumose tentacles, usually branched in all directions like tiny trees. Here is radiism. Down its body run five double rows of suckers, exactly resembling in structure and function those of the Star-fish and Urchin. Here again is radiism. But the arrangement of the internal organs is mostly bilateral. There is a distinct anterior and posterior extremity. In some species two of the double rows of suckers are undeveloped and useless for progression, and the other three rows are placed on a sort of flat disk, which, therefore, becomes a belly. At length we come to species in which the suckers entirely disappear, the body is lengthened and worm-like, and no trace of the radiate form is left, except the circle of minute tentacles which surround the mouth. Finally these vanish too; and we find in the obscure Spoonworms (Thalassema), animals of cylindrical shape, with a proboscis, having a long furrowed appendage on one side,-one of those debateable forms of which naturalists cannot agree in determining the true position; some assigning it to the Echinodermata, others placing it with the AnNELida, or Worms proper.

We have spoken of the suicidal habits of the Brittlestars. The Sea-cucumbers have the same unhappy tendencies, but their modus operandi is different. Sir John Dalyell has observed them lose the tentacles, with the dental cylinder, the mouth, œsophagus, lower intestinal parts, and the ovarium, separating from within, and leaving the body an empty sac behind. Yet it does not perish. In three or four months all the lost parts are regenerated, and a new funnel, composed of new branches as long as 
the long body of the animal, begins to exhibit the same peculiarities as the old one, though longer time be required to attain perfection. Other species of the Holothuria divide spontaneously through the middle into two or more parts, all becoming ultimately perfect by the development of new organs. The animal may even lose and regenerate its organs more than once.

The Sea-cucumbers are mostly small with us ; * but in the shallow seas of the tropics they attain the size of the juicy vegetable after which they are named. They are esteemed as delicacies by the omnivorous Chinese; and the fishing for them, with the subsequent processes of preparing and bringing them to market, forms an important branch of commercial industry in the Oriental seas. Some of the species are two feet in length and seven or eight inches in circumference, but others are much less. The larger sort are sometimes obtained by spearing them upon the rocks in shallow water; but the ordinary mode of obtaining them is by diving in from three to five fathoms, and collecting them by hand: a man will bring up thus eight or ten at a time. They are prepared for the market by being split down one side, boiled, and pressed flat with stones; then being stretched on bamboo slips, they are dried in the sun and afterwards in smoke, and packed away in bags. In this state the article, now called trepang, is put on board the junks, and is in great demand in China for the composition of nutritious soups, in which that singular people so much delight. The quantity of this article of food annually sent to China from Macassar

* Cucumaria frondosa,-the "King of the Sea-cucumbers,"-is occasionally taken in the Shetland seas, a foot and upwards in length. 
amounts to $8333 \mathrm{cwt}$. ; the price of which varies according to the quality (for there are more than thirty varieties distinguished in the market), from thirty shillings sterling to upwards of twenty guineas per cwt. The extent of the traffic may be inferred from the number of vessels employed in it: Captain Flinders was informed, when near the north coast of New Holland, that a fleet of sixty proas, carrying a thousand men, had left Macassar for that coast two months before, in search of this sea-slug: and Captain King was assured that two hundred proas annually leave Macassar for this fishery. They sail in January, coasting from island to island, till they reach Timor, and thence steer for New Holland, when they scatter themselves in small fleets, and having fished along the coast, return about the end of May, when the westerly monsoon breaks up.

The changes which occur in the development of the Echinodermata are not less wonderful than other passages of their history. Until lately we knew nothing of the infancy of the Star-fishes, but Johann Müller has, with great skill, industry, and success, solved this problem. The first condition of every Echinoderm is the same-an egg-like body, covered with cilia, resembling an Infusorium. Changes take place, and we presently see another form assumed, which varies in some degree in the different families. We lately had the pleasure of finding in our dip-net several little larvæ of a Brittle-star-the first that had ever been seen in our seas; and one of these we will select for description.

A painter's long easel affords the only object with which to compare the little creature ; for it consists of 
four long slender calcareous rods, arranged two in front and two behind, with connecting pieces going across in a peculiar manner, and meeting at the top in a slender head.

On this shelly, fragile, and most delicate frarnework, as on a skeleton, are placed the soft parts of the animal, a clear gelatinous flesh, forming a sort of semi-oval tunic around it, from the summit to the middle, but thence downwards the rods individually are merely encased in the flesh without mutual connexion. The interior of the body displays a large cavity, into which a sort of mouth ever and anon admits a gulp of water. Delicate cilia cover the whole integument, and are particularly large and strong on the flesh of the projecting rods.

The appearance of this most singular animal is very beautiful ; its colour pellucid-white, except the summit of the apical knob, and the extremities of the greater rods, which are of a lovely rose-colour. It swims in an upright position, with a calm and deliberate progression. The specimens which we have seen were not more than onefortieth of an inch in length.

From this form the Brittle-star is developed, but in a manner unparalleled in any other class of animals. The exterior figure is not gradually changed, but the star is constructed within a particular part of the body of the larva, "like a picture upon its canvas, or a piece of embroidery in its frame, and then takes up into itself the digestive organs of the larva." The plane of the future Star-fish is not even the plane of the larva, but one quite independent of, and oblique to it. Strange to tell, the young Star does not absorb into itself the body of the 
larva, which has acted as a nidus for it, but throws it off as so much useless lumber-flesh, rods, and all !

Thus does Science continually say to us, startled by discovery after discovery, each more strange than its predecessor-

\footnotetext{
"There are more things in heaven and earth, Horatio, Than are dreamed of in your philosophy."
}

In Plate IV., some of the forms of Echinodermata are represented. In the right-hand corner is the Rosette Brittle-star (Ophiocoma rosula), sprawling its snake-like arms over a rock. Beside this, on the left, the globose crustaceous case of the Common Urchin (Echinus sphora), denuded of its spines, displays the arrangement of its constituent plates, and the form of the tubercles. Above, a Purple-tipped Urchin (E. miliaris) is mounting the perpendicular rock by means of its numerous sucker-feet; and on the right of this, swimming freely through the water, is seen the singular pellucid larva of a Brittle-star. The reader must be pleased, however, to understand that, whereas all the other objects are depicted of their natural size, this is greatly magnified; a violence to nature indispensable to its representation at all, since it is really no larger than the hole which would be made by a fine needle in a piece of paper, or the period which terminates this paragraph. 


\section{CHAPTER XIII.}

\section{Helminthia (Intestinal Worms).}

Few things are more wonderful in the range of physical science than the fact, that the bodies of living animals form the world in which other animals pass their lives; and few things are more calculated to humble the arrogance of man, and to "stain the pride of his glory," than the knowledge that he carries about with him, and in him, multitudes of creatures that fatten upon his flesh, dwelling securely in the midst of his organs and tissues, and rioting unmolested on his various solids and fluids. At least eighteen or twenty species of internal parasites have been enumerated as infesting the internal cavities and tissues of the human body; and almost every other animal has species peculiar to itself, as well as some which are common to several.

A few of the more characteristic of these forms we will now briefly consider; and, repulsive as the subject undoubtedly is, we shall discover not a few proofs of Divine wisdom and benevolence in the provisions made for the sustenance and safety of vermin so unprepossessing as these.

In the substance of the liver, or other cellular organs 
of the human body, there are frequently found imbedded certain globular bodies of pearly whiteness, varying in size from that of a pea to that of a large orange. It is a simple bag of membrane, without any orifice or any organs, but filled with albuminous fluid. It exhibits no sign of life, no feeling, even when touched or irritated; but if pricked, the contained fluid is forcibly spirted out, from the elasticity of the membranous walls.

The increase of this creature, which is known by the term Acephalocystis, is peculiar. That kind most frequently found in the human subject develops buds or gemmce from the internal surface, which grow into globular sacs, and at length separate themselves and float at liberty in the fluid of the interior. These in turn repeat the same process, producing a progeny within themselves, and thus successive generations are found to exist, developed one within another, like those hollow toys which represent a fruit, and which, on being opened, reveal a smaller of the same kind, that another, and another, till the examiner is tired of opening.

Now is this an animal or not? A very eminent authority, Professor Owen, thinks not. "It seems to me," he observes, "to be most truly designated as a "gigantic organic cell,' not as a species of animal, even of the simplest kind." *

Yet how closely this treads on the heels of the Cysticer$c u s$, such as is often found in vast numbers in the fat of swine, communicating to it that appearance which is known as "measly." It is a bladder in all respects like the preceding, except that at one part it is drawn off to a length- 
ened point, the very extremity of which is perforated, forming a mouth through which the juices of the animaltissue are absorbed into the sac. Here, then, are indubitable characteristics of a living independent being. Here is a stomachal cavity in which foreign matter is assimilated, and this is imbibed through a distinct mouth.

But more ; a provision is needed for the attachment of the parasite while it is thus drawing its nutriment, and this is given in a twofold mode. First, around the sides of the extremity of the lengthened neck are placed four oval suckers, adapted for adhering to a smooth surface; and, secondly, around the oval aperture there is a double circle of minute recurved hooks, which, fixing into the surrounding flesh, anchor the mouth securely, while, at the same time, by the irritation which they produce, they cause the vital juices to flow more abundantly to the wounded part, and thus increase the sustenance of the parasite.

Other forms differ from this chiefly in the increased number of their organs ; the bladder, for instance, is furnished with many such heads, as in that species which infests the brain of sheep; or the head, if single, is a protrusile proboscis, armed with many rows of recurved spines; or, if there be but one head, and that armed with but two rows of hooks and one series of suckers, the neck is greatly developed and divided into a great number of segments, while the bladder is diminished to a comparatively small swelling at the hinder extremity.

We are thus brought to consider that horrible pest, the Tape-worm (Tania), which consists of a ribbon-like body, formed of square flattened segments, sometimes amounting to five hundred in number, and attaining an aggregate 
length of sixty, or even a hundred feet. When we remember that these enormous bodies are supported within the intestinal canal of the higher kinds of animals-man among the number-their history assumes a strange interest, coming, as it does, into such close intimacy with our own.

The joints of the Tape-worm become much smaller at the fore part, diminishing at length so excessively as to form a very attenuated neck, at the top of which is placed a little globose head, furnished with a mouth, two rows of hooks, and four suckers, in nowise differing from those organs in the Cysticercus. A head like this, however, "supported on a neck so slender, would be quite unable to insure secure attachment for the enormous body it is destined to support; additional and firmer anchorage must therefore be provided: this provision has accordingly been made. Upon the margin of each segment has been placed a strong and prominent sucker, so constructed as to adhere with a firm gripe to the smooth walls of the intestine where the creature has established its abode ; every joint is, therefore, safely fixed in situ, and it thus becomes no easy matter to dislodge a worm like this from its numerous anchorages." *

But what is extraordinary and altogether unparalleled in the economy of the Tape-worms is this, that while, as regards certain organs and functions, each is a single independent animal, in others each is a compound of hundreds of distinct animals. Thus there is but a single mouth and a single alimentary system, while, in respect to the reproductive apparatus, every one of the segments is a

* Jones's Lectures on Nat. Hist., i. 152. 
perfect animal, supplied with complicated male and female organs, and capable of producing a multitude of fertile eggs, quite independently of all the other segments. The segments that contain mature eggs are usually detached from the rest, and separately expelled from the body of the patient.

We have hitherto spoken of these different forms of parasitic worms as so many distinct species, for so they have, up to a late period, been considered by naturalists, taking their places in our zoological systems unchallenged under not only specific but distinct generic appellations. But the observations of an eminent German physiologist, Von Siebold, go far to prove that the Cystoid Worms are but the earlier undeveloped stages of the Tænioid forms, and not only so, but that these larval creatures assume quite different forms and possess different habits according to the kind of animal within whose body they live. That, for example, the microscopic egg or embryo of a Toenia, evolved in the intestinal canal of a dog or cat, if taken with food into the stomach of a rat, finds its way invariably to the liver, and becomes a Cysticercus, while if it be swallowed by a sheep, it travels by some recondite road to the brain, and is transformed into that parasite so fatally known as producing the "staggers," Comurus. Let either of these now, in turn, be swallowed by the carnivorous quadruped, and a Toenia is the invariable result.

But these facts are so curious that our readers may be pleased to read the observations themselves, as recorded by their learned author:-

"I was the first to advance, in the second volume of my 'Manual of Physiology,' published in 1844, the state- 
ment that the Cystoid worm, which lives as a parasite in the livers of rats and mice (the Cysticercus fasciolaris), was nothing but a stray I'cenia which had become vesicular, and which was in fact the Tape-worm of the Cat ('Tonia crassicollis). . . . . In the experiments made at the Institute of the University of Breslau, these transformations took place as soon as the liver of a mouse or rat, previously ascertained to contain a Cysticercus fasciolaris, had been devoured by a cat. In the stomach of the cat, the livers of these rodents were digested, whilst the worms contained in them remained unhurt; this parasite lost the caudal vesicle filled with fluid, and was then to be seen without a tail in the chyme of the stomach and small intestines of the cat, where, finding itself in a suitable place, it became developed in the articulated form of a Tape-worm (Tcenia crassicollis) with adult sexual organs."

More recently Dr Von Siebold has obtained further results with Cysticercus pisiformis, which is frequently met with in the coats of the intestines of the hare and rabbit.

"These Cystoid worms, the size of which did not exceed that of a pea, and which were still contained in the cyst of the intestinal membrane, were introduced by means of milk into the stomachs of some young dogs, to the number of from thirty to sixty individuals to each, These dogs were then killed by means of chloroform at various intervals of time, and the contents of the stomach and intestines carefully examined, when the worms which had been swallowed as food were readily observed in various states of development.

"Two hours after they were swallowed, all the Cystoid worms still remained in the stomach, but in most cases 
the cysts in which they had been enveloped had disappeared; at the same time most of the worms which had been deprived of their cyst had also lost their terminal vesicle, which had either been digested or still adhered in fragments to the abdominal extremity. All the worms found in the stomach, whether with or without their vesicle, had their head and neck withdrawn into the body.

"Three hours after ingestion there were no longer any worms in the stomach; they had all passed with the chyme from this organ into the small intestine. Then, after having lost their cyst and terminal vesicle by the digestive action of the stomach, they all, without exception, as though feeling themselves at home, had again pushed out the head and neck. In all, a distinct lesion was perceptible at the abdominal extremity, at the point where the terminal vesicle had existed.

"In dogs killed several days after the ingestion of the Cysticerci, these worms were found greatly increased in size; the largest had attained a length of three inches, the smallest of one inch. The body, at first merely wrinkled transversely, now distinctly exhibited the articulations, and the point torn by the loss of the vesicle actually presented a cicatrix.

"After twenty or twenty-five days, the worms were several inches in length; they were articulated to the extremity of the abdomen, and the last of their joints still bore the cicatrix above mentioned, which was still very perceptible; traces of sexual organs even were already to be discovered in the posterior segments.

"At the end of eight weeks the worms had attained a great length (the longest were from 36 to 39 inches). 
The sexual character of their posterior segments was completely developed, a great number of ova in a state of maturity being contained in them. Some individuals had already separated their last joints in a perfectly mature state.

"In the Cysticercus pisiformis thus elongated, I recognise the Tcenia serrata of the dog. The extremity of the head, the form of the segments, the nature of the organs of generation, and, above all, of the mature ova of this worm, agreed exactly with the same parts of the Toenia serrata. There was no longer therefore any doubt that the Cysticercus pisiformis of the hare and rabbit is to the Tcenia serrata of the dog what the Cysticercus fasciolaris of the mouse and rat is to the Tcenia crassicollis of the cat.

"The Tcenia serrata is rarely found in watch-dogs or house-dogs, but more commonly in coursing-dogs ; which is easily explained by the fact, that the latter frequently devour the intestines of hares and rabbits captured in the chase, and consequently swallow the Cysticercus more frequently than other dogs." *

From these and other carefully conducted observations, it seems established that the Cystoid worms are only the Cestoids imperfectly developed, "their bodies being encysted in the caudal segment, and this being, as it were, dropsically distended." + The development of the embryo into the Cestoid state, or its arrest in the Cystoid, appears to depend on the nidus in which it is lodged, and this on the habits of the involuntary nurse ; if the embryo lodge in a herbivorous animal, it becomes only a Cystoid worm,

* Ann. des Sci. Nat. 3d ser., xvii. $377 \%$

† Dr Carpenter. 
but if it pass into the carnivorous animal, it becomes Cestoid.

Besides " the staggers," our sheep-farmers are but too familiar with a disease that occasionally decimates their flocks, and which they term "the rot." It chiefly attacks the sheep when pastured in low wet meadows, and is caused by the excessive multiplication of a worm known as the Fluke (Distoma hepaticum), which infests the livers of these and other animals. It resembles a minute sole, about an inch long, with a sucking disk at each end, each of which was formerly supposed to include a mouth (whence the name " double-mouth ;") but the posterior one has been ascertained to be a simple imperforate sucker. From the true mouth proceeds a single digestive canal, which soon divides into two main stems, one passing down each side, and giving off secondary ramifications as they proceed, which branch like the fingers of a hand, or the twigs of a shrub, and thus spread over the whole body. As all the branches are ordinarily filled with dark bilious matter, they can be distinctly seen within the pellucid white flesh, forming two beautifully ramifying trees.

Closely resembling the Fluke in their soft gelatinous flesh, their flattened form, and the ramification of their digestive canal, are the little worms called Planarice, that are found in great numbers on the submerged vegetation of our rivers and ponds. They are generally minute and black; but we have some marine species on our coasts that are much larger, and are ornamentally tinted.

"These creatures, notwithstanding their apparent helplessness, are found to live on worms or insect larvæ; 
neither do they scruple much, if other prey be scarce, to eat their fellow-creatures. To accomplish this, the little cannibals are gifted with a very curious kind of mouth; one, indeed, which has no parallel in any other race of beings. This mouth consists of a long fleshy funnel, plaited like a fan, which can be folded up or spread abroad at pleasure. Should a worm approach, this funnel is unfolded and applied around the body of its prey, which, thus retained, in spite of all its struggles, is soon sucked and emptied of its juices.

"Another circumstance connected with the history of these animals worthy of mention, is their great tenacity of life. If a Planaria be cut in two, so trifling does the occurrence seem, that either part moves on as if quite unconscious of having lost its better half, and straightway can repair the little inconvenience thus produced, the missing portions soon growing again.

"Nay, sometimes they divide spontaneously into two animals, each of which, perfect in all its parts, evinces all the powers of the original being." *

An extraordinary creature was discovered by Dr Nordmann, infesting the gills of one of our commonest river fishes-Cyprinus brama-and to which he gave the appropriate appellation of the Twin-worm (Diplozoon paradoxum). It is not more than one-fourth of an inch in length, but consists of two bodies, precisely resembling each other, united by a central band, exactly in the manner of the Siamese youths, whose exhibition excited so much attention in England and America a few years ago. We might have supposed that, like the human monstrosity in ques-

* Jones's “ Lectures on Natural History," i. 157. 
tion, the Twin-worm was formed by the accidental union of two individuals, if abundant observation had not proved that this is the common mode of life belonging to the species.

Each portion of the animal is complete in all its organs and economy ; possessing its own sets of suckers, its own mouth, its own digestive canal, with its tree-like ramifications, its own perfect generative system, and its own elaborate series of vascular canals,-every organ or set of organs in the one-half finding its exact counterpart in the other.

It scarcely detracts from the marvellous character assumed by this "Twin-worm," that, according to recent observations, the two halves have already enjoyed a phase of existence as distinct individuals. The organic union, or "fusion" of two such individuals, is necessary to the development of the generative system, which, up to that event, is wanting in each constituent half.

All the intestinal Worms that we have been speaking of exhibit a low degree of organisation, and a very simple structure. No nervous system has been detected in them; and the digestive canals are simple excavations in the soft pulpy flesh of the body, without any orifice for the discharge of excrementitious matters. But there are other kinds in which a much higher type of structure obtains; the nervous and muscular systems are distinct ; the digestive canal is a tube, isolated in the midst of a visceral cavity with a proper outlet; and the reproductive apparatus is distributed to distinct sexual individuals.

To this tribe belong the various sorts of Thread-worms, not a few of which infest the human body. The common 
Round Worm (Ascaris lumbricoides), so frequently found in children, is a familiar example. Professor Owen gives some curious details of the fertility of this species, which might well terrify us, but for the reflection with which he subsequently consoles us. "The ova are arranged in the ovarian and uterine tubes, like the flowers of the plantago, around a central stem or rachis. There are fifty in each circle-that is to say, you might count fifty ova in every transverse section of the tube. Now the thickness of each ovum is $\frac{1}{500}$ th of a line, so that, in the length of one line, there are 500 wreaths of 50 eggs each, or 25,000 eggs ! The length of each division, or horn of the uterus, is 16 feet or 2304 lines, which for the two horns give a length of 4608 lines. The eggs, however, gradually increase in size, so as to attain the thickness of $\frac{1}{60}$ th of a line : we, therefore, have at the lower end of the horn sixty wreaths of ova in the extent of one line. The average number through the whole of the extraordinary extent of the tube may be taken at 14,000 ova in each line, which gives sixty-four millions of ova in the mature female Ascaris lumbricoides!

"The embryo is not developed within the body in this species ; the ova may be discharged by millions, and most of them must, in large cities, be carried into streams of water. An extremely small proportion is ever likely to be again introduced into the alimentary canal of that species of animal which can afford it an appropriate habitat. The remainder of the germs doubtless serve as food to numerous minute inhabitants of the water; and the prolific Entozon may thus serve these little creatures in the same relation, as the fruitful Cerealia in the vegetable 
kingdom stand to higher animals, and minister less to the perpetuation of their own species than to the sustenance of man." *

The researches of MM. Ercolani and Vella, $t$ on the embryogeny and development of the Nematoid (thread-like) Intestinal Worms, have revealed some details which, though not so startling as those discovered by Dr Von Siebold on the Tænioids, possess considerable interest.

"The Thread Worms do not undergo a true metamorphosis ; the changes observable in the embryo are only phases of developments ; but as in the Tænioids the generative organs are the last formed, and are not perfect till the complete development of the animal.

"The cessation of movement and the fluidity of the body in the Nematoids are not sufficient signs of the death of these animals, as they recover from this state as soon as they are placed in warm water; even in the state of embryos, although completely dried up, they return to life very quickly by this means. The Nematoid worms consequently die with great difficulty; the ova and embryos are endowed with a marvellous tenacity of life ; they even exhibit signs of life after immersion for six days in alcohol of 30 degrees.

"This tenacity of life, joined with the power of development of the ovum when placed in circumstances different from those in which it lives naturally, besides giving evidence of new and important facts, destroys the strongest arguments employed by many naturalists in favour of heterogeny. ${ }^{+}$

* Comp. Anat.; i. 76. (Edit. i.)

† Comptes Rendus, 24th April 1854.

$\ddagger$ Heterogeny, a total difference of form between parent and offspring. 
"The ova of the Nematoids, after passing into the bodies of animals with their food, insinuate themselves into the walls of the intestine, so that their presence completely escapes detection. In this position these ova undergo a sort of incubation, and the embryo becomes sufficiently developed to return into the intestinal cavity, where it is afterwards to pass its life." 



\section{PART II.}

\section{LIFE, IN ITS INTERMEDIATE FORMS.}



WORMS.

\section{CHAPTER XIV.}

ANnelida (Worms).

The forms of animate existence which we have briefly examined in the previous chapters, may be likened to the humbler ranks of society; the Vertebrata are certainly the aristocracy; but between these there ranges a great middle class, the most populous, the most ingenious, and in some respects the most interesting, of the whole. They constitute the important divisions which naturalists term Articulata and Mollusca.

We have alluded to the populousness of these sections : a single subdivision of one of them (INSECTs) is believed to be at least twenty times as numerous in species as all other animals put together.*

We do not expect our readers to study technical zoology at the breakfast-table, nor to make a dish of prawns the

* Some years ago, an eminent zoologist gave the following table as his estimate of the probable number of existing species of animals, deduced from facts and principles then known. Later discoveries tend to increase rather than to diminish the estimate.

$\begin{array}{lrrrrrrrrrrr}\text { Quadrupeds } & \ldots & \ldots & 1,200 & \text { Worms } & \ldots & \ldots & \ldots & \ldots & \ldots & 2,500 \\ \text { Birds ... } & \ldots & \ldots & \ldots & 6,800 & \text { Radiata } & \ldots & \ldots & \ldots & \ldots & \ldots & 1,000 \\ \text { Reptiles } & \ldots & \ldots & \ldots & 1,500 & \text { Polypes, } & \text { \&c. } & \ldots & \ldots & \ldots & \ldots & 1,530 \\ \text { Fishes } & \ldots & \ldots & \ldots & 8,000 & \text { Testacea } & \ldots & \ldots & \ldots & \ldots & \ldots & 4,500 \\ \text { Insects } & \ldots & \ldots & \ldots & 550,000 & \text { Naked Testacea } & \ldots & \ldots & \ldots & 600\end{array}$
making an aggregate of 577,600 species. (Swainson's "Geog. and Classif. of Quadrupeds," p. 28.) 
text of a lecture ; but still, if the function of the palate have not utterly extinguished that of the eye, they can scarcely have picked one of those dainty animals to pieces without having observed that it is encased in a sort of armour composed of many rings, the edges of which overlap, and which thus work one within the other. This circumstance forms the most prominent characteristic of a grand division of living beings, which are thence called Annulosa (ringed), or ARticulata (jointed). Another mark of distinction is that their skeleton is external ; the outer skin, hardened in most cases into a horny crust, affording attachment to the muscles, and giving by its solidity and resistance precision and force to their contractions. In some cases, indeed, this structure is less obvious, the skin being rather membranous than crustaceous, but even there it is more tough and leathery than the internal parts.

But the most important distinction of all, though it is one which is appreciated only by the anatomist, is the condition of the nervous system. That remarkable substance, neurine-which is the material seat of all sensation, and the proximate source of all motion, the ultimate link of matter, whereby the spirit lays hold of it-is either not discernible at all in the inferior creatures we have been considering, or else exists only in the form of slender threads, without any centres of accumulation. We now no longer find it in this rudimentary condition. In the Articulate animals there is a distinct arrangement of the nerves, which, in general, run down the middle of the body in two parallel cords, united at certain intervals by knobs or aggregations of the nervous substance, called 
ganglions, which send forth ramifying threads on each side, thus distributing sensibility to all parts of the body.

There is in all these creatures a distinct head, * furnished with various organs of sense ; and for the supply of these the nervous matter is more abundant there than in other parts, forming a thick ring round the gullet and uniting into an enlarged ganglion above it. In conformity with this concentrated condition of the nervous system, the animals with which we have now to do display a perfection of sense, an energy of motion, and a versatility of instinct, which are unknown to those ranks that are below them in the vital scale. In all these qualities, as well as in the physical peculiarities which we have enumerated, there exists considerable diversity; so that the great division before us is naturally divided into several subordinate, but still important groups.

We cannot in these pages review every link in the vast chain of Nature, though we may safely predicate that there is not one which would not well repay the investigation by some fresh evidence of the perfections of the Godhead; not one which would not testify with fulness and clearness-

"The hand that made us is divine!"

The humblest class of Articulated animals is that of the Worms (ANNELIDA), which are not very remotely separated from those lengthened forms of Echinodermata, which we lately considered. An Earth-worm or a Leech is not, indeed, an articulate animal, strictly so called; but it

* In some of the Worms, indeed, as well as in the Rotifera, the head does not exist in its ordinary distinct form, but the organs of sense are present, and the exception is more apparent than real. 
is an annulose one, for its body is composed of an immense number of rings, which, partially slipping one within the other, impart the power of alternate contraction and elougation, which is so remarkable in these creatures.

Scarcely a single oyster can be dredged from deep water -especially if the ground be rocky-which is not more or less covered with shelly tubes, that sprawl and twist over its surface in various contortions, so firmly adhering to it as not to be removed without fracture. Stones, pieces of crockery, broken glass, and all sorts of shells, are liable to be overspread with these white pipes, after they have been immersed a short time in the sea; and similar structures occur, of a smaller kind, about the pebbles that lie on the shore near low-water mark. These are the dwellings of marine worms called Serpula.

If we select a shell on which is seated a cluster of these pipes, and put it into a basin of sea-water, we shall soon be delighted with a brilliant spectacle. Let us suppose the tubes to be of that kind which is about as thick as a tobacco-pipe, which is adherent for the most part of its length, but rears upwards at its extremity, and displays a smooth circhiar mouth (Serpula contortuplicata). Down in the depth of the interior we presently discern what resembles a cork of a bottle, gradually pushed up till it reaches the orifice, which it accurately fits. It is a conical stopper, of a brilliant scarlet hue, marked with a number of ridged lines all diverging from the centre.

The stopper still emerges, and we see that it forms the end of a long slender stem, which is slowly pushed out to make room for other emerging organs in the form of a double fan of scarlet threads radiating from a sort of 
collar, and arranged somewhat like two petals of a flower, with a deep bend or sinuosity where they unite.

The extreme beauty of the display cannot but elicit our admiration ; we raise a finger to point out some particular item to a companion, when, lo! the whole apparatus disappears like a vision; with the speed of thought the whole has been retracted into the pipe, the stopper entering last of all, and tightly closing the aperture

Our friend Serpula is an exceedingly prudent personage, and will not soon emerge fro $m$ his strong castle again, after receiving such a fright as the lifted finger gave to his sensitive ganglia; and when he does, it will not be without great caution. Meanwhile, as we are waiting his reappearance, we will briefly discuss some points of his organisation.

Those beautiful fan-shaped petals are gills, the breathing organs of the animal, whereby he derives from the seawater the oxygen necessary for the renewal of the blood, which is constantly exhausted in the building-up of the various tissues. Their situation at the anterior extremity of the body is a wise provision, since they can by this arrangement be periodically bathed in the surrounding water, with the least possible exposure of the animal. In other species, however, which do not inhabit tubes, the gills are situated on other parts of the body. Thus in the common Lug (Arenicola), or Mud-worm, so well known to every fisherman for its value as bait, the gills form little tufts of a crimson hue on the rings of the middle part only. While on the exquisite Leaf-worms (Phyllodoce) they resemble heart-shaped leaves, arranged in a row on each side throughout the entire length. 
That singular stopper, of which the function is so manifest, is one of a pair of tentacles ; organs which in general are exactly alike. Here, however, one is destined to close the orifice, and as one only could perform that office, the other is quite plain, a simple thread, while this is enlarged into a conical plug. What wise contrivance is manifested here!

We wondered at the extraordinary rapidity with which the timid animal disappeared on alarm, and are curious to know the mechanism by which it is effected. Each of the rings of which the body is composed carries on each side a little wart-like foot, within which is a bundle of horny bristles, like the filaments of a hair-pencil, capable of being protruded and withdrawn. The microscopic structure of these is most elaborate, but we cannot detail it here ; it may be sufficient to say that it is by the protrusion of these pencils in turn, which press backwards against the sides of the tube, that the animal pushes its foreparts out.

But the retreat requires a more powerful machinery for its extraordinary fleetness ; and this deserves a more close investigation. On carefully examining a Serpula recently dead, we observe, by means of a lens, a pale yellow line running along the upper surface of each foot, transversely to the length of the body. This is the border of an excessively delicate membrane, and on placing it under a high power (say 300 diameters) we are astonished at the elaborate provision here made for prehension. This yellow line, which cannot be appreciated by the unassisted eye, is a small muscular ribbon, on which stand up edgewise a multitude of what we may call combs, or rather sub- 
triangular plates. The edge of each plate is cut very regularly into six sharp teeth, which curve in one direction, and one other, curved so as to face these. The combs stand side by side, parallel to each other, along the whole length of the ribbon; and there are muscular bands or fibres seen affixed to the smaller end of every plate, which doubtless give it independent motion. We have counted one hundred and thirty-six plates on one ribbon; there are two ribbons on each thoracic segment, and there are seven such segments; hence we may compute the total number of prehensile comb-like plates to be about one thousand nine hundred, each of which is wielded by muscles at the will of the animal; while, as each plate carries seven teeth, there are between thirteen and fourteen thousand teeth hooked into the minute cavities and roughnesses of the interior surface of the cell, when the animal chooses to descend. No wonder, with so many muscles wielding so many grappling hooks, that the retreat is so rapidly effected!

The bundles of bristles which line the wart-like feet, are very extensively found in this class of animals; and in some species they exhibit strange and singular forms, resembling the fantastic but formidable weapons of some semi-savage people. Thus in a flat scaly worm (Polynoe), common enough under stones at the water's edge, the armoury consists of several sorts of weapons. First, there are long lances made like scythe-blades set on a staff, with a hook at the tip to capture the fleeing foe, and bring him within reach of the blade. Among them are others of similar shape, but with the edge cut into delicate slanting notches, which run along the sides of the 
blade, like those on the edge of our reaping-hooks. These are chiefly the weapons of the lower bundle; those of the

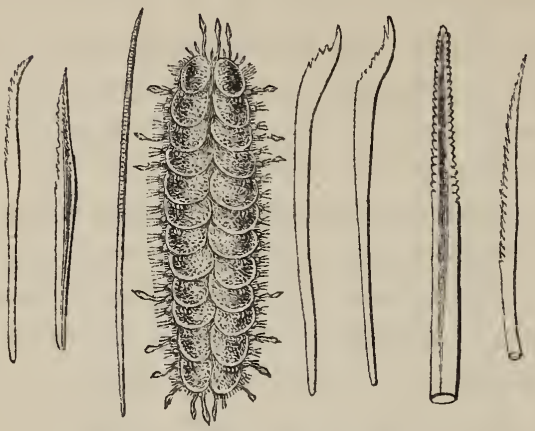

Polynoe-(with its lances magnificd.)

upper are still more imposing. The outmost are short, curved clubs, armed with a row of shark's teeth to make them more fatal ; these surround a cluster of spears, the long heads of which are furnished with a double row of the same appendages; and lengthened scimitars, the curved edges of which are cut into teeth like a saw. To add to the effect, imagine that all these weapons are forged out of the clearest glass instead of steel ; that the larger bundles may contain about fifty, and the smaller half as many, each ; that there are four bundles on every segment, and that the body is composed of twenty-five such segments; and you will have a tolerable idea of the garniture and armature of this little worm, that grubs about in the mud at low-water mark.

Some of the Worms, both of the sea, and of freshwaters, manifest a singular power of self-multiplication. In one or two species of Syllis, and in some of the genus 
Nais, the last segment of the body increases in size, and becomes marked with segments, which grow more and more distinct ; in time, a head begins to form at the anterior end, which is furnished with antennæ. At length this strangely-made animal breaks off from the parent, and enters upon an independent existence. The facts have been denied; but we can give the testimony of personal observation to their truth, having witnessed the process in both the genera above mentioned.

Many of the marine Worms are remarkable for gorgeousness of colouring; and not a few display opaline reflections and metallic changes of hue of great splendour. There is a species, by no means rare on our coasts, called the Sea-Mouse (Aphrodite), which rivals the hummingbirds in the magnificence of its array. It is a curious animal in many respects. The form is unusual, at least in this class, being somewhat oval ; it is a flattened, unshapely creature, about an inch and a half in breadth, and some three or four inches long, of a dusky brown hue, except at the sides, which are clothed with a dense coat of long, slender bristles. It is in these that the creature's glory resides. This clothing reflects the most glowing prismatic colours, crimson, scarlet, orange, yellow, green, blue, and purple, ever varying according to the angle at which the rays are reflected to the observer's eye. Thus are verified the lines so familiar to our infancy :

"Let me be dress'd fine as I will,

Flies, worms, and flowers, exceed me still."

In another allied species the side bristles exhibit a structure, which admirably adapts them for weapons of defence. The tip of each bristle is a barbed spear, being 
beset on two sides with numerous points directed backwards. As these bundles of spears are retractile, however, the tender flesh of the animal would be liable to laceration when they are withdrawn into the interior of the foot; but a beautiful provision is made to meet this emergency. Each of the barbed javelins is furnished with two membraneous blades, between which it is enclosed, in repose ; these prevent the points from coming into contact with its own flesh, while they readily open, and offer no impediment to the extrusion of the weapon.

In the common Earth-worm (Lumbricus), the rings are very numerous, and each ring is furnished with eight retractile bristles, by means of which it traverses its long burrows. Mr Charles Darwin has satisfactorily proved that earth-worms are most valuable agents in fertilising lands, especially in undisturbed pastures, gradually covering the surface with their casts, and thus forming a layer of finely pulverised earth of the richest character. A field which had been limed was examined after about eighty years, when the lime was found to be evenly covered, to the depth of thirteen inches, with this animal mould."

The Leeches (Hirudo, \&c.) are not provided with bristles for locomotion; but a compensation is given them in the form of a sucking disk at each extremity. They move, as is well known, by the alternate adhesion and detachment of each sucker. The Medicinal Leech (H. medicinalis) performs its useful office, under the concealment of one of these suckers ; and hence its mode of action is not generally known. Its mouth is furnished with three 
small semi-oval tubercles arranged in a triangle, the upper edge of each tubercle being cut into minute but sharply serrate teeth. When a vacuum is made beneath the anterior sucker, these tubercles are brought into close contact with the skin of the patient: proper muscles then move them to and fro in a saw-like fashion, when the minute teeth presently cut through the skin and superficial vessels, and the blood flows profusely, under the atmospheric pressure, into the stomach of the Leech.

It is very remarkable that blood is not the natural food of the Leech; and that the fluid which it so greedily swallows does not pass into the intestine, but remains in the stomach for many months; and, what is still more curious, it does not coagulate during the whole of that time, as it would do in an hour if exposed to the air, but continues to retain its fluidity. Hence it has been not unreasonably concluded that this habit is rather a special provision ordained by the Divine mercy to render these creatures subservient to the alleviation of human suffering than necessary to supply the wants of the animals themselves.

We must not, however, suppose that the "convenience, health, or safety" of man is the only object of the creative wisdom of God. There are numberless provisions expressly made for the comfort and wellbeing of the inferior creatures themselves; and no creature is so mean, worthless, or humble, but it has been the object of His paternal care in multitudinous instances, a few of which only, doubtless, we are cognisant of. Two or three examples of benevolent foresight and curious contrivance have been mentioned in this paper, and the enumeration 
might be extended almost ad libitum: but these are sufficient to shew that God cares not only for sparrows, but even for worms also.

What, then, shall we infer from hence? Shall we take up the infidel sentiment of the poet, so unjustly belauded-

" He sees with equal eye, as God of all, A hero perish or a sparrow fall ; Atoms and systems into ruin hurl'd, And now a bubble burst, and now a world ?"

Nay, rather, let our comfortable conclusion be, that which the Lord Jesus teaches us to draw from analogous examples : "If God therefore so clothe the grass of the field, which to-day is, and to-morrow is cast into the oven, shall he not much more clothe you?" "Ye are of more value than many sparrows." 
CENTIPEDES.

\section{CHAPTER XV.}

\section{Mrrinpoda (Centipedes).}

There is a small class of animals, familiar enough to all, because several species are common in every garden, which seem but slightly removed above the AnNeLiDA we lately considered. If we take one of the many-ringed sea-worms, a Nereis or a Phyllodoce, for example, and compare it with a Scolopendra from beneath a stone, or a Julus from a decaying tree, we shall be at once struck with the resemblance in structure between the two forms; the leading character in each case being that the greatly lengthened body is composed of numerous segments, each the counterpart of the others, and each bearing a lateral pair of short limbs.

The limbs in the Myriapod are made of distinct joints, which is not the case with the Annelid; the integument of the body is of a firmer and more horny character ; and the stiff segments are separated by a thin flexible membrane, so that considerable freedom of motion is allowed; but these modifications have respect mainly to the sphere of action of the animal, which is terrestrial ; a greater degree of firmness and compactness being necessary for vigorous movements on the solid earth, than for those performed in water. 
Air now becomes the medium of respiration, and, accordingly, this function is carried on by a new set of organs, called trachece. These are pipes which ramify throughout the whole body, communicating with the atmosphere by certain minute orifices (spiracles), situated one on each side of every segment.

There is considerable diversity between the animals of this class in organic development. The feeble inert Julus is but little elevated above the Worm; its body being divided into forty or fifty segments, each of which carries two pairs of minute and powerless feet. Its mouth is furnished with a pair of horny plates, with toothed edges, which are brought into contact by a movement from right to left. The head bears a pair of thread-like horns, evidently organs of sense; these are shadowed out in the appendages of the heads of many ANNeLIDA ; but being now, for the first time, distinctly jointed, a new name is given them,-that of antennce. These organs henceforth occupy an important place in the economy of the ARTICULATA.

In the Centipede (Scolopendra), we have a much more vigorous and formidable creature. The most obvious change from the Julus is the concentration of its parts; the segments are greatly reduced in number, but proportionally developed in size ; they are furnished with more powerful muscles, and each bears but a single pair of limbs, which are longer, more distinctly jointed, and endowed with greater powers of motion. Besides the cutting blades, with which the mouth is armed in common with the Julus, the Scolopendra is endowed with peculiar weapons of offence in the form of a pair of stout curved 
pointed fangs, working transversely in front of the head. Each of these fangs is perforated, and bears a bag of virulent poison, which is infused into the wound made by the point, exactly like the venom of the viper. The fangs are moved by very powerful muscles, so that, wielded by an animal of acute perceptions, and of considerable strength and swiftness, it may be reasonably expected that they become the ministers of speedy death to multitudes of insects on which the Centipede habitually feeds. Even man has learned to dread their power; the species are numerous in all tropical countries, where many of them attain a large size; not infrequently being seen a foot in length, and an inch in breadth; the bite of these species is much more formidable than the sting of the Scorpion, always producing fever, and sometimes death.

As if this were not enough to make the Centipedes formidable, some kinds appear to be endowed with that mysterious power, possessed by certain fishes also, of communicating electric shocks to other creatures. A smart discharge, quite sensible to the human nerves, is said to be given by Geophilus electricus, a lengthened slender species, not uncommon in our gardens. This same species is also luminous in the dark, giving out a pale blue gleam from every part of its body. We once had an opportunity of making some observations on this interesting luminous creature, which are recorded elsewhere,* and to which we therefore refer our readers.

The animals of this class undergo certain changes of form in their progress from infancy to the adult condition; these, however, can scarcely be called metamor- 
phosis. They rather consist of a progressive increase of the number of limbs, and of segments. At birth, the Julus is destitute of limbs, which do not appear till after the first moult. Three pairs are now developed, and with these the little creature must be content until the second moult, after which it possesses seven pairs. These are placed on the foremost segments, the posterior rings being, as yet, destitute of limbs. The third moult occurs when the animal is a month old; it has now twenty-two segments, and twenty-six pairs of feet. Thirty-six pairs of feet signalise the fourth moult; and after the fifth, there are forty-three pairs, and thirty segments. Finally, in the adult condition, thirty-nine segments are distinguished in the male, and sixty-four in the female.* 


\section{CHAPTER XVI.}

\section{InSECTA (Insects).}

WE have now to do with a host of creatures, which, though of minute dimensions, are sufficiently conspicuous in many aspects to have been objects of popular interest in all ages. We find no longer the soft gelatinous bodies, sluggish habits, and indeterminate forms, which have so generally characterised the races through which we have passed; but active and agile animals, of firm and solid parts, furnished with well-appointed limbs, liberally endowed with organs of sense, in full variety and perfection, and displaying a versatility of instinct, and a measure of intelligence that would scarcely be surpassed by the noblest of the brute creation. The mailed and powerful Beetle, the soaring Butterfly, the predaceous Dragon-fly, the industrious Bee, the sagacious Ant-are representatives of the Class of Insects.

The unparalleled number of species included in this division, and the consequent abundance and variety which exist in the details of structure and habits, render it difficult to give anything like a popular view of the whole Class within reasonable limits. Probably above 150,000 species of Insects exist in the cabinets of European collec- 
tions; by which word "species" we mean animals as distinct from each other as the Rat from the Mouse, or the Blackbird from the Thrush ; races of animals, each of which has descended from an original first parent, created distinct and separate at the beginning of the world.

Insects are composed of rings, or annular segments, like the ANNeLIDA ; and a caterpillar, which is an immature butterfly or moth, is much like a Worm; but in the full-grown Insect we see a manifest condensation of form, the segments being generally compacted together, except at two points, where division is very manifest. Thus, if we look at a Wasp, we see that it is distinctly divided into three portions, the head, the trunk (thorax), and the body (abdomen); separated by constrictions so deep as nearly to cut off the mutual connexion of these parts. All perfect or full-grown Insects shew the same divisions, though not commonly so strongly marked. The appellations "Insecta" and "Entoma" (whence entomology) have been hence given to the Class, these Latin and Greek terms signifying "cut into."

The perfection which is bestowed on the organs of sense in these animals, especially when we consider their minuteness, is calculated to fill us with adoring admiration of the skill of "the Great Workmaster." Take an example from the eyes, which are of several kinds, evidently designed for distinct modes of vision, of which we, who have but one sort of eyes, can form no adequate notion. The Bee and many other insects have on the crown of the head a number, usually three, of simple glassy eyes, set like " bull's-eyes" in a ship's deck; and besides these a great compound eye on each side, consisting of a multitude of 
lenses aggregated together upon the same optic nerve. The microscope reveals to us that the compound eye of an Ant contains fifty lenses ; that of a Fly, four thousand ; that of a Dragon-fly, twelve thousand ; that of a Butterfly, seventeen thousand; and that of a species of Mordella (a kind of beetle), the amazing number of twenty-five thousand. Every one of these regular, polished, and manysided lenses, is the external surface of a distinct eye, furnished with its own iris, and pupil, and a perfect nervous apparatus. It will thus be seen that each hexagonal facet forms a transparent horny lens, immediately behind which is a layer of pigment diminishing to a point in the centre, where it forms a pupil ; that behind this a long six-sided prism, answering to the crystalline and vitreous humours in the human eye, extends, diminishing to its lower extremity, where it rests upon the retina, or network expansion of the optic nerve. Some of the minuter details of this exquisite organisation are still matters of conflicting opinion; but these we omit, as our purpose is rather to convey to our readers a general idea of the structure of this complex organ of vision. "This also cometh forth from the Lord of Hosts, which is wonderful in counsel and excellent in working." (Isa. xxviii. 29.)

With very few exceptions, the animals of the previous Classes are confined to the waters; the density of such a medium being requisite for the support of their soft and feeble bodies. But the solid external investiture of Insects, and their well-jointed limbs, impart to them sufficient firmness and precision of motion to range the earth and air ; many species being endowed with organs which enable them to swim, run, or fly at their pleasure. Pro- 
fessor Owen thus eloquently speaks of the various powers of these indefatigable little creatures :-

"Some traverse the surface of the earth with a succession of steps too swift for definition; some by leaps so extraordinary as to have excited the powers of the dynamical calculator from the earliest periods. The waters also have their insect population, some swiftly cleaving the clear element, some gyrating on the surface, while others creep along the bottom. Nor are the activities of the aquatic insect confined to that lower sphere. The Nepa, or the Dytiscus, at the same time, may possess its organs of creeping, of burrowing, and of flight; thus, like Milton's fiend, it is qualified for different elements, and

' Thongh straight, rough, dense, or rare,

With head, hands, wings, or feet, pursues its way,

And swims, or sinks, or wades, or creeps, or flies.' "*

The muscular strength of insects is immense. We once were surprised by a feat performed by a Beetle (Oryctes maimon) common in the United States. Wehad put the insect, for want of any box at hand, beneath a quart bottle full of milk upon a table, the hollow at the bottom allowing him room to stand upright. Presently, to our surprise, the bottle began slowly to move and glide along the smooth table, propelled by the muscular power of the imprisoned insect, and continued for some time to perambulate the surface, to the astonishment of all who witnessed it. The weight of the bottle and its contents could not have been less than three pounds and a half; while that of the beetle was about half an ounce, so that it readily moved a weight 112 times exceeding its own. A 
better notion than figures can convey will be obtained of this feat by supposing a lad of fifteen to be imprisoned

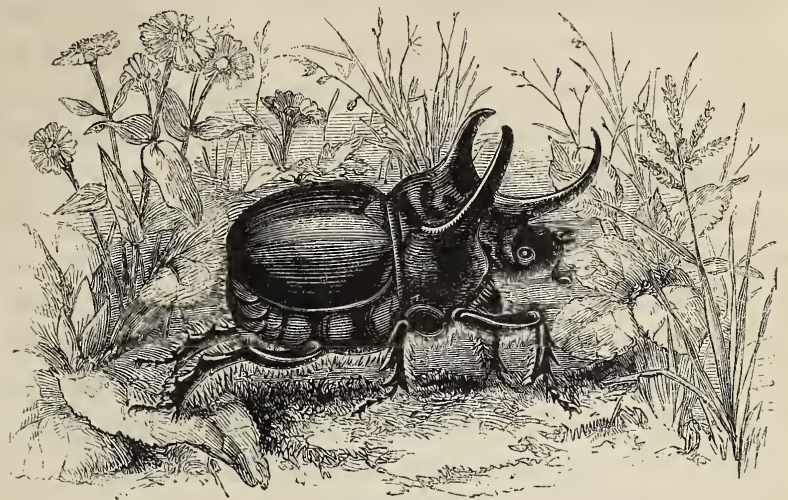

Oryctes maimon.

under the great bell of St Paul's, which weighs 12,000 lbs., and to move it to and fro upon a smooth pavement by pushing within.

Mr Newport has given other instances of insect-power equally remarkable. Having once fastened a small kind of Carabus, an elegantly formed Ground Beetle, weighing three and a-half grains, by a silk thread, to a piece of paper, he laid a weight on the latter. At a distance of ten inches from its load, the insect was able to drag after it, up an inclined plane of twenty-five degrees, very nearly eighty-five grains; but when placed on a plane of five degrees' inclination, it drew after it one hundred and twenty-five grains, exclusive of the friction to be overcome in moving its load, as though a man were to drag up a hill of similar inclination a waggon weighing two tons and a half, having first taken the wheels off. 
According to the same excellent authority, the Stag Beetle (Lucanus cervus) has been known to gnaw a hole an inch in diameter through the side of an iron canister in which it was confined, and on which the marks of its jaws were distinctly visible, as proved by $\mathrm{Mr}$ Stephens, who exhibited the canister at one of the meetings of the Entomological Society.

Let us look at the powers of Insects exercised in the act of flying. The House-flies (Musca domestica), that wheel and plar beneath the ceiling for hours together, ordinarily move at the rate of about five feet per second; but if excited to speed, they can dart along through thirtyfive feet in the same brief space of time Now in this period, as Kirby and Spence observe, " a race-horse could clear only ninety feet, which is at the rate of more than a mile in a minute. Our little fly, in her swiftest flight, will in the same space of time, go more than one-third of a mile. Now compare the immense difference of the size of the two animals (ten millions of the fly would hardly counterpoise one racer), and how wonderful will the velocity of this minute creature appear! Did the fly equal the race-horse in size, and retain its present powers in the ratio of its magnitude, it would traverse the globe with the rapidity of lightning." "* Some of the flies that haunt our gardens shoot along so rapidly that the eye cannot follow them in flight.

Nor are these tiny creatures less masters of the arts of running and leaping. De Lisle mentions a fly so minute as almost to be invisible, which ran nearly six inches in a second, and in that space was calculated to have made 
one thousand and eighty steps! This, according to the calculation of Kirby and Spence, is as if a man whose steps measured only two feet, should run at the incredible rate of twenty miles in a minute.

Every one has had occasion to observe, not always without an emotion of anger, the leaping powers of the Flea (Pulex irritans). A bound of two hundred times its own length is a common feat; as if a man should jump twelve hundred feet, or a quarter of a mile! What a pity that Insects were not allowed to be competitors in the athletic games of old!

With regard to their organisation, all Insects in the mature state are armed with three pairs of legs; which are divided into several parts, as, the hip, the thigh, the shank, and the foot, by distinct hinge-joints: the foot itself (tarsus) consists of several jointed pieces, and is usually terminated by two hooks, and often furnished with adhesive pads, or other organs accessory to locomotion. In most of the tribes there are also wings, two pairs in general (but in one extensive Order the hinder pair is obliterated) ; each of these organs consists of two films of highly elastic membrane, stretched over a frame-work of strong tubes, as the silk of an umbrella is expanded over its ribs. In the Order Coleoptera (Beetles), the fore pair are thick, leathery, and opaque, chiefly serving as shields to protect the hind pair in repose; and in some other Orders they are somewhat coriaceous ; while in the beautiful Lepidoptera (Butterflies), the transparency of both pairs is concealed by a covering of minute feather-like scales, overlapping each other, reflecting various colours, and arranged in a mosaic of inimitable beauty. 
The power of these organs, so delicate and filmy in appearance, we have before alluded to, but it may be illustrated by another anecdote. Leeuwenhoek has recorded a remarkable instance, in which he was an eyewitness of the comparative capabilities of the Dragon-fly and the Swallow, as relates to the perfection of their flight. The bird and the insect were both confined in a menagerie about a hundred feet long; and apparently their powers were fairly tested. The swallow was in full pursuit, but the insect flew with such astonishing velocity, that this bird of rapid flight and ready evolution was unable to overtake and entrap it ; the insect eluding every attempt, and being generally six feet before it.

The organs of the mouth vary much in form and function in different insects. In a Beetle they consist of two pairs of jaws, generally hooked and toothed, working horizontally, and an upper and an under lip, closing the mouth above and below. Each lower jaw bears onc or two filaments, consisting of several joints ; and a similar pair is affixed to the lower lip. These filaments are called palpi, and are supposed to be highly endowed organs of touch. They greatly resemble the antennce, or horns of many joints, which project from the front of the head; but these latter are considered to be organs of hearing.

If we look at a Gnat piercing our hand with its bloodsucking tube, or a Butterfly pumping up the nectar of a flower through its spiral tongue, or a Fly dissolving grains of sugar with the fleshy lips of its proboscis, we shall not very readily allow them any analogy with the apparatus of jaws and lips which we have just described. Yet great as is the dissimilarity, it is now established, that all these 
forms of mouth are but modifications of the same model, adapting it to different functions. The sheath, horny and tubular in the Gnat, soft and muscular in the Fly, is the lower lip; the piercing lancets in the former are the jaws, which are inconspicuous in the latter. The elegant coiled spire of the Butterfly consists of two tubes, which are the lower jaws, greatly lengthened; and the labial palpi, stout and hairy, stand up on each side of them : the other essential parts can be detected only by the skill of the anatomist.

Some of the most interesting of the phenomena which occur in the economy of Insects, are the transformations which they exhibit in their progress of growth; the changes of their form being frequently so great, that it would be impossible, but for the testimony of experience, to aroid the conclusion that the same insect, in infancy, youth, and adult age, belonged to widely distinct and remote orders of existence. We shall enter into some details of this interesting subject in our next chapter. 


\section{CHAPTER XVII.}

\section{INSECTA (Insects).}

\section{Continued.}

How delightful is the season, when the Butterflies begin to spangle the fields and woodlands! Welcome visitants they always are, in their airy grace and beauty ; not less welcome than the flowers on which they alight, and whose brilliant hues and delicate petals are rivalled by their painted and filmy wings.

"The Butterflies are come !" Yes, it sends a thrill of pleasure through the heart, after the long dreary winter, to see the first Butterfly of the season sailing on its broad sylphic pinions in the warm beams of a calm April morning. Perhaps it is the pretty little Orange-tip (Mancipium cardamines), that attendant on early spring, coursing along some rural lane; or the Brimstone (Gonepteryx rhamni), hovering over a perfumed cluster of primroses, itself scarcely to be distinguished from one of them. Perhaps it is the Admiral (Vanessa Atalanta), whose fine scarlet bands afford so rich a contrast to its black velvet wings; or the Peacock ( $V . I 0)$, with its gorgeous violet eyes; or the Tortoise-shell ( $V$. urtica), clouded with yel- 
low and orange and black,-busy among the lowly nettles, attentive to the grand occupation that forms "The Whole Duty of Butterflies," - the providing for the continuance of the race, by depositing here an egg and there an egg, on the stems or beneath the leaves of those grim and formidable weeds. But even if it is one of much humbler pretensions, the White (Pontia brassica) of our kitchengarden, still it is a Butterfly, and we look upon it with a hearty welcome, forgiving, and for the moment forgetting, all the robbery it committed upon our cabbage before it was born.

And these frail creatures are worthy of our kindly regard, not only for their association (true children of the sun, as they are) with all that is most lovely in scenery, and most delightful in season, but because of their own personal claims to our admiration. If we capture that Red Admiral or Peacock that is so intent upon the nettles, what a glorious creature should we think we had obtained if we had never seen anything like it before! How light and papery, yet how strong and effective, are these broad wings! with what an elegant pencil has this pattern of beautiful colours been traced! But stay! let us look closer at this painting, aiding our sight with a pocketlens. It is a most exquisite mosaic, fashioned out of innumerable coloured pieces, of regular shape and arrangement.

If we look at our fingers' ends with which we have touched, though ever so lightly, these pencilled surfaces, we see that some of the colouring is transferred to them; and if we have pressed the wing, as in seizing it for the purpose of capture, we find that the finger presents the 
pattern of the touched part in all its beauty. Now by touching with the charged finger-end a strip of glass, and placing this latter beneath a microscope, we discover an extraordinary specimen of the Divine handiwork. Hundreds of objects are left adhering to the glass plate, which we know not whether to call scales or feathers. They display considerable variety of form, but the most common is oval, or semi-oval, with a little projecting stem or quill at one end. They are thin and flat, transparent and membranous in texture, with several ribs running lengthwise, the points of which project beyond the end of the scale.

These scales, then, produce the beautiful party-coloured patterns of a Butterfly's wing; but of positive colour they possess individually no trace under the microscope, save a dull smoky appearance. It is by the separation and reflection of the prismatic hues that they appear beautiful, but by what law some reflect none but red, some none but yellow, some none but blue rays, we know not.

On examining the wing that has been denuded of its coloured scales, we see a transparent, dry, brittle membrane, pitted with innumerable punctures arranged in lines; these are the depressions in which the stems of the scales were originally planted. They were so ordered that the extremity of one scale reposed on the base of its successor, overlapping and concealing its stem, so that the arrangement resembled that of tiles or slates on a roof. We have said they are innumerable; the expression is not literally exact, but you will think it excusable when you hear that Leeuwenhoek computed the number of scales on a Silkworm Moth (Bombyx mori), to exceed 400,000 ; and those which bespangle the wings of the 
great tropical Moths and Butterflies, some of which expand eight or nine inches, must be vastly more numerous, since the size of the scales does not at all depend on the dimensions of the wing.

The whole Class of Insects is subject to metamorphosis ; that is, the same individual animal in the course of its progress from infancy to adult age assumes an appearance and form, with organs both external and internal, different at different stages of its life. In none of the Orders are these transformations more remarkable than in that which we are now considering, the elegant Order LEPIDOPTERA, the Butterflies and Moths.

The parent Butterfly, seeking on restless wing for the plant which shall form a suitable food for her unborn young, at length lays on its leaf an egg, cementing the tiny atom to its surface by a natural glue, which immediately hardens. In a few weeks a minute Caterpillar breaks from the prison, and frequently commences existence by devouring with its powerful jaws the horny eggshell which it has just vacated. But vegetable matter, is its proper diet, and, by the providence of its mother, it finds its habitation cast on a plant which is suitable for its nourishment; it is like an ox placed in the midst of an unbounded pasture.

The little worm feeds, and feeds, and feeds, with wonderful voracity: it does nothing else in short, and consequently grows with rapidity. It soon finds its skin too strait for it, for this can stretch only to a certain extent, and has no power of actual growth as ours has, and the horny parts, as the head and feet, cannot even expand, being quite rigid. What must be done? It splits its 
skin and throws it off; a new one, soft and expansile, having been prepared beneath it. This presently hardens, and when by the rapid growth of the Caterpillar this is stretched to its utmost capacity, it also is split and cast off ; and a similar process is repeated four or five times in succession.

By this time the insect has attained its full size; it has not yet, indeed, finished life, but it will need to eat no more ; all its nourishment is taken in the Caterpillar state, which it now prepares to quit for that of the Chrysalis. No one would have recognised the worm-like Caterpillar as the offspring of the aerial Butterfly; perhaps one might say, without a figure, " $\mathrm{He}$ is so changed that his own mother would not have known him," but the character in which the masquerader next appears is as little like either. Look at the stiff Chrysalis, all points and angles, immoveable except for a slight wriggle in his armour, tied up to the stalk of a plant, like a knave to a whipping-post, and say what he is like! Certes, you will not guess (supposing you are not of the illuminati) either Caterpillar or Butterfly.

The process of transformation is well worthy of being witnessed, and we will describe it as we once had the pleasure of observing it, in the case of one of those beautiful large species known as Swallow-tails. It was an American Butterfly, but so very closely allied to our fine native species the Papilio Machaon, and the scarce $P$. Podalirius, that should you ever be so fortunate as to witness the transformations of either of these magnificent insects, you will see that the one process is the exact counterpart of the other. 
When the Caterpillar has attained its full size, it crawls to the under-part of a branch, and spins a little knob of silk, of which it takes hold with its hindmost false legs : it then spins a girdle, composed of many contiguous threads of silk, fastened at each end; making a bow large enough to admit the body, and intended to support the Chrysalis; this, when finished, the Caterpillarputs over its head. It continues in this state about two days and a half, during which time it has gradu-

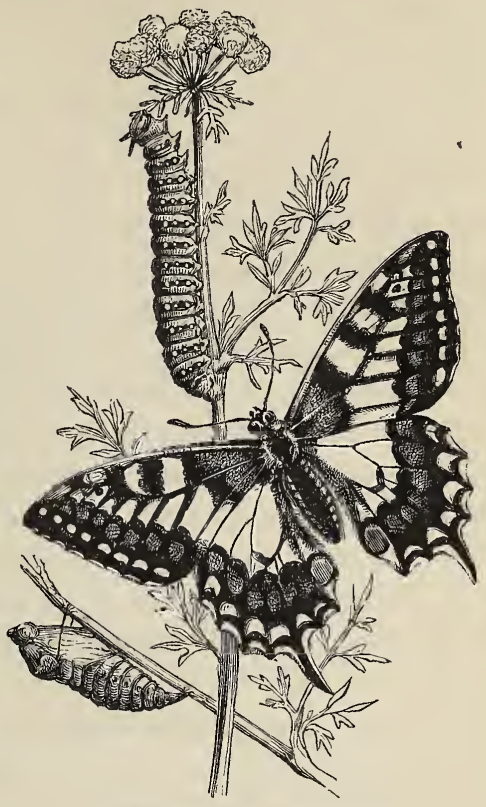

Transformations of Butterfly. ally lost its power of holding on by the feet, and rests with its whole weight upon the knob and cincture of silk. It now casts off its Caterpillar skin, and enters the Chrysalis state. By good fortune we were happy enough to see this change take place in one of our captives. The Caterpillar appearing very uneasy and restless, we watched it at intervals for about half an hour; when, by strong and apparently painful inflations, a slit was made in the back of the third ring or segment, and the Chrysalis forced itself 
through ; gradually extending the slit forwards, till the head was split and separated, and backwards for several rings. The skin was then gradually pushed down : we had wondered how it would get through this part of the business, for the weight of the Caterpillar pressed the silken girth very tightly round the body; but there seemed no real difficulty ; the loose skin being worked backwards by the motion of the segments. When it was pushed down to the extremity, the tail of the Chrysalis was thrust out underneath, and pressed upwards to take hold of the little knob of silk; this being done, the old skin was jerked off by the writhing of the body. The silken cord was now round the body, between the sixth and seventh rings, and the Chrysalis twisted and turned, till it got the girth three rings nearer the head, about the middle of the wingcases; the skin was so soft and the silk so slender, that it cut into the wing-cases, so far as to be invisible, but no ill resulted from this circumstance to the perfect Butterfly.

The newly transformed Chrysalis is soft, with the skin resembling in consistence wetted parchment; its shape is not very remote from that of the Caterpillar; in the course of an hour or two, however, it materially alters its form. Some of its segments contract and condense, prominent angles appear, the skin roughens and becomes very rigid, and the creature has assumed the condition in which it will pass a sort of torpid vegetative existence, through some nine or ten months in the year, or even more.

In the case of which we are speaking, the transition to the Chrysalis state occurred near the end of August, and 
it was not until the middle of July of the following year that the Butterfly was matured.

When this period of second birth approaches, - so apt an emblem of the resurrection, that the ancient Greeks, who used the same term ( $\Psi v \chi \grave{\eta}, p s y c h e)$ to signify a butterfly and a soul, called the resurrection "the hope of worms,"-it is manifested by a change in the appearance of the Chrysalis. The skin becomes very thin and fragile, and, for some days before the exclusion, the colours, spots, and marks of the perfect Butterfly are distinctly perceptible, through the transparent integument, but all in miniature.

At length the hour arrives; the Chrysalis, which for some hours has appeared uneasy, wriggling, and apparently inflating its body, succeeds in splitting the thin and brittle skin of the back. The imprisoned Butterfly pushes out; the head with its palpi and antennæ and its spiral tongue, and the legs, are all drawn out of their several sheaths, the latter limbs are thrown forward, and the insect stands on them, weak and staggering. It rests a moment or two, then proceeds; the painted wings now appear, minute and hanging against the sides like wet paper, but perfect in their colours and markings. The Butterfly is free!

It essays to lift its wings, but these organs, all soft and flabby as they are, are utterly unfit for flight. But see, a change is coming over them! They are swelling irregularly, crumpling up, puckering into folds here and there, as their vessels are distending with fluids from the body. They look hopelessly spoiled. Though small at first, they were at least symmetrical ; but now they look like pieces of wet paper crushed up in the hand and partially opened, 
and the further the work proceeds the worse it appears to grow. But by and by, they begin to become smooth and even again; the distension and expansion have reached to every part in an uniform ratio, and wings of full size and perfect form are developed, still, however, soft, flaccid, and pendent. A quarter of an hour more removes this defect; the elegant organs momentarily acquire rigidity; at length the insect can raise them to an erect position. As soon as this is attained, the beautiful creature marches to and fro, as if rejoicing in its new powers, and proud to display them; but in reality testing the capabilities of its organs, and perhaps accustoming itself, by repeatedly opening and shutting its wings, to the practice of those muscular movements on the force and precision of which its flight will depend.

At length it launches into the air, and sails away to the inviting flowers, a happy denizen of a new element.

Processes essentially parallel with those above described take place in the history of all Insects, though the varieties of habit produce a certain amount of variety in the details. Not a few, as the Insects of the orders ORTHOPterA and Neuroptera, are active in the pupa state; but, in general, as in Beetles, Bees, and Flies, the creature in this stage is motionless, swathed and helpless, like the chrysalis of a Butterfly or Moth. Of the furmer condition the Dragon-fly (Libellula) may afford us an example. The early stages of this vigorous flier are passed beneath the waters. The female, poising her body over the surface of some pool, deposits her eggs, which sink to 
the bottom, where they are speedily hatched. The larva is a somewhat uncouth, broad, and flat, olive-coloured animal, rather spider-like, having six sprawling legs, which crawls about the mud at the bottom of ponds, or glides by a singular mechanism through their waters. The hinder extremity of the body is furnished with several leaf-like processes, capable of being brought closer together, or opened at pleasure. These close the orifice of a cavity, whose sides are very muscular. When the Insect wishes to move rapidly, it opens this cavity, which thus becomes filled with water ; then, by a contraction of the walls of the cavity, the water is forcibly ejected in a stream as from a syringe; and, by the re-action produced by the impact of the jet d'eau upon the surrounding fluid, the creature shoots ahead, with its legs closely packed along its sides.

But the most singular part of its structure is its face. "Conceive," says the graphic and eloquent Kirby, "your under lip to be bony instead of fleshy, and to be elongated downwards, so as to wrap over your chin, and extend to its bottom; that this elongation is then expanded into a triangular convex plate, attached to it by a joint, so as to bend upwards again, and fold over the face as high as the nose, concealing, not only the chin and the first-mentioned elongation, but also the mouth and part of the cheeks : conceive, moreover, that to the end of the last-mentioned plate are fixed two other convex ones, so broad as to cover the whole nose and temples; that these can open at pleasure transversely like a pair of jaws, so as to expose the nose and mouth, and that their inner edges, where they meet, are 
cut into numerous sharp teeth, and spines, or armed with one or more long and sharp claws, you will then have as accurate an idea as my powers of description can give of the strange conformation of the under-lip of the larva of the tribes of Libellulina (Dragon-flies), which conceal the mouth and face precisely as I have supposed a similar construction of your lips would do yours. You will probably admit that your own visage would present an appearance not very engaging while concealed by such a mask; but it would strike still more awe into the spectators were they to see you first open the two upper jaw-like plates, which would project from your temples like the blinders of a horse; and next, having, by means of the joint at your chin, let down the whole apparatus, and uncovered your face, employ them in seizing any food that presented itself, and conveying it to your mouth."

Such is the larva, from which the pupa does not differ in any respect, except that the rudiments of the future wings are seen budding out from the thorax. It is no less active, no less fierce, no less voracious than the larva. When the time of its transformation approaches, it crawls out of the water up some aquatic plant, or on a twig upon the bank, where it remains a while for the skin to dry. Presently, a crack appears down the back, and the fly begins to emerge, as represented in the lower left-hand figure of the accompanying engraving. As soon as the feet are free, it invariably bends backward, and hangs with its head downward, as if exhausted, for some minutes. Then it rears itself up, catches hold of the twig with its hooked feet, and draws the extremity of its body out of the pupa-case, leaving the latter firmly fixed by its own 
feet to the support. The wings are minute, soft, and dense, but they soon expand (as described in the case of the

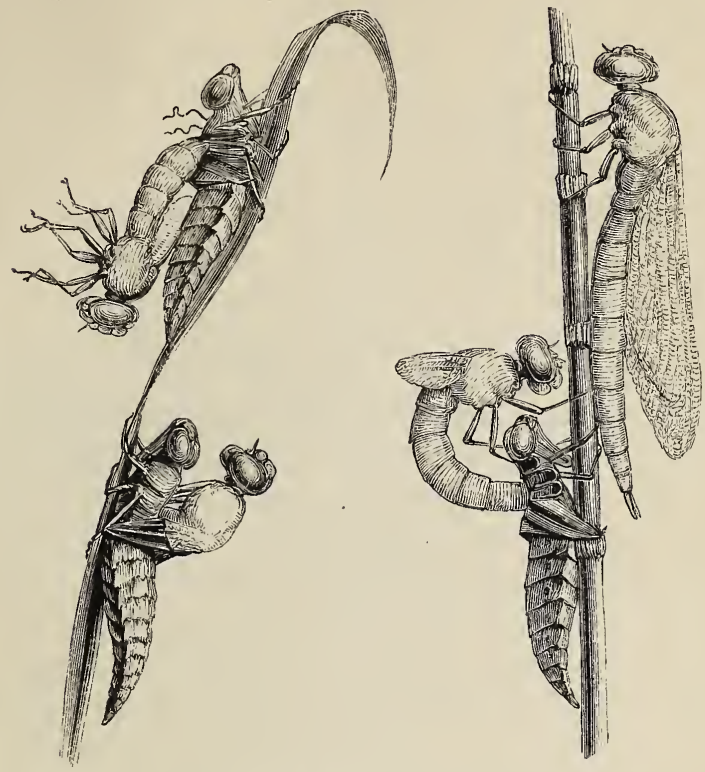

Transformations of Dragon-fly.

Butterfly), and acquire the firmness, transparency, and gloss which are so admirable in the perfect Insect. 


\title{
CHAPTER XVIII.
}

\author{
INSECTA (Insects).
}

Continued.

IN Insects we perhaps reach the highest point of comparative perfection among invertebrate animals, whether we regard the condensation of their organs, the solidity of their skeleton, the consequent vigour and precision of their movements, the concentration of their nervous system, or the manifold intelligence which they display. That wonderful adaptation of means to ends, which, so often recurring as we study the instructive actions of animals, calls forth more than anything else our recognition and praise of an all-wise Creator, is nowhere more conspicuous than in Insects; and is pre-eminently seen in what have been felicitously termed the architectural habits of such species as prepare habitations for themselves, or protections for their offspring.

Most of our readers are familiar with that exquisite solution of a geometrical problem*-the honeycomb.

* Reaumur, the eminent French entomologist, proposed to M. König, one of the ablest mathematicians of his day, the following problem :- "Amongst all possible forms of hexagonal cells, having a pyramidal base composed of three similar and equal rhombs, to determine that which could be constructed with the least expenditure of material." The mathematician undertook the solu- 
They have learned that the industrious Bees, impelled by nature to live in society, combine to form a common structure of cells, for the reception of the eggs and young, which are to form the future commonwealth, and the store of food which is necessary for their nutrition. This work is to be formed out of wax-a substance that does not exist as yet, but which is to be elaborated by a natural chemistry from the bodies of the Bees themselves. The cells are perfect hexagons, divided from each other by the thinnest possible walls that the material will sustain, and built in double series, the bottom-point of one being the point between the bases of three others, which open in the opposite direction. Now, it is found by observation, that the walls are not built up in those thin plates, which we see them to be when perfected; but, on the contrary, that the wax is laid down in rounded knobs, out of which the cells are then excavated by the jaws of the workers, each one knowing exactly, by her wondrous instinct, how much may be pared away, without breaking into the domains of her fellow-artificers, who are similarly excavating on every side of her.

But the labours of the Hive-Bee, though truly admir-

tion of this very beautiful theorem, and at last demonstrated that, among all kinds of cells with pyramidal bases, that would require the least quantity of material which should have its base composed of three rhombs, the angles of which should measure respectively $109^{\circ} 26^{\prime}$ and $70^{\circ} 34^{\prime}$. M. Maraldi, another eminent naturalist, had in the meanwhile calculated, with as much accuracy as he was able, the real angles met with in the cell of the Bee, which he had estimated, the former at $109^{\circ} 28^{\prime}$, the latter at $70^{\circ} 32^{\prime}$, leaving only two minutes of difference between the calculation and the result of measurement; and more recent researches, conducted with the delicate instruments of modern science, have shewn even that slight discrepancy to be erroneous, and proved that the figures pointed out by mathematical research, and those adopted by the insectlabourer, are precisely identical._'Jones's "Nat. Hist. of Anim.," ii. 235.) 
able, are equalled, if not indeed surpassed, by those of the social Wasps; though these latter, because they do not minister to our wants, and perhaps, also, because of their irascibility, are viewed with a dislike, which has tended to avert from their architecture that measure of popular attention which it well deserves.

The common Wasp (Vespa vulgaris) conceals her work beneath the surface of the earth ; there she builds a subterranean city. We say "she," for it is observable that the populous commonwealth which teems forth on the uncovering of a "Wopse's nest," is exclusively the progeny of one mother Wasp, which has survived the winter; and the city was built, or at least founded, by her alone.

She first finds or makes an excavation in some hedgebank-a winding gallery a foot or more in length, and an inch in diameter, opening at length into a capacious chamber, as large as a butter-firkin, or larger. This being prepared, she seeks her materials for building. These are not wax, but paper. From wirdow-sills, weather-beaten palings, old posts, and similar sources, the industrious insect collects the minute surface-fibres with her mandibles, bruising them, and moistening them with a liquid from her mouth, until they form a pappy substance, which is nothing else than a true paper.

"With this material the mother Wasp begins to line the roof of her burrow, always building from above downwards. The round ball of fibres which she has previously kneaded up with glue, she now forms into a leaf, walking backwards, and spreading it out with her mandibles, her tongue, and her feet, till it is almost as thin as tissuepaper. 
"One sheet, however, of such paper as this would form but a fragile ceiling, quite insufficient to prevent the earth falling down into the nest. The Wasp, accordingly, is not satisfied with her work till she has spread fifteen or sixteen layers, one above the other, rendering the wall altogether nearly two inches thick. The several layers are not placed in contact like the layers of a piece of pasteboard, but with small intervals or open spaces between, appearing somewhat like a grotto built with bivalve shells, particularly when looked at on the outside. This is probably caused by the insect working in a curvilineal manner.

" Having finished the ceiling, she next begins to build the first terrace of her city, which, under its protection, she suspends horizontally, and not like the combs in a bee-hive, in a perpendicular position. The suspension of which we speak is also light and elegant, compared with the more heavy union of the hive-bees' combs. It is, in fact, a hanging floor, immoveably secured by rods of similar materials with the roof, but rather stronger. From twelve to thirty of these rods, about an inch or less in length, and a quarter of an inch in diameter, are constructed for the suspension of the terrace. They are elegant in form, being made gradually narrower towards the middle, and widening at each end, in order, no doubt, to render their hold the stronger.

"The terrace itself is circular, and composed of an immense number of cells, formed of the paper already described, and of almost the same size and form as those of a honeycomb, each being a perfect hexagon, mathematically exact, and every hair's-breadth of the space com- 
pletely filled. These cells, however, are never used as honey-pots by Wasps, as they are by Bees; for Wasps make no honey, and the cells are wholly appropriated to the rearing of their young. Like other Hymenopterous Insects, the grubs are placed with their heads downwards; and the openings of the cells are also downwards; while their united bottoms form a nearly uniform level, upon which the inhabitants of the nest may walk.

"When the foundress Wasp has completed a certain number of cells, and deposited eggs in them, she soon intermits her building operations, in order to procure food for the young grubs, which now require all her care. In a few weeks these become perfect Wasps, and lend their assistance in the extension of the edifice; enlarging the original coping of the foundress by side walls, and forming another platform of cells, suspended to the first by columns, as that had been suspended to the ceiling.

"In this manner several platforms of combs are constructed, the outer walls being extended at the same time; and, by the end of the summer, there are generally from twelve to fifteen platforms of cells. Each contains about 1060 cells-forty-nine being contained in an inch and a half square, and, of course, making the enormous number of about 16,000 cells in one colony. Réaumur, upor. these data, calculates that one vespiary may produce every year more than 30,000 Wasps, reckoning only 10,000 cells, and each serving successively for the cradle of three generations. But, although the whole structure is built at the expense of so much labour and ingenuity, it has scarcely been finished before the winter sets in, when it becomes nearly useless, and serves only for the abode of a 
few benumbed females, who abandon it on the approach of spring, and never return; for Wasps never make use of the same nest for more than one season." *

Some Hymenopterous Insects excavate cells, for the habitation of their young, out of solid timber. The large and beautiful Violet Bee (Xylocopa violacea) of Spain, for example, bores a cylindrical hole into a post to the depth of fifteen inches, the first inch being horizontal, and the rest perpendicularly upwards. The sawdust which accumulates from the action of her jaws, she stores up in a little heap, for future use. Having completed her tunnel, she lays an egg at the furthest extremity, gluing it to the wood. She then collects the farina of flowers, and, making it into a paste with honey, covers with it the new-laid egg, and fills a space of the tunnel of about an inch in length.

Now the store of sawdust comes into request. Grain by grain she carries it in, and, with her glutinous saliva, cements it in the form of a ring to the tunnel wall, immediately under the food she has treasured up. When this has hardened, she carries in more grains, and cements them in a narrower ring to the former, proceeding thus till the whole space is occupied, and a transverse partition is formed of cemented sawdust, which completely seals up the egg and food in a closed chamber, and forms a floor for the attachment of a second egg. This she provides for and seals up also, and so proceeds till she has divided the tunnel into ten or twelve cells, each occupied by an egg, and sufficient food to meet the wants of the grub until its arrival at the winged state.

$$
\text { * “Insect Architecture," } 75 .
$$


It is evident that, since the earliest-laid egg will be hatched first, and will soonest come to maturity, it will want its liberty before its younger brethren are ready for theirs. But it is imprisoned at the very end of the tunnel ; how, then, can it be freed, without destroying all the other cells in its course? This emergency is provided for. A back-door is prepared, in the shape of a gallery, leading sideways from the furthest cell to the surface of the post; this the young Bee has the instinct to avail itself of ; the rest following in succession, each breaking through its own floor, and then finding a clear passage.

There is a Bee somewhat resembling the Hive-bee, but rather stouter (Megachile centuncularis), common in summer in our gardens, which lines the tunnels that she bores in firm earth with portions of the leaves of rose-beeches. These she cuts into the required patterns with inimitable rapidity and accuracy, and forms them into thimble-like cells within the tunnel, fitting the end of one into the mouth of another, and storing each cell with an egg, and the needful store of food.

But the workmanship of this species is excelled by that of another, the Poppy Bee (Osmia papaveris). Her hole resembles in form a Florence flask, but is no more than one-third so large. The walls are made very smooth, and thus prepared for her most exquisite tapestry.

The material used for this purpose, "is supplied by the petals of the scarlet field-poppy, from which she successively cuts off small pieces of an oval shape, seizes them between her legs, and conveys them to the nest. She begins her work at the bottom, which she overlays with three or four leaves in thickness, and the sides have never 
less than two. When she finds that the piece she has brought is too large to fit the place intended, she cuts off what is superfluous, and carries away the shreds. By cutting the fresh petal of a poppy with a pair of scissors, we may perceive the difficulty of keeping the piece free from wrinkles and shrivelling; but the Bee knows how to spread the pieces which she uses as smooth as glass.

"When she has in this manner hung the little chamber all round with this splendid scarlet tapestry, of which she is not sparing, but extends it even beyond the entrance, she then fills it with the pollen of flowers mixed with honey, to the height of about half an inch. In this magazine of provisions for her future progeny she lays an egg, and over it folds down the tapestry of poppy-petals from above. The upper part is then filled with earth."*

Many other examples might be given of the wonderful instinct of Insects manifested in the construction of dwellings, as those of the Mud-wasps (Pelopeus) of America, the Termites of tropical Africa, and the Ants of all countries. For these, however, we must refer our readers to works specially devoted to the economy of Insects.

$$
\text { * “Ins. Arch." } 55 .
$$




\section{CHAPTER XIX.}

\section{InseCta (Insects).}

\section{Continued.}

Thrs Class of minute animals is so immense, that it would be impossible within our limits to give a hundredth part of what is on record concerning them, even if we omitted all technical details, and confined ourselves to that which is popularly interesting. The study of the whole Class is felt to be far too large for one human life to embrace with any degree of completeness, and hence we hear of men eminent as coleopterists, lepidopterists, hymenopterists, \&c., from their having devoted themselves to some one or other of the subordinate groups of this vast assemblage. We shall just give a bird's-eye view of these subdivisions, indicating here and there some of the more prominent points of interest for which each is distinguished.

Chief among them stands, by universal consent, the order of Beetles, principally because they are the most "perfect" of Insects. By this term "perfect" as applied to structure, which has sometimes stumbled uninitiated students, we do not, however, mean to imply that a House-fly or a Bug is not as perfectly adapted for its mode of life as a Beetle, nor that it is in the least degree less worthy of an 
Omnipotent Creator. The word is used by naturalists in a technical sense, to express the degree in which we find those peculiarities developed that constitute any particular group. Those peculiarities of structure, for example, that make an Insect what it is, and not a Worm or a Crustacean, are found to be present in the greatest intensity, and in the fullest combination, in the group of Beetles, and hence we say that these are the most perfect of their class. A Beetle is not more perfect as an animal than any other, but it is a more perfect insect, or rather, more perfectly an insect.

You may very readily identify a Beetle by its mouth being armed by two pairs of forceps-like jaws, and by its fore-wings being hardened into leathery sheaths for the hinder wings, and meeting in a straight line down the centre. The technical name Colæoptera, or Sheath-wings, expresses the latter character in Greek.

Many species of this group are pre-eminent for beauty of colour, especially the many-coloured refulgence of burnished metal, as in the Buprestidce, and the Cetoniadice, and the Eumolpidce, and others; and the lustre of the richest precious stones, as in many of the Diamond-beetles and others of the Curculionida, whose wing-sheaths under a lens look as if they were dusted with pounded gems.

The Glow-worm, that lights our hedge-banks with its feeble spark in the soft summer nights of July, is a Beetle, and so is the Firefly of the West Indies, that carries a pair of flaming lamps upon his back. The pretty scarlet Lady-bird, that appears to have had a "favourable eruption" of black buttons, is a little Beetle that every child knows and loves; and the dreadful Death-watch, that scratched the doom of our great-grandmothers on their 
bedposts, is one still smaller. Very few of this great group render the slightest direct service to mankind; we do not at this moment recollect any but the Cantharis, or Blister-fly, which is useful in surgery.

Those insects which have the fore-wings somewhat leathery, but less rigid than those of Beetles, and sheathing the lower pair in such a way that their edges overlap each other, are called OrTHoptera, or Straight-wings. The Locust, Grasshopper, and Cricket, all of which make a crinking sort of music by rubbing their stiff wings in various ways over each other, are of this sort: and so is the Earwig, that spoils our dahlias, by eating holes in their tender petals, and the ferocious Mantis of the tropics, that holds up its sawlike arms as if in the attitude of prayer (hence called Prie-Dieu), but really watching to smite down any unwary fly that may be passing, and to seize it between the locking-spines of its fore-arms.

Who that has sauntered by a river's side in the burning noon of summer is not familiar with the arrowy Dragonfly? He swoops down in wide curves, and just touches the water in his rushing flight, and turns, and darts to and fro, with a speed and a power that seem to mock the ringnet of the eager insect-hunter. The sun's ray gleams from the ample pinions as they speed past our eyes, as from surfaces of polished steel, and the long and slender body that is poised behind is clad in mail of green, and azure, and gold. Ha! we have struck down the bold warrior with our cane, and there it lies, spinning round in the grass, and rustling its beautiful wings, with tremulous vibrations, in its fruitless attempt to fly. Poor creature, thou wilt fly no more! no more will the vigorous impulses 
of those filmy pinions bear thee aloft on the thin air, and carry thee in impetuous evolutions after thy tiny prey! But what elegant organs these wings, now still in death, are! they are like plates of talc of extremest thinness, through which expands a network of nerve-ribs, a lace that no collar on fair lady's neck ever equalled; every component thread of which is a tube communicating with the air-pipes or lungs of the body! How appropriate is the term Neuroptera, or Nerve-wings, for such Insects as these!

And now we come to the "industrial" classes, to use an expressive term of modern coinage. The Butterflies are fine ladies that go a-shopping among the flowers, the Beetles are the starred and jewelled nobility, the Dragonflies are warriors, true knights-errant furnished with the pomp and circumstance of war; but the humble, useful, ever busy Bee is an artisan-a representative of that class who are "fruges producere nati;" and not less industrious and skilful (though far from so serviceable to us) are its cousins, the Wasp and the Ant. The architectural instincts of these Insects we have briefly treated in the preceding chapter.

This order is termed Hrmenoptera, or Membrane-wings; but the technical distinction between these and those which we have just dismissed is that these possess, at least in one sex, a horny tube at the extremity of the body, which is sometimes connected with a poison-bag; and is called a sting, and at others is simply an instrument for the piercing of animal or vegetable substances, in order to deposit eggs in them. But a much more obvious difference is found in the character of the wings, which are so 
shaped that the hind pair seem as if cut out of the fore pair, with which they interlock by means of small hooks during flight, so that both might readily be mistaken for a single pair. The nervures are commonly stouter, and form a wider network, and the membrane is generally less delicate than in the preceding Order.

All the forms of Insects which we have been enumerating agree in one point, viz., that their mouth is furnished with biting jaws; those that follow, on the other hand, have the same organs, but so modified in development and altered in function as to constitute a sucking, pumping, or piercing apparatus. The elegant LEPIDOPTERA, or Scale-wings, including the Butterflies, which are active by day, the sonorous-winged Hawkmoths, that probe tubular flowers in the twilight, and the Moths, which swarm in the early hours of night, constitute the next order. Their chief peculiarities have been already mentioned, and we shall therefore merely mention the Silkworm, the caterpillar of an Oriental moth, now naturalised throughout the civilised world, as another example of an Insect to which man is largely indebted.

An extensive group is called Hemiptera, or Half-wings, because the majority of them have the fore-wings curiously varied in texture, the basal portions being of a stiff leathery consistence, while the terminal part, separated from the former by an abrupt line, is thin and membranous. The vast tribe of Bugs comes here, all of them repulsive and disgusting from their rank purgent odour, but in many cases adorned with rich colours, and often bearing the most bizarre forms. Here, too, are usually placed, though distinguished by some entomologists, the insects which 
produce the lac of India, and the splendid dye called "cochineal" of tropical America. The sole possession of the latter insect was an object of jealous care with the government of the Spanish colonies, and so highly was it valued by other nations, that our own East India Company offered a reward of L.6000 sterling to any one who should be so fortunate as to introduce it into their dominions. That object has been effected, and cochineal is now cultivated in many countries.

Finally (for we need not stop to describe the few parasite, darkness-loving, uncomely insects that belong to the wingless orders), we have the order of Diptera, or Twowings, including the Gnats, the House and Flesh Flies, whose chief distinction is indicated in their name. This is a populous group, and many of its members display habits and instincts which are highly entertaining; perhaps none more so than those of the common Gnat, from the construction of its tiny boat of eggs, to its emergence from the water, empowered to suck our blood in its merciless practice of phlebotomy. 


\title{
CHAPTER XX.
}

\author{
Arachnida. \\ (Spiders, Scorpions, and Mites.)
}

THE common consent of mankind regards most of those creatures of which we are about to speak with revulsion and abhorrence ; and it must be confessed that the closer examination which the scientific naturalist bestows on them, has only resulted in more firmly fixing upon them the stigma of a bad character,-decidedly, undeniably bad. The poet's verdict is true, when he calls the Spider-

"Cunning and fierce-mixture abhorr'd."

Bloodthirsty and vindictive, treacherous and cruel even to their own kind, bold and prompt in warfare, ever vigilant, full of stratagem and artifice, highly venomous, lurking in darkness, endowed with curious instincts, and furnished with many accessory means for the capture and destruction of other animals-the Spiders and Scorpions do not move our esteem, it must be confessed ; and an entomologist of the highest eminence, ${ }^{*}$ carrying out the notion that the seen things of nature are symbols and pictures of the unseen and spiritual, views in these creatures the

* Kirby, Bridgewater Treatise. 
types of the evil spirits; a supposition not unwarranted by the expression of our Blessed Lord, "Behold, I give unto you power to tread on serpents and scorpions, and over all the power of the enemy!" * Yet even these repulsive animals are the handiwork of Infinite Wisdom; and half-an-hour may be worse spent than in briefly running over some of the peculiarities of their structure and habits.

And, first, a few words on their structure. They may at once be distinguished from true Insects by having four pairs of legs instead of three. They exhibit a greater condensation of outward form, there being generally but one division, that which separates the abdomen from the fore part, which latter, because it includes in one the parts answering to the head and chest of insects, is commonly called the cephalothorax. The head is destitute of antennoe, but those organs are replaced by a pair of claws terminating either in a single hook, or in pincers. The eyes are always simple lenses, sometimes moderately numerous, and then usually arranged in groups, and occasionally placed at the summit of a sort of pillar on the back, a provision which must greatly assist circumspection.

Internally, also, the organisation is more condensed, and of a higher type than in Insects. The nervous knots or ganglia are few and central, sending out radiating threads to the circumference and extremities. The breathing organs are either lungs, enclosed in bags, or radiating air-tubes (trachece), which communicate with the atmosphere by minute slits in the skin. The Spiders and Scorpions belong to the former category, and are named 
Pulmonaria; the Harvest-men and Mites to the latter, and are called Trachearia.

We naturally associate Spiders with cobwebs, and the faculty of spinning threads from the hind part of the body is one of their most marked characteristics; but all do not make webs, properly so called. In the south of Europe and in the West Indies, certain large Spiders belonging to the genus Cteniza are called Trap-door Spiders, from their singular architectural instincts. The female excavates a burrow in soft earth, an inch in diameter, and six to ten inches in depth; this is lined with a dense tapestry resembling paper, formed of her silk; and the mouth is closed with a circular door, formed of many layers of silk, with pellets of earth interwoven into the exterior, but which is so smooth on the interior, and so accurately formed, as to fit the orifice with the utmost accuracy; while a hinge of silk at one part of the circumference allows the lid to be raised for the exit of the owner, when it closes by its own elasticity.

Judging from specimens which we have examined in Jamaica, the lid is always punctured with a number of holes, such as might be made by a very fine needle, which penetrate through the whole substance, the light being clearly seen through each hole. We have conjectured that the object of these orifices may be the admission of air and light into the cell, when the lid is tightly closed, for the comfort of the inmate. The Spider habitually resides in her well-built house, coming abroad to hunt, and retreating with her prey to the bottom of her domain.

In the hot parts of the world, Spiders (Mygale) closely allied to these are found, which are often of immense size. 
very hairy, and usually black, gray, or reddish-brown in colour. These monsters prey even upon small birds; a statement which has been denied upon insufficient grounds, but which rests on the concurrent testimony of such men as Perty, Stedman, Moreau de Jonnès, and Palisot de Beauvois. They do not, however, spin nets, but steal upon their prey, and overcome it by violence.

The Spider which is so common in our houses, filling the angles of rooms, the crevices of old walls, and the interstices of the foliage in shrubs and hedges, with a dense web, belongs to the sedentary division. It is the Tegenaria domestica of zoologists. The web is nearly horizontal, with a tube at the inner part, within which the Spider is ordinarily lodged, motionless, with its head projecting and its fore feet stretched out upon the expanse of the web,-

\section{"And hush'd in grim repose, expects its insect prey."}

No sooner does a thoughtless fly alight on the web, than out rushes the Spider with lightning rapidity, seizes it with her fangs, and carries it into the den to be sucked and exhausted of its juices. Walckenaer thus describes her domestic economy: "She constructs a bag of silk shaped like a purse, ballasted with bits of plaster, for the suspension of her cocoon. The orifice of the bag she covers with a little web, on which she sits, watching without ceasing for the appearance of her offspring. Her cocoon, formed of fine web, contains about 150 eggs, which are laid in May and June." *

There is a little Spider (Argyroneta aquatica), found occasionally in ponds and rivers, which turns its spinning 
powers to a curious purpose. It forms a residence beneath the surface of water, which, like our diving-bells, is filled with air. It is commonly said that she first spins loose threads, connecting the stems of water-plants, among which she weaves a little cell, which she then manages to fill with air successively carried down in bubbles from the surface, in some unknown manner. But Baron Walckenaer, who writes from personal observation, describes the process differently. The abdomen is covered with a close down, which does not permit the water to wet the skin; when beneath the surface the whole body is enveloped in a coat of air, so that it resembles a ball of quicksilver.

"When the Argyroneta would construct its nest, it swims to the surface, and, head downward, protrudes the extremity of the abdomen, dilating its spinnerets, and then dives with rapidity. By this process she produces a little bubble of air, which, independent of the silvery coating which envelopes the body, appears as a little globule attached to the tail. She swims to the stalk of the plant to which she would fix her nest, and,

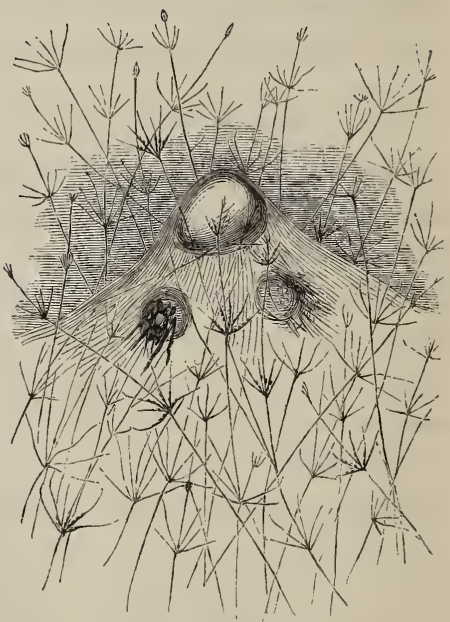

The Water-Spider. touching it with the bubble, the air detaches itself and adheres to the plant. The Spider then remounts to the 
surface, collects another air-bubble, which she adds to the former. When she has, in this manner, sufficiently enlarged her balloon of air, she encloses it with silk of extreme whiteness. Within this balloon, which is open below, she then sits in a reversed position. She then stretches through the water irregular threads, which converge to her habitation, and which arrest minute water-mites and other insects. These are seized, and carried within doors to be eaten, but sometimes the prey is borne to the surface, and devoured on the bank." *

The accuracy of these observations has been recently confirmed by Professor Bell.

Among the largest and best known of our native species is the handsome Garden Spider (Epeira diadema). Its form is familiar to every one in the latter part of summer and autumn, its plump abdomen gray or fawn colour, elegantly spotted with white, and its legs widely extended, as it hangs head downward on its perpendicular web, which is formed of concentric circles of fine thread, on a frame-work of radiating lines. This geometric web is a beautiful example of an insect-manufacture. Having formed the foundation of her net and drawn the skeleton of it, by spinning a number of rays converging to the centre, she next proceeds, setting out from that point, to spin a spiral line of unadhesive thread, like that of the rays which it intersects, and to which she attaches it, and, after numerous circumvolutions, finishes it at the circumference. This line, together with the rays, serves as a scaffolding to walk over, and it also keeps the rays properly stretched. Her next labour is to spin a spiral line 
from the circumference towards the centre, but which stops somewhat short of it; this line is the most important part of the snare. It consists of a fine thread studded with minute viscid globules, like dew, which, by their adhesive quality, retain the insects that fly into the net.* The skilful constructor then stations herself in the very centre, where she patiently hangs head downward ; and, her feet extended upon the rays, "lives along the line," until the arrest of some unwary fly rouses her to vigorous action. Approaching the struggling victim, she pours out her glutinous web in extraordinary profusion, directing it by means of her great hind feet in a broad and dense ribbon around the fly, whose every limb is rapidly enveloped by it. The pointed poisonous claws are now plunged into its body, and the juices sucked at leisure.

The threads of a Spider's web, fine as they are, must not be considered as simple filaments, but as ropes composed of many strands. The spinning apparatus consists of four little teats or warts at the hinder extremity of the body. The upper pair of these are perforated at their tips with innumerable holes of inconceivable minuteness, so as to resemble a colander, and through each of these holes proceeds a thread. The lower pair are similarly perforated, but are set in addition with a number of prominent tubes, which furnish threads also. Within the body at this part there are several bags filled with gummy matter, which at the will of the animal is forced through the orifices, and hardens into elastic silk on exposure to the air. The Spider applying the ends of the teats to any fixed object, the gum adheres, and by her progress a cord

* Blackwall, in Zool. Jourral, v. 181. 
is drawn out which consists of as many constituent threads as there are minute orifices in her spinnerets.

Want of space forbids us to do much more than allude to the renowned Tarantula (Lycosa tarentula) of Italy. The bite of this Spider is reputed to produce lethargy, melancholy, and delirium, which are only to be cured by the influence of music exciting the patient to dance. It is now pretty well established that these pretended cures were "got up" for the sake of imposing on the credulous. The Spider itself belongs to a very extensive genus, represented. in almost all countries, and everywhere displaying the same habits. They live on the ground, rumning swiftly; the females carrying their large egg-case about with them during the breeding season, and refusing to part with it; or, if forcibly deprived of it, becoming stupid, and, as it were, stunned, utterly regardless of personal safety, till the dear object is restored, when, in an instant, animation and vigour return.

As there is a Spider which descends by means of its web into the depths of the water, so there are others which, by the same medium, ascend to the regions of the clouds. These are the Gossamer Spiders (Linyphia, Theridion, \&c.), minute species, scarcely exceeding in size a pin's head. They have the power of shooting out filmy threads into the free air, which, on some undetermined principle, usually thought to be connected with electricity, rise with considerable buoyancy, and at length carry up the little aeronaut with them. After a while, becoming saturated with moisture, they descend, and large tracts of ground are frequently seen, in autumn, covered with the delicate films of flocculent web. 
The last Spider which we can here notice is the little Hunter (Salticus scenicus), which, in its zebra-like marking of black and white bands, is frequently seen leaping on window-sills and garden-fences, in the burning sun of summer. Its manners cannot be better described than in the words of old Evelyn :- "Such I did frequently observe at Rome, which, espying a fly at three or four yards' distance upon the balcony where I stood, would not make directly to her, but crawl under the rail, till, being arrived to the antipodes, it would steal up, seldom missing its aim ; but if it chanced to want anything of being perfectly opposite, would at first peep, immediately slide down again, till, taking better notice, it would come the next time exactly upon the fly's back. But if this happened not to be within a competent leap, then would this insect move so softly, as the very shadow of the gnomon seemed not to be more imperceptible, unless the fly moved; and then would the spider move also in the same proportion, keeping that just time with her motion, as if the same soul had animated both these little bodies; and whether it were forwards, backwards, or to either side, without at all turning her body, like a well-managed horse. If, however, the capricious fly took wing and pitched upon another place behind our huntress, then would the spider whirl its body so nimbly about as nothing could be imagined more swift; by which means she always kept the head towards her prey, though, to appearance, as immoveable as if it had been a nail driven into the wood, till, by that indiscernible progress (being arrived within the sphere of her reach,) she made a fatal leap, swift as lightning, upon the fly, catching him in the poll, where 
she never quitted hold till her belly was full, and then dragged the remainder home." *

There are several hideous forms of the group in tropical climates, of which the best known is that of the Scorpions. It is impossible to look on one of these, and not be reminded of a lobster-the great palps, with stout dilated pincers, resembling closely the claws of that much more respectable crustacean. The Scorpions are widely scattered; several are found in the south of Europe, but it is in the tropics that they most abound. The Scorpio afer of the East Indies grows to six inches in length, and its sting is rather a formidable affair. We once experienced the effects of a West Indian Scorpion's venom, which were, however, not more severe than those of a wasp's or bee's sting. The weapon is a hooked, very acute joint at the extremity of a six-knobbed tail, within which is a bag of subtile poison, infused into the wound through two minute slits near the point. These animals lurk under stones and in dark crevices, living on beetles and other insects, which they catch with their claws. Tiny species closely resembling them, except that the tail and the sting are wanting, are common in old books and papers, and sometimes parasitically infesting insects. These constitute the genus Chelifer, and form the connecting link between the Scorpions and the Harvest-men or Shepherdspiders (Phalangium), which are so common in autumn, remarkable for the great slenderness and length of their many-jointed legs, which continue to move a long time after being separated from the body.

The tribe of Mites comprises small and generally very

* "Travels in Italy." 
minute animals. Scarlet is their favourite livery, and it often has the appearance of satin or velvet. The Watermites (Hydrachna) are merry little creatures that scuttle along through the water of our pools, looking like tiny globules of red sealing-wax. The Cheese-mite (Siro domesticus) is so common, that possibly, gentle reader, you may have emulated the feats of Samson, slaying thousands at a time, and that with a jaw-bone. If you are fond of dogs or of cattle, you have also, doubtless, made the acquaintance of a vile creature called a Tick (Ixodes), which attaches itself to the poor brutes in some spot inaccessible to their efforts-such as behind the ears, or at the root of the tail-and then, plunging a beak of sharp horny lancets into the flesh, sucks the blood, till its own body is gorged and swollen from the size of a hemp-seed to that of a horse-bean, when it drops off to make room for another bloodthirsty sucker. And, finally, some of these creatures (Sarcoptes) of minute dimensions, burrowing beneath the skin, become the cause of certain highly infectious cutaneous diseases, which are unhappily too common where cleanliness is neglected. 


\section{CHAPTER XXI.}

\section{RoTIFERA (Wheel-bearers).}

NeARLy two centuries ago, a great impetus was given to physical science by the application of the newly-invented Microscope to substances so minute, that their forms, or at least their structure, could scarcely be appreciated by the unassisted sense. The waters were found to be teeming with living creatures of multitudinous kinds, constituting what might be called a new world of life. The excessive minuteness of these creatures being their most obvious character, and the imperfection of the instruments as yet in use permitting no more than a vague perception of their exterior figure, it was natural that they should be associated in one group, under the term Animalcules.

More precise observation has, however, determined that, among these minute forms, are comprised animals of very various grades of organisation. Some are the simplest creatures known, as the Monads, of which we treated in the first chapter of this volume; some are not animals at all, but plants of a very low grade, endower, with animal-like powers of locomotion; some are the larvæ of Insects; some are minute ANnelida and Crustacea; and a considerable number, of high interest from their beauty, their sprightly motions, their perfect transparency, 
and their comparatively complex structure, constitute a peculiar class of themselves, under the title of RotifERA.

The relation which this group bears to other recognised classes of animals, has been a matter of some debate. It seems generally admitted that they come into the Annulose Division; and we are inclined to place them above the AnNelida, having relations both with Insecta and Crustacea, and forming a link by which the lowest forms of these highly-organised creatures are linked with the highest Infusoria.

The earliest known species is one of the most abundant; and though it is not so typical of the class as many others, being one of the lowest forms in organisation, yet as it exhibits, with peculiar clearness, the characteristic movement which has given a name both to itself and its class, it is popularly considered as the representative of the whole. We allude to the common Wheel-animalcule (Rotifer vulgaris), which is found in most collections of fresh water, and in vegetable infusions that have stood exposed for a few days.

The form of this tiny creature, which does not exceed $\frac{1}{30}$ th of an inch in length, is spindle-shaped or barrelshaped, the lower part tapering to a slender foot, of many joints, capable of being sheathed, telescope-fashion, one within another, and the upper part expanding into two circular disks set with vibrating cilia. It is the motions of these cilia which are so peculiar and characteristic of the whole class; they immediately arrest the attention of the observer, who is struck with wonder to behold what appear to be the dark teeth of two cogged-wheels, set side by side horizontally, and running rapidly round with the 
ceaseless regularity of a complex piece of machinery. The early observers supposed that the wheels really did rotate, though they found it impossible to imagine how any part of a living animal could do so. And no beholder can wonder at their supposition, for with all our knowledge of how the phenomena is produced, it is almost impossible, while looking at it, to persuade ourselves that there is not an actual rotation of the parts. The explanation of the appearance has been already given:* it is a rotatory progression of waves caused by the rhythmical bending and straightening of cilia, in themselves stationary. The effect of this movement is to produce circular vortices in the surrounding water, which are made conspicuously manifest when any minute particles of solid matter are held in suspension; as when a little carmine or indigo is mixed with the water. In this case, the coloured atoms are caught, and involved in the rapid rotation, passing off after many gyrations, in a continuous thick stream from a point between the two wheels, like the dense black cloud of smoke that streams away behind a steamer's funnel.

The objects of the ciliary rotation are principally two. When the animal is stationary, adhering to foreign substances by the extremity of its foot, the vortices bring ever fresh particles of water to be respired, and whatever atoms fit for food may be floating in the vicinity; the whirls leading to a central point, at which is placed the entrance to the stomach. On the other hand, when the animal relinquishes its foot-hold and commits itself to the open water, the cilia act like a steamer's paddle-wheels, 
and row it swiftly along in any given direction at the creature's will.

The skin in this species is membranous, but somewhat firm, folded upon itself at certain points of the circumference, so that one portion can, to a certain extent, be sheathed within another, as in the ANNELIDA and in the larve of INSECTS. In many genera, however, the integument hardens into a firm horny shell (lorica), which takes different forms, the most common being that of a tortoiselike box, as in Brachionus, \&c., with a wide orifice in front (often armed with projecting spines) for the protrusion and expansion of the ciliary wheels, and a smaller one in the rear to give issue to the flexible-jointed foot, which commonly terminates in two pointed toes. The structure and composition of this integument are similar to those of Insects and Crustacea.

Owing to the crystal transparency of these tiny creatures, we are enabled, with the aid of microscopic powers, to discern their internal structure and economy with a clearness which no dissection would avail to shew; even were not dissection precluded by their minuteness. They are thus perceived to possess a comparatively high condition of organisation. The muscular, the nervous, the digestive, and the reproductive systems are, in particular, well developed.

Long and broad ribbons of muscular texture pass from organ to organ, playing freely in the general cavity of the body, their contractions and extensions plainly visible. These are very numerous, some passing down longitudinally, others transversely, their extremities being inserted into the lining tunic of the integument. Sometimes the muscles 
take the form of slender but lengthened threads, and others are seen, crossing, in various directions, like a net, the ampler viscera. From this rich muscular development, the movements of the ROTIFERA are very varied and vigorous.

The nervous system is very peculiar and remarkable in this class. It exists in a form wholly without parallel in the Invertebrate Classes, namely, that of a single mass, well defined, and often of immense comparative size, which, in spite of all our reluctance, we can compare only to the brain of the VerTEBRATA. This great nerve-mass is placed in the head of the animal, and commonly carries, seated on its hinder part, a red eye (sometimes two) of simple structure, apparently composed of a lens and a pigment mass. The great ganglion sends off a pair of threads to the nape, where they unite into a small ganglion below an organ of sense, which, in its most ordinary form, is a tubular projection, furnished with a terminal tuft of hairs, and which appears to be the representative of the antennæ in INsECTS. In a few cases we have detected threads of extreme tenacity floating in the cavity of the body, which we believe to have a nervous character; but besides these, we know of no offshoots from the great central brain. It is certain that nothing answerable to the double chain of ganglia, united by threads, and running down the length of the body, that are so characteristic of the ANNuLOSA generally, exists in this class.

Scarcely less anomalous is the condition of the mouth. Far down in the body is seen an oval pellucid mass, containing a curious array of symmetrical pieces that work vigorously on a central table, like a pair of hammers on an anvil. Strange as is its position, this organ is nothing 
else than the mouth, its place being caused by the inversion of the fore parts of the body, permanently in some species, as Rotifer, but in others, as Scaridium, Furcellaria, \&c., transiently, the mouth being brought to the exterior when in action. The hammer-like pieces are the representatives of the upper jaws (mandibula), and the two halves of the table-like piece, against which they work, are the representatives of the lower jaws (maxillce) of InsECTS.

The food, after having been subjected to the pounding and crushing action of these hammer-like jaws, passes off behind through a slender gullet into a capacious stomach, into which bile is poured from glands (either a single pair or very numerous) which are appended to it. This is succeeded by an intestine, and this by a rectum, which terminates in an orifice behind the foot.

It is a curious circumstance that there exists one genus in this Class-hence named Asplanchna-which has no intestine nor any posterior outlet to the stomach, the foecal portions of the food being regurgitated and expelled from the mouth. Still more remarkable is the fact, that all the males in the Class are entirely destitute of the digestive apparatus ; neither mouth, jaws, gullet, stomach, nor intestine being found, nor any vestiges of these organs, in any male Rotiferon.

So far as has been observed, the sexes are separate throughout the class. The peculiarity just noticed is not the only one that distinguishes the sexes. The male Rotifera are invariably smaller, less fully organised, and more short-lived than the females; they commonly have scarcely any resemblance to their partners, though the 
males of all the species have a very close similarity to each other.

The females produce and deposit, one at a time, very large oval eggs, enclosed in a brittle shell. The young appear in the perfect form, being subject to no metamorphosis, and for the most part with all their organs complete. In some of the lower forms, as Stephanoceros, Melicerta, \&c., the young are hatched in a grub-like condition, from which the tentacles, disk, \&c., develop themselves by gemmation.

The genera just alluded to, and some others, are incapable of locomotion, except in earliest infancy; the young soon attaching themselves by the foot to some solid object. They now secrete and throw off from the surface of their body successive coats of gelatinous matter, which form an erect cylindrical case around them, into which they can wholly retire for protection, by contracting their fore parts on alarm. In general, this tube is simply gelatinous and transparent, except that it sometimes becomes partially opaque when old, by the adhesion to its exterior of Diatomacece, floccose particles, \&c.; but in one species (Melicerta ringens), which hence becomes invested with a high interest, the tubular case is strengthened by a layer of solid pellets, manufactured by the animal for the occasion, and deposited, pellet by pellet, and layer upon layer, just like the bricks in a piece of masonry.

This species is one of peculiar beauty, and any of our young readers who possess a microscope, or have access to one, will do well to obtain an hour's examination of it. Fortunately, it is by no means a rare animal in still waters where aquatic plants grow: the slender, much divided 
leaves of Myriophyllum are pretty sure to be more or less studded with the erect tubes, which are quite visible to the naked eye.

On being brought under the microscope with a power of 100 or 150 diameters, you can see a tall chimney of a yellowish-brown hue, standing on a leaf, slightly widening from the bottom upwards, and terminating in an irregular edge. Presently, a pellucid body peeps from the summit, like a sweep out of the chimney-top (pardon the similitude), and, rising higher and higher, suddenly unfurls a disk of four expansive petals, not altogether unlike those of a Heart's-ease, but made of crystalline material, and set round the margins with a row of those beanteous cilia, whose dark waves chase each other in ceaseless play, up and down, round and round, in the most charming manner.

Behind the disk, which by a bend of the upper part of the body is brought to assume a vertical position, there is a little hemispherical cavity on the surface, which is lined with cilia, and this is connected by a series of cilia with the sinus of the two great upper petals of the disk.

The ciliary wave, after making the circuit of the disk, passes off behind in a great current through the sinus just alluded to, carrying with it all the floating particles that are not fit for food, or that have not been carried into the mouth. These particles are hurled along until they reach the little hemispherical cavity, in which they are caught and whirled round and round with great rapidity. Here, too, they are probably mixed with some glutinous secretion, and the effect of the gyration is the consolidation of the particles into a little globular pellet. No sooner is this ready, than the animal quickly bends forward its 
body till the cavity touches the edge of its case, where the globule is deposited. The erect position is now assumed again, materials for a new globule begin to accumulate, and in a minute or two this is ready, and is deposited beside its predecessor ; and thus the case is swiftly built up, brick by brick. 


\section{CHAPTER XXII.}

Crustacea (Crabs and Shrimps).

THE dark, mysterious world of waters hides many a "moving creature that hath life;" and the solitary pacer along the black line of sea-weed that bounds the domains of earth and sea, or the curious Paul Pry that is ever and anon peering into nooks and holes and crannies in the surge-worn rocks, is continually surprised by some strange being, some minim of existence it may be, uncouth and slow, or lithe and elegant, and rapid as lightning; dull and sombre as suits its obscure retreat, or bright and gailytinted from the solar ray; some new combination or modification of organs; some novel exhibition of instinct, habit, or function; that awakens his admiration, and, if he be accustomed to turn from the creature to the Creator, elicits the tribute of praise to Him who made all things for His own glory.

The Crustacea pre-eminently make the waters their home; they are the aquatic division of that mighty host of living things, that range under the title of Articulata. The Insects, Spiders, and Mites, counting their armies, as they do, by hundreds of thousands, leave, with scarcely an exception, the sea untouched; and though a goodly number of these are found in the fresh waters of river, lake, 
and pool, they are few compared with the vast body. The solid earth and free air constitute their sphere of existence. The Crustacea, on the other hand, though represented by a few species that crawl on the land, and more efficiently in fresh waters, mostly range the sea, dwelling, according to the diversity of their structure and instinct, from the sunny surface to the unilluminated depths; from the shallows of the shore to the boundless solitudes of the ocean; from the genial waves of the Equator to the icefields of the Pole, to "Arctos and eternal frost."

Nor let this last assertion be considered as a sounding platitude with which to sweep the sentence round gracefully; for it is literally true: as far into the dreary regions of the Pole as our bold explorers, or still hardier whalefishers have penetrated, they report the Arctic Sea to swarm with small Crustacea. One little species, in particular, found in immense numbers beneath the ice, was turned to account in the temporary sojourn of the discovery expeditions in winter quarters, The men had often noticed the shrinking of their salt meat which had been put to soak, and a goose that had been frozen, on being immersed to thaw, was, in the lapse of forty-eight hours, reduced to a perfect skeleton. The officers afterwards availed themselves of the services of these industrious little anatomists, to obtain clean skeletons of such small animals as they procured, merely taking the precaution of tying the specimen in a loose bag of gauze or netting, for the preservation of any of the smaller bones that might be separated by the consumption of the ligaments.

In most respects, CrustaCeA are so much like Insects, that the older naturalists, and the illustrious Linnæus 
among the number, arranged them under the great class InsECTA. They have, however, a greater number of limbs; the full provision being five pairs of true feet, and three pairs of organs, which (because of a certain ambiguity in their function, like that useful piece of furniture of which we read-

\section{- Contrived a double debt to pay,}

A bed by night, a chest of drawers by day,")-

are called foot-jaws. Besides these, a great number of the species have five or six pairs of jointed limbs attached to the under-side of the abdomen, which are generally used for progression, and are called false-feet. Their mouth is furnished with three pairs of jaws and two pairs of antennæ. It must be borne in mind, however, that the total complement of these members is not found present in every species, some of them being wanting in certain extensive groups.

The researches of a naturalist who has paid much atten-

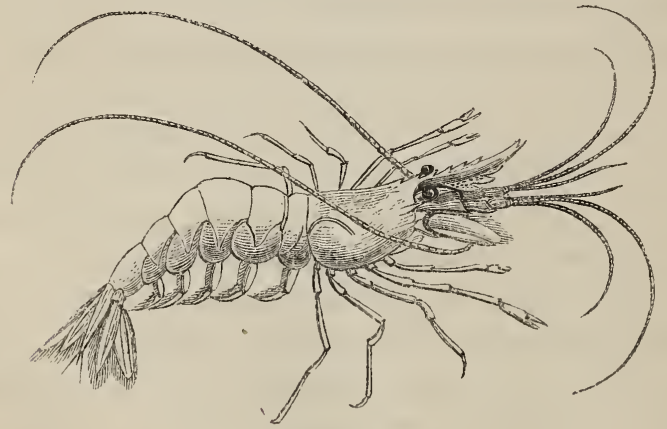

Prawn.

tion to this class, Mr Spence Bate, have shed a flood of 
interesting light on the office of the organs last-named.* Any one may easily identify them in the Lobster or Prawn. Take the latter. On each side of the long sword-like and spiny beak that projects above the head, there is an organ consisting of three stout joints, at the tip of which are three threads, of which two are of great length, and formed of numberless rings, and the third is short. These organs, then, constitute the inner pair of antennce. Below these there is a pair somewhat similar, but they consist each of five joints, and one long thread, with a large flat plate on each side. These are the outer antennce. The former are the organs of hearing, the latter those of smelling.

In the living anirnal, the inner antennæ are always carried in an elevated posture, and are continually flirted to and fro with a rapid jerking motion that is very peculiar, striking the water every instant. It is very conspicuous in the Crabs, from the shortness of the organs in question. When next our readers, gazing on the tenants of those wonderful marine tanks at the Zoological Gardens in the Regenit's Park, see a Crab tapping the surrounding water, and, as it were, feeling it-they may understand that he is trying it for the vibrations of sound : it is the action of vigilant listening, which never relaxes its guard.

To help the perceptions of the animal, the many-jointed filament which strikes the water is fringed with hairs of great delicacy, standing out at right angles to the stalk, so that the slightest vibrations cannot fail to be conveyed to the sensorium. This may be called the outer ear; but in the interior of the basal joint, which is large and swollen, there is a cochlea, or inner ear, having calcareous walls of 
delicate texture, to the centre of which passes the auditory nerve.

The outer antennæ differ greatly from the inner in their internal structure, though they resemble them so much in form. In the Crabs, the basal joints form a sort of box or compact mass, with an orifice on the side next the mouth, closed or opened at pleasure by means of a little door with a hinge, on the interior side of which a long bony lever is fastened, with the necessary muscles attached to it. In the Lobster and Prawn the door is wanting, but the orifice is protected by a thin membrane; and in some of the lower forms it is placed at the end of a strong spine or projection. In all cases, however, the orifice "is so situated that it is impossible for any food to be conveyed into the mouth without passing under this organ; and of this the animal has the power to judge its suitability for food by raising the operculum [or door] at will, and exposing to it the hidden organ-the olfactory." Who can refrain from exclaiming, at the sight of such beautiful, such exquisite contrivances for the safety and wellbeing of creatures so mean, "Great and marvellous are thy works, Lord God Almighty!"

The "crust," or skin which envelopes the body, in these animals, differs from that of INSECTs, inasmuch as it generally contains a considerable portion of carbonate of lime. In many of the smaller forms, as in the Shrimps and Prawns, it takes the consistence of thin transparent horn; but in the larger, as the Lobsters and Crabs, it acquires a great density, is perfectly opaque, and of the hardness of true shell, or even of stone. In the tips of the stout 
claws of the Crab (Cancer pagurus) we see it at its maximum of induration.

The breathing organs furnish another point of diversity between the Crabs and Insects. In the latter they are air-pipes, in the former gills; always contrived, though under many modifications of form and position, to extract the vivifying oxygen from water, and not from the atmosphere. Even the terrestrial species, as the common Woodlouse or Button (Oniscus), that rolls itself up into a ball in our gardens, need a certain degree of moisture to surround them, and hence they crawl out of their damp retreats only in wet weather. In the common Crab the gills are those long, finger-like, pointed pyramids of whitish substance often called "dead men's fingers," that are seen in two groups, when the carapace or "shell" is removed. If we examine them, we shall find each pyramid to consist of a vast multitude of thin membranous plates closely packed together, but yet admitting the water to flow freely between them, which is kept in constant circulation by means of innumerable cilia with which the surfaces are clothed.

The increase of the race is effected only by means of eggs, no Crustacean that we remember bringing forth its young alive. Every one is familiar with the eggs, "spawn," as they are termed-of the Prawn, the mass of intensely red globules that is carried beneath the belly, and that is so difficult to remove. The difficulty arises from the manner in which the false feet, all fringed as they are with fine hairs, penetrate the mass ; and thus we perceive another use of these organs, besides that of locomotion, already alluded to. 'The eggs, as they are laid, are de- 
posited on the false feet, and are carried about by the female parent until near the period of hatching. In some of the Opossum-shrimps (Mysidce) the eggs are carried in one or two oval pouches beneath the thorax; while in the curious little Water-fleas (Cyclopida), and the still more remarkable Epizoa, the eggs are carried on each side of the tail in two oval or cylindrical bags, generally of large size, and sometimes of such length as to exceed that of the whole animal besides.

Like InseCts, the CRUSTACEA undergo a metamorphosisperhaps with one or two exceptions. No one, uninstructed, could possibly recognise the earliest stage of the common Shore Crab (Carcinus moenas). A hemispherical carapace or shell, not so big as a small pin's head, sends up from its centre a long, pointed, curved spine, while another spine curves downwards from the front beneath the body like a beak; the eyes are without stalks; there are two pairs of jointed feet, ending in tufts of stiff bristles; and a long jointed body carried straight behind, which ends in two bundles of diverging spines. Such is the grotesque character under which our little masquerader makes his "first appearance on any stage." After a time he drops his outer garments, and assumes a second form-widely different from the former, and still sufficiently remote from the ultimate one ; and it is not till the third moult that the little creature, now grown to the size of a hempseed, begins to be recognisable as a Crab; though even now he has several stages to pass through, several doffings of coats and trousers, before he is quite a proper Shore Crab, comme il faut.

This periodic casting of the skin is a needful provision 
for growth in these animals, as in Insects ; in them it is confined to the caterpillar state, in which alone growth takes place ; but here it prevails, because growth is continued, long after the perfect form is attained. The rigidity of the encasing armour forbids the possibility of increase in its capacity. The growth, therefore, is periodic. At certain intervals the hard crust is thrown off in several pieces, a new crust having been prepared beneath, which is at first soft, flexible, and expansile. The body, now freed, instantly enlarges in all directions, and, in a few minutes, has attained the full extent of growth needed. The crust at once hardens, and in a brief space becomes as inflexible as was its predecessor, admitting no further enlargement either of its own surface or of the contained organs. The animal usually undergoes this process in the most retired situation it can find, instinctively conscious of its unprotected condition when soft, and apparently feeling sick and feeble.

Another interesting circumstance in the economy of this Class, and the last we shall at present notice, is the power of renewing injured or lost limbs. If one of the joints of a Crab's leg be wounded, it would bleed to death but for this provision. The animal, however, wisely adopting the saw of "Young Jem" in our nursery-rhyme-

"Better lose part than all"-

stiffens the hurt limb, and suddenly throws it off, the separation invariably taking place at the point where the second joint is united with the first. A small gland is placed here, according to Mr H. Goodsir,* which supplies

* Ann. of N. H., vol. xiii., p. 67. 
material for future legs as required. "When the limb is thrown off, the blood-vessels and nerve retract, thus leaving a small cavity in the new-made surface. It is from this cavity that the germ of the future leg springs. A scar forms over the raw surface caused by the separation, which afterwards forms a sheath for the young leg." "As the growth advances, the shape of the new member becomes apparent, and constrictions appear, indicating the position of the articulation ; but the whole remains unprotected by any hard covering until the next change of shell, after which it appears in a proper case, being, however, still considerably smaller than the corresponding claw on the opposite side of the body, although equally perfect in all its parts." *

* Jones's “General Outline," p. 343. 


\section{CHAPTER XXIII.}

Crustacea (Crabs and Shrimps).

\section{Continued.}

Perears the most singular of all animal existences, and certainly the most remarkable of the Class to which they belong, are those Crustaceans which constitute the Order ErizoA, so called from their parasitical habits. The grand principle of economy is so perfectly carried out in Creation, that not only is every spot of inorganic nature turned. to account in providing for some existences proper to it, but even the bodies of living animals are made to afford a dwelling-place and a feeding-ground for multitudes of other creatures. The intestines, the layers of muscle, the coats of the eye, the sinuses of the skull, afford, as we have already seen,* in different animals, a home for certain creatures of strange conformation, which are found under no other conditions, and are thence called Intestinal Worms, or more correctly ENTOZOA, i. e., animals which live within other animals. The gills of fishes, the breathing pouches, the interior of the mouth, and various parts of the surface of the body, become, on the other 
hand, the residence of another group, the Epizos, of which we are speaking.

Though these two groups of parasitic animals are very diverse in zoological rank, or, in other words, in the degree of complexity which their structure exhibits, they merge into each other by imperceptible gradations, so that there are some intermediate forms (as there almost always are on the confines of great groups), which it is very difficult to arrange in either Class, because this would involve their violent separation from near kindred. It must be borne in mind that our lines of demarcation are artificial, though, for perspicuity's sake, we must draw them somewhere.

One of the most interesting points in the economy of these creatures is the variety which is displayed in their armature. Deprived, for the most part, of limbs, or having these members when present strangely disguised, it was necessary to their existence that they should be furnished with some means of affixing themselves firmly to their prey, and various are the mechanical contrivances which serve this purpose. There is a minute Worm (Gyrodactylus) which lives upon the gills of certain species of the Carp tribe, whose adhering disk, when viewed beneath the microscope, is most formidable to behold. It is armed all around its circumference with sharp curved hooks, while its centre is provided with a pair of much larger hooks, all intended to be plunged deeply into the flesh of the unfortunate fish, while the blood is sucked at leisure. In Caligus, a creature a hundred times as large as that just named, found on various marine fishes, the object is effected by an array of hooked fangs and pincer- 
like claws, combined with sucking-disks, while a slender tube pierces the flesh and pumps up the vital juices. Chondracanthus, - which looks like a tiny doll dressed up in a long petticoat, fantastically studded all over with curved prickles,-clings to the gills of the John Dory by means of its stout hooked foot-jaws, of which there are three pairs.

More strange still is the furniture of the Lerneopoda. Here two long arms proceed from the thorax, which, curving forward, meet at their tips in front of the head, and uniting, carry a knob or button, which, being thrust into the flesh of some miserable Shark or Salmon, maintains the needful hold for the robber's operations. A similar creature (Achtheres), that infests our common Perch, has a contrivance more elaborate still : the two arms unite as before, but the knob at the point of junction now becomes a bell-shaped cupping-glass, beset within its rim with an array of recurved hooks. Hanging by means of this grappling-iron to the gums of the fish, it allows its body to swing without fear or danger of dislodgment, in spite of the currents that are perpetually flowing through the mouth and gills. In some very long and slender forms constituting the family Penelladce, parasitic upon the bodies of fishes, as the Sprat and Anchovy, the entire head is plunged into the tissues of the prey, sometimes into the eye, and is retained there by a curved prong which proceeds backward from each side of the head, exactly on the principle of an anchor. An additional firmness is secured to the Lernea, which infests the gills of the Cod, by the prongs or flukes of the anchor being furnished with processes shooting off irregularly on all sides, which, being 
imbedded in the flesh, like the roots of a tree in the soil, resist all opposing influences to drag it away. This form is one of the most bizarre of the whole ; for, besides this strange rooting head which is concealed, the exposed body resembles a twisted sausage, without limbs, to which the external ovaries hang, like rolls of thread twined loosely together.

Every ditch and pool is tenanted by tiny nimble creatures, which move through the water by a succession of little leaps, whence they are called Water-fleas. Sometimes the ponds swarm with them to such a degree that the fluid contents seem not water but blood, or other strange liquid, according to the colour of the little animals. These belong to the Order Entumostraca, and, though small, many of them being undistinguishable without microscopic aid, they are highly curious. Many of them are enclosed, either wholly or in great measure, in a shell, which takes the form of two convex plates, either soldered together down the back, or united there by a hinge, leaving the opposite edge free for the protrusion of the head and feet. The close resemblance of the latter (Cypridida) to the bivalve shells of Mollusca is remarkable.

In general these little animals have but a single eye in the middle of the forehead, which is of large size in proportion, round, and generally of a brilliant red hue, glistening like a ruby, so that it furnishes a beautiful study under the microscope. In the common Water-flea (Daphnia pulex), the eye is bluish black, evidently composed of about twenty crystalline lenses, and though quite included within the shell, its motions, which are quick and partly rotatory, can be distinctly perceived. 
For the protection of the eggs in this genus there is a peculiar provision. They are proportionally large and few in number, and, when laid by the mother, are not committed to the free element, but are deposited in a sort of chamber between the valves of the shell, above the animal's back. Here they are carried until the young are hatched; and even for some days more the little ones avail themselves of the same safe retreat, until they are strong enough to get their own living.

For the most part in this Order, however, the eggs are excluded in two large oval bags, which hang behind the parent, one on each side, these bags (external ovaries) being frequently each as large as the whole animal. When matured the young escape, and the sacs slough away, to be soon replaced by a new pair.

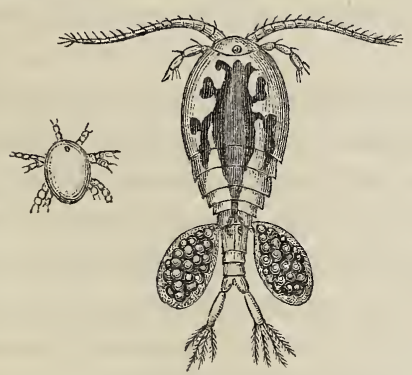

Cyclops-in its young and mature states.

Some of this race are not enclosed in shells : the genus just alluded to (Cyclops) and its fellows have the upper parts protected by a large buckler and hollow horny rings, much like the armour of the Shrimp and Lobster, and some are deprived of everything answering to a shield. Of the latter sort, which is, however, the exception to the general rule, is the Brine-shrimp (Artemia salina), which delights in the intensely salt pits of salt-works, as at Lymington, and elsewhere.*

* See an interesting account of this Shrimp in "Excelsior," vol. i., p. 229. 
The hiatus between these "Insects in Shells," as the appellation Entomostraca signifies, and the true Crabs, is occupied by an immense host of creatures still small, but generally of a size above that of the Water-fleas. They are commonly jointed throughout, without any carapace or buckler on the fore parts of the body. The terrestrial species are arranged here, of which the garden Armadillo, or Woodlouse, already alluded to, is a familiar example. They approach the nearest of the Crustacea to the true Insects. Many of them have the faculty of rolling themselves more or less completely into a ball, like the hedgehog, and apparently for the same purpose, of opposing a passive resistance to annoyance. The Orders IsOPODA and АMPHIPODA, distinguished inter se principally by the structure of the limbs, are composed of these forms, which, though they are of various interest, we are compelled summarily to dismiss.

And thus we come to the most highly endowed representatives of the Class, one of the most remarkable characteristics of which is that their eyes, instead of being imbedded in the head, or at most immoveably seated on the surface, are placed at the tip of horny, jointed stalks, which can be swayed about in various directions, greatly increasing the animal's range of vision. Hence this Order is called PoDophthaLim, or Stalk-eyed Crustacea.

The strangest of these are the Glass-crabs (Phyllosoma), animals of extraordinary beauty, found abundantly in the tropical oceans, swimming at the surface far from land. One species has been recently taken on the British shores. They look like an oval plate of the purest glass, with a broad tail and slender divergent limbs, so transparent and 
colourless that they can scarcely be detected but for the eyes, which are of a lovely blue hue, and are carried at the end of long stalks.

Our common Prawns (Palcemon) are beautiful examples of pellucid structure; and when alive, they form, from this circumstance, from the dark-brown lines with which they are adorned, from their elegant shape, and sprightly, graceful motions, very interesting objects in a marine Aquarium ; the more so as they are among the most easily kept, being readily reconciled to captivity, and keeping themselves in health and condition, without trouble to their possessor, on the animalcules and garbage that else would accumulate on the bottom. Their manner of feeding, by the hand-like use of their long slender claws, which seize the food and present it to the mouth; the brushes of hair with which some of the feet are fringed, serving as cleansing organs, and the effective way in which these are made to reach all parts of the body, and to keep it scrupulously clean; the flapping of the false feet beneath the abdomen in the process of ordinary swimming; the occasional sudden stroke upon the water of the broad tail-plates when the creature is alarmed, causing it to shoot backward with the rapidity of thought to the distance of several inches; the structure ef the eyes, and the singular reflection of a candle from their interior, like the flash of a policeman's bull's-eye; and even the internal organs, the pulsation of the heart, and the passing of the food, as masticated, into the stomach, can all be seen and studied to advantage in these parlour pets. An hour's observation on their organisation and their manners, if our readers have the opportunity of watching any marine Aquarium, 
would furnish a most interesting and instructive lesson in physiology.

The broad plates which expand like a fan at the tail of the Prawns and Lobsters, form their great resource for swift and sudden locomotion. The common Lobster is said to be able to dart back by this means thirty feet, with the fleetness of a bird on the wing; and when we think of this feat, we must not forget the great density and resistance of such a medium as water, in which it is accomplished. The existence of these plates, and the great development of the abdomen which carries them, distinguish these from the proper Crabs, which have no terminal plates, and in which the abdomen is reduced to a thin flap bent under the body and pressed close to it, except when it is forced out of place by the spawn, which the females deposit between it and the thorax.

Some of the Crabs have the power of swimming, but it is by a very different mechanism from that of the Lobsters; and it affords us one of the many examples which the naturalist is constantly meeting, with, of the infinite resources of the wisdom of God in creation. In the common eatable Crab (Cancer pagurus), with the exception of the foremost pair of limbs, which are expanded into powerful grasping claws, all the feet are terminated by a short sharp-pointed toe. But we have some species common on our shores (Portunus, \&c.), in which the hindmost legs have the last joint dilated into a broad, thin, oval plate, which being fringed, as are also the other joints, with stiff hairs, constitute oars, and being worked in a peculiar manner, row the animals swiftly to and fro, at the surface or through 
the deeps. Others, which are more strictly oceanic, display the same structure in a yet higher degree.

It is impossible to walk along a beach by the edge of the tide without observing many univalve shells running to and fro, with an agility far greater than that of the sluggish mollusks, whose houses they originally were. On looking closely at them, we see the antennæ, eyes, and claws of what seems a minute Lobster projecting from each. If we take it up, the jealous little rogue withdraws into the house, pulling his legs after him, and claps one stout claw upon the other, in such a way as effectually to bar the intruder's entrance. We may smash the shell upon a stone, and thus execute a forcible ejection (it is no more than he deserves, for the house is not his own, and he pays no rent), and then we see that the hinder parts are curiously distorted and twisted, to fit it for tenanting a spiral shell. It is not a Lobster at all, but a Hermit-crab (Pagurus), and this is the mode of life for which it is created. The abdomen is covered with a soft skin instead of a shelly crust, and therefore needs protection; and this is provided by the instinct which teaches the Crab to search for some empty univalve shell of suitable size, and to appropriate it for himself. Some laughable scenes occur when the old house becomes too strait for him to live any longer in it, and his growing bulk compels him to look out for a new lodging. Like a sound philosopher, he never loses grasp of the old shell till he has found a better.

Tropical countries have many species of Crustacea, which, from their terrestrial habits, are denominated Landcrabs. Those of the West Indies (Gecarcinus) make burrows in the soft earth, whence they wander by night for 
forage. Once in the year they are said to come down from the mountains in troops, surmounting every obstacle in their way to the sea; after depositing their eggs in the water they return much enfeebled. Of the habits of an East Indian species (Thelphusa cunicularis), Bishop Heber thus speaks in his interesting Journal: "All the grass through the Deccan generally swarms with a small Landcrab, which burrows in the ground, and runs with considerable swiftness, even when encumbered with a bundle of food as big as itself ; this food is grass, or the green stalks of rice, and it is amusing to see the Crabs sitting, as it were, upright to cut their hay with their sharp pincers, and then waddling off with their sheaf to their holes as quickly as their sidelong pace will carry them."

And since they are so anxious to get out of our sight, we will take the opportunity to make our bow to them and the whole tribe of Crabs and Shrimps together. 


\section{CHAPTER XXIV.}

\section{Cirripedia (Barnacles).}

WHOEVER is familiar with the rocky coasts of our sea-girt isle, is aware that that belt of rock which is included between the levels of high and low tide, is ordinarily studded with millions of little shelly cones, often packed so closely together, that there is not proper standing room for them, so that the individual cones are forced out of their proper shape, and compelled to rise into a lengthened distorted form.

He may chance, moreover, to have seen a log of timber drifted in from the wide ocean, or the bottom of a ship just returned from a twelvemonth's tropical voyage, either of which has probably displayed numbers of singular beings, which he may be disposed to associate with the Bivalve Mollusca that he finds on the sandy beach. For they consist of a flattened shell, composed of many pieces, usually of a blueish-white hue, marked with orange, but set at the end of a more or less lengthened stem of a wrinkled gristly substance, by which it is firmly attached to the submerged timber.

Now the stony cone seated on the rock, and the delicate multivalve swinging at the end of the long footstalk, are members of the same class-they are both Barnacles. In 
order to see their affinity, nothing more would be needful than to detach a piece of the rock, and a fragment of the timber, each with one or more of its tenants adhering, and plunge both into a glass of sea-water. Presently you would see, within the open mouth of the cone, two little shelly pieces separate, and out comes a most exquisite apparatus. It is something like a hand of many slender fingers, thrust forth, opened, closed again with a clutch, and drawn in.

Look now at the delicately coloured valves of the stalked kind. These separate, and a similar hand is thrust out, makes its clutch, and disappears. The structure of both, and the action, are the same. The principal differences are the absence of the footstalk in the former case, and the soldering together of the valves into a conical shape. The one represents the Acorn or Sessile Barnacles (Balanid $x$ ), the other the Stalked Barnacles (Lepadidce).

The "hand" thrown out is a beautifully adapted implement for the capture of prey. The Lepas, indeed, possesses in its footstalks a little more freedom of motion than the firmly-soldered Balanus; but both are fixed, and are therefore incapable of pursuing their prey. They are hence dependent for subsistence on such minute animalcules as the currents of the waters may bring within reach; and the constantly recurring clutches help to increase these currents. But they do more. If we examine each of the long "fingers" (cirri) which compose the hand, and which are set in expansible pairs, we shall see that it is composed of a great number of joints, whereby it is endowed with great flexibility, and that it is also studded with fine but stiff bristles, which stand out at right 
angles from the surface. Now the "fingers," expanded like a fan, and curved like a half-open hand, make the framework of a net, while the transverse bristles, those of each "finger" meeting and interlocking with those of the next, constitute a series of meshes occupying the interstices, and the whole, cast out and withdrawn, form a most efficient strainer of the water, arresting every minute atom, living or dead, which, being then passed down to the mouth at the bottom of the net, is either swallowed or rejected, according as it is fit for food or worthless.

The Barnacle, whether sessile or stalked, passes through a series of metamorphoses, which shew that, although its appearance and instincts when adult have a great resemblance to those of the MollusCa, its affinities are truly with the Crustacea. It begins life in a form exactly like that of a young Entomostracous Crustacean, with a broad carapace, a single eye, two pairs of antennæ, three pairs of jointed, branched, and well-bristled legs, and a forked tail. It casts off its skin twice, undergoing, especially at the second moult, a considerable change of figure. At the third moult it has assumed almost the form of a Cypris or Cythere, being enclosed in a bivalve shell, in which the front of the head, with the antennæ, is greatly developed, equalling in bulk all the rest of the body. The single eye has become two, which are very large, and attached to the outer arms of two bent processes like the letters $U U$, which are seen within the thorax.

In this stage the little animal searches about for some suitable spot for permanent residence; a ship's bottom, a piece of floating timber, the back of a whale or turtle, or the solid rock. When its selection is made, the two antennæ, 
which project from the shell, pour out a glutinons gum or cement, which hardens in water, and firmly attaches them. Henceforth the animal is a fixture, glued by the front of its head to its support. Another moult now takes place; the bivalve shell is thrown off, with the great eyes, and their U-like processes, and the little Cirriped is seen in its true form. It is now in effect a Stomapod Crustacean, attached by its antennæ, the head greatly lengthened (in Lepas, \&c.), the carapace composed of several pieces (valves), the legs modified into cirri, and made to execute their grasping movements backwards instead of forwards, and the whole abdomen obliterated or reduced to an inconspicuous rudiment. 


\section{CH $\triangle$ PTER XXV.}

Polyzoa and Tunicata.

WE speak of the "scale of animal life," as if species rose above species in a perfectly regular linear series, as to their development in organisation, like the steps of a ladder, beginning from the lowest, simplest forms of life, and proceeding step by step, without any interruption, till we arrive at the highest, MaN, "who was made after the image of God." This is, perhaps, the common notion among those who have ever attempted to consider the matter philosophically, - to contemplate Creation as a whole, a system, a plan. And the notion is aided by our systematic books. We are compelled, by the very nature of a book, to treat of creatures in this linear manner; we cannot do otherwise : we must begin with something, then go on to something else, and so proceed till we leave off. Nobody has yet invented a book in which the pages shall run on in parallel or complex series, instead of successive; nor would it be possible to read it otherwise than successively, if it could be so written.

However, there is much in nature to confirm the common notion. Linear series we find everywhere. Proofs may be found in these very pages; we have treated of 
animals whose structure manifestly ascends in uninterrupted gradation, such as that beautiful chain we noticed in the Echinodermata, for instance. It is not that the principle is not correct, but that it is not true throughout: it is not the only principle.

In fact, we find, in tracing up linear gradations, points occurring ever and anon, where, though the series does not break, other series link themselves on laterally, which may themselves be pursued linearly, and which in like manner send off side-chains, which link with other linear series.

Let us illustrate this by a homely simile. Let us suppose that a person with eyes capable of only microscopic vision had before him a purse made of netted beads, and was endeavouring to discover the plan on which it was constructed. $\mathrm{He}$ is able to see but a single bead at a time. He takes one and numbers it; perhaps names it : and is conscious that another is in contact with it; this also he numbers; and finds a third, and a fourth, and so on, running on in straight succession. He presently concludes that he understands the structure; it is plainly a linear series. But soon he comes to a bead-perhaps it is number 10-which has in contact with it not only the number 11 , but also a bead at each side. If he leave the original line, which he finds he can follow on if he so choose, he will discover that either of these lateral beads is the first of a series, which leads on linearly, till by and by, after sundry offshoots and bends, he comes into the original line at bead number 20 , or 35 , or 150 , as the case may be. And from the offshoots of these secondary chains, he can pursue similar chains ever branching off 
and ever merging into one another. Now this would be very puzzling; and it would not be till after a great deal of examination in detail, and a great deal of "putting two and two together," and many happy guesses, that he would at length master the idea of a quincuncial plan-the order of a net.

But suppose that the net, instead of being woven on a single plane, as all our nets are formed, were made to increase in every possible direction-a net to be estimated by solid instead of superficial measure, like the cells which go to make up the pulp of an apple-how would the plan be complicated! And how much more of protracted observation and study would be necessary before the inquirer could master this model by the slow study of a bead at a time!

Now, we do not mean to say that the great plan of Creation can be correctly represented by a series of meshes in a plane, nor by a mass of cells in a solid, nor by circles set circularly till a larger circle is formed, and many of these set to constitute a still larger circle, and then again others still larger; we will not set our seal to any of those models, which have been from time to time proposed with great confidence as "the natural system." But the comparison may help some of our readers better to appreciate the fact, that while there is a beautiful order in creation, the existence of which is readily discovered, it is an order, not simple, but highly complex in its relations.

A notable example of the breaking down of the linear arrangement occurs in a series of creatures which we have now to introduce to our readers : a series which, com- 
mencing at a point far lower than that to which we have ascended in our previous observations, rises in uninterrupted gradation, though not without many lateral relations, to the very highest type of animal existence.

If we have been in the habit of picking up sea-weeds from the shore where they have been washed by the waves, or from the little sheltered rock-pools where they delight to grow, we have often seen spread over their smooth fronds what looks like a little piece of muslin, only that it is more delicate, more filmy. It adheres quite firmly to the surface, so that it cannot be rubbed off ; and if we apply our thumb-nail to it, we discover that, thin as it is, the substance of which its subtile meshes are composed is stony or shelly in its nature, and so hard as to scratch the nail. What is it? It is one of the sea-mats (Membranipora pilosa).

We bring the magnifying power of a pocket-lens, or a microscope, to bear on it, and our sense of beauty is at once gratified. We see a net-work of glassy cells, each closely resembling a slipper in shape, arranged in the most orderly manner side by side, yet so that the opening of one shall be in contact with the middle of its nearest neighbour, sidewise, while the toe of the slipper touches the heel of the next, lengthwise. The margin of the orifice is a little thickened, like the binding of a slipper, and there are springing up from this rim six short spines which arch over the opening, and a very long one from the front which runs up in the line of the instep. The slipper-like cell is trausparent as glass, but in the substance are seen many oval bladders or cavities.

These cells are so many houses inhabited by active 
animals. In the specimens which you pick up on the beach nothing more than this would be seen, however closely you might examine them, but in our sample just taken out of the water, we shall be able to shew much more. The broad orifice surrounded by spines is covered during life with a very delicate elastic membrane, stretched across it like the head of a drum, and towards the front of this there is a slit with two lips in the form of a crescent. From the lips of the slit a case or tube of the thinnest possible skin passes through the middle of the cell, within which plays a polype to and fro, capable of protruding itself to a great extent, as well as of retreating far into the depths of its cell, according to its pleasure. In the latter state the animal is bent upon itself with a double fold, somewhat like a person lying in bed with his knees tucked up; but when it wishes to expand itself, two pairs of muscles, which are seen in the form of threads on each side, draw the body forward, and the skin that envelopes it turns inside out, just as we draw off a stocking. It gradually protrudes from the slit as it unfolds, and then displays a number of long tentacles which are regularly packed side by side in a bundle; but when these are quite protruded, they suddenly expand into the shape of an elegant bell or cup. The appearance of the animal is now very beautiful; it is as clear as spun glass; the sprightly motions which it exhibits increasing its beauty. Each of the thread-like tentacles seems to have a double row of black teeth, like the cogs of a watch-wheel which run rapidly along in ceaseless course ; those of one side of the tentacle running towards the tip, and those of the other side towards the base. Striking and beautiful, 
however, as this motion is, so that it is impossible to look at it without admiration, it is not really a progression of any of the parts. This appearance of moving teeth is caused by very fine cilia, the nature and action of which have already been explained. It will be sufficient here to say, that the combined action of the whole of the cilia forms a whirlpool, the centre of which is the mouth at the bottom of the bell of tentacles, and that every atom that comes within range is sucked in and engulphed.

This is a representative of a class of animals called Polyzos ; it contains numerous genera and species differing much in the form and arrangement of the cells, but displaying a remarkable uniformity in the structure of the animals themselves. In many species the series of cells

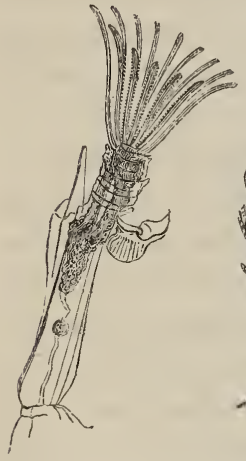

Bugula avicularia (nat. size), and a cell magnified, shewing the expanded polypide, and a " bird's-head." is attached to a foreign body only by its base, standing erect, often spread out and divided like a much-cut leaf, or set in single order, one cell springing out of the tip of another, and bearing a third on its extremity, with occasional branchings, so that the total structure resembles a tiny shrub.

Many of these creatures bear highly curious appendages, than which we know scarcely anything more interesting as a microscopical study. Take, for example, Bicellaria ciliata, or Bugula avicularia. On the outside of some of the cells in these species there is a little tubercle, to which is articulated, by a 
slender joint, an organ which has been aptly compared to the naked head of a vulture. This organ has a beak with two mandibles, the lower of which alone is moveable, opening and shutting like that of a bird, but with far greater width of gape, as the lower mandible can be opened till it extends behind in the same line with the upper. Each edge of the mandible (in the first-named species) is furnished with five strongly projecting teeth; the lower has a single tooth at its point, which fits into the notch between the terminal pair of the upper. The whole back of the head is transversely wrinkled.

The movements of this strange appendage are in keeping with its curious structure. The whole head ordinarily sways to and fro upon the slender joint of the poll at intervals of a few seconds; but besides this motion, which is even, though rather quick, the lower mandible which commonly gapes to its utmost extent, now and then, at irregular intervals, closes with a strong sudden snap, much like the snapping of a turtle's jaws, and presently again opens and leisurely resumes its former expansion. We may distinctly see the muscles which move the lower mandible; they occupy the position of the palate and extend back to the inner surface of the skull, if we may borrow such terms from the organ which this organ mimics. It is very interesting to witness these singular motions, and it is scarcely possible to observe them without believing that the animal exercises an active volition in performing them.

But the observation of these "bird's heads" suggests curious questions. Do they form a part of the polype's organisation? Why, then, are they found attached to some cells of a specimen while others are destitute of 
them? Why do some specimens possess them and not others? Why are some species of a genus furnished with them while some are destitute of any such appendages, though essentially the same in every other respect? No light is thrown on these questions by anatomical examination. It would appear that the animal within is quite independent, organically, of the "bird's head," for, as Dr Reid has remarked, and as we have personally observed in several species, the "bird's head" continues to move for a considerable time after the death and decomposition of the polype. It has been suggested that the use of the organ is to grasp and kill passing animalcules, which then may be drawn into the cell by means of the ciliary currents of the tentacles; and this appears not improbable, and receives confirmation from the toothed structure of the beak.

The organ in question, with its singular function, may minister to the support of the common life in another way less direct but not less effective. The seizure of a passing animal, and the holding of it in the tenacious grasp until it dies, may be a means of attracting the proper prey to the vicinity of the mouth. The presence of decomposing animal substance in water invariably attracts crowds of infusory animalcules, which then breed with amazing rapidity, so as to form a cloud of living atoms around the decaying body, quite visible in the aggregate to the unassisted eye, and these remain in the vicinity, playing round and round until the organic matter is quite consumed. Now, a tiny Annelid or other animal, caught by the bird's head of a Polyzoan and tightly held, would presently die; and though in its own substance it might 
not yield any nutriment to the capturer, yet by becoming the centre of a crowd of busy Infusoria, multitudes of which would constantly be drawn into the tentacular vortex and swallowed, it would be ancillary to its support, and the organ in question would thus play no unimportant part in the economy of the animal.

Many members of this Class possess organs analogous to these, but differing considerably in the details of their construction; and some are also furnished with long stiff bristles, which, moving freely on a joint at the base, can be made, at the will of the animal, to sweep across the face of the cell with considerable force, perhaps with the view to clear it of any extraneous matters that might otherwise annoy or hurt it. Some genera, which have no organs answering to these, inhabit membranous cells instead of shelly ones, as Bowerbankia and its allies; in others, the cells are immersed in a firm fleshy mass, as is the case with the Alcyonidiadce.

From the PolyzoA the transition is easy and short to the Tunicata. The essential structure is the same in both. The body consists of a sac, with two orifices, usually placed near together, or the discharging one on one side, and a little below the receiving orifice. The circle of tentacles around the mouth of the Polyzoan is reduced in the Tunicate (Ascidia) to short processes, which guard the orifice, and a similar circle is conferred upon the discharging one. On the other hand, there now appears a distinct breathing organ in the form of a hanging bag of membrane, the inner surface of which is covered with oblong cells, set in rows, and these cells are lined with cilia, whose movements resemble those of a toothed wheel. 
The breathing cilia are, in short, transferred from the projecting tentacles to the interior of the body. There is, moreover, in the Tunicata a pulsating heart, and also a circulation of blood.

In many families of this Class the individual animals are aggregated together like those we have just described, having a common corporate, as well as an individual life. Such are the brilliantly-coloured masses, like stars set in coloured jelly, that are common on sea-weeds and submerged stones. These are Botryllidce. We know of no example of an isolated Polyzoan; they are all compound animals, though in a few cases the cells stand up singly and remotely, from the common uniting root-thread; but in the Tunicata we find many examples of single life. Of this sort are the strange uncouth creatures that are so abundantly brought up by the dredger from the seabottom, attached to stones and old shells, and resembling a bag of tough leathery skin, with two orifices, and hence called Ascidia, from the Greek word à $\sigma$ kòs, a leather bottle. Some of these are large, rough with irregular lumps and depressions, and opaque; others are smaller, smooth, pellucid, and brilliantly coloured. If they are plunged into a vessel of sea-water we see the orifices periodically opened wide, and suddenly contracted to a point; and by careful observation we may detect the entering and outgoing currents of water that pass through these apertures.

There are some species which, though not strictly compound, are aggregated together in a highly curious manner. Such are the Salpa, which are found sivimming in the free ocean; sometimes solitary, sometimes united into long flexible chains of transparent animals, which swim with 
serpentine movements. The genus Pyrosoma contains animals aggregated in another manner. These are lengthened Ascidians, united to each other so as to compose a long free tube, open at one extremity and closed at the other. This is also an oceanic genus, and is remarkable for being vividly luminous, the light displaying the most gorgeous and varied hues. We shall close this chapter with an extract from Mr Bennet's "Wanderings," in which he records his own observations of these interesting animals.

"On the 8th of June, being then in lat. $0^{\circ} 30^{\prime}$ south, and long. $27^{\circ} 5^{\prime}$ west . . . late at night, the mate of the watch came and called me to witness a very unusual appearance in the water, which he, on first seeing it, considered to be breakers. On arriving upon the deck, this was found to be a very broad and extensive sheet of phosphorescence, extending in a direction from east to west, as far as the eye could reach. The luminosity was confined to the range of animals in this shoal, for there was no similar light in any other direction. I immediately cast the towing-net over the stern of the ship, as we approached near the luminous streak, to ascertain the cause of this extraordinary and so limited phenomenon. The ship soon cleaved through the brilliant mass, from which, by the disturbance, strong flashes of light were emitted, and the shoal, judging from the time the vessel took in passing through the mass, may have been a mile in breadth. The passage of the vessel through them increased the light around to a far stronger degree, illuminating the ship. On taking in the towing-net, it was found half filled with Pyrosoma (Atlanticum?), which shone with a beautiful pale-greenish light, and there were also 
a few shell-fish in the net at the same time. After the mass had been passed through, the light was still seen astern, until it became invisible in the distance, and the whole of the ocean then became hidden in darkness as before this took place. The scene was as novel as beautiful and interesting." 


\section{CHAPTER XXVI。}

Conchifera and Gastropoda (Shell-fish).

SucH of our readers as are familiar with the fish-market at Southampton have, doubtless, often seen a large sort of shell-fish which are sold under the name of "Old Maids." The fishwoman, perhaps herself an "old maid," will tell you that these humble sisters of hers, these rivals in celibacy, are dug up from the muddy margin of the harbour, into which their burrow descends a foot or more deep ; that the hunter for them is aware of their presence by a jet of water spirted from the mouth of the hole as soon as they become aware of his, a fact of which his approaching footsteps inform them; and that he instantly plunges his narrow spade or fork in an oblique direction, and raises the unlucky bivalve, with a cloud of mud and water, into the air.

Now, if we examine one of these "Old Maids," which naturalists designate as the Sand Gaper (Mya arenaria), we find that we have an animal closely resembling those Ascidice that we lately described. It is enclosed in a leathery wrinkled coat, with the two orifices placed near the end of a rather long tube; the intermal anatomy differs little from that of tho creatures just named, ex- 
cept that there is an opening in the side for the protrusion of a moveable fleshy organ called the foot; but externally there is this peculiarity, that, in the substance of the coat, there are formed two valves or convex plates of stony substance (shell), which are united along one side by a hinge, and enclose the soft parts, as the leaves of a book are contained within the covers.

This, then, is a bivalve shell-fish, as it is commonly (though incorrectly) named, and it is the representative of an extensive Class of animals, found all over the world, in fresh and salt waters, and designated CoNCHIFERA, or "Shell-bearers." There is, it is true, very great diversity in the details of form and structure that we find in this immense assemblage of animals; but all these variations can be easily traced by insensible gradation to this primal form, and thence to those lower types which we have already described. Sometimes the orifices for receiving and discharging water are prolonged into two distinct tubes with fringed extremities, as in that lovely and delicate shell that inhabits our sandy beaches, called, from its diverging rays of pink and yellow, the Setting Sun (Psammobia vespertina), where the two tubes, when fully extended, are twice the length of the shell. At other times we find the tubes again reduced to simple openings, and one of these forming a mere slit, scarcely to be distinguished from the common opening of the coat or mantle, as in the Mussels (Mytilida). This separation of the mantle, again, occurs in various degrees, from its condition as a mere orifice for the protrusion of the foot, to that of the Oysters (Ostreadce), where it is open all round, a fleshy counterpart of the shelly valves, bordered by a 
short but close fringe. In the beautiful Pectens, "the butterflies of the Mollusca," the mantle is still further modified, for it is furnished with four rows of long moveable contractile tentacles, and with two rows of eyes that sparkle and glow like the most brilliant gems.

Another and a parallel modification takes place in the breathing organs, which, instead of being a

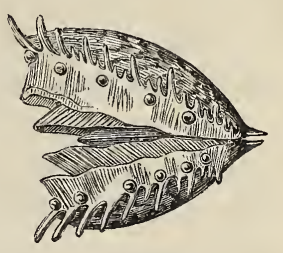
closed sac, as we saw it in the Ascidice, become thin flat leaves, much like the folds of the mantle or the shell-valves, which are placed a pair on each side. Their structure is no less modified than their form, for instead of oval ciliated cells on the internal surface, each of the four leaves (in the Pecten, for instance) consists of a vast number of straight, slender, transparent filaments, evidently tubular, arranged side by side, so that 1500 of them would be contained within the length of an inch. Strictly, however, these are but one filament, excessively long, bent upon itself again and again, at both the free and the attached end of the gill-leaf, throughout its whole extent. This repeated filament is armed on each of two opposite sides with a line of vibrating cilia, the two lines moving in contrary directions, exactly as on the tentacles of the PolrzoA, which are the breathing organs there; by this action a current of water is made continually to flow up and down each of these delicate filaments; so that the blood which circulates in their interior (for they are, doubtless, blood-vessels) is continually exposed, throughout this its long and tortuous course, to the action of oxygen. 
Like all organic functions, the action of these cilia is not under the will of the animal. If, during life, a small portion of the gills be cut off, the motion of the cilia will convey the fragment swiftly away, with a smooth easy motion, through the surrounding fluid, in a definite direction. It does not even cease with the life of the animal. A specimen which we examined had been dead at least fifteen hours, yet when we placed the torn fragments of the branchice, one after another, beneath the microscope, the energy of the ciliary action, as the wave flowed with uniform regularity up one side and down the other of every filament, filled us with astonishment. Even the next morning, twenty-six hours after death, when the tissues of the filaments were partially dissolved, the ciliary motion was still going on, on portions that preserved their integrity.

The leaves which form the mantle are useful, not only for protecting these gills and the other delicate organs which are situated within their embrace, but for manufacturing the valves of the shell. This process has been ably described by Professor Rymer Jones, as it takes place in the Scallop (Pecten maximus), and we shall quote his words :-

"It is the circumference or thickened margin of the mantle alone which provides for the increase of the shell in superficial extent. On examining this part, it is found to be of a glandular character, and, moreover, not unfrequently provided with a delicate and highly sensitive fringe of minute tentacula. Considered more attentively, it is seen to contain in its substance patches of different colours, corresponding both in tint and rela- 
tive position with those that decorate the exterior of the shell.

"When the animal is engaged in increasing the dimensions of its abode, the margin of the mantle is protruded, and firmly adherent all round to the circumference of the valve with which it corresponds. Thus circumstanced, it secretes calcareous matter, and deposits it upon the extreme edge of the shell, where the secretion hardens and becomes converted into a layer of solid testaceous substance. At intervals this process is repeated, and every newly-formed layer enlarges the diameter of the valve. The concentric strata thus deposited remain distinguishable externally, and thus the lines of growth marking the progressive increase of size may easily be traced.

"It appears that at certain times the deposition of calcareous substance from the fringed circumference of the mantle is much more abundant than at others; in this case ridges are formed at distinct intervals; or if the border of the mantle at such period shoots out beyond its usual position, broad plates of shell, or spines of different lengths, are secreted, which, remaining permanent, indicate, by the interspaces separating successively-deposited growths of this description, the periodical stimulus to increased action that caused their formation.

"Whatever thickness the shell may subsequently attain, the external surface is thus exclusively composed of layers deposited in succession by the margin of the mantle; and seeing that this is the case, nothing is more easy than to understand how the colours seen upon the exterior of the shell are deposited, and assume that definite arrangement characteristic of the species. The border of the mantle 
contains in its substance coloured spots; these, when minutely examined, are found to be of a glandular character, and to owe their peculiar colours to a pigment secreted by themselves; the pigment, so furnished, being therefore mixed up with the calcareous matter at the time of its deposition, coloured lines are formed upon the exterior of the shell wherever these glandular organs exist. If the deposition of the colour from the glands be kept up without remission during the enlargement of the shell, the lines upon the surface are continuous and unbroken; but if the pigment be furnished only at intervals, spots or coloured patches of regular form, and gradually increasing in size with the growth of the mantle, recur in a longitudinal series wherever the paint-secreting glands are met with." *

The shell increases in thickness no less than in diameter ; and this also is effected by the mantle; the calcareous matter being deposited, layer after layer, on the interior surface of the valve. There are no pigment-glands on the general surface of the mantle, and hence the interior of shells is always white or destitute of colour, except that brilliant iridescence which we are so familiar with in many shells, which constitutes mother of pearl. This prismatic reflection depends on strice, or impressed lines, of microscopic minuteness, on the surface, and can be produced artificially on several substances. Pearls themselves are merely quantities of this calcareous matter poured out in abundance at one spot, often to surround some atom of sand, and thus prevent its edges from wounding the sensitive mantle.

* General Outline, 385. 
If we now come to the other great Class of shelled animals, that named GASTROPODA, we find we have to make a considerable leap to pass the hiatus. For, in fact, there is no very close relation between the Bivalves and the Univalves. Possibly species may yet be discovered which will supply the links that are wanting; but this is scarcely likely. Not that there is no transition. If we take that interesting shell called the Cap of Liberty, or the Torbay Bonnet (Pileopsis Hungaricus), we cannot but be struck with the resemblance which it bears to a single valve of such a shell as the Heart (Isocardia cor); and in some of its near allies, as the little Cup and Saucer (Calyptrea Sinensis), there is a subordinate shelly plate in the interior, which has been considered as the vanishing representative of the second valve.

The form of the shell in this Class is that of a cone, with the apex on one side of the centre. In the Limpets (Patella), the cone is short and low, and therefore unmistakeable; in the Torbay Bonnet the summit is a little rolled over, the commencement of that spiral form which we see in the Whelk and the Snail. Nay, if we take the extremes of this condition, as we see in the long manywhorled shells of the genera Turritella, Scalaria, and the like, it is not difficult to trace the same form, a cone drawn out to great length and twisted spirally on an axis.

The animals of these shells are much higher in organic development than the Conchifera. They have a distinct head, with organs of touch, of vision, of hearing, and of smell, and a mouth armed with a complex array of teeth for the purpose of rasping away the solid food on which they subsist. They have the faculty of locomotion, the 
under surface of the body being dilated into a flat muscular foot, the action of which may be observed by any one who chooses to look at a snail gliding up a pane of glass. This great muscular crawling disk is so characteristic as to have given name to the Class, Gastropoda, from two Greek words, signifying "belly-footed."

A cabinet of shells is a beautiful and interesting sight; the rich, varied, and delicate colours, the pearly iridescence, the elaborate patterns, the porcellaneous texture, the perfect polish, the exquisite sculpture, and the graceful forms which we see profusely displayed there, must

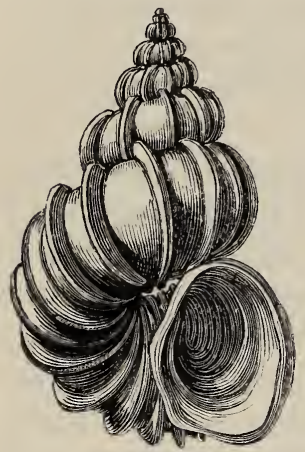

Wentletrap. always delight the eye. No wonder that the conchologist regards his treasures, the spoils of every sea and every shore, as "an assemblage of gems," and that he delights to exhibit them as les delices des yeux et de l'esprit. The prices that have sometimes been given for rare or beautiful specimens would be considered fabulous, were they not capable of indubitable proof. "In 1753, at the sale of Commodore Lisle's shells, at Longford's, four Wentletraps (Scalaria pretiosa) were sold for seventy-five pounds twelve shillings, viz.,-one not quite perfect for sixteen guineas; a very fine and perfect one for eighteen guineas; another for sixteen guineas; and a fourth for twenty-three pounds two shillings."

But higher prices than these have been given. That in Mr Bullock's Museum, supposed to be the largest known, 
brought at his sale the sum of twenty-seven pounds, and was estimated, in 1815, at double that value ; and there is a tradition that a specimen was sold in France for 2400 livres, or 100 louis!

Before we dismiss these examples of the great and populous "middle-class" of animal life, we must give a momentary glance at the Cuttles and Squids (CerHaloPODA), which, while they possess much in common with the Univalve MolLusca, rise still higher in the scale than they, are still more favoured in the development of function and structure, and lead us insensibly to the verge of the animal " aristocracy," the Vertebrata.

Strangely enough, the aspect and contour of these fierce and formidable creatures, the highest of all Invertebrate animals, bring us back to the lowest ; for a Cuttle-fish with its cylindrical body, its mouth at the extremity, and a circle of long flexible fleshy arms radiating around it, is (in form at least) just a Polype over again. There is, it is true, an immense difference in structure : the Cuttle is encased in a fleshy mantle, which is sometimes expanded into swimming fins, has a large head with staring eyes, a stout horny beak, like that of a parrot, of formidable power, and its arms are furnished with rows of sucking disks that act like cupping-glasses, and serve as so many instruments of prehension. Internally there is a shelly or horny plate which passes down through the substance of the mantle, and vestiges of a bony skeleton begin to appear in the form of a cartilaginous box which incloses the brain, and represents the skull of Vertebrate animals. Some species reside in an ample shell, as the Paper and Pearly Nautilus, both celebrated for their beauty. 
A curious circumstance in the economy of these creatures is the secretion of a peculiar fluid of a most intense blackness, lodged in a vessel, variously situated in different species, and spouted out at the will of the animal. This substance, frequently called ink, from the use to which it was anciently applied, mixes freely with the water, diffusing an impenetrable obscurity for some distance around, by which the animal often escapes from danger; thus, as our illustrious Ray wittily remarked, hiding itself, like an obscure or prolix author, under its own ink.

And lest any of our readers should slily add "ecce signum!" we will say no more about the Mollusca at this present. 


\section{PART III.}

\section{LIFE, IN ITS HIGHER FORMS.}



FISHES.

\section{CHAPTER XXVII.}

\section{Pisces (Fishes).}

Is passing from one country to another, we do not find any boundary lines in nature corresponding to those which we see upon our maps. There may be a gradual change of features, indeed; as the vegetation that characterises Spain differs from that of France, and this latter from that of Prussia; but the traveller is not conscious of any abrupt change, the last mile of his journey on one side of either frontier being pretty much the same as the first mile beyond it. We speak, too, of the various ranks and classes of society : the labourer, the artisan, the tradesman, the manufacturer, the merchant, the professional man, the scientific man, the statesman, the peer, the prince, the sovereign; but the homes, the raiment, the manners of these, though characterised by well-marked diversities and peculiarities, are not separated by broad lines of demarcation, but pass imperceptibly into each other. The diversities exist in nature, but the boundary lines are arbitrary.

So it is in Natural History. The student will do well to bear in mind continually that those subdivisions of organic beings which we call Classes, Orders, Families, and Genera, are but convenient aids for recording and re- 
membering facts. There is but one division which exists in nature,-that of Species. Each Species is separated from every other Species by an impassable boundary (whether we can in all cases determine it practically or not). It was originally created distinct, and distinct it remains. But the group of Species which we call a Genus is a merely arbitrary collocation ; convenient, indeed, as we before said, and to a certain extent natural, inasmuch as it is a formula for expressing the community of certain characters ; but still arbitrary, inasmuch as it might be made more or less extensive, according to the pleasure of the naturalist who chooses the characters on which it is made to rest. And so of all the higher groups.

The great Division of animal existences which we propose now to consider presents peculiarities of structure and function, which we can seize and identify with great precision when we look at it as a whole. But if we examine the points of contact between it and the great groups -we have dismissed, we find these broadly-marked distinctions becoming evanescent, and melting into those of the conterminous phalanx.

One grand distinction of the higher animals is commemorated in the title by which they are generally known,-Vertebrata. They possess an internal skeleton composed of many pieces, and formed of a substance which is not deposited, layer by layer, like the shells of MoLLUSCA, but is capable of growth in the manner of fleshy tissues, being permeated both by blood-vessels and nerves, and undergoing a perpetual change in its component atoms. In its simplest form this substance is flexible and elastic, and is called cartilage; but by the addition, in various 
degrees, of the calcareous element, it becomes hard, solid, and inflexible, and we call it bone.

Now, as in the highest forms among the Moluusca we saw the external skeleton of shell gradually vanishing, and traces of an internal skeleton of cartilage appearing, (as the cranial ring, or skull, and the fin-plates, of the Cuttle-fishes) - so in the most rudimentary of the FisHEs, as the Lamprey, and that curious creature the Sea-hag (Myxine), and, more markedly still, in the dubious Lancelet (Amphioxus), the spinal column, instead of forming a series of distinct bones, is an undivided rod of cartilage ; in the latter two instances horny, flexible, and bearing the closest resemblance to the "pen" of the common Squid.

Perhaps it will be well to examine the nature of this distinctive skeleton as we find it in its normal development. Its most important element is the spinal column, which con-
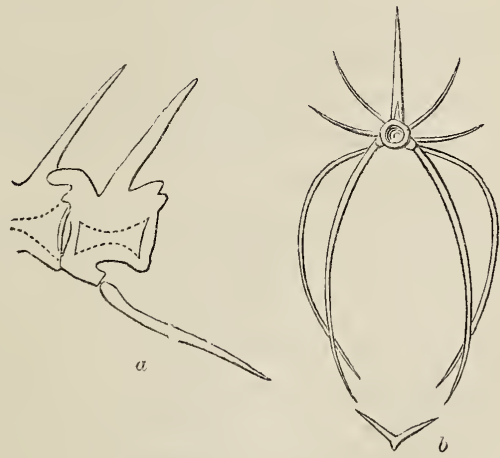

Vertebræ of a fish.

a. Lateral aspect.

b. Front aspect.

sists of a linear series of pieces attached to each other, and 
running longitudinally through the animal. These pieces are called vertebrce. The best way to study a vertebra is to take that of a Fish,-one of the joints from the backbone of a Cod for example, since in this Class we find it most simply and yet most perfectly developed. We thus perceive that it is composed of several parts :-1. The central cylinder; 2. the superior arch, formed by two sloping side pieces, between which the spinal marrow passes; 3 . the superior spinous process, projecting upward from the union of these pieces ; 4 . the two lateral processes; 5 . the inferior arch, formed as the superior is, protecting great bloodvessels; 6 . the inferior spinous process, pointing downward.

A number of the vertebrce at the fore part of the column are so far modified in shape and proportion of parts as to be identified only by close study and comparison. They constitute the skull, a capacious chamber of bone formed to contain the brain, which is but the aggregation of several pairs of ganglia greatly developed.

In front of these bones there is placed another series, arranged in pairs, constituting the face; some of these are excavated into cavities to protect the organs of sense, and others form the jaws, \&c.

These may all be considered as integral parts of the vertebral column ; but besides these, there are important accessories yet to be noticed. First, there are a number of slender bones, which are articulated to the transverse processes of the vertebrce, and arch outwards and downwards. They form two series: 1. The hyoïd arches, which spring from the skull: these are minute in the human skeleton; but in some animals, especially in Fishes, they are large and important, forming the great frame- 
work which carries the gills. 2. The ribs, which are in general developed in a ratio inverse to that of the hyoïd arches. Secondly, we find two pairs of limbs, each consisting of several pieces articulated to each other, and free at one extremity, while the other is jointed to the spinal column, or suspended in the muscles of the body.

Such is a brief enumeration of the essential parts of an internal skeleton, which, when examined in detail, with intelligence of the purpose which every part is intended to subserve, forms one of the noblest monuments of the wisdom of God that can be found in creation. It must be observed, however, that the various portions are seen in various degrees of development in different classes of animals, and that some of the constituents are occasionally either very rudimentary or entirely wanting.

Not less important in the economy of a vertebrate animal is the condition of the nervous system. To this, indeed, the skeleton is ancillary. There is a great concentration of nervous matter in the fore part of the animal, constituting the brain, whence cords are given forth to the organs of sense, which are mostly situated in the vicinity. From its hinder part proceeds the spinal marrow, running along a tube formed by the superior arches of the vertebræ, and giving off a number of threads on each side in symmetrical pairs. The spinal marrow itself is not homogeneous, but is composed of four cords fused together, of which the upper pair is destined to convey the commands of the will to the voluntary muscles, while the lower pair receives the sensations which are conveyed from without. Hence they are respectively termed the motor and the sensitive tracts of the spinal cord. 
In like manner every lateral nerve is double, arising by two distinct roots, the one from the motor, the other from the sensitive tract.

Besides these, there are series of nerves, extensively ramified, which do not originate from either brain or spinal column, but from scattered ganglia situated in various parts of the body, and destined to supply those important organs whose motions are independent of the will, and which are therefore distinguished as the organic or vegetative system.

The blood is, in every case, composed of red "globules" or (more properly) disks, suspended in a watery fluid. It circulates through two series of vessels, which ramify to every part of the body. The one series-that of the veins-receives the assimilated nutriment from the digestive system, and conveys the blood, so reinforced, but exhausted of its oxygen, to the heart, a great muscular chamber, which alternately contracts and expands without intermission. By these movements, the contained volume of blood is urged forward, in whole or in part, to the lungs, or (in such animals as are aquatic) to the gills, where it is brought into proximity with fresh oxygen, either from the inhaled air or water. This element readily combines with the blood through the excessively attenuated coats of the vessels, and revivifies it, restoring at once its brilliant red hue. Thus renewed, the vital fluid is returned to the heart, whence it is forced into the other series of vessels called arteries, which carry it forward to all parts of the body, and at length, uniting with the veins by excessively minute tubes called capillaries, situated at the circumference, and having built up 
the whole structure of the living temple in its course, it takes its return journey as we at first described it.

The lowest Class of the great Vertebrate Division is that of FisHes. They are distinguished by the simplicity of their outline, by their respiring by gills instead of lungs, by the enormous development of their hyoïd apparatus, by their cold blood, by the modification of their limbs into fins, and by the possession of accessory organs of the same kind, especially the tail-fin, which is their grand instrument of locomotion. All these characteristics are, more or less obviously, dependent on the great fact of their aquatic life.

We have already adverted to the existence among the Mollusus of the rudiments of an internal skeleton, by which that great division overlaps, so to speak, the present. On the other hand, we find in most FisHes remnants of the external skeleton neither few nor unimportant, by which they manifest their affinity with the creatures below them. The scales of the majority of Fishes, the bony plates which we see in the Trunk-fish (Ostracion) and in the "Tittlebat," which every truant schoolboy knows, the recurved spinous tubercles with which the Thornback's skin is studded, and the opercular bones or plates that cover the gills, - what are all these but portions of an external skeleton, in no way belonging to that series of bones which belongs to the fish as a vertebrate animal ? The rays of the fins which are not limbs (as the dorsal, the anal, and the caudal), and the blade-like bones penetrating the flesh to which these are jointed, must also come into the same category.

The scales which form the covering of most fishes are 
highly instructive objects. " Examined separately," says Professor Jones, "each scale is found to be partially imbedded in a minute fold of the living and vascular cutis, to which its under surface is adherent. Every scale is, in fact, made up of superimposed laminæ of horny matter secreted by the cutis, precisely in the same way as the shelly covering of a mollusc; and by maceration the different layers may readily be separated, the smallest and most superficial being, of course, the first formed, while the largest and most recent are those nearest to the surface of the living skin: as far as relates to the mode of growth, therefore, there is the strictest analogy between the scale of a fish and a shell. Various are the forms under which these scales present themselves to the ichthyologist; sometimes, as in the Eel, they are thinly scattered over the surface of a thick and slimy cutis; * more generally they form a close and compact imbricated mail; in the Pipe-fishes (Syngnathidoe) the whole body is covered with a strong armour composed of broad and thick calcareous plates; and in the Coffin-fishes (Ostracionidce) the integument is converted into a strong box made up of polygonal pieces anchylosed together, so that the tail and the fins alone remain moveable." +

The bones which compose the proper skeleton have little density or hardness in any fishes; and in one large subdivision-that containing the Sturgeons, Sharks, and Skates-they are wholly composed of cartilage. In the latter, which, in this as well as some other respects, are the lowest forms in the Class, we find, however, analogies and peculiarities which raise them above the highest.

* Or, rather, imkedded in its sutstance.

† "Gen. Outline," p. 506. 
Teeth, which are so characteristic of VERTEBRATA, are nowhere found in such variety of form, and function as among Fishes. They are not confined to the jaws, but are found by turns in almost every one of the bones that compose the mouth, though not in all species. They are generally simple spines, curved backwards; but innumerable modifications of this form occur. Thus the jaws of the deadly Shark are flat and lancet-like, the cutting edges being notched like a saw; the front teeth of the Plaice and the Flounder are compressed plates; some, as the Wrasse, have flat grinding teeth; others, as the Sheep's-head, have the grinding surface convex; and others, as the genus Chrysophrys, have convex teeth so numerous and so closely packed over a broad surface, as to resemble the paving-stones of a street. The beautiful Chrtodons of warm climates, on the other hand, have teeth which resemble bristles, and these are set close together like the hairs of a brush; while the Perch of our own rivers has them still more slender, minute, and numerous, so as to resemble the pile of velvet. Another of our well-known fishes, the bold and fierce Pike, is armed with teeth scarcely less formidable in size, form, and sharpness, than the canines of a carnivorous quadruped. In number, also, there is a great variety. The Pike, the Perch, the Cat-fish, and many others, have the mouth crowded with innumerable teeth, while the Carp and the the Roach have only a few strong teeth in the throat, and a single flat one above; and the Sturgeon, the Pipe-fish, and the Sandlaunce, are entirely toothless.

The eye in this Class presents a beautiful example of adaptation to the medium in which they live. From the 
density of water being so nearly the same as that of the aqueous and vitreous humours, these have scarcely any power to refract the rays of light; and hence a high magnifying power is given to the crystalline lens. Its form is that to which the very highest possible power is assigned - a perfect sphere, and the density of its texture is very great. But as the power of a lens and the nearness of its focal point are in the same ratio, it was needful to bring the retina, or curtain on which the image is painted, very close to the lens; and this is done by diminishing the vitreous humour behind it, and thus flattening the sphere; while a provision is made for maintaining this shape in certain plates of bone or cartilage, imbedded in the tough coat of the eye, called the sclerotica.

The eye is never protected by an eyelid in fishes; the pupil is very large and incapable of contraction; and another peculiarity is, that (at least in many species) the one eye is moved independently of the other.

The last organ we have space to notice at present is the air-bladder, which is found in most of the bony fishes. It is usually of a lengthened form, attached beneath the spine; but its shape is subject to some variety. Thus, in the Hedgehog fishes it is two-lobed, like a Dutchman's breeches; sometimes it is a double sac; in the great Card family, and in the Electric Eels, it is divided into two compartments by a transverse partition, which, in the former case, is perforated to allow an intercommunication. In one of the Cat-fishes (Pangasius), it is divided into four compartments, and in others into many irregular cells. Thus, the air-bladder closely approaches in structure the lowest form of the lung in air-breathing Vertebrata, as 
FISHES.

in the Axolotes and the Newts, in which this organ is a simple bladder, and in the Frogs and Toads, in which it is subdivided into large cells; and it may, therefore, be considered as the first rudimentary appearance of an aerial respiratory apparatus.

With regard to its function, in Fishes, it appears primarily to be connected with swimming. Being condensed by muscular pressure, or allowed to expand, it renders the body either heavier or lighter; and thus enables the fish to swim at any height in the water according to its pleasure. In general, the roving and surface-swimming species are furnished with the organ in question, while such as haunt the bottom are destitute of it; and this arrangement well agrees with the function we have ascribed to it. Yet it cannot be denied that there are some most unaccountable deviations from this rule. Thus, the Gurnards, which are ground-fishes, are well furnished with bladders; the two British species of Surmullet are deprived of the organ; while the Tropical species, which have the same habits, are provided with one. Again, of surfacefishes, our common Mackerel has no bladder, while the Spanish and Coly Mackerels, which have exactly the same manners, are each furnished with one.

In many cases the bladder is hermetically sealed, but, in some instances, it communicates by a tube with the stomach, or the gullet. The air which it contains appears to be a secreted gas; it is found to be, in some cases, oxygen, and in others, strange to say, nearly pure nitrogen. The former gas occurs chiefly in species that live in very deep water.

The blood, as already observed, is cold; that is, it com- 
monly takes the temperature of the surrounding water; in some of the swift oceanic Fishes of the Mackerel family, however, such as the Tunny and the Bonito, the blood is found to be $10^{\circ}$ higher than the temperature of the surface of the sea, even within the Tropics: the flesh of these Fishes is dark and dense. The blood-disks are sometimes circular, sometimes oval. They are larger than those of Mammalia and Birds; smaller than those of Reptiles, and especially than those of AмpHiBra.

The irritability of the muscular fibre is considerable, and is long retained. Fishmongers take advantage of this property, to produce rigid muscular contraction, after life has ceased, by transverse cuts and immersion of the muscles in cold water: by this operation, which is called "crimping," the firmness and density of the muscular tissue are increased.

In our next chapter, we shall enter into some details of the instincts and habits of Fishes, and some other matters connected with the Class, of more popular interest than these structural peculiarities, which, we fear, will prove but a dry morsel to many of our readers. 
FISHES.

\section{CHAPTER XXVIII.}

\section{Piscess (Fishes).}

\section{Continued.}

As the innate selfishness of our hearts always prompts the question, cui bono? -it may be as well to commence this chapter with a few particulars of the usefulness of FisHes in ministering to our bodily wants. The value of fish as an article of human food has been appreciated in all nations and all ages. The earliest pictorial records of Egyptian every-day life are largely occupied with the capture and preservation of these animals; various forms of nets, the fish-spear, the hook and line, are all in requisition; and strings of fishes, split and salted, and hung out to dry, remind us of scenes familiar enough to the writer of these pages-the cod-fisheries of Newfoundland. A1lusions to the hook and line occur in the most ancient of writings-the Book of Job; and, in the Mosaic law, "whatsoever hath fins and scales in the seas and in the rivers" was freely given to Israel for food. The most remote and savage tribes feed largely on a fish diet; and the ingenious devices and implements employed by the islanders of the Pacific Archipelago far exceed in variety, 
and in their elaborate effectiveness, those produced by European art. Every sea, from the Pole to the Equator, is stocked with fishes; they abound in the rivers and lakes of all climates; even the "tarns" and little basins scooped out of the summits of mountain-ranges, hold species of interest and value peculiar to themselves. So that the beneficent Providence of God has thus stored up inexhaustible magazines of wholesome, palatable, and nutritious food, and placed them within reach of man for the supply of his necessity-the stimulus and the reward of industry.

The fisheries of Britain are of national importance; the amount they contribute to the public wealth is immense; and they are regulated, even in many minute details, by repeated enactments of solemn legislation. An enumeration of the species which form the objects of our fisheries is itself startling:kinds, sea-bream, mackerel, scad, dory, atherine, gray mullet of two kinds, gar-fish, salmon, herring, pilchard, shad, cod, haddock, pout, whiting of two kinds, pollack, hake, ling, burbot, torsk, turbot, holibut, sole, flounder, plaice, dab, eels of three species, conger, thornback, skate of several kinds, - are all taken in quantities and brought regularly to market; not to speak of many other kinds, such as perch, trout, char, pike, carp, roach, tench, \&c., which are taken for the table, chiefly from our rivers, for individual amusement.

The quantity of human food thus taken yearly from the water is enormous; an idea of it may be formed from the fact, that, of one species alone, and that a very local one, being confined to the western extremity of our island- 
the pilchard-the Cornwall fisheries yield 21,000 hogsheads annually. What, then, must be the produce of all the species above enumerated, all round the indented coasts of Britain and Ireland? We have no sufficient data to determine the commercial value of British fisheries; but it has been loosely estimated by $\mathrm{Mr} \mathrm{M}$ 'Culloch at $£ 3,500,000$, and by Sir John Barrow at $£ 8,300,000$, per annum.

The possibility of capturing fishes of any particular species at any given time, with tolerable certainty, in such numbers as to constitute a fishery, is dependent on certain instincts and habits in such species, leading them to associate in multitudes in particular localities at particular seasons. The most prominent of these instincts is connected with reproduction. It is essential to the hatching of the spawn (or eggs) of most fishes, that it be deposited in comparatively shallow water, within reach of the vivifying influences of light and heat. Hence, as the season of spawning draws nigh, the various kinds leave the deep water, and approach, in countless hosts, the shores, where they are readily seen and captured. And it is a most beneficent ordination of God's providence, that, at this season, they are in the very best condition for food: let the spawn be once deposited, and the fish is worthless. What is more vile than "a shotten herring?"

Any one who will look with curiosity at the "hard roe" of a Yarmouth Bloater, may form a notion of the extent to which fishes obey that primal law, "Be fruitful, and multiply, and fill the waters in the seas" (Gen. i. 22); for this hard roe is nothing else than the accumulation of eggs in the ovary of a female fish: every seed-like grain 
an egg, and all to be laid in the course of a few daysthe contribution of one individual herring to the population of the seas ! It would be no sinecure to count them; but, partly by counting, partly by weighing, approximations have been made to a knowledge of the extent of a fish's family. Six millions of eggs have been estimated to lie in the roe of a single cod!

How, of course, an immense proportion of this number comes to nothing; perhaps three-fourths of these eggs are devoured by other fishes, or voracious creatures of one kind or other, almust before they well reach the bottom; and of the proportion that is hatched, multitudes find a speedy termination of existence in the maw of their watchful and numerous enemies. For, as a general rule, fishes are universally carnivorous; every species preying without mercy upon all others that it can master and swallow. Some curious examples of this voracity are on record. Mr Jesse speaks of a Pike, to which he threw in succession five Roach, each about four inches in length. "He swallowed four of them, and kept the fifth in his mouth for about a quarter of an hour, when it also disappeared." At a lecture delivered before the Zoological Society of Dublin, Dr Houston exhibited as " a fair sample of a fish's breakfast," a Frog-fish, two feet and a half long: in the stomach of which was a Cod-fish, two feet in length; the Cod's stomach contained the bodies of two Whitings of ordinary size; and the Whitings in their turn held the half-digested remains of many smaller fishes, too much broken up to be identified.

"Harsh seems the ordinance, that life by life

Should be sustained; and yet, when all must die, 
And be like water spilt upon the ground, Which none can gather up, the speediest fate, Though violent and terrible, is best. Oh, with what horrors would creation groan, What agonies would ever be before usFamine and pestilence, disease, despair, Anguish and pain, in every hideous shapeHad all to wait the slow decay of nature!

Life were a martyrdom of sympathy ;

Death lingering, raging, writhing, shrieking torture :

The grave would be abolished; this gay world

A valley of dry bones-a Golgotha-

In which the living stumbled o'er the dead

Till they could fall no more, and blind perdition

Swept frail mortality away for ever.

'Twas wisdom, mercy, goodncss, that ordain'd

Life in such infinite profusion-Death

So sure, so prompt, so multiform, to those

That never simn'd, that know not guilt, that fear

No wrath to come, and have no heaven to lose."

MONTGOMERY.

The statement has been common, in books of natural history, that fishes manifest no parental affection or care; that the spawn, having been deposited in the proper situation, the parents' work is done, and all their solicitude ceases. It is possible that this may be the general rule; but it is not without numerous exceptions. As early as the time of Fabricius, it was known that the male Lumpsucker kept a strict watch over the spawn when laid, defending it with the most obstinate courage. And recent observations have added not a few other examples of parental care among fishes, not exceeded by the devotion of the mother bird. Within a few months of the writing of these pages, a most interesting detail has been published by $\mathrm{Mr}$ Warington, of the nest-building instincts and tender care of the commonest of British fishes-the tiny Stickleback, that swarms in every pool. 
In the month of May the male Stickleback, which is then adorned with the most brilliant tints-his nuptial dress-begins to make a nest. For this purpose he selects small woody fibres, rootlets, \&c., which he collects one by one; and, carrying them to the selected place, inserts them into the ground, and skilfully interweaves them, so as to form a ring. Now and then he collects minute bits of gravel, and brings mouthfuls of sand, all of which he lays upon the fibres to keep them steady. Thus a thick ring of interlaced materials is at length made, with a hole in each of the two opposite sides, through which the fish can squeeze himself. During the whole time the little creature resents the least intrusion on his operations, attacking his fellow fishes with the utmost fury, and driving them to a distance. The house being ready, the lady is invited to take possession; and the following curious scene ensues:-

"The female fish came out of her hiding-place, her attention being fixed apparently on the nest; when immediately the male became, as it were, mad with delight. He darted round her in every direction, then to his accumulated materials, slightly adjusted them, fanned them, and then back again in an instant. This was repeated several times. As she did not advance to the nest, he endeavoured to push her in that direction with his snout: this not succeeding, he took her by the tail and by the side-spine, and tried to pull her to the spot, then back to the nest; and having examined the two small openings alluded to, he thrust his nose in at the lower, and gradually drew himself under the whole of the materials, making 
his exit at the opposite one, as though to prove to her that everything was prepared for spawning." *

The female now deposits her spawn in the nest; and is immediately repulsed by the male as earnestly as she had been invited. The nest is then opened by the male to the action of the water, which, by a peculiar motion of his body, called in the previous extract " fanning," constantly repeated, is driven in currents over the spawn. This proceeds for about ten days; at the end of which period the male sets himself to destroy and scatter the materials of the nest, so as to leave a space of clean gravel about three inches in diameter. Let $\mathrm{Mr}$ Warington tell us what next:-

"Watching carefully, for a short time, to understand what all this busy alteration indicated, I at last had the pleasure of observing, by the aid of a long-focused pocket lens, some of the young fry-of course most minute creatures-fluttering upwards here and there, by a movement half swimming, half leaping, and then falling rapidly again upon or between the clean pebbles of the shingle-bottom. This arose from their having the remainder of the yelk still attached to their body, which, acting as a weight, caused them to sink the moment the swimming effort had ceased.

"Around all the space above mentioned, and across it in every direction, the male fish, as the guardian, continually moved. And now his labours became still more arduous than they had been before, and his vigilance was taxed to the utmost extreme; for the other fishes, three of them twenty times larger than himself, as soon as they 
perceived that the young fry were in motion, used their utmost endeavours continuously to pounce upon the nest and snap them up. The courage of this little creature was certainly now put to its severest test; but, nothing daunted, he drove them all off, seizing their fins, and striking with all his strength at their heads and at their eyes most furiously. All the assistance that could possibly be afforded him was of course rendered, short of actual interference, by keeping them pretty well fed, in order to allay, if possible, their voracity. Another circumstance, which appeared to add greatly to the excitement that he was constantly subjected to, arose from a second female fish, being in spawn, endeavouring most pertinaciously to deposit her ova in the same locality, and hence rushing frequently down towards the spot. But the male fish was ever on the alert; and although he did not strike at her in the furious way he attacked the larger ones, yet he kept continually under her, with the formidable back-spines all raised erect, so that it was impossible for her to effect her apparent object.

"The care of the young brood, while encumbered with the yelk, was very extraordinary; and as this was gradually absorbed, and they gained strength, their attempts to swim carried them to a greater distance from the parent fish; his vigilance, however, seemed everywhere; and if they rose by the action of their fins above a certain height from the shingle bottom, or flitted beyond a certain distance from the nest, they were immediately seized in his mouth, brought back, and gently puffed or jetted into their place again. This was constantly occurring; the other fishes being continually on the watch to devour the 
stragglers, and make a savoury morsel of these Lilliputian truants. Indeed, the greater number of the whole brood must have fallen a prey to their voracity, as it was only some three or four that reached a size to place them beyond the power of their destroyers."*

Some of our fishes perform long migrations in order to deposit their spawn. The Salmon, for instance, ascends rocky rivers from the sea, overcoming various barriers, and leaping up cascades, to accomplish its purpose, with indomitable perseverance and energy. The Eel, on the other hand, descends rivers to spawn in the brackish waters of estuaries, displaying equal determination. Of this a curious example is said to occur annually in the vicinity of Bristol.

Near that city there is a large pond, immediately adjoining which is a stream. On the bank between these two waters a large tree grows, the branches of which hang into the pond. By means of these branches the young Eels ascend into the tree, and from thence let themselves drop into the stream below, thus migrating to far distant waters, where they increase in size, and become useful and beneficial to man. A casual witness of this circumstance remarked that the tree appeared to be quite alive with these little animals. The rapid and unsteady motion of the boughs did not appear to impede their progress.

Did space permit, we could furnish many entertaining details of manners in this Class of animals, in their various modes of taking prey; but we must content ourselves with one. An interesting example of what we may be allowed to call skill, is afforded by the instincts of some 
of those beautiful little tropical fishes called Chætodons. In the East Indies these are kept in vases for the purpose of witnessing their unerring archery, as their feats in this way are highly amusing. The manners of these little fishes (abundantly confirmed by subsequent testimony) were first described by $\mathrm{Dr}$ Schlosser, in a communication to the Royal Society, on the authority of Mr Hommel, the Governor of the Hospital at Batavia.

The little fish alluded to (Chelmon rostratus) "frequents the shores and sides of the sea and rivers in search of food: when it spies a fly sitting on the plants that grow in shallow water, it swims on to [within] the distance of

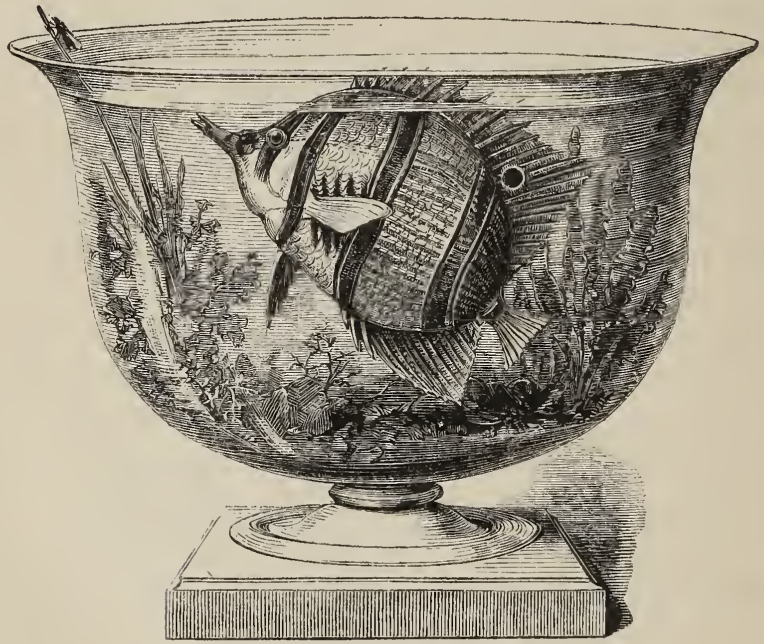

The Fly-shooter.

four, five, or six feet; and then, with a surprising dexterity, it ejects out of its tubular mouth a single drop of 
water, which never fails striking the fly into the sea, when it soon becomes its prey.

"The relation of this uncommon action of this cunning fisi raised the Governor's curiosity; though it came well attested, yet he was determined, if possible, to be convinced of the truth by ocular demonstration. For that purpose he ordered a large wide tub to be filled with seawater; then had some of these fish caught and put into it, which was changed every other day. In a while they seemed reconciled to their confinement; then he determined to try the experiment.

"A slender stick, with a fly pinned on at its end, was placed in such a direction on the side of the vessel as the fish could strike it. It was with inexpressible delight that he daily saw these fish exercising their skill in shooting at the fly with an amazing velocity, and never missed their mark." *

* “Phil. Trans." for 1764, vol. liv., p. 89. 


\section{CHAPTER XXIX.}

\section{Amphibia (Frogs and Toads).}

"To any person," observes the eloquent historian of British Reptiles, "capable of appreciating the interest attached to the study of physiological phenomena, the contemplation of an animal which at one period of its life is endowed exclusively with the organs of aquatic respiration, resembling the gills of fishes, with means of locomotion adapted only to a constant residence in the water, and with a digestive apparatus fitted exclusively for th assimilation of vegetable food, assuming by degrees the function of atmospheric respiration, acquiring limbs which are formed for leaping on land with great strength and agility, and manifesting the most voracious carnivorous appetite, will not only excite feelings of the deepest admiration, but necessarily lead to the investigation of the laws by which such extraordinary changes are governed, and of the relations which they bear to the theory of continuous affinity, and to that of progressive development through the whole of the animal kingdom." *

Such phenomena are exhibited by the Toads, Frogs, and Newts, the familiar representatives of that limited

* Bell's “Brit. Rept.," p. 72. 
Class of animals whose scientific appellation we have inscribed at the head of this chapter. They thus afford a beautiful link in that tissue of "chain-mail" which constitutes the Plan of Nature; for they evidently hold an intermediate position between the FisHes, whose respiration is exclusively aquatic, and the true RePTILES, in which this vital function is exclusively aerial.

Let us look a little more closely at this curious point,the metamorphosis which the AmpHiBIA undergo, and the accompanying change in the character of their breathing organs. In the month of April, in almost every ditch and pool in the country, we see large masses of clear jelly, with black dots distributed at even distances throughout, or long strings of the same substance, in which the black dots are arranged in a double row. The former is the spawn of the Frog, the latter that of the Toad; and each dot is the maturing embryo of a single egg, which latter is a clear globe of about one-fifth of an inch in diameter. When the spawn is laid, the embryo is an opaque globule, darker at one side than at the other. In a few days, however, this begins to take the form of an animal-the head, the body, and the tail being distinct, as the little creature lies on its side within the egg, coiled up in a semicircle. Soon a kind of wart buds from each side of the neck-the future gills; and currents of water are seen to stream to and from these important, but as yet minute, organs.

As time passes, the gills divide into branches, the nostrils and the eyes appear, and traces of the mouth may be discerned. Meanwhile, the power of voluntary movement, at first confined to the head and tail, increases; and the 
little prisoner, as if impatient of confinement, tries to straighten itself by spasmodic efforts, and at length succeeds in rupturing the skin of the egg and becomes free.

It is now a Tadpole-a fish-like creature, without limbs, with an enormous head, and a body thinned off to

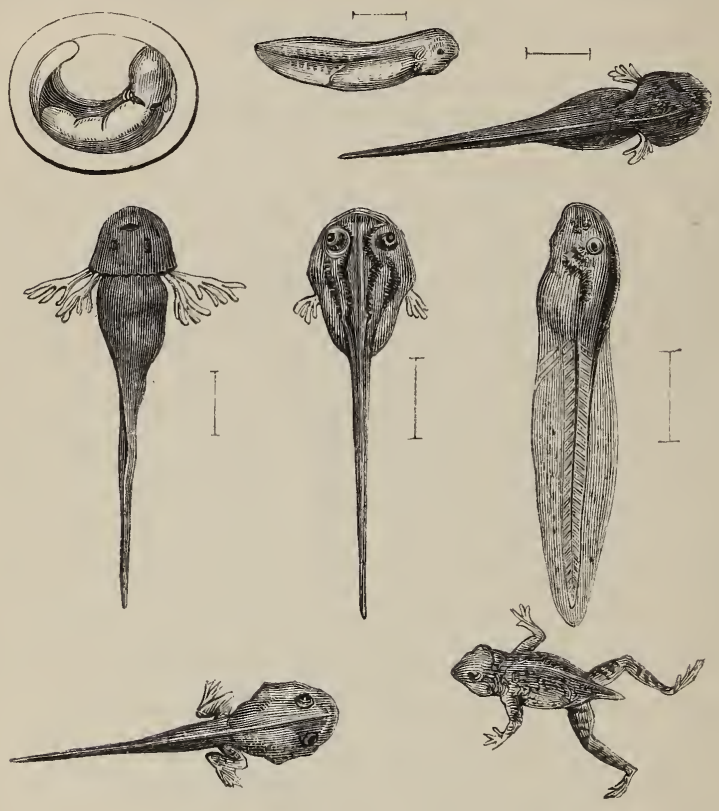

Transformations of Frog.

a long tail, which is furnished with a broad finny expansion above and below. The gills now attain their greatest size, and consist on each side of a pair of much-branched tufts, which, under the microscope, present a most inter- 
esting spectacle. The blood, forced from the heart in regular pulsations, is seen to diverge into each of the main gill-stems, sending off lateral streams to every tiny branchlet : the red globules are seen to chase each other along: the tortuous vessels, to pass to the extremity of every ramification, and then, turning, follow a backward course, until they reach the heart, the fountain from whence they issued.

But now these organs begin to disappear : they gradually diminish, until at length they can no longer be discerned externally, though their function is carried on in a cavity of the body on each side. The little animal increases rapidly in size, but does not change this its fish-like form for a considerable period, though minor modifications may be traced. Thus the mouth becomes developed, the eyes are perfectly formed, and the tail-fin grows greatly in perpendicular breadth, and is a powerful organ of locomotion. The little Tadpole begins greedily to devour vegetable matter, and manifests the effect of this diet in the change of its own hue from a dull black to a soft olivegreen, with golden specks on the under parts.

At length the period approaches when the Tadpole must leave its aquatic life, and become terrestrial; -at least it must cease to respire water, and must derive its vitality from the air. The first step to such a change, is the development of limbs. First appear the hind-legs, in the form of a pair of minute budding warts, which lengthen, become bent, and shoot forth tiny toes at the extremity. The fore-legs, always a little later than the hind, accompany the latter in their gradual progress. As the new organs of motion are acquired, the old one-the vibrating 
tail with its fin-is lost. It is not thrown off, but its substance is gradually absorbed into the body. As this process takes place during the growth of the legs, when it is completed, the Tadpole has become a little Frog. The minute orifices which admitted the water into the gill-chamber have, at the same time, become closed, and breathing is henceforth performed exclusively by means of lungs, which are capacious sacs, subdivided internally into large cells.

Such, then, is the metamorphosis which obtains in the most elevated forms of this Class, as our common Frog and Toad; and it may be witnessed with slight precautions by any one who will take the trouble to collect a mass of spawn from the nearest ditch, and transfer it to a fiesh-water aquarium. In the Newts, which are no less common, the metamorphosis is less complete, and we perceive in their ultimate condition a closer alliance with Fishes ; since their limbs are small and feeble, their broad finny tail is retained through life, and is the principal organ of locomotion; for; in general, they continue more exclusively aquatic in their mode of life than the adult Frog or Toad.

The eggs of the Newts are not deposited in a mass, but singly, and that under interesting conditions. Professor Bell thus describes the process in the case of our largest and finest species, the Common Warty-newt (Triton cristatus), the males of which are conspicuous enough in the vessels of the dealers in aquatic animals, in Covent Garden Market and elsewhere, by their roughened blackish upper parts, their high notched back-fin, and their rich orange under-parts, spotted with black. The female is of less brilliant hues, and is destitute of the tail fin. 
"The period when the deposit of the eggs commences, depends upon the season; but the time when the greater number are produced, is during the months of May and June; and it is worthy of notice, that the different species of Newt are found depositing their eggs during a much longer period of the summer than the tailless Amphibia, such as the Frog and Toad. At the time I have mentioned, if the leaves of the various species of aquatic plants be observed, many of them will be found folded together; and within the fold a single egg of the Newt will be discovered. It is, however, necessary for accurate observation from the commencement, that the female Newt be taken and placed in a vessel of water with the plants in question, that she may deposit the egg under the eye of the observer. The best plant for the purpose is the Polygonum persicaria, which is ordinarily chosen by the animal in its natural habitat. A large glass globe is a good vessel for the purpose of observation; but if it be wished to employ a larger one, I may be allowed to recommend the largest-sized foot-bath made of white ware. This vessel I have often used for keeping many aquatic animals; and if a layer of Roman cement be placed at the bottom, and a few pebbles, or a stone of sufficient size, be fixed by the cement at one end, the objection to the slipperiness of the vessel will be obviated, and the animal will also have the opportunity of coming above the surface at pleasure.

"The manner in which the eggs are deposited, is very interesting and curious. The female, selecting some leaf of an aquatic plant, sits, as it were, upon its edge, and, folding it by means of her two hinder feet, deposits a 
single egg in the duplicature of the folded part of the leaf, which is thereby glued most securely together, and the egg is thus effectually protected from injury. The manner in which this is effected is highly interesting, and may be readily observed by any one. As soon as the female has in this way deposited a single egg, she quits the leaf; and after the lapse of a short time seeks another, there to place another egg." *

Passing from these familiar creatures, we find in foreign countries a few forms, which, though repulsive in aspect and manners to the common observer, are of high interest to the physiologist, because they manifest a still closer affinity with the class we last considered. The Hellbender (Menobranchus) of the United States, the Axolute (Axolotus) of Mexico, and the Proteus of Austria, are large Newts, which never lose their gills through life, but permanently perform an aquatic respiration simultaneously with an aerial one. In all these animals, the limbs are reduced to a rudimentary condition; and in the Siren of Carolina, which also has a permanent double respiration, the hind limbs are totally wanting. Finally, the Amphiuma of the same region, which has an orifice in the neck, but has no external gills at any period of life, has the appearance of an Eel, with four minute rudimentary feet; and the bones of the spine present on each surface that concavity which belongs to the vertebrce of Fishes.

Of these creatures one of the most interesting is the Proteus ( $P$. anguinus), which inhabits the waters of great subterranean cavaties in the limestone formation of Southern Europe. One of the most romantic and splendid

$$
\text { * Op. cit., pp. 123, } 122 .
$$


caverns in the world is the grotto of the Magdalene, near Adelsburg, in the duchy of Carniola. The whole of that region consists of bold, craggy rocks and mountains of limestone formation, perforated with spacious branching caverns, in whose awful recesses sleep the sluggish waters of vast subterranean lakes, whence many rivers take their origin. In these dreary reservoirs, over which a gleam of light has never played, save when the torch of the inquisitive traveller is flashed back from the unruffled surface, are found many Protei, swimming through the waters or burrowing in the mud which is precipitated by them. Specimens have been thrown up by water from a subterraneous cavity at Sittich, about thirty miles distant from the grotto of the Magdalene; and the species is said to exist in the caves of Sicily.

Sir Humphry Davy, in his "Consolations in Travel," has graphically described the appearance, habits, and localities, of this singular animal. We have room but for the following extract, which bears on the point already insisted on in the preceding notes-the intermediate position of the creature between Fishes and ReptiLes :-

"At first view you might suppose this animal to be a lizard, but it has the motions of a fish. Its head, and the lower part of its body, and its tail, bear a strong resemblance to those of the Eel; but it has no fins, and its curious branchial organs are not like the gills of fishes; they form a singular vascular structure, as you see, almost like a crest round the throat, which may be removed without occasioning the death of the animal, which is likewise furnished with lungs. With this double apparatus for supplying air to the blood, it can live either below or 
above the surface of the water. Its fore feet resemble hands, but they have only three claws or fingers, and are too feeble to be of use in grasping or supporting the weight of the animal; the hinder feet have only two claws or fingers, and in the larger specimens are found so imperfect as to be almost obliterated. It has small points in the place of eyes, as if to preserve the analogy of nature. It is of a fleshy whiteness and transparency in its natural state, but when exposed to light its skin gradually becomes darker, and at last gains an olive tint. Its nasal organs appear large, and it is abuudantly furnished with teeth, from which it may be concluded that it is an animal of prey; yet in its confined state it has never been known to eat, and it has been kept alive for many years by occasionally changing the water in which it was placed."

Specimens which have been kept for some time in England, have been observed to shroud themselves in the darkest part of the vessel in which they were placed, when the covering was taken off in order to inspect them; and to betray a sense of uneasiness by their actions when exposed to the light of open day, creeping round the sides of the vessel, or under the shelter of any substance which threw a partial sharlow on the water. Though these animals lived many months, and were healthy and vigorous, they were not supplied with any food, nor is it certainly known on what they subsist, though there is every reason to believe them carnivorous.*

Confined in a state of nature to the darkness of perpetual midnight in the recesses of its gloomy caverns, the 
faculty of sight would be thrown away upon the Proteus. Accordingly it is found that though it possesses the rudiments of eyes, they are reduced to specks of excessive minuteness, and are, besides, covered by the common skin of the head. And this leads us to mention the curious fact that there exists a subterranean fauna, existing chiefly in mines and caves, every individual of which is totally blind by nature. Numerous species have been lately brought under the notice of naturalists, especially from the great caverns of North America, none of which can be identified with any known supraterranean species, and every one of which is sightless.

We have hitherto spoken only of that measure of respiration which is effected either by means of gills, or of lungs, or of both together. But experiments have shewn that the adult Amphibian needs yet a further supply of oxygen, which it obtains through the whole surface of the skin. A Frog has been kept alive for forty days after having been subjected to the total privation of its lungs.

In order, however, that the skin should be fit for the performance of this function, it is absolutely essential that it be maintained in a moist state: dryness of the skin is speedily fatal, A beautiful provision is made for the supply of the requisite superficial moisture, by a secretion from the skin itself. "The extent of the skin is, however," observes Professor Bell, "so great that the whole internal moisture of the animal would speedily be exhausted, unless a reservoir were provided for an extraordinary demand; and I now proceed to shew what this reservoir is, and by what means it is replenished. Every one knows that when a Frog is hastily seized, or even quickly 
pursued, it voids a considerable quantity of water, which is generally, but erroneously, supposed to be the urine. This water is limpid and pure, containing no traces of the usual component elements of the urinary secretion. It is contained in a sac, which has also been mistakenly believed to be the urinary bladder. This is the reservoir to which I have alluded. When, therefore, the Frog is happily placed in a damp atmosphere, or in water, the skin absorbs a quantity of water, which there is every reason to believe is secreted into the bladder just mentioned, where it is kept in store until the dryness of the skin requires a supply for the purpose of respiration, when it is again taken up and restored to the surface by which it had been first absorbed." *

Thus in ten thousand instances the Christian philosopher is reminded of the loving-kindness of the Lord, which is over all His works. Every creature that $\mathrm{He}$ has made is sustained in life, and health, and comfort, and abundance, for its appointed time, by His ever-watchful and beneficent care. And nothing is neglected, nothing forgotten;-the Proteus in its dark cavern, and the Frog in its stagnant pool, are as lovingly remembered as the Eagle in the clouds, or the Lion in his lair. "He openeth his hand and satisfieth the desire of EVERY LIVING THING."

"If, ceaseless, thus the fowls of heaven He feeds, If o'er the fields such lucid robes He spreads, Will He not care for you? ye faithless! say ; Is He unwise? or are ye less than they? 


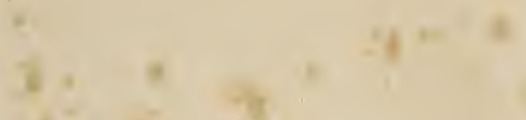

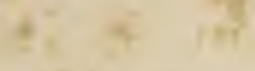

ty 10 ,

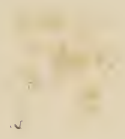




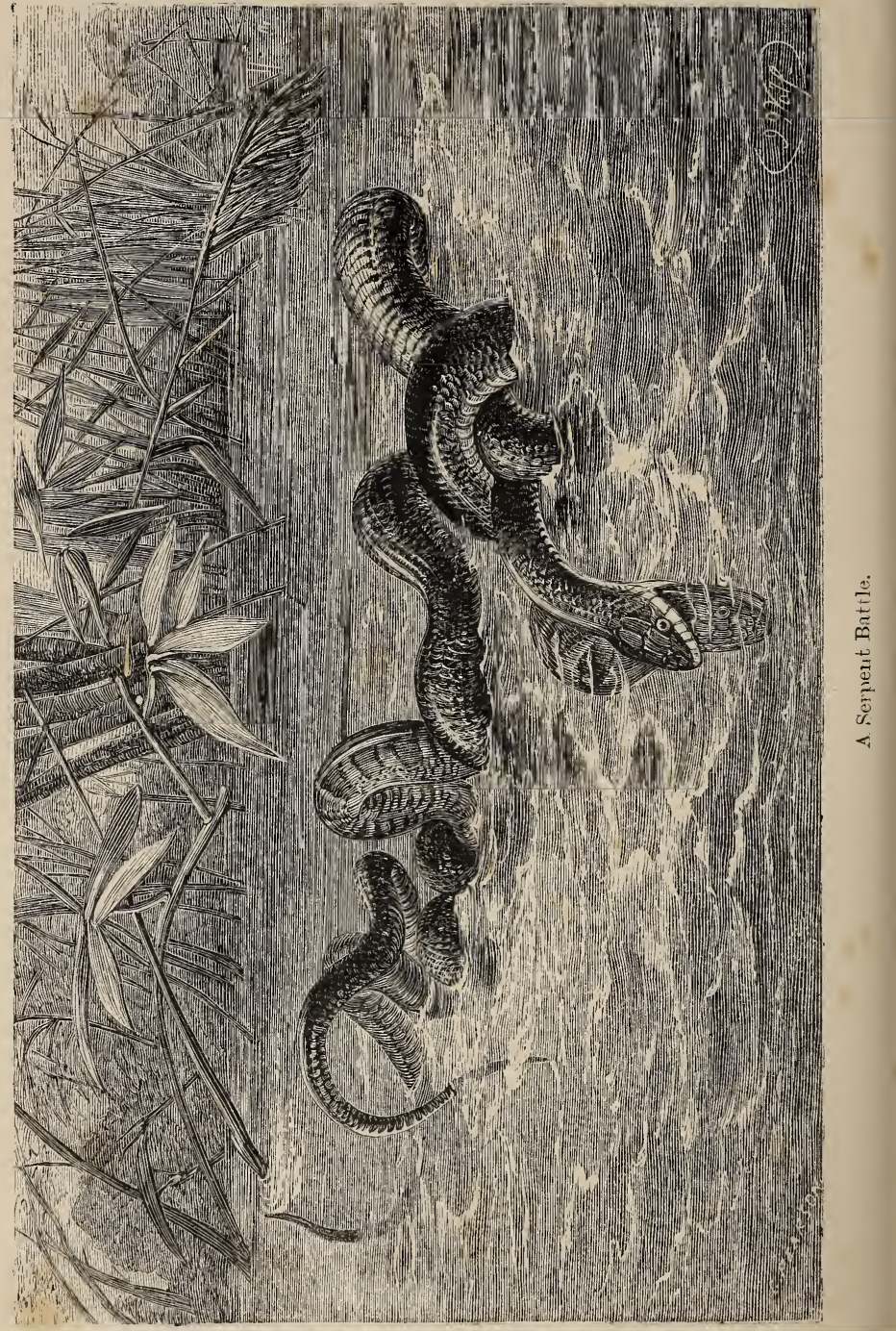




\section{CHAPTER XXX.}

\section{ReptiLia (Reptiles).}

Like the Fishes and the Amphibians, the animals of which we have now to speak are cold-blooded: that is, their power of producing heat in the process of breathing is so small, that their temperature scarcely rises above that of the medium, whether air or water, in which they reside. Like FisHes, they are mailed; their bodies are protected by a hard and dry skin, which takes the form of overlapping scales, or compact broad plates or shields, or, as in some of the Lizards, a combination of these two. They increase by eggs, which are laid singly, and are always enveloped in a calcareous covering, which, according to the greater or less ratio of the earthly element, is a parchmentlike skin, or a hard and brittle shell. In the latter case, the eggs have a close resemblance to those of Birds. In several respects there is an advance in organisation over the Amphibians ; the heart is composed of two auricles and one ventricle; the respiration is performed by means of lungs exclusively; and there is no metamorphosis in the Class, the animals presenting the perfect form even from the egg.

There is more diversity in form and structure among the animals that compose this Class than among those of 
any other of the great Vertebrate Division. Look at the ponderous Tortoise enclosed in an unyielding box, with an orifice in front and behind just large enough to allow him to poke out his head and limbs. Look at the grim Crocodile lurking in the river reeds, with his enormous jaws bristling with conical teeth, his body covered with bony shields, and his lashing serrated tail. Look at the Chameleon running on the leafy twig, with his shagreen coat, his great inflated head, his long tongue shot out to capture a distant fly, and his slender tail-tip coiled round the branch to hold fast. And finally, look at the tortuous Snake as he lies basking on the sunny bank, in gleaming scales, darting out his forked tongue in play: see how he lies in twisted coils; and now mark how, footless and limbless as he is, he glides away on alarm, leaving only an undulating trail in the dust where he passed!

Surely all these various creatures are not formed on the same model! Surely there can be no community of structure here which can bind together into one group forms so remotely diverse! Yes, diverse as they are, they possess characters in common, which more than outweigh their differences, and the whole are united into a chain of many links, which, by a beautiful gradation, conduct us from one to the other.

Many of these animals are more or less noxious; and some of them are terribly fatal to other creatures, and to man himself; hence, a certain amount of popular prejudice against the whole Class exists, and the innocent, which far out-number the noxious, share the reputation, and are visited with the hatred and aversion due to their malific fellows. Yet there are points in their history, which make 
them not unworthy of our attention. The changeable lustre of many, especially of the tropical Lizards and Snakes; the elegance and grace of their movements; the provisions made for their defence in their formidable weapons; peculiarities in their organisation whereby they are fitted for their appointed spheres and habits;-these, and many other details which our space forbids us even to enumerate here, render the study of herpetology no less attractive than any other branch of natural science.

The Serpent may be considered as the characteristic form of this Class of beings; at least, our thoughts more spontaneously recur to the lithe and winding Snake, than to any other shape, when the word Reptile is pronounced; as, indeed, the idea of creeping * is most perfectly realised in the gliding movements of an animal absolutely without limbs.

There is something exceedingly interesting in this very action. The rapid gliding of a Snake is performed by means of the numerous ribs (which in the skeleton look like the feet of a Centipede), and the broad plates (scuta) which go across the belly. The action and the discovery of its nature are described by Sir Everard Home in the following words :- "When the Snake begins to put itself in motion, the ribs of the opposite sides are drawn apart from each other, and the small cartilages at the end of them are bent upon the upper surfaces of the abdominal scuta, on which the ends of the ribs rest; and, as the ribs move in pairs, the scutum under each pair is carried along with it. This scutum, by its posterior edge, lays hold of

* The words herpetology, reptile, serpent, creep, have all one derivation: є̇ $\rho \omega \omega$ is their common parent. 
the ground and becomes a fixed point from whence to set out anew. This motion is beautifully seen when a Snake is climbing over an angle to get upon a flat surface. When the animal is moving, it alters its shape from a circular or oval form to something approaching a triangle, of which the surface on the ground forms the base. The Coluber and Boa having large abdominal scuta, which may be considered as hoofs or shoes, are the best fitted for this kind of progressive motion. . . . . An observation of Sir Joseph Banks, during the exhibition of a Coluber of unusual size, first led to this discovery. While it was moving briskly along the carpet, he said he thought he saw the ribs come forward in succession, like the feet of a caterpillar. This remark led me to examine the animal's motion with more accuracy, and, on putting the hand under its belly, while the Snake was in the act of passing over the palm, the ends of the ribs were distinctly felt pressing upon the surface in regular succession, so as to leave no doubt of the ribs forming so many pairs of levers, by which the animal moves its body from place to place."

Many of the Serpents habitually live among the branches of trees, and most species can climb the smooth trunks with facility; not, however, by encircling the branch or bole in spiral coils, as artists who probably never saw a Snake in motion ridiculously represent them, but by a direct upward gliding, the body extended nearly in a straight line.

As all the Serpent tribes are carnivorous, and almost all feed on living active animals, often of much greater bulk than the diameter of their own mouths, while yet they invariably swallow their prey entire, it becomes a problem of interest how this is effected. They are fitted for their 
work by a peculiar mode of articulation in the bones of the head. All the bones of the skull are very loosely put together, but the jaws are remarkably expansible. In the first place, the lower jaws are much longer than the skull, commencing behind its base; secondly, they are not hinged to the upper jaw, but are suspended at the end of a pair of long slender bones, which are attached to the hind part of the skull by muscles and tendons so as to be very moveable; thirdly, the two branches of the lower jaw, which in higher animals are soldered, as it were, together, are in the Serpents simply bound by ligaments. The result of the whole arrangement is, that the mouth is capable of a most enormous expansion.

Most of our readers are familiar with descriptions of the mode in which the great tropical Snakes-the Boas of the West, or the Pythons of the East-take and gorge their prey. A Serpent, whose body at its largest part does not exceed the thickness of a footman's leg, and whose head is not wider than a lady's hand, will readily swallow a goat. We say " readily," because the process is regular and ordinary, but it is slow and tedious, and painful to read of, and much more to witness. We will not repeat the details here, but merely allude to a contrivance by which the function of breathing is allowed to proceed during the protracted interval of swallowing, when the whole throat of the Serpent is distended almost to bursting by the descending prey, and the whole head and jaws appear irremediably dislocated. These animals are furnished with peculiar muscles for bringing forward the larynx, or entrance to the windpipe, during the action of swallowing, as has been demonstrated by Mr Joseph H. Green; and Mr Broderip 
has observed that the larynx is at such a time protruded as much as a quarter of an inch beyond the edge of the dilated lower jaw.*

Most Serpents master their prey by open violence; and the large species of the tropics embrace it in repeated coils of their bodies, which are then contracted with great muscular force, so as to crush and compress their victim to death. But other kinds are furnished with a more securely fatal power, in the presence of two long, hooked, tubular teeth in the upper jaws. 'These teeth, or fangs, are open at each extremity, and the base communicates with a vesicle, which is a reservoir of powerful poison, secreted by glands spread over the cheeks. When a Rattlesnake or a Viper makes its attack, it commonly elevates the head and draws it somewhat back; then with lightning-rapidity it strikes forward, piercing its enemy with the projecting fangs; at the same instant the poison-bag, which has been just filled by the secretion, poured forth under the excitement of rage, is compressed by its proper muscles, and the deadly fluid is injected through the tubular tooth into the wound.

In the harmless Snakes (or rather those which are not poisonous), each of the upper and under jaws is set with a number of small, but very sharp teeth, pointing backwards; the palate is also armed with two similar rows, so that there are six lines of teeth in the mouth. Owing to the loose jointing of the bones before mentioned, the two sides of the head are capable of being moved to and fro separately, with a sort of see-sawing action. When the teeth have been struck into the victim, this alternate advance of the sides 
of the face begins, and as the backward inclination of the teeth allows the food only to move in one direction, it is gradually drawn, by a constantly shifting of the hold on either side, into the throat.

There is a South African Snake (Deirodon), the mouth of which is deprived of teeth, yet it is destined to feed on the eggs of birds. The apparent defect in this case has been pointed out by Professor Owen as a beautiful example of special contrivance. "If," observes that great physiologist, " the teeth had existed of the ordinary form and proportion in the maxillary and palatal regions, the egg would have been broken as soon as it was seized, and much of its nutritious contents would have escaped from the lipless mouth of the Snake in the act of deglutition; but owing to the almost edentulous state of the jaws, the egg glides along the expanded opening unbroken, and it is not until it has reached the gullet, and the closed mouth prevents any escape of the nutritious matter, that the shell is exposed to instruments adapted for its perforation. These instruments consist of the inferior spinous processes of the seven or eight posterior cervical vertebræ, the extremities of which are capped by a layer of hard cement, and penetrate the dorsal (upper) parietes of the csophagus; they may be readily seen even in very young subjects, and in the interior of that tube, in which their points are directed backwards. The shell being sawed open longitudinally by these vertebral teeth, the egg is crushed by the contractions of the gullet, and is carried to the stomach, where the shell is no doubt soon dissolved by the gastric juice."*

It might be expected that the ferocity of animals so

$$
\text { * "Odontography." }
$$


exclusively carnivorous, so energetic, and so well furnished for rapine as Serpents, would sometimes direct their arms against each other. Perhaps our readers may not be displeased to see the report of a conflict of this sort, in which the prowess of the combatants, their equality of force, their perseverance, and their fury, are graphically described by a gentleman who declares himself to have been an eyewitness of the scene. Of course the story depends on the veracity of the writer; but we may be permitted to observe that some details of the description, which a naturalist can appreciate, and which could scarcely have been invented, seem to indicate that the picture was drawn from the life.

The story is narrated by Mr St John in his "Letters of an American Farmer." After describing the size and strength of some hemp-plants, around which a wild vine had formed natural arbours, he thus proceeds :- "As I was one day sitting, solitary and pensive, in this primitive arbour, my attention was engaged by a strange sort of rustling noise at some paces distance. I looked all around without distinguishing anything, until I climbed up one of my great hemp-stalks; when, to my astonishment, I beheld two Snakes of a considerable length, the one pursuing the other with great celerity through a hemp-stubble field. The aggressor was of the Black kind, six feet long; the fugitive was a Water Snake, nearly of equal dimensions. They soon met, and, in the fury of their first encounter, appeared in an instant firmly twisted together; and whilst their united tails beat the ground, they mutually tried, with open jaws, to lacerate each other. What a fell aspect did they present! Their heads were compressed to a very small size; their eyes flashed fire; but, after this conflict 
had lasted about five minutes, the second found means to disengage itself from the first, and hurried towards the ditch. Its antagonist instantly assumed a new posture, and, half-creeping, half-erect, with a majestic mein, overtook and attacked the other again, which placed itself in a similar attitude, and prepared to resist. The scene was uncommon and beautiful; for, thus opposed, they fought with their jaws, biting each other with the utmost rage; but, notwithstanding this appearance of mutual courage and fury, the Water Snake still seemed desirous of retreating towards the ditch, its natural element. This was no sooner perceived by the keen-eyed Black one, than, twisting its tail twice round a stalk of hemp, and seizing its adversary by the throat, not by means of its jaws, but by twisting its own neck twice round that of the Water Snake, he pulled it back from the ditch. To prevent a defeat, the latter took hold likewise of a stalk on the bank, and, by the acquisition of that point of resistance, became a match for his fierce antagonist. Strange was this to behold; two great Snakes strongly adhering to the ground, mutually fastened together by means of the writhings which lashed them to each other, and stretched at their full length; they pulled, but pulled in vain; and, in the moments of greatest exertion, that part of their bodies which was entwined seemed extremely small, while the rest appeared inflated, and now and then convulsed with strong undulations rapidly following each other. Their eyes appeared on fire, and ready to start out of their heads. At one time the conflict seemed decided; the Water Snake bent itself into great folds, and by that operation rendered the other more than commonly outstretched; the next minute the 
new struggles of the Black one gained an unexpected superiority; it acquired two great folds likewise, which necessarily extended the body of its adversary, in proportion as it had contracted its own. These efforts were alternate; victory seemed doubtful, inclining sometimes to one side, sometimes to the other, until at last the stalk to which the Black Snake was fastened suddenly gave way, and, in consequence of this accident, they both plunged into the ditch. The water did not extinguish their vindictive rage, for by their agitations I could still trace, though I could not distinguish, their attacks. They soon reappeared on the surface twisted together, as in their first onset: but the Black Snake seemed to retain its wonted superiority; for its head was exactly fixed above that of the other, which it incessantly pressed down under the water, until its opponent was stifled, and sank. The victor no sooner perceived its enemy incapable of further resistance, than, abandoning it to the current, it returned to the shore and disappeared." 


\title{
CHAPTER XXXI.
}

\author{
Reptilia (Reptiles).
}

\section{(Continued.)}

There may often be seen on sunny banks in summer, basking in the genial beam of noon, a little Reptile, well known under the appellations of Blind-worm and Slowworm. As it lies motionless, you might almost fancy it a foot's length of thick iron wire, slightly polished, for it is almost equal in thickness in every part, and its surface gleams with a metallic lustre in the bright sun. Here is the village apothecary coming up the lane, poring over a book with spectacles on nose; let us ask him if he can tell us anything about it. "Oh yes! it is the Anguis fragilis of Linnæus!" and he passes on. Oh! the Brittle Snake! for such is the English of those two Latin words.

But here is Hodge the hedger : perhaps from his occupation he may have some acquaintance with the bit of dingy wire : what say you, Hodge? "Tis a Zneak !" and he makes a spiteful blow with his stick across the back of the poor animal, with the apologetic asseveration, "Tis a deadly pizon varmin!" But see, the blow has effectually demolished it, and that in a strange manner; for, as if it had been made of glass, it has snapped across in four or 
five places; and we at once perceive the propriety of one of its Latin appellations, that of "fragilis."

Science and ignorance agree, then, that the Slow-worm is a Snake; but science and ignorance are both mistaken, for the creature is a Lizard. The assertion seems paradoxical, when we think of the two pairs of well-developed limbs, each armed with five jointed and clawed toes, that the Lizard possesses, and of the way in which it uses them to scamper away from our intrusion beneath the heath and furze; but it is true that the slender, limbless, snake-like Slow-worm is, in all the most important points of its anatomy, a Saurian, and not a Serpent. Undoubtedly it is one of the links by which these two very diverse forms are bound together, and, like all such links, forms a most interesting subject of study. The degeneration and gradual disappearance of the limbs, in the progress of the various genera that, like so many stepping-stones, bridge over the wide passage from the Lizard to the Serpent, are phenomena peculiarly worthy of observation; and we cannot do better, in bringing them before our readers, than to quote the words of the eloquent historian of "British Reptiles," in his account of this very Slow-worm :-

"From the well-known family of the Scinks, or Scincidce, with their true legs and five-toed feet, down to the present species and its immediate congeners, every possible gradation is to be found in the development of the anterior and posterior extremities. Agreeing, as they all do, in the Saurian character of the structure of the head, the consolidation of the bones of the cranium and jaws, and the narrow and confined gape, so different from these parts in the true Serpent, they yet approach the latter in the com- 
parative length of the bodies, and in the gradual diminution and ultimate disappearance of the extremities. In the genus Scincus, for instance, the limbs are already less robust than those of the true Saurians; the two pairs are also more distant from each other, in consequence of the greater comparative elongation of the body. There are as yet five perfect toes on each foot, which, however, are shorter and more even in their relative proportions than in the true Saurians. These deviations become increased in the genus Chalcides, and still more in Seps, which has a very elongated body, the limbs extremely small, and the toes only four or three on each foot. In Monodactylus a further reduction takes place in the development of the limbs, which have dwindled to a mere little undivided finger; they are still, however, four in number; but in the genus Bipes the anterior ones have wholly disappeared, and are found in a rudimentary state under the integument, the posterior ones constituting only small undivided processes. These also being removed, the Ophidian form of the present genus, and those of Tortrix, Typhlops, and others, with all the Amphisbcenadce, succeed, in which the bones of the shoulder, the sternum, and the pelvis, exist in a more or less rudimentary condition, and lead us toward the true Snakes, in which all these parts are lost, excepting the rudiment of a posterior extremity, which in the Boa appears externally in the form of a small horny hook, or holder, on each side of the vent." *

Besides the Slow-worm, we have in the British Isles but two representatives of the vast Lizard group-the Order Sauria. One of these is the elegant Sand Lizard of our * "British Reptiles," p. 40. 
sandy heaths (Lacerta agilis), which is beautifully marked along the sides with eye-like spots, and sometimes occurs of a rich variegated green hue. The other is the smaller, but more common, Viviparous Lizard (Zootoca vivipara), whose interesting peculiarity is expressed in its name, that of producing a living progeny, most Reptiles laying eggs. The difference between these two conditions is, however, less important than it at first appears; for there is every reason to believe, that in this case, as well as in that of the Viper (Pelias berus), which is also viviparous, the eggcovering, which is merely a parchment-like membrane, and very thin, is ruptured in the act of parturition.

The most remarkable genus in this Order, and, indeed, in many respects, the most extraordinary and anomalous of all Vertebrate animals, are the Chameleons, of fabulous and poetic celebrity. They are Lizards inhabiting trees in the warmer countries of the Old World, with a great development of head, and a shagreened skin. As the Monkeys of South America are fitted for their arboreal habits by grasping hands and a prehensile tail, so is the Chameleon, by a curious modification of the common Lizard organisation. The toes are five, as in the majority of Saurians, but these are arranged in two sets, three in one set and two in the other, each set being enveloped in the common skin as far as the claws. These two parcels of toes are opposed to each other, and thus each foot forms a true grasping hand, and is used in the manner which this structure indicates; the Chameleon moving with slow and deliberate steps, always grasping with a firm hold the branch on which it is creeping, before the other feet are relaxed for a fresh step. The tail is round and prehensile 
at the tip, like.that of the American Monkeys; its under surface is roughened with small granulated papilloe, as is that of the toes also, probably in order to the more delicate perception of the surface grasped. The tongue affords an analogy to the same organ in the Woodpeckers, no less singular than that of the feet; for, though ordinarily concealed within the mouth, it is capable of being darted forward at its insect prey, and, being furnished with a glutinous secretion, secures it by its adhesiveness.

A most extraordinary aspect is communicated to these

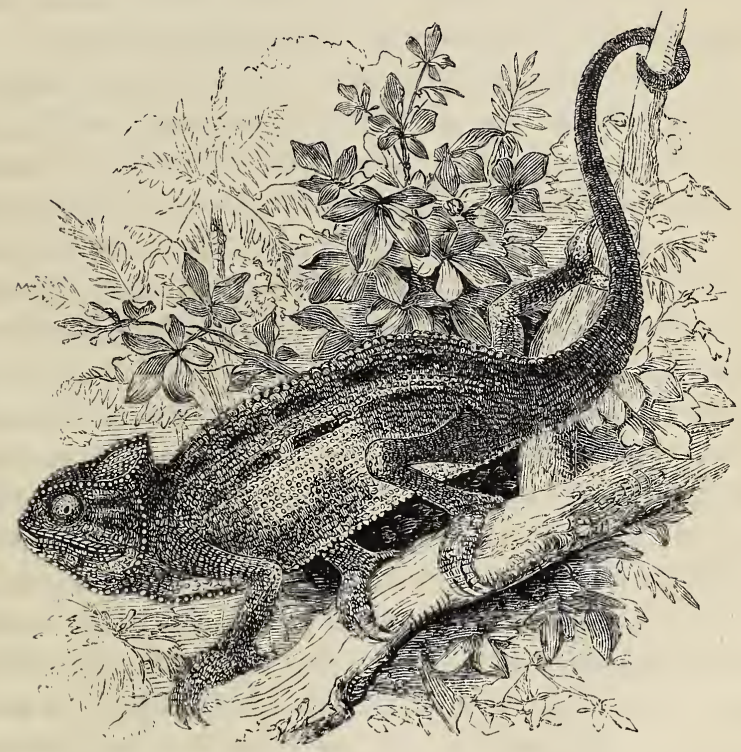

Chameleon.

Reptiles by the structure and movements of their eyes. 
In the first place, the head is enormous, and, being threesided, with projecting points and angles, makes a sufficiently uncouth visage; but the eyes which illuminate this notable head-piece must, indeed, to borrow for the nonce the phraseology of Barnum, "be seen to be appreciated." There is on each side an immense eye-ball, full and prominent, but covered with the common shagreened skin of the head, except at the very centre, where there is a minute aperture, corresponding to the pupil. These great punctured eye-balls roll about hither and thither, but with no symmetry. You cannot tell whether the creature is looking at you or not; he seems to be taking what may be called a general view of things;-looking at nothing in particular, or rather, to save time, looking at several things at once. Perhaps both eyes are gazing upwards at your face; a leaf quivers behind his head, and in a moment one eye turns round toward the object, while the other retains its upward gaze: presently a fly appears; one eye rapidly and interestedly follows all its movements, while the other leisurely glances hither and thither, or remains steady. Accustomed as we are to see in almost all animals the two eyes move in unison, this want of sympathy produces an effect most singular and even ludicrous. The Lizards are not in all cases the little, leaping, timid, playful creatures that we commonly associate with the name. The aquatic Monitors (Varanidoe) of both continents are truly formidable. M. Leschenault de Latour saw one attack a young stag as it attempted to swim across a river, striving hard to drown it. The deer was too active on this occasion, but the same zoologist found the thigh-bone of a sheep in the stomach of one that he 
dissected. The tail in this group is very muscular, and is compressed throughout its length; it thus forms a powerful swimming organ, especially as its upper edge is frequently surmounted with a crest of flattened elevated scales. These large and powerful Lizards, which are often five feet in length, and stout in proportion, usually endeavour to overcome their prey by dragging it into a river and drowning it.

In all these particulars we see an approach to those mighty tyrants of tropical rivers, the Crocodiles, which have been celebrated from remotest antiquity as the very impersonation of bestial power and ferocity. The noble description of Leviathan in the book of Job-the climax of those majestic interrogatories wherewith Jehovah withered the pride of his too audacious servant-is a picture of one of these Reptiles, drawn from the life by the master-hand of Him who made it.

"Who can open the doors of his face? his teeth are terrible round about. His scales are his pride, shut up together as with a close seal. One is so near to another, that no air can come between them. They are joined one to another, they stick together, that they cannot be sundered. By his neesings a light doth shine, and his eyes are like the eyelids of the morning. Out of his mouth go burning larnps, and sparks of fire leap out. Out of his nostrils goeth smoke, as out of a seething-pot or caldron. His breath kindleth coals, and a flame goeth out of his mouth. In his neck remaineth strength, and sorrow is turned into joy before him.

"The flakes of his flesh are joined together: they are firm in themselves; they cannot be moved. His heart is 
as firm as a stone; yea, as hard as a piece of the nether mill-stone. When he raiseth up himself, the mighty are afraid: by reason of breakings they purify themselves. The sword of him that layeth at him cannot hold: the spear, the dart, nor the habergeon. He esteemeth iron as straw, and brass as rotten wood. The arrow cannot make him flee: sling-stones are turned with him into stubble. Darts are counted as stubble: he laugheth at the shaking of a spear. Sharp stones are under him: he spreadeth sharp-pointed things upon the mire.

"He maketh the deep to boil like a pot; he maketh the sea like a pot of ointment. He maketh a path to shine after him; one would think the deep to be hoary. Upon earth there is not his like, who is made without fear. He beholdeth all high things: he is a king over all the children of pride."-Јов xli. 14-34.

The most prominent characteristics of the Crocodile of the African rivers are here distinctly painted. The impenetrable nature of the integument, a sort of surface-bone; its arrangement in strong square scales, set firmly edge to edge, one against another in close array; the peculiar fiery glare of the eyes; and above all, the serried teeth, which, to the number of thirty or more on each side of each jaw, are never concealed by lips, giving to the animal, even when tranquil, the terrific appearance of a grinning rageare all points that scientific naturalists have dwelt on in their descriptions of these monsters. When we remember that they are among the most gigantic of all animals, far exceeding the Elephant-the Crocodile of the Nile being asserted to attain a length of twenty-five feet-we shall 
acquiesce in the propriety of the concluding epithet"King over all the children of pride."

If space in these pages permitted, we should delight to trace the transition, through the fierce Chelydra of Florida, from the Crocodiles to the Tortoises. But we must be content with directing our readers' attention to the contrast which subsists between one of these latter, enclosed as it is in an immoveable box of bone, with only an opening in front at which to poke out its head and hands, and a similar hole behind for its tail and hind limbs, waddling along with painfully slow and heavy tread;-the contrast, we say, between such a creature and the lithe Snake, the very type of flexibility, altogether destitute of limbs, yet shooting along with an undulating velocity that the eye of the gazer can scarcely follow. 


\section{CHAPTER XXXII.}

\section{Aves (Birds).}

Everyody loves Birds. The pinafored schoolboy dares the awful frown of the pedagogue, and his birch too, that he may peer into the brambles and hedgerow-trees, for the callow young which he desires to rear. The fair maiden teaches her pet canary to hop on her finger and take his sugar from her own sweet lips, bestowing on him the kisses which many a bigger biped would be proud to share. The solitary weaver, gray with premature age induced by ceaseless toil, hangs his thrush in wicker outside his shattered casement, and throws his shuttle more blithely as he listens to the mellow notes which carry him back to the fields and groves of his boyhood. The weather-beaten sailor greets the little land-bird with a hearty welcome, that flutters on feeble wing around his ship, clinging to the shrouds and stays, and loves the tiny messenger that tells him of his approach to his native shore. The world's care must have indurated that heart, indeed, that can hear without a gush of emotion the sweet melody of a singing-bird!

We must not, however, just now consider the bird as a loveable little pet, but look at it physiologically as an animal-as one of the meshes in the grand net-work of organic existence. We call it a biped, but structurally a 
bird is a quadruped. Look at a plucked pigeon, and see how it differs in the matter of limbs from a skinned rabbit, except that the fore legs have no feet or toes at their tips. After all, the pensioner's child, who respectfully submitted that " mother didn't like always to have the hind leg of the chicken," was not so far wrong. The bird is, in fact, a quadruped adapted for flight. To this end the fore limbs are greatly lengthened and strengthened, as to them is assigned the office of beating the air by successive strokes, and thus impelling the body through that fluid, as a boat is rowed by oars. Flying, like swimming, is but rowing through the medium, instead of on its surface.

In order to make these limbs effective, to render them capable of long-sustained energetic action, they must be moved by stout, dense, and powerful muscles. Every one knows that the most fleshy part of a bird-and especially of a flying bird, such as a pigeon, as distinguished from a running one, such as a fowl-is the mass that lies on the breast-bone. Now this mass of flesh, or rather these masses, one on each side, are the great pectoral muscles, one end of which is inserted on the broad surface of the breast-bone, and the other end is spread along the bone of the shoulder or upper-arm. For the attachment of these great muscles, there must be a great breadth of surface; and see how skilfully this is provided in the form of the breast-bone! It is a firm buckler of great width planted across the viscera; while, as even this extent would not have been sufficient, the surface is greatly increased by a high keel or ridge of bone that rises from its centre, to each side of which the muscles are attached.

But the stroke made by such a limb, however muscular, 
upon the air, would be comparatively powerless as a means of locomotion, if that limb were in the condition which it presents when the cook puts the bird on the spit. The breadth of the oar and its hold upon the element through which it is to move are, therefore, increased by a most admirable contrivance. The quill-feathers, inserted along one edge of the arm, and radiating outwards and backwards, like a fan, answer the purpose proposed. Just look at the quill-feather from a bird's wing. With how small an expenditure of material is a broad surface obtained! How slight and apparently feeble is the structure, when examined fibre by fibre; and yet how firmly and compactly it binds together, and how strongly the expanded web resists the air! Breadth, strength, and lightness were the requisites, and, incompatible as they might have appeared, they are here exquisitely combined.

Even such instruments as these, however, would not avail to lift the animal from the earth, and to bear it with ease and rapidity through the thin air, were its body of the same density as that of a quadruped. It must, therefore, be made buoyant, and this buoyancy is secured by several concurrent ordinances. In the first place, the whole of the muscles are abundantly supplied with blood, which passes through a heart of four chambers, with a rapidity far greater than that which obtains in terrestrial animals. Secondly, to supply the oxygen which is required for the vitalising of this swiftly circulating blood, a peculiar system of respiration is required. The lungs are very large-spongy masses of blood-vessels lying along each side of the back-bone, and bound down to it: through these the bronchi, or divisions of the windpipe, pass; and, opening into the general cavity 
of the chest, admit the air freely into every part of the interior: nay, more; the atmospheric air bathes every blood-vessel of any considerable size throughout the body, passes into the hollow bones of the limbs, and even penetrates between the muscles, and into great membranous cells beneath the skin.*

The consequence of this copious supply of oxygen to the blood, not only in the lungs, but in every part of its course, is a great increase of its heat, which far exceeds that of the most warm-blooded quadruped. The heat pervading the whole of the animal tissues is communicated to the air, which, as we have just seen, is so extensively distributed about the body; and thus the bird is not only rendered light by being blown out with air, but that air is brought up to a very high temperature, and so rarefied, and made very buoyant.

The animal heat thus generated must not be allowed to escape too rapidly; and hence a body-clothing is provided, which of all substances is perhaps the most effective nonconductor of caloric. A feather is in itself a study. When we look at the whole covering of a bird, we cannot help observing how soft, how light, how smooth, how compact, how warm it is; and if we examine each feather separately, there is not less to admire in the details of its structure. It consists of two parts; a light but firm shaft formed of a

* This peculiarity was once brought strongly under our own observation in the case of a pelican (Pelecanus fuscus), which we were dissecting. The whole inner surface of the skin on the trunk was cellular, especially on the breast, forming an immense congeries of membranous bladders, inflated with air. As an example of the free intercommunication that exists between the tissues of the body, it may be mentioned that, in this specimen, the great gular pouch, when filled with water (to the amount of screnteen pints), allowed it to escape by dripping from a wound in the outer joint of the wing. 
pithy substance, hollowed at the lower end into a horny tube, containing the blood-vessels by which it is sustained; and the vane, a double series of parallel thin plates, one on each side the shaft, set at an angle to it, which are themselves furnished at their edges with a similar though smaller series. In all feathers which are destined to strike the air, these branchlets are hooked into one another, so as to present a continuous surface of astonishing firmness.

The relation which the general clothing-plumage of the body bears to flight-though less direct and obvious than that of the quills-is by no means small. "From the mode in which the feathers, and all their parts, are laid upon the bird, it presents a smooth surface upwards and forwards, so that the animal can move in either of these directions, with very little resistance from the friction of the air. When it moves in either of them, the resistance of friction does not increase so rapidly as the rate of motion; because the pressure smooths the feathers, and causes the air to take less hold on them. This property, which arises in part from the texture of the upper surface of the feathers, but chiefly from the way in which they are formed and placed, is of equal service to birds when they must perch, or otherwise remain at rest, so as to abide the blast, as when they fly exposed to it. Perching or flying, when a bird is in the wind it always faces the current; and thus offers the least resistance both by its form and its feathers. "When, however, the feathers are taken in the opposite directions, they offer as much increase of resistance as they offer diminution when they are taken above or in front. The wings are always more or less hollow on the under sides, and they take hold of the air by millions of fibres; 
so that a bira', with its flying feathers on the stretch, would fall much more slowly than one would suppose from the difference between its specific gravity and that of the air.

"The resistance which all the feathers on the body of the bird offer to motion backwards is still greater; and it increases with the force which tends to move the animal in that direction. The instant that it begins to be driven backwards, so that a current against its body is produced, the points of the feathers rise, and take the wind with so many fibres, that the resistance is very similar to that made by a scaly fish, when one attempts to draw one of these by the tail; and every one who has angled, and accidentally caught even a common trout in that way, knows that an ounce weight is as difficult to land when so hooked as a pound weight is when hooked by the head. But the feathers of birds rise much more in proportion than the free edges of the scales upon any fish; and they are every way as well formed for holding on in the air, as those are for holding on in the water. Thus the bird may be said to resist motion backwards in the air, by throwing out the point of each feather like the fluke of an anchor."*

The jaws of a Bird are not furnished with teeth, as are those of a Fish, an Amphibian, a Reptile, or a Mammal, for the purpose of seizing, dividing, or chewing the food. The place of these organs is effectually supplied by a casing of horn, terminating in a point at the tip, and brought to an edge on each side of each jaw. This modification is familiarly known to us as the beak or bill of the Bird. In the Birds of prey, the beak is a keen carving-knife; the

$$
\text { *Mudie's "Nat. Hist. of Birds," } 37 .
$$


Peregrine Falcon is said to pluck, to disjoint, and to carve its prey with as clean a cut and as prompt a skill as the most accomplished "table-anatomist" could display. In the Woodpeckers, which dig out their food and excavate their dwellings from the solid timber of trees, the beak is an effective chisel. In the Snipe and Woodcock it is a

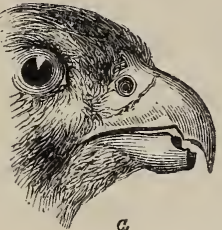

a. Beak of Falcon.

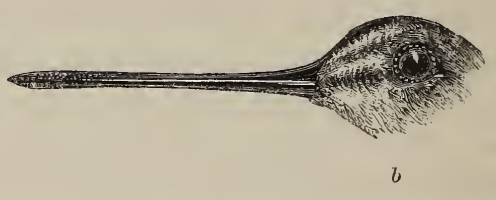

b. Beak of Snipe.

long and slender probe, furnished at the tip with copious nerves of sensation, for feeling in the deep earth of bogs and marshes. In the Parrots it is a climbing hook, a sort of third foot (or rather hand) as well as a fruit-knife. In the Ducks it is a pair of flat spoons, for scooping up the slush of ponds; and in the Gannet it is a strong and sharp fish-spear.

Versatile as is the beak in different tribes of birds, it nowhere performs a proper masticating function; it may divide flesh; it may crack a nut, and, with the assistance of the tongue, shell it; it may separate the grain from the husk, as we see the Goldfinch and Canary constantly do with their hempseed; but the nearest approach to a chewing action that we at this moment recollect, is the bruising down of hard seeds by means of a knob in the middle of the palate, as in the Buntings (Emberizada). The consequence of this general absence of masticating power is, that 
the food is swallowed entire. When the food is flesh, the process of digestion is sufficiently simple and rapid to need no preparation; but in the case of the hard grains and seeds that constitute the staple diet of so large a number of species, a peculiar provision is requisite for grinding-a sort of internal mill.

This organ, well known as the gizzard, is endowed with immense power for grinding and crushing; it is almost wholly made up of two semi-globular masses of dense muscle, the two opposing faces of which are coated with a layer of thick leathery skin. Between these the vegetable substances to be ground are dropped from the crop, just as the corn is dropped from the hopper between the millstones; and the force exerted when these faces work on each other is immense, and all but irresistible. The facility with which substances the most hard, angular, and even acute, are ground down, and that with perfect impunity to the coats of the gizzard, is proved by the researches of Plater, Réaumur, Redi, and Spallanzani. The experiments of the last named philosopher possess the highest interest: he introduced tin tubes variously strengthened with wire, into the stomachs of Turkeys, and invariably found them crushed, flattened, broken, and variously distorted. Thick balls of glass were broken, ground down, and in a few hours completely pulverised. Pieces of glass with sharp, jagged edges, shared the same fate, without in the least wounding the callous skin of the gizzard. Needles were cast into a ball of lead, so that their points projected a quarter of an inch, and, being encased in a soft substance, were thrust down the throat of a Turkey; in twenty-four hours the points were broken off close or rubbed down, and 
the gizzard uninjured. "Finally," says Spallanzani, "I fixed twelve small lancets, very sharp both at the points and edges, in a similar ball of lead. They were such as I use for the dissection of small animals. The ball was given to a Turkey-cock, and left eighteen hours in the stomach; at the expiration of which time that organ was opened, but nothing appeared except the naked ball, the twelve lancets having been broken to pieces. I discovered three in the large intestines, pointless and mixed with the other contents; the other nine were missing and had probably been voided. The stomach was as sound and entire as that which had received the needles.

"Two Capons, of which one was subjected to the experiment with the needles, and the other with the lancets, sustained them equally well. My next wish was to know how much time elapsed before the beginning of the fractures; and by repeated experiments on Turkeys, I found that these sharp bodies begin to be broken and lose their shape in two hours. This, at least, happened in two individuals of the species; in one, four of the lancets, and in the other, three of the needles, were broken within that space; the others were blunted, but continued fixed in the balls."*

Turning from these experiments, which, however important in a physiological view, certainly have an appearance of cruelty, let us for a moment glance at Birds in a more inviting aspect, as the songsters of the groves-the myriad performers in the sweet orchestra, whose notes thrill our ears and hearts, in those spring mornings that are so delightful, when the freshness and loveliness of nature is like the opening of the gate of Eden. Nor less in balmy sum* "Dissertations," i. 19. 
mer nights, when the Dipper, the Sedge-warbler, and above all, the Nightingale, are awake, and pouring forth rich and solemn melody. "He that at midnight," says Izaak Walton, "when the very labourer sleeps securely, should hear, as I have very often, the clear airs, the sweet descants, the natural rising and falling, the doubling and redoubling of her voice, might well be lifted up above earthe, and say, Lord, what musicke has Thou provided for Thy saints in heaven, when Thou affordest bad men such musicke upon earthe!"

One might make a volume with extracts from the poets in honour of the Nightingale-from Homer, who fancies her wailing and mourning her woes, down to Coleridge, who considers it high treason against common sense to suppose there is anything melancholy in Nature.

$$
\text { "We have learn'd }
$$

A different lore: we may not thus profane Nature's sweet voices, always full of love And joyance! 'Tis the merry Nightingale, That crowds, and hurries, and precipitates With fast, thick warble his delicious notes, As he were fearful that an April night

Would be too short for him to utter forth His love-chant, and disburthen his full soul Of all its music! . . . .

. . . . Far and near,

In wood and thicket, over the wide grove, They answer and provoke each other's songs,

With skirmish and capricious passagings, And murmurs musical, and swift jug, jug; And one low, piping sound, more sweet than all, Stirring the air with such an harmony, That should you close your eyes, you might almost Forget it was not day."

The Mocking-bird (Orpheus polyglottus) of the Western World, rivals the Nightingale in the compass, mellowness, and brilliant execution of its song, which it also delights to 
trill forth on moonlight nights, making the woods to ring again. We have listened enraptured to the united melody of dozens of these birds together, in the orange-groves of Jamaica, during those beautiful nights when a tropical moon looks down from the vertical sky in dazzling lustre, when the air is cooled by the fresh land-breeze from the mountains, and thousands of fire-flies are sailing in and out at the dark edges of the woods, like living sparks of fire. Then the birds, each taking his stand on the topmost twig of an orange or lime-tree, pour forth, one after another, their gushing songs, now one answering his fellow, now all singing together as if eager to drown each other's voice; now one alone is heard for a few moments, then the others rush anew into the contest, which is often maintained till after midnight.

The song of Birds is closely connected with the reproduction of the race. There are a few species, it is true, as the Redbreast, that protract their melody into autumn, and even into winter; but the grand chorus of the woods and fields comes in and goes out with spring. It is the male, almost exclusively, that is the performer; he begins to sing his love-song as he woos his mate, while the hedges are yet leafless; he sings blithely in the intervals of his labour, as he assists to build the nest; and he sings almost without intermission from morning till night, to cheer his spouse in her patient duty of incubation. As soon as the parental duties cease, we hear little more of "the voice of the bird."

And thus we are introduced to that miracle of instinct, the Bird's nest; which must, however, be the special subject of another chapter. 


\title{
CHAPTER XXXIII.
}

\author{
Aves (Birds).
}

\section{Continued.}

WE well remember the wondering delight with which, in childish days, we gazed on a Chaffinch's nest. An elder companion had found it in the fork of an oak, and climbing up to the place, he drew aside the leafy twigs and revealed the beautiful little dwelling to our eager eyes. The particular construction of that particular one, we cannot, of course, pretend to describe, for it is a great many years ago, and the note-book was not then so familiar to our hand as it has been since, but a vivid impression of the general appearance remains. Indeed, the spruce, smart little Chaffy builds one of the prettiest of British nests; the Goldfinch's is somewhat more compact, and, being composed more of one substance, is neater, but we scarcely know whether we do not more admire the Chaffinch's. Of course you have seen both; Chaffy's certainly, because it is so common and so easily found.

What a beautiful cup of interwoven moss it is !-at least the frame-work, the exterior! The pretty feathermoss (Hypnum) is chosen for this, because it grows in long strings, and binds well together; but this is only the outer 
wall. Wool is the staple; you may see the busy birds in spring collecting the straggling tufts of wool that hang on the thorn-bushes around the sheep-pasture, and carrying off the prizes in their bills : watch one home, and you will have no difficulty in discovering the whereabouts of its domestic economy. But be merciful; look, but touch not! Well does the skilful little architect know the felting properties of wool! how, when the fibres are placed in contact, and rubbed and pressed, they unite and bind together into a cloth-like texture, like the substance of a hat, or a piece of drugget. God has put into her feeble sensorium this instinctive knowledge, and how effectively she uses it! Tuft after tuft of wool is brought, pulled and spread out thin, and applied to the interior of the mossy cup, each layer placed evenly round, so that the thickness shall grow uniformly, and each addition united to the fixed portion by the pressure of the bird's breast, she sitting in the hollow and moving briskly round and round, pressing the wool with all the force of which she is capable. A sort of sewing process goes on at the same time; for individual fibres of the wool are passed around projecting branches of the moss, and, being inserted into the walls by means of the bill, are seized on the opposite side, drawn tight, and passed through again and again, every effort adding to the strength, compactness, and neat appearance of the growing nest. The united cobwebs of the spiders that lurk in hedges and banks are also brought into requisition for this sewing work; bits of cotton and thread from the neighbouring dwellings, and many other substances : and thus the house is made. But it is not quite ready yet; it must be strengthened on the outside, by intertwining 
BIRDS.

long strings of moss around the contiguous branches, and binding them with felted wool, thus weaving the bush itself into the common structure. It is because of this connexion that it is next to impossible to take a nest without so damaging it as nearly to destroy all its beauty ; it can. not be removed without being almost torn to pieces. Then it must be adorned with little bits of gray and yellow and green lichens, stuck on the outside and bound down with cobweb, which doubtless greatly improve the beauty of their house in the eyes of the tasteful owners- $\mathrm{Mr}$ and Mrs Chaffy.

Well, then, the exterior is finished :-now it must be lined. Moss and wool are soft and warm, but something softer and warmer must be procured before it is a fit cradle for five naked tender birdlings. Besides, it must be made smoother than it is. Now the birds go a-searching along the lanes and over the commons for stray hairs, especially those of cows and of rabbits and hares; these they introduce, and, coiling them round the cavity, render it beautifully smooth and globular. The soft small bodyfeathers of other birds are then sought, particularly those of the ducks in the farm-yard, and interwoven with the hair; and the structure, now complete, is looked on with complacency by the industrious pair. The Chaffinch, however, does not make so much use of feathers for lining as some other of our small birds.

The Goldfinch, as we have said above, makes a more compact structure than this, as it is careful not to leave a single projecting sprig of moss or filament of down, binding down the whole into a smoothly felted surface. It is fond of moss and wool, but does not much use hair or 
feathers for a lining, preferring the down of catkins, of the coltsfoot, cotton-grass, and other downy plants of the season. It has been, however, observed, that birds will commonly take the materials for building which they can most easily procure, within certain limits of resemblance of course, and always having regard to their suitability, and to the general plan and style of the building. "On the 10th of May, 1792," says Bolton, "I observed a pair of Goldfinches beginning to make their nest in my garden; they had formed the groundwork with moss, grass, \&c., as usual, but on my scattering small parcels of wool in different parts of the garden, they in a great measure left off the use of their own stuff, and employed the wool. Afterwards I gave them cotton, on which they rejected the wool, and proceeded with the cotton; the third day I supplied them with fine down, on which they forsook both the other, and finished their work with this last article. The nest, when completed, was somewhat larger than is usually made by this bird, but retained the pretty roundness of figure and neatness of workmanship which is proper to the Goldfiuch."*

But we, in this country, have no nest that can compare for neatness with the tiny structures built by the Humming-birds of the Western hemisphere. That of the smallest of birds, the Vervain Humming-bird (Mellisuga humilis) of Jamaica, we have often had an opportunity of seeing in those lovely hesperidan glades. It is usually affixed to the upper side of a horizorital twig of bamboo, just over a joint, so that the diverging twigs are embraced by its foundation. Fancy a little hemispherical cup, about as big as 
the half of a walnut, made of a bay-coloured down, the produce of the silk-cotton tree, most compactly interwoven, and mingled with the glossy down of an Asclepias. Externally it is quite covered with spiders' webs, crossed and recrossed in every direction, and made to adhere by some viscous substance, evidently applied after the web was placed, probably the saliva of the bird. These webs are used to confine little bits of pale-green lichen, which are stuck about here and there, and impart a rustic prettiness to it. To see a bird sitting in a cup like this is very amusing. Small as is the species, it seems impossible that it should be able to crumple itself up sufficiently to be contained in so tiny a cavity, especially when two eggs are lodged in the bottom; but the incubation is managed. The head and tail are both excluded, the latter projecting erect; the belly and feet alone are contained within the circumference, which they completely fill.

A volume* of great interest has been written, devoted exclusively to the various kinds, forms and materials of birds' nests; and the subject is far from exhausted. We, as yet, know comparatively little of the nests which are constructed by the hundreds of species of birds from foreign, especially intertropical, countries, that crowd the shelves of our museums. Yet, among those with which intelligent travellers have made us acquainted, are found some of the most curious and admirable examples of the constructive faculty.

Thus the Baya, or Indian Sparrow (Ploceus Philippensis), described by Sir William Jones and others, is said to make a nest "of grass, which he weaves like cloth, and shapes.

$$
\text { * Rennie's “Architecture of Birds." London, } 1831 .
$$


like a bottle, suspending it firmly on the branches, but so as to rock with the wind, and placing it with its entrance downward to secure it from the birds of prey. His nest is usually suspended over water, and it is popularly believed that he lights them with fire-flies, which he is said to catch alive at night, and confine with moist clay or with cowdung."

This novel mode of lamp-lighting is so strange, and almost incredible, that it has been doubted by some; but the testimony of independent observers of veracity, who set themselves to examine the facts, confirms the vulgar supposition, that illumination is the object desired.

The interior of this pensile nest contains several apartments, used by the parent birds for different purposes: one of them, consisting of a little thatched roof over a perch, without a bottom, protects the cock bird from the sun or rain, as he cheers the sitting hen with his song.*

In South Africa, a curious pendent nest is formed by the Tchitrec, one of the flycatchers. Le Vaillant thus describes it, on the authority of his intelligent Hottentot hunter, Klaas: "In one of our journeys through a wood of mimosas, in the country of the Caffres, he discovered and brought me this nest, having seen, he said, and particularly observed, a male and female Tchitrec occupied in constructing it. It is remarkable for its peculiar form, bearing a strong resemblance to a small horn, suspended with the point downwards, between two branches. It greatest diameter was two inches and a half, and gradually diminishing towards the base. It would be difficult to explain the principle upon which such a nest had been built, particu-

* Forbes's "Oriental Memoirs," i 119. 
larly as three-fourths of it appeared to be entirely useless and idly made; for the part which was to contain the eggis, and which was alone indispensable, was not more than three inches from the surface. All the rest of this edifice, which was a tissue closely and laboriously woven of slender threads taken from the bark of certain shrubs, seemed to be totally useless. The interior of the nest was not furnished with any sort of soft material, such as down, wool, or hair; but as the female had not laid her eggs when Klaas brought it to me, it is probable that the nest was not quite finished; a fact, indeed, proved by the birds being still at work at the time." *

In Jamaica, we have seen an interesting nest made by a

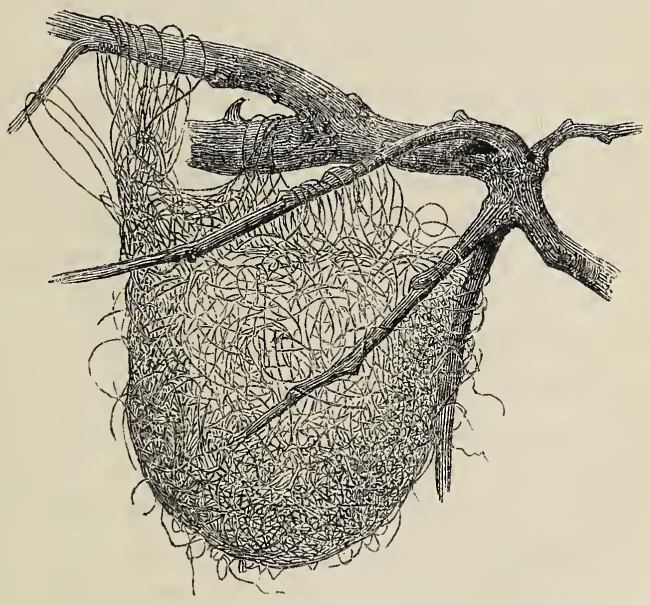

Nest of Banana-bird.

Starling, of brilliant black and yellow plumage, and pro* “Ois. d'Afrique," iii. 129. 
vincially known as the Banana-bird (Icterus leucopteryx). It is a deep purse, suspended by two opposite points of its margin, between two parallel twigs of a tree, and composed sometimes of horse hair, sometimes of long vegetable fibres which can scarcely be distinguished from hair. "The hairs or threads are procured one by one, and carried to the selected spot, where they are deposited in a loose heap. From this accumulated mass of material, the work is carried on, and progresses rapidly when once begun. When a few threads are laid and interlaced for the base, the work becomes perceptible and interesting. Both birds work together: one, taking a thread and weaving-in one end, holds down the loose part with his beak, while his mate takes the ends of others projecting, and lays them tightly down over it, interweaving them with others. Other threads are crossed in the same manner, in every direction, until a slight but very compact purse is made, resembling a loose cloth. As it hangs, the texture is so thin that a person below can discern the eggs or young within." *

An old lady in America, to whom Wilson was shewing a similar nest to this, asked him, half in jest, half in earnest, if he did not think it possible that birds might be taught to darn stockings; There are some nests in the British Museum, which half incline us to think that the owners might learn to hem handkerchiefs. They are those of the Tailor-bird of India (Orthotomus longicauda), a beautifully plumaged member of the family of the Warblers. "It first selects a plant with large leaves, and then gathers cotton from the shrub, spins it to a thread by means of its long bill and slender feet, and then, as with a needle, seu's 
the leaves neatly together to conceal its nest. . . . Often," says the describer, "have I watched the progress of an industrious pair of Tailor-birds in my garden, from their first choice of a plant, until the completion of the nest and the enlargement of the young." * Other authorities affirm that it "picles up a dead leaf and sews it to the side of a living one."

Probably, as with our native birds, some diversity exists in the materials and in the workmanship of different individuals of the same species. Mr E. L. Layard, in his "Notes on the Ornithology of Ceylon," where he describes this little bird as "everywhere common," says :- "It builds in broad-leaved shrubs. The nest is generally composed of cottony fibres mingled with horse-hair, and enclosed between two leaves, whose edges are sewn together with cobweb. I once saw a nest built among the narrow leaves of the oleander (Nerium odorum). It was constructed entirely of cocoa-nut fibres, and at least a dozen leaves were drawn into the shape of a dome, and securely stitched together, a small entrance being left at one side." $\dagger$

One of our native birds, the Long-tailed Tit (Parus caudatus), familiarly known by the homely names of "Pokepudding," "Long Tom," \&c., makes a nest which has been much admired for the ingenuity of its construction, combining security, warmth, compactness, and beauty. It is a hollow ball of moss and wool, profusely lined with soft feathers, and having only a small hole for entrance; not unfrequently the structure is prolonged into the shape of a bottle, the entrance being through the neck. But the bottle-nests of the Pensile Grosbeak of Africa (Loxia pen-

* Forbes's "Oriental Memoirs," i. 55.

f “Annals N. H.," Oct. 1853. 
silis) far exceed ours in ingenious adaptation for security and defence. Pringle describes them as suspended, twenty or more from a single tree, attached to the tips of those twigs that hang over a precipice. The body of the nest is spherical, and the entrance, which is always from below, is through a cylindrical gallery of twelve or fifteen inches in length, which projects from the body, exactly like the neck of a chemist's retort. The whole fabric is most ingeniously and elegantly woven of a species of very tough grass. The object of the precaution displayed in the construction, and in the position chosen, is evidently the protection of the eggs and young from the baboons and monkeys that would otherwise devour them.*

We must reluctantly close our enumeration of singular nests, with one, whose chief curiosity is the exhibition of that social instinct, which, as in the bees, wasps, and ants, among Insects, prompts each individual to work on a common plan for the general good. The Pensile Grosbeaks, just described, associate in their domestic economy, but there is no union of labour. Another bird of the same family, and of the same country-the Sociable Grosbeak (Loxia socia) of South Africa-builds in concert a huge irregular sloping roof of thatch around the stem of a tall tree, beneath the eaves of which each pair of birds builds its own nest. So numerous are they, however, that the nests are in contact with each other, and appear to form but one structure, distinguished only by the little aperture of each. Le Vaillant describes one roof which he examined, which contained beneath its eaves three hundred and twenty inhabited cells. 
We have devoted this article to nests; but there are some examples of architectural skill among birds, which require a passing notice, though they are constructed for a very different purpose. We allude to the playing galleries of the Bower-birds of Australia, specimens of which may be seen in the British Museum and in the Zoological Gardens at the Regent's Park. The Spotted Bower-bird (Chlamydera maculata), for instance, collects twigs and sticks, and builds them so as to form a long tunnel or gallery, cylindrical interiorly, where it is lined with long grass. The birds then bring together large quantities of stones, shells, and fragments of bone, with which the floor is paved; this pavement, which expands beyond the opening at each end, serves to strengthen the structure and keep it steady. Besides this, they carefully search for the gaily-coloured feathers of parrots and other birds, which they interweave into the sides of their bower, and also arrange the whitest stones and shells in the most conspicuous places, with a keen eye to ornament. The gallery being complete, the birds use it for play, chasing each other through it; and that not only by pairs, but numerous individuals associating to use (and, therefore, probably to build) the same gallery. One of these bowers, now in the British Museum, was, when found, four feet long and eighteen inches high. 


\section{CHAPTER XXXIV.}

\section{Mammalia (Quadrupeds).}

$\mathrm{Br}$ universal consent, those animals which we generally call Quadrupeds are placed in the highest rank of organic life. Perhaps it would be scarcely true to say that a Guinea-pig or an Ant-eater is superior in energy and development to a Falcon, superior in those characters which determine relative rank in being; but this only shewswhat we have had repeated occasion to state-that the range of animal existences cannot be included in a linear series. The Ant-eater and the Guinea-pig are members of a great group of creatures, which are manifestly associated together by a closer bond than that which allies them, or any one of them, to other creatures; and this great group possesses, as a whole and characteristically, though in degrees differing inter se, the various senses, powers, and faculties, both bodily and mental, that belong to an animal in a higher state of development, than any other equivalent group.

The term "Quadruped" is applicable to this Class, not in scientific strictness, but only in popular freedom of speech. One whole Order-that of the Whales and Dolphins-is entirely destitute of the hinder pair of limbs, and the external form of their body is fish-like, as are also 
their habits of life and the medium in which they reside; yet these animals have far greater and more important affinities with Quadrupeds than with Fishes, and must therefore be grouped with the former rather than with the latter.

The term "Mammalia," derived from mamma (the female breast), suggests a character of great physiological value and of invariable application, by which the creatures of this class are distinguished from all others. They suckle their young, which are in all cases brought forth alive (i.e. not enclosed in eggs), and are nourished for a time with milk, a fluid secreted in the body of the female parent.

As, with the trivial exception of the Bats, which flutter in the air, the sphere of this Class is the solid earth or the dense water ; the provisions for that energetic respiration and for that high temperature of the blood, which are necessary for Birds, are wanting here. In other respects, however, the respiratory and circulating systems do not essentially differ in the two Classes.

The jaws are, almost invariably, furnished with teeth, which play an important part in the economy of the animal, being intimately associated with its sustenance. They are solid pieces of bone covered with a much harder substance called enamel, which grow out of sockets in each jaw. They are placed in single series, and vary much in form, according to the nature of the food which sustains the animal, as well as according to their position in the mouth. In Man, there are in each half of each jaw two front teeth with a chisel-like edge, called Incisors, or cutting teeth; one more pointed, called the Canine, or Dogtooth, or sometimes Eye-tooth; two somewhat flattened at 
the top with single fangs, called False Molars; and three behind all with compound fangs, and broad, somewhat hollow surfaces, called True Molars or grinders. In those races which feed exclusively on flesh, the molar teeth partake of a cutting character, while in those that subsist on grain and herbage, the molar or grinding structure prevails throughout the whole. Sometimes the incisors are curiously developed: in the Squirrel, Rat, and similar animals (RoDentia), they project forwards in a curve, meeting at an angle, and are continually growing; in the Elephant, they stand out in the form of huge curved tusks ; and in the Narwhal, one is commonly undeveloped, while the other grows into a long spirally-twisted straight tusk, like a horn, in front of its head. The Whale has no teeth, but a series of horny plates, parallel to each other, depends from the upper jaw, and constitutes the valuable substance called whalebone. In the Ant-eaters, and some others of the Edentata, there are no teeth at all, while the Armadillo has ninety-six, and some of the Dolphins have a hundred and fifty.

Considerable variation, suggesting diversity in function and habit, is also found in the forms assumed by the extremities. The Carnivorous tribes, the Rodents, and some others, are furnished with paws, divided into toes, which are terminated by claws; and thus their feet are not only supports in walking, but are endowed with a grasping, tearing, or scraping power. On the other hand, the feet of the 'Thick-skinned and Ruminant tribes are encased in solid hoofs of horn, which may be single, as in the Horse; double, as in the Sheep; three, as in the Rhinoceros; four, as in the Hog; or five, as in the Elephant. A hoofed 
foot can never be anything else than an instrument of locomotion. In the Apes and Moukeys, the feet become hands; all of them having a thumb set on a different line from the other toes, and susceptible of being opposed to

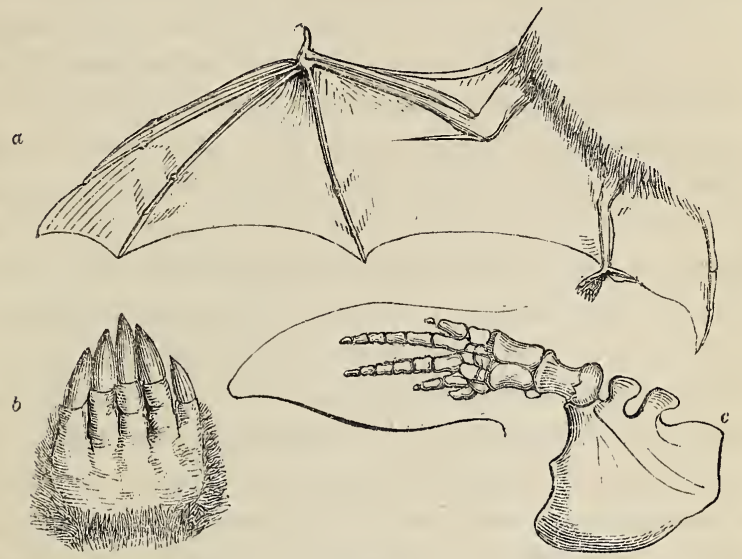

Handis of

$a$. Bat; $b$. Mole; $c$. Dolphin.

them, whereby the prehensile power is immensely increased, and the capabilities of the organ are greatly varied.

In all these cases, all of the extremities are of the same form, but there are some in which the fore and hind feet differ from each other. Thus, in the Bats, while the hind feet have five short clawed toes, the fore ones have the first four fingers immensely lengthened, like the ribs of an umbrella, across which a delicate membrane is stretched, and thus the fore limbs become organs of flight. And in Man, who, by his organic nature, comes into this Class, the feet are merely fitted for walking, while the anterior extremities, forming hands incomparably more delicate and more 
versatile than those of the Apes, are capable of executing by their skill or power the wonderfully various requirements of his reason. Finally, the anterior members of the Whales, which, as has been already observed, are all that they possess, are mere swimming fins, the bones of the toes being imbedded in a dense and leathery skin, which reveals no trace of their individual form or division.

The body in the Mammalia is covered more or less densely with hairs, which, if less elaborate and complex than the feathers of Birds, are still interesting in their structure. A hair is a long pointed cylinder of horny substance, formed within a minute cavity on the surface of the body, and growing by continual additions to its base. The cavity is lined by a reflection of the common skin, and contains a vascular pulp well supplied with nerves and blood-vessels. From the surface of this pulp the horny substance of the hair is secreted, which, perpetually increasing from below, pushes upward the portion already formed, and thus increases in length.

"Various are the appearances," observes Professor Jones, "and widely different the uses, to which epidermic appen. dages, in every way analogous to hair, both as relates to their cornposition and mode of growth, may be converted: the wool of the Sheep, the fur of the Rabbit, the spines of the Hedgehog, the quills of the Porcupine, the scaly covering of the Manis, and even the armour that defends the back of the Armadillo, are all of them but modifications of the same structures, adapted to altered conditions, under which the creatures live. Even the horn upon the snout of the Rhinoceros is but an agglomeration of hairy filaments formed upon a broad and compound pulp. The 
nails and claws that arm the fingers and toes, the corneous sheath that invests the horns of the $\mathrm{Ox}$ and Antelopenay, the hoofs of herbivorous quadrupeds, are all epidermic secretions from the vascular cutis, or, in other words, are hairs altered in their form and extent, according to the exigencies of the case." *

Many of the hoofed Quadrupeds are armed with horns, which differ greatly in structure from those of the Rhinoceros and the Ox. Those of the Deer family, whether palmated like those of the Elk, branched like those of the Stag, or simple like those of the American Roes, are annual growths of bone, which are shed and renewed periodically. In an old well-antlered Hart, a "Stag of ten," such as our old poets delight to describe, the process of renewal is one of amazingly rapid energy. In the spring the bony knobs on the skull, covered with skin, begin to swell, tides of blood rush to the head, and great heat and tenderness characterise the prominences. The arteries deposit bone with great rapidity, and the budding-horns grow daily, still covered by a vascular skin, which is, indeed, a tissue of blood-vessels. The skin is covered with a dense short hair, which is technically called "the velvet."

At length the horns, with their branches and antlers, are fully formed, and are still covered with this velvety skin, which is highly sensitive. The arteries now begin to deposit a rough ring of bone around the base, which grooves, through which the great arteries pass. Gradually these grooves are filled up with bony matter, and the arteries, compressed by the constantly added matter, transmit less and less blood to the "velvet," until at * “Gen. Outline of Anim. King.," p. 688. 
length the latter receives no more. It now dies for lack of sustenance : shrivels, dries, and peels off in shreds, or is rubbed off by the animal against the trees and palings. The horns are now no longer sensitive, but can be used as effective weapons of offence. After a time, however, the thick ring of bone begins to be absorbed, particle by particle, and the absorptive process goes on until a complete separation of the horn is effected, which then falls off by its own weight from the basal prominence. The latter is presently covered with skin, and awaits the return of spring to bud anew.

The geographical distribution of animals is a subject of great interest to the naturalist; that is, the manner in which we find particular species either spread over considerable portions of the world, confined to small tracts of country, or appearing in remote but isolated regions. No countryaffords more interesting phenomena connected with this subject than the continent of Australia with its circumjacent islands. Excluding the Seals and Whales of its coasts, the Mammalia known to inhabit this great regionas large as Europe-amount to about a hundred and twenty species, the whole of which are absolutely confined to it. Of these about a hundred are marked by some remarkable peculiarities of structure, which have induced zoologists to separate them from all other MammaLia, forming them into a Sub-class by themselves, under the name of MarSUPIALIA. In order to appreciate the importance of these facts, we must look at the part which this Sub-class plays in the zoology of other parts of the world. The total 
number of terrestrial Mammalia known may amount to about 1700 species, of which 137 are Marsupialia. The facts will be better seen if placed in juxtaposition, thus :-

The Australian region contains

The whole world besides contains

\section{... 120 terrestr. Mammalia.}

100 Marsupialia.

... 1580 terrestr. Mammalia.

37 Marsupialia.

Thus we find the Marsupial Mammalia almost confined to Australia, and Australia almost confined to them.

The most obvious peculiarities which distinguish these animals, and which have conferred upon them their scientific designation, are the immature condition of the young at the time of birth, and its reception into a pouch (marsupium) or fold of the skin on the abdomen of the female, in which it is protected from exposure to the air and injury; while suspended from the teat, to which it is very early attached, it gradually assumes the form of its adult condition, and acquires the powers necessary for its independent existence. For sume time, however, after it is able to procure its own living, and to run and play by the side of its mother, the young Marsupial instinctively flees to the maternal pouch for protection on the approach of danger.

But besides these more obvious peculiarities, there are others scarcely less important, which are recognised by the comparative anatomist. Diversities in the reproductive organs, in the arterial system, and in the structure of the brain ; the open condition of the skull, the bones of which remain permanently separate ; the tendency to a multiplication of the teeth; the presence of marsupial bones in the skeleton, even where the marsupium itself is not developed; and the absence of a true voice,-all manifest a departure 
from the high development of the placental MammaLia, and an approach to that of the oviparous Vertebrata in general, and to that of the REPTILIA in particular.

This affinity with RePTILES is most marked in two very singular little animals, the Echidna and the Ornithorhynchus. They are the lowest forms of Mammalia, displaying some points of similarity to Birds, but more to the Lizards, especially in the structure of the sternum or breast-bone, of the shoulder, and of the limbs generally. The latter in particular, known as the Duck-bill, caused no little astonishment and even suspicion, among zoologists, when the first specimens were sent from New Holland to Europe. Here was a four-legged animal, covered with hair, but having the feet webbed like a water-fowl, and furnished with a beak closely resembling that of a duck ! For a long time it was believed that the reproduction of this most anomalous creature was by means of eggs ; but it is now ascertained to produce living young, which are suckled like those of other quadrupeds. Mr G. Bennet has described, in a very interesting Memoir, * the habits of life of these curious creatures.

Few as are the members composing this Sub-class, they include what we may consider as the parallels or representatives of most of the Orders of the typical Mammalia. Thus the Opossums, in their opposible thumbs, seem to represent the Monkeys, the little Myrmecobius the Shrews, and the Kangaroos the Ruminants; while more strongly drawn analogies exist between the Dasyuri (the "Zebrawolf," "Native-devil," \&c., of the Australian colonist) and the Carnivord, between the Phalangistce and Petauri, and * "Trans. of Zool. Soc.," vol. i. p. 229. 
the Rodentia, and between the Duck-bill and Spiny Ant-eater, and the Edentata.

The largest and most attractive, as well as most valuable animals of this Class, are the Kangaroos (Macropus). Every child is familiar with its elegant taper figure, its gentle deer-like face, its short fore-feet dangling at its breast as it stands erect on its long and powerful hind limbs and its immense tail. There are few, moreover, who have not read of its singular mode of progression, by vast leaps, through the Australian scrubs. Its flesh is excellent venison, and the European settlers hunt it with hound and horse. $\mathrm{Mr}$ Gregson describes in a graphic manner a fine run of eighteen miles, performed by an old boomer, as the Great Kangaroo is called, andadds the following more general notes of its habits, with which we dismiss the Marsupialia:-

"We did not measure the distance of the hop of the Kangaroo; but on another occasion, in which the boomer had taken along the beach, and left the prints in the sand, the length of each jump was found to be fifteen feet, and as regular as if they had been stepped by a sergeant. When a boomer is pressed, he is very apt to take to the water, and then it requires several good dogs to kill him; for he stands waiting for them, and as they swim up to the attack, he takes hold of them with his fore-feet, and holds them under water. The buck is very bold, and will generally make a stout resistance; for if he cannot get to the water, he will place his back against a tree so that he cannot be attacked from behind, and then the best dog will find him a formidable antagonist. The doe, on the contrary, is a very timid creature, and I have even seen one die of fear." *

* Gould's "Mamm. of Austr." 


\section{CHAPTER XXXV.}

Mammalia (Quadrupeds).

\section{Continued.}

A YEAR or two ago, the great "lion" in the Zoological Gardens, which all London was running to see, was an uncouth, lanky, low-limbed creature, with extraordinary longitude of snout, and as conspicuous bushiness of tail. An ample apartment, duly indexed and labelled, as became the rarity of the tenant, was assigned to it, so that it could not only be well seen, but thoroughly examined. Its colours, sober brown and silvery gray, and its fine collar of black velvet edged with white, redeemed its odd figure from the character of vulgarity; but the manner in which it walked was something quite original. Its fore-legs were short, but very stout and muscular, and terminated in enormous olaws, which were habitually bent in under the feet, so that the animal rested on their outer surfaces, pretty much in the same fashion (if we may use a homely simile familiar to Londoners) as your maid-of-all-work supports herself on her left knuckles when she cleans the door-steps.

This was the Great Ant-bear (Myrmecophaga jubata), from South America, a harmless creature, notwithstanding 
its muscular strength. It feeds on ants, and on termites, or white ants, as they are called, whose great houses of cemented earth, that are so common in tropical forests, are torn to pieces by these great claws, that the swarming insects may be exposed and devoured. And this last operation is not less singular than other parts of the economy of this creature. Its mouth, long and tubular, is entirely destitute of teeth, but contains a tongue of great length, ordinarily folded on itself, and capable of rapid protrusion to a long distance. When the termites crowd to the broken surface of their nest, as is their custom, the shrewd Ant-bear darts into the midst of them his long tongue covered with a glutinous secretion, and as swiftly draws it back into his mouth, densely covered with the adhering insects.

This curious animal is a fair representative of a group which includes the lowest forms of the true or placental Mammalia-the Class Edentata. As Australia is the great centre of the Marsupialia, so South America is the home of the Eventata, of which the Sloths and the Armadillos are, after the example just described, the most important living members. But recent discoveries have exhumed from the soil of the same continent other and far more gigantic representatives of the Class, the Megatheriums and Mylodons, the vast bulk of whose bones indicates that their strength must have been as irresistible as their forms were colossal. Professor Owen, who built up, bone by bone, that noble "skeleton of an extinct gigantic Sloth," that stands-a monument of his skill and knowledge-in the Museum of the Royal College of Surgeons, has given some interesting deductions respecting its mode of life. 
He concludes that the Mylodon-a leaf-eater, like its modern cousins the Sloths of Brazil-having partly exposed the roots of a living tree, by means of its powerful front claws adapted for digging, was accustomed to rear itself up on the broad tripod formed by its own immense hindfeet and its strong tail, and embracing the trunk of the tree with its fore-feet, put forth all its mighty strength in striving to overthrow it. "The tree being thus partly undermined, and firmly grappled with the muscles of the body, the pelvis, and the hind limbs, animated by the nervous influence of the unusually large spinal cord, would combine their forces with those of the anterior members in the efforts at prostration. And now let us picture to ourselves the massive frame of the Megatherium, convulsed with the mighty wrestling, every vibrating fibre re-acting upon its bony attachment with a force which the strong and sharp crests and apophyses loudly bespeak: extraordinary must have been the strength and proportions of that tree, which, rocked to and fro, to right and left, in such an embrace, could long withstand the efforts of its ponderous assailant."

The populous Class of mostly small quadrupeds, known as Rodentia, or Gnawers - of which the Rabbit and the Rat are familiar examples-rise but little, in the scale of organization, above the Edentata. They display but little intelligence, have few means of defence, are timid and feeble, and as they are the prey of many enemies, they are preserved from extermination only by their amazing fertility. Their peculiar dentition is, moreover, intermediate between the toothless condition of the Ant-bears and that of the well-armed jaws of the higher quadrupeds; for they are 
altogether destitute of canines, and their incisors, which are separated by a great blank space from the molars, are furnished with enamel only on one side. They project from the front of each jaw in a curve; and, as they have no roots, but spring from a pulpy germ deeply embedded in their sockets, they are

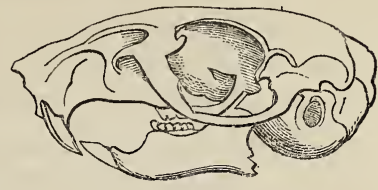

Skull of Rodent. continually growing. These peculiarities have a direct relation to the habits of the animals; for they live upon food, usually hard and solid, which they gnaw away atom by atom, with the tips of these projecting teeth. For this work it is needful that the tips of the teeth, which meet and play upon each other, should have a sharp chisel-like edge, and this result follows from the provision above mentioned, that the hard enamel is confined to the front side of the tooth; the bony portion of the tip, being soft, wears away more rapidly than the enamel of the front, which thus always presents a sharp cutting edge. The constant growth, too, just balances the ordinary wear of the teeth in eating, so that they are maintained in constant opposibility to each other. The perfec. tion of this balance becomes manifest, when, by accident, one of the incisor teeth is lost; for, in this case, the opposite tooth, having no wear, grows out to a monstrous length, maintaining its original curve throughout, and becomes a tusk, which in time presents a bar to the reception of food, and death by starvation ensues.

Strange as it may be thought, there is an affinity by no means obscure, between these minute animals and the 
greatest of quadrupeds-between the Mouse and the Elephant. Not to speak of the similarity in form of many of their bones, and their jaws formed of parallel laminæ, the latter is, like the former, destitute of canines, while its incisors assume a curved direction, and project from the mouth as great tusks. The molars of the Elephant, like those of the Guinea-pig, are composed of a number of vertical transverse laminæ of bone, each covered with enamel, cemented together by a third substance closely similar to ivory. "This last substance, being much softer than the enamel, wears away faster by the mastication of the food, so that the enamel remains considerably higher, and, in this manner, the surface of each grinder acquires a ribbed appearance, as if originally formed with ridges. From very accurate observations which have been made on the Asiatic Elephant, it appears that the first set of grinders, or milk-teeth, begin to cut the jaw eight or ten days after birth, and the grinders of the upper jaw appear before those of the lower one. These milk-grinders are not shed, but are gradually worn away during the time the second set are coming forward, and, as soon as the body of the grinder is nearly worn away, the fangs begin to be absorbed. From the end of the second to the beginning of the sixth year, the third set come gradually forward as the jaw lengthens, not only to fill up this additional space, but also to supply the place of the second set, which are during the same period gradually worn away, and have their fangs absorbed. From the beginning of the sixth to the end of the ninth year, the fourth set of grinders come forward, to supply the gradual waste of the third set. In this mauner, to the end of life, the Elephant obtains a set 
of new teeth, as the old ones become unfit for the mastication of its food."*

In the Ruminantia generally the dentition is still incomplete; the incisors are absent from the upper jaw, the gums forming there a callous pad to receive the action of the lower teeth. Canines are found only in a few families.

It is not until we reach the Unguiculate or Clawed quadrupeds that we see the full complement of teeth. Among the Carivivora, for example, both the upper and under jaws are armed with molars, canines, and incisors; the molars terminate in triangular cutting lobes, the canines are stout, conical, and pointed; and the incisors numerous, but small, flattened, and chisel-shaped. And this seems to be the most perfect form of dentition in the Animal Kingdom, that which belongs to a type of organization in which the characteristic attributes of an animal are most fully developed.

Let us, then, examine one of the Cat tribe (Felidce) a little more in detail. How admirably every part of the structure is adapted to one end-the capture and destruction of living active prey - and how thoroughly all the organs, and all the parts of the body, are ancillary to each other! The feet-the front pair in particular-are armed with five strong, hooked, compressed, sharp talons. These are the weapons principally relied on for dealing the deathblow; it is needful, therefore, that they be kept always clean, pointed, and in order. A beautiful mechanism secures this. Every child knows, who has handled the velvet paw of a Cat, that, in its ordinary condition, the talons are quite concealed, but that in excitement they * Corse, in Brewster's "Encyciop." 
are forcibly thrown forward. The last joint of each toe, the tip of which is encased by the claw, is, in rest, drawn back, either upon, or at the side of, the preceding joint, by the force of two elastic ligaments. From this position it is in an instant extended, by the contraction of a muscle beneath the toe, the tendon of which passes under the head of the last joint, as under a pulley, and is attached to the base of the claws. When the contraction ceases, the claw again springs back to its place, and lies concealed in a deep fold of the skin.

The ordinary mode in which a feline animal, from the Lion down to the House-cat, disables its victim, is by a sudden powerful blow with the fore-paw. To make this stroke effective, it is necessary that the arm should be moved by vigorous muscles. Perhaps some of our readers may have felt, to their cost, how stinging a blow can be inflicted by the paw of an angry Cat. It has been truly observed, that, in the limbs of the Felida, we behold the finest display of muscular development which can be conceived. The dissected arm of a Lion or Tiger is a subject worthy the study of an artist. The muscles are dense, well-knit, short, but peculiarly thick and firm, and they are arranged for flexure or extension, for turning the face of the paw upward or downward, for the forward, lateral, or downward stroke, exactly as they are in man. The Tiger has been known to fracture the skull of a man with one stroke of its paw.

The Cats do not in general pursue their prey by the exercise of speed, but either creep up stealthily towards it until they arrive near enough to make the fatal bound, or lie in wait for its approach. Then, when the keen eye, 
well practised to judge of distance, esteems the requisite proximity attained, one vigorous bound brings the active murderer full on its victim with prodigious force; the paw, with distended claws, inflicting a violent blow at the moment of descent. For these movements there are peculiar provisions. The lithe and flexible spine, accompanied by the power of the muscles, enables the Cat to throw itself forward with these sudden energetic bounds; while the same properties, combined with the shortness, freedom, and flexibility of its limbs, allow it to crouch close, to creep along with the belly on the ground, as every one has seen the domestic Cat do, when contemplating a mouse, or any other object which awakens her energy. The noiseless tread, also, so essential to the animal's purpose in stealing unperceived on its victim, is provided for, partly by the retraction of the claws already noticed, partly by the soft fur in which the feet are imbedded, but principally by the spongy pads which are seen beneath the toes. These pads have another use, even more important still; for they serve by their elasticity to lessen the shock, which otherwise would ensue to the nervous system, in descending from their vigorous bounds.

The prey being thus slain, or at least disabled, other ordinances of supreme Wisdom become apparent in providing for its appropriation. The teeth, already alluded to, come into requisition. A grinding action is not required; the flesh has merely to be divided into portions sufficiently small to be swallowed, and hence the teeth are all cutters. Look at what, from their normal action in other animals, we call the molars; their summits form lancet-like edges, clothed with the hardest enamel, and the 
lower ones shut close within the upper. Hence the action of these teeth is exactly that of the blades of a pair of scissors, and the flesh and sinews are divided with the greatest ease and precision.

The sharp and prominent bony ridges of the skull, the strength and form of the zygomatic arches, and the size of

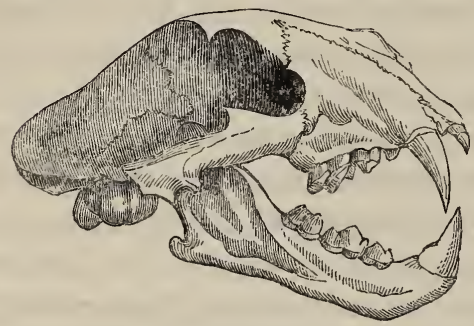

Skull of Tiger. the temporal fossa, indicate the immense extent and volume of the muscles that move the jaws, the force of which is increased by the simplicity of the movement required. There is no approach to that lateral working of the jaws upon each other, which we practise when we eat; nothing but a chopping or cutting action, the jaws having only a hinge movement. The muscles of the neck and breast are also particularly large and powerful in the Cats, to enable 'them to carry off or drag away their prey. A Lion has been seen to bear away a young bullock in his mouth, as a cat would carry a rat.

During the process of cutting up and swallowing the flesh of the still quivering and palpitating prey, the warm blood flows freely, and this appears to be eminently grateful to the palate of the carnivorous tribes. They frequently pause in the process to lick the flesh, and thus to promote the flow of blood by exposing new blood-vessels. To enable them to effect this, there is an exquisite provision. Every one is aware that the tongue of the common 
Cat is rough, and that the sensation produced by its licking is that of a rasp or file. This depends on numerous and close-set horny papilla, which project from the surface, the points being all directed backwards. When the Lion or Tiger, therefore, licks the reeking flesh, this structure of the tongue rapidly rasps away the surface. It is brought into action again when the teeth can detach no more flesh from the skeleton, the tongue now rasping off every fragment that adheres to the surface of the bones.

We might pursue this subject into further minutiæ of detail; but enough has been said to shew the mutual relation of every part of an organized being; and that, in all creatures, certain definite ends having been prescribed, all the organs are constructed and arranged, like the bands, and wheels, and cranks, and joints of an elaborate machine, to attain those ends in the most complete manner, and with the least possible waste of energy.

We are not writing for Atheists, or we might say with Paley: "The marks of design are too strong to be gotten over. Design must have had a designer. That designer must have been a person; that person is GoD." But we perceive more than His entity, more than His foresight; we perceive His benevolence, His care, His tenderness; and these to be so large as to extend to all His works. "The young lions roar after their prey and seek their meat from GoD. . . . These wait all upon Thee; that Thou mayest give them their meat in due season. That Thou givest them they gather: Thou openest Thine hand, they are filled with good. The glory of the LonD shall endure for ever : the Lond shall rejoice in His works." * 


\section{CHAPTER XXXVI.}

\section{Mammalia (Quadrupeds.)}

\section{Continued.}

IT has been a question among zoologists whether or not Man ought to be considered as an animal, and to take his place in the System of Nature with a generic and specific name. Sume have decided in the affirmative, as Linnæus, who places Homo sapiens at the head of his Primates, and Cuvier, who creates an order, "Bimanes," for the express reception of the human species. Others, as Aristotle, Ray, and Swainson, exclude him from their systems, and refuse to assign him a zoological place. The grounds of this exclusion are tersely expressed by the present Archbishop of Canterbury, in the following words: "There is nothing philosophical in the comparison of a being possessed of improveable reason with one that is governed by natural instinct, because there is no just affinity between the talents which are compared." *

We incline to think, however, that both these hypotheses are true. Man, in regard to his body and soul, is an animal, and is to be compared with other animals;he is the highest form in the highest Class ; while it is in 
regard to his spirit, the moral consciousness of responsibility, the principle which constitutes him capable of worshipping God, that he is separated from the brute creation, and placed per se. The contrast between Man and Beast is not a contrast between reason and instinct, common, and almost universal as is this supposition, for it.can be readily shewn that these two mental qualities, though very different, are by no means incompatible; that in point of fact the Dog is endowed with reason as well as instinct, and that Man performs many actions which are purely instinctive, as well as those which are prompted by reason. We shall presently adduce some examples in proof of the former of these propositions.

What is the nature of Spirit, or How that principle can be defined, by the possession of which Man is raised above companionship with the Ape and the Dog, is a question which we will not attempt to answer. "In the image of God made He man." The Creator, who spoke all other terrestrial existences into being by His almighty word, condescended to "breathe into the nostrils" of Man, whom He had formed out of dust, "the breath (or spirit) of life." Thus his spiritual part was a direct emanation from the Deity, who had respect to the wondrous plan, devised before the foundation of the world, whereby the creature Man was to be brought into the closest union with Himself. Here is the true dignity of Man : it is not that he is a reasonable being; it is not that he is a moral being; but it is that, by an act of stupendous grace, his being has been shared by the everlasting God, who became partaker of his flesh and blood, * in order that he might become a partaker

* Heb. ii. 14. 
of the Divine nature.* "Behold what manner of love the Father hath bestowed upon us, that we should be called the sons of God!"

To some it may appear strange that we should consider the possession of $a \mathrm{soul}$, as well as a body, common to the Brutes with Man, and may possibly startle even some who do not fall into the general mistake of confounding the soul with the spirit. Yet it is evident that the inferior creatures do manifest mental attributes. "The phenomena," observes Dr Prichard, "of feeling, of desire and aversion, of love and hatred, of fear and revenge, and the perception of external relations, manifest in the life of brutes, imply, not only through the analogy which they display to the human faculties, but likewise from all that we can learn or conjecture of their particular nature, the superadded principle, distinct from the mere mechanism of material bodies. That such a principle must exist in all beings capable of sensation, or of anything analogous to human passions and feelings, will hardly be denied by those who perceive the force of arguments which metaphysically demonstrate the immaterial nature of the mind." +

One of our most eminent physiologists has expressed the same opinion. "When," observes Dr Carpenter, "we contrast the actions of Man and of the higher Vertebrata, with those of the lower, we cannot but perceive that we gradually lose the indications of Intelligence and Will, as the sources of the movements of the animal; whilst we see a corresponding predominance of those which are commonly denominated Instinctive, and which are performed (as it would appear) in immediate respondence to certain sensa- 
tions, without any intentional adaptation of means to ends on the part of the individual; although such adaptiveness doubtless exists in the actions themselves, being a consequence of the original constitution of the nervous system of each animal performing them. It cannot be doubted by any person who has attentively studied the characters of the lower animals, that many of them possess psychical endowments, corresponding with those which we term the Intellectual powers and Moral feelings in Man; but in proportion as these are undeveloped, in that proportion is the animal under the dominion of those instinctive impulses, which, so far as its own consciousness is concerned, may be designated as blind and aimless, but which are ordained by the Creator for its protection from danger, and for the supply of its natural wants. The same may be said of the Human infant, or of the Idiot, in whom the reasoning powers are undeveloped." *

* "Princip. of Comp. Physiol." (Ed. 1854), p. 693.-We cannot refrain from quoting the same writer's interesting marginal note to the above passage :"The highest development of the purely instinctive tendencies, with the least interference of intelligence, is to be found in the class of Insects; and above all in the order Hymenoptera, and in that of Neuroptera, which is nearly allied to it. It is, of course, impossible to draw the line between the two sources of action with complete precision : but weobserve, in the habits of Bees and other social insects, every indication of the limitation of the power of choice, and of the domination of instinctive propensities called into action by sensations. Thus, although Bees display the greatest art in the construction of their habitations, and execute a variety of curious contrivances beautifully adapted to variations in their circumstances, the constancy with which individuals and communities will act alike under the same conditions, appears to preclude the idea of their possessing any inherent power of spontaneously departing from the line of action to which they are tied down by the constitution of their nervous system. We do not find one individual or one community clever and another stupid ; nor do we ever witness a disagreement or any appearance of indecision as to the course of action to be pursued by the several members of any republic. The actions of all tend to one common end, simply because they are performed in respondence to impulses which all alike share. For a Bee to be 
Instinct has been defined* as a natural impulse to certain actions which animals perform without deliberation, and without having any end in view, and without knowing why they do them. It differs from intellect by the unerring certainty of the means it employs, the uniformity of its results, and the perfection of its works prior to, and independent of, all instruction or experience; and lastly, by the pursuit of nothing beyond what conduces directly either to the continuation of the individual or the propagation of the kind. But the arts of rational creatures proceed slowly through diversified and oft-repeated experiments, while the means they employ are always various, and seldom the best and most appropriate. $\dagger$

Assuming the correctness of this diagnosis, let us examine the source of the actions recorded in the following anecdotes :-

"The battering-train going to the siege of Seringapatam had to cross the sandy bed of a river that resembled other rivers of the Peninsula, which leave, during the dry season, but a small stream of water running through them, though their beds are mostly of considerable breadth, very heavy for draught, and abounding in quicksands. It happened that an artilleryman, who was seated on the tumbril of one of the guns, by some accident fell off, in such a situadestitute of its peculiar tendency to build at certain angles, would be as remarkable as for a human being to be destitute of the desire to eat when his system should require food. Still the author would by no means maintain that there are, even among Bees, no manifestations of intelligence; for a careful study of their habits shews that they do profit by experience, in a manner that shews a certain amount of educability. And this faculty may not improbably be connected with the presence of a rudimentary cerebrum, which is capable of being distinguished from the sensorial centres that constitute the principal part of their cephalic ganglia."-1bid. p. 694.
* Beattie, "Mor. Sci." I. ii. § 8.
中 "Penny Cyclop." xi.i. 497. 
tion that in a second or two the hind-wheel must have gone ever him. The Elephant, which was stationed behind the gun, perceiving the predicament in which the man was, instantly, without any warning from its keeper, lifted up the wheel with its trunk, and kept it suspended till the carriage had passed clear of him."*

"While an old man was wandering by the side of one of the largest tributaries of the Almand, he observed a Badger moving leisurely along the ledge of a rock on the opposite bank. In a little time a Fox came up, and, after walking for some distance close in the rear of the poor Badger, he leaped into the water. Immediately afterwards came a pack of hounds at full speed in pursuit of the Fox, who by this time was far enough off floating down the stream, but the luckless Badger was instantly torn to pieces by the dogs." +

"A gentleman was engaged in the amusement of coursing, when a Hare, closely pressed, passed under a gate, while the dogs followed, by leaping over it. The delay caused to her pursuers by this manœuvre seems to have taught a sudden and useful lesson to the persecuted creature, for as soon as the dogs had cleared the gate and overtaken her, she doubled and returned under the gate as before, the dogs again following and passing over it. And this flirtation continued backwards and forwards until the dogs were fairly tired of the amusement, when the Hare, taking advantage of their fatigue, quietly stole away." *

Of Dogs numberless well-authenticated stories are on record (and almost every one can add to the number from

* "Twelve Years' Military Adventure." p "Zoologist," ij.

‡ Loudon's Mag. N. H., iv. 
his own circle of information or observation), which indicate a comparatively high degree of reasoning power. Who has not observed the intelligence of those Dogs which lead the blind through crowded thoroughfares and dangerous places, always awake, not to their' own comfort, but to the safety of their unconscious masters? Montaigne has seen one of these Dogs along the ramparts of a town leave a smooth and uniform path and take a worse, in order to lead his master from a too close proximity to the edge.

M. Fred. Cuvier, in his highly interesting description of an Orang, brought to France by M. Decaen, makes the following statement. After alluding to its love for its owner, he says: "This principle of affection generally induced our Orang to seek the society of those persons with whom it was acquainted, and to shun solitude, which was at all times displeasing to it. On one occasion it exhibited for this purpose a very remarkable degree of intelligence. It was kept in a small room off a large saloon, usually occupied by the members of the family, and had frequently been observed to mount a chair which stood contiguous, for the purpose of unbolting the door and joining the rest. of the company. At length the chair was removed to a distant corner of the room for the express purpose of preventing the intrusion; but scarcely had the door been shut than it was again opened, and the Orang was seen in the act of descending from the identical chair, which he had carried back again to its old situation, to enable him to mount up to the height of the bolt. It is certain that the animal had never been taught to act in this manner, nor had he ever seen others do so; the whole affair was the result of his owu natural reason, and differed in no respect 
from what a human being would have done in like circumstances."

And is not this a legitimate deduction? and will it not apply to all the examples we have enumerated, and to thousands of others? The Elephant had never been taught to lift wheels when they threatened to crush fallen men; nor the Fox to transfer his own peril to a stray Badger; nor the Hare to run to and fro under a gate; nor the blind man's Dog to give a wide berth to the rampart's verge. The actions were not the results of education, of habits induced by training. Neither were they, or any of them, marked by "unerring certainty in the means," or " uniformity in the results," nor can it be said that they were "performed independently of all experience;" they differed in toto from instinctive actions. Every one of them indicates a reasoning power, combining cause with effect, using the light of past experience, or perceiving the suitability of some resource to present emergency, and that, in one or two of the cases, as in those of the Fox and the Hare, with a sudden promptitude which in man would have been admired as presence of mind. Why should we hesitate to call it so here?

Instances are not wanting in which the inferior animals have manifested a capacity for comprehending some of the more abstract notions, such as time, number, and language -notions which certainly have little in common with instinct. Southey, in "Omniana," mentions two Dogs which were able to count the days of the week. One of these, he says, belonged to his grandfather, and was in the habit of trudging two miles every Saturday to cater for himself in the shambles. "I know," he adds, "a more extraordinary 
and well authenticated example. A Dog, which had belonged to an Irishman, and was sold by him in England, would never touch a morsel of food upon Friday."

"The Oxen that served in the royal gardens of Susa, to water them, and turn certain great wheels to draw water for that purpose, to which buckets were fastened. (such as there are many in Languedoc), being ordered every one to draw a hundred turns a-day, they were so accustomed to this number, that it was impossible by any force to make them draw one turn more; but, their task being performed, they would suddenly stop, and stand still." *

As proofs that Brutes can acquire some knowledge of human language, we may mention the following facts and anecdotes out of many. Mr W. C. Martin says :- "We have two dogs, a spaniel and a terrier, both of small size; and if, by way of trial, in the course of conversation we say, in the ordinary tone of voice, and without looking at them, 'I am sure there must be a cat somewhere about the house,' they are instantly excited, and search in every place for the animal, to which they bear instinctive hatred." + Dr Gall says that Dogs learn to understand not merely separate words or articulate sounds, but whole sentences expressing many ideas. In his treatise, "Sur les Fonctions du Cerveau," is the following passage:- "I have often spoken intentionally of objects which might interest my Dog, taking care not to mention his name, or make any intonation or gesture which might awaken his attention. $\mathrm{He}$, however, shewed no less pleasure or sorrow, as it might be, and, indeed, manifested by his behaviour that he had:

* Montagne's “Essays," ii. 12. † "Hist. of the Dog," 99. 
perfectly understood the conversation which concerned him. I had taken a bitch from Vienna to Paris; in a very short time she comprehended French as well as German, of which I satisfied myself by repeating before her whole sentences in both languages."

Elephants habitually perform certain duties on the mere verbal promise of special rewards, which it would be very dangerous to withhold when the condition is accomplished.

But one of the most remarkable examples on record of this faculty, is the following story of a Spaniel, avouched by the personal knowledge of a zoologist of deserved repu. tation. "One morning, as the lady to whom the spaniel belongs was lacing her boots, one of the laces broke. She turned to the dog, and playfully said, 'Oh dear! I wish you would find me another boot-lace;' and having managed with the broken one, thought no more about it. On the following morning, when she was again lacing her boots, her spaniel ran up to her with a new silken boot-lace in his mouth; not only to her great amazement, but that of the family. Where the dog had obtained the boot-lace no one could tell; but, doubtless, he had purloined it from some workbox or similar repository." *

The same naturalist has mentioned several instances in which a communication was made by one animal to another of certain events that had occurred to the former, and of a definite and intelligent common action resulting.

Every observant reader must be aware that the Brutes -especially those which, being domesticated, come more frequently under our notice-display many of what, in 
ourselves, we call moral feelings or affections, whether good or bad; but, perhaps, all are not cognisant of the extent of the category. We could readily cite anecdotes to prove that love, hatred, jealousy, gratitude, pity, sympathy, faithfulness, obedience, sorrow, joy, pride, revenge, and even conscience of guilt, are attributes of the bestial, no less than of the human soul. Some of these are too commonly witnessed to need illustration, but we shall cite a few examples.

The affection of the Dog for his human friend is so fervent, so tender, that it is scarcely surprising that it should sometimes beget that horrid accompaniment-jealousy, with which in our nobler bosoms it is so often associated. Nor is it only of their own species that Dogs are jealous; any intruder that appears to share the regard which they had been accustomed to consider exclusively their own, beeomes an object of fierce hatred. M. Blaze mentions a Dog which died of consumption, because its mistress received home an infant that had been put out to nurse. He growled whenever he saw her kiss the child. In 1841, a bull-dog in Paris flew upon and killed a child of six years old, in the arms of his mother; the only reason for this ferocity being that the little fellow had been in the habit of caressing another Dog in the sight of the savage animal, which had always, before this, been kept chained.

As to pride, it is well known in the East that the Elephant receives pleasure from his gorgeous trappings, and moves with a more stately step, and with manifest appreciation of his honours, when bedizened in scarlet and gold. Pliny relates that one of the elephants of Antiochus, having been deprived of his silver ornaments for refusing to 
sound the depth of a river, rejected his food, and actually died under the sense of his disgrace.

The same intelligent creature shall afford us an illustration of sympathy, so strong as to overcome even the obedience habitual to the animal. Bishop Heber saw an old half-starved elephant fall under his work, and being unable to rise, another of very large size was brought to assist him. "I was much struck," says the good Prelate, "with the almost human expression of surprise, alarm, and perplexity in his countenance, when he approached his fallen companion. They fastened a chain round his neck and the body of the sick beast, and urged him in all ways, by encouragement and blows, to drag him up, even thrusting spears into his flanks. He pulled stoutly for a minute; but on the first groan his companion gave, he stopped short, and turned fiercely round with a loud roar, and with his trunk and fore-feet began to attempt to loosen the chain from his neck."

Dr Abel, in his minute account of the manners of a Bornean Orang, speaks of the fits of passionate anger into which he would sometimes fall. "If repeatedly refused an orange, when he attempted to take it, he would shriek violently, and swing furiously about the ropes; then return and endeavour to obtain it: if again refused, he would roll for some time like an angry child upon the deck, uttering the most piercing screams, and then suddenly starting up, rush furiously over the side of the ship, and disappear. On first witnessing this act, we thought he had thrown himself into the sea; but, on a search being made, we found him concealed under the chains."

The worthy Doctor says that this act, in a rational 
being, would have been called the threatening of suicide. Was it anything else in this Ape? Was not the act evidently the result of a process of reasoning, founded on his observation of the value his master set on him, and comprehending the sorrow which the supposed loss would produce? The cautiousness which determined that it should be only a deceptive loss was a refinement of intellect, almost human; it reminds us of that inimitable line of Burns's-

\section{"Spak o' loupin' owre a linn."}

A kindred animal-the Siamang-shall afford us an example of a mental principle very like conscience. The Dog and Cat, however, often display its workings as well. In Mr Bennet's "Wanderings," there is an account of this Ape, which he was keeping. In the cabin, there was a piece of soap, which had excited the Siamang's cupidity, and for the abstraction of which he had been several times scolded. One day Mr Bennet, while engaged in writing, happened to see the Siamang engaged in his thievish practices. "I watched him," says the observer, "without his perceiving that I did so; he occasionally cast a furtive glance towards the place where I sat. I pretended to write; he, seeing me busily engaged, took up the soap and moved away with it in his paw. When he had walked half the length of the cabin, I spoke quietly, without frightening him. The instant he found I saw him, he walked back again, and deposited the soap nearly in the same place whence he had taken it; thus betraying, both by his first and last actions, a consciousness of having done wrong.

We shall close these anecdotes with a very touching one, 
illustrative at once of the most tender and faithful love, and of the deepest sorrow. After the Battle of Aughrim, the bodies of the Irish were left where they fell, to the birds of the air and the beasts of the field. Among them was an Irish officer, who was killed and stripped in the battle. But his faithful Dog discovered his remains, and guarded the body day and night; and though he fed with other dogs on the slain around, yet he would not allow them or anything else to touch the body of his master. When all the dead bodies were consumed, the other dogs departed; but this one used to go in the night to the adjacent villages for food, and presently return to the place where his master's bones only were then left. Thus he continued from July, when the battle was fought, till January following, when one of Colonel Foulk's soldiers, who was quartered in the neighbourhood, happening to go near the spot, the Dog, fearing he came to disturb his master's bones, rushed upon the man, who unslung his musket on the instant, and shot the poor animal dead. He expired faithful as he had lived.

Here we take a respectful leave of our readers. We have sought to lead them, rapidly but not unobservantly, through the wide range of animated being. Our course has been like that of a railway-passenger through a varied and fertile country: it is but a small portion of the expanse that falls under his brief and rapid glances, but then this affords him a fair sample of the whole. We have left untouched multitudes of details, not less interesting in themselves, nor less suggestive than those which we have noticed; but these may suffice to be the spokesmen of the vast band 
who with one accord render unceasing praise-not less eloquent because silent to the ear of sense-unto Him who made them all for His own glory. Let us listen to and join in their song-the song of "every creature which is in heaven, and on the earth, and under the earth, and such as are in the sea, and all that are in them:"-

"Blessing, and HONOUR, AND GLORY, AND POWER, BE unto Him that SITTETH UPON THE THRONE, AND UNTO THE LAMB, FOR EVER AND EVER!"

"THOU ART WORTHY, O LORD, TO RECEIVE GLORY, AND HONOUR, AND POWER; FOR THOU HAST CREATED ALL THINGS, aNd for Thy pleasure they aRe, AND Were CREATEd!" 


\section{INDEX.}

Acephalocystis, 117.

Aciueta, 15.

Equorea, so.

Amæba, 22.

Amphibia, 274-284.

Anemones, Sea, 65,

Animal, Characteristics of, 25.

Ant-eater, 336.

Ascidia, 236.

Asplanchna, 200.

Aurelia, S5.

Barnacles, 223.

Beak of Birds, 309.

Bees, 170, 175

Beetles, 179.

Bilateralism, 110.

Birds, 304-325.

Bird's-foot Star, 105.

"Bird's-head," 233.

Blister-fly, 180.

Botryllus, 236.

Bower-bird, 325.

Breastplate, High Priest's, 21.

Brittle-star, 96.

Bugula, 232.

Butterfies, 15 S.

Cake-urchin, 105.

Carabus, 153.

Carnivora, 341.

Cat, 341.

Cells, 3.

Centipedes, 145-148.

Cephalopoda, 247.

Chameleon, 298.

Chelmon, 272.

Cilia, 4, 241.

Cirripeds, 223.

Cochineal, 183.

Conchifera, 240 .

Corals, 73.
Crab, 209, 220.

Creation, Plan of, 227.

Crickets, 180.

Crocodile, 301.

Crustacea, 204-222.

Cuttles, 247.

Cyanæa, 78.

Cyathina, 74 .

Cydippe, 87.

Cysticercus, 117.

Design in Creation, 345.

Dog of blind man, 352 .

Dogs, Faculties of, 353, 356, 359.

Dragonfly, 166, 180.

Duck-bill, 334 .

Earth-worm, 142.

Edentata, 337.

Eel, 271.

Elephant, 340, 350, 356.

Epizoa, 214.

Euglena, 21.

Feathers, 306.

Feather-star, 93.

Fisheries, 263.

Fishes, 251-273.

Five-finger, 101.

Flea, 155.

Fluke, 124.

Flying, Organs for, 305.

Fox and Badger, 351.

Frogs, 274.

Garden-spider, 189.

Gastropoda, 245.

Generations, Alternation of, 63,83 .

Geographical Distribution, 332.

Gizzard, 311.

Glass-crabs, 218.

Glow-worm, 179. 
Gnat, 183.

Gossamer-spider, 191.

Hairs, 330.

Hare, Sagacity of, 351 .

Helminthia, 116.

Hermit-crab, 221.

Holothuriadæ, 110.

Horns, 331.

Hunting-spider, 192.

Hydra, 29, 50-57.

Infusoria, 11.

Insects, 149-183.

Insects, Architecture of, 170 .

Insects, Transformations or, 161 .

Instinct, Nature of, 348 .

Kangaroo, 335 .

Land-crabs, 221.

Laomedea, 59-64.

Leaf-worms, 137.

Leech, 142.

Lepas, 224.

Lily-stones, 91.

Limpet, 245.

Lingthorn, 99.

Lizards, 296.

Lobster, 220.

Lucernaria, 77 .

Lug, 137.

Luminosity, 80 .

Mammalia, 320 .

Man, 346.

Marsupialia, 332.

Medusæ, 76 .

Melicerta, 201.

Microglena, 30.

Mites, 193.

Mocking-bird, 313 :

Mollusca, 227-248.

Monads, 9.

Monitors, 300.

Mussels, 240.

Mylodon, 338 .

Nais, 141.

Nautilus, 247.

Nests of Birds, 315.

Banana-bird, 321.

Baya, 319.

Chaffinch, 315.

Goldfinch, 317.

Humming-bird, 318.

Long-tailed Tit, 323.

Pensile Grosbeak, 323.

Sociable Grosbeak, 324.

Tailor-bird, 322.

Tchitrec, 320.
Newt, 278.

Nightingale, 313 ,

"Old Maids," 239.

Orang, Intelligence of, $352,357$.

Oryctes, 152.

Oysters, 240.

Pandorina, 21.

Paramecium, 18.

Pecten, 241.

Planariæ, 124.

Polygastrica, 17.

Polypes, 49.

Polyzoa, 232.

Portuguese Man-of-war, S8.

Prawn, 206, 219.

Proteus, 280.

Pyrosoma, 237.

Quadrupeds, 326 .

Radiism, 110.

Reptiles, 285-303.

Rhizostoma, 80 .

Rodentia, 338.

Sallee-man, 89 .

Salmon, 271 .

Salpa, 236.

Scale of Animal Life, 227.

Scales of Butterflies, 160.

Scales of Fishes, 257.

Scale-worm, 139.

Scorpions, 193.

Sea-cucumber, 111.

Sea-mat, 230.

Sea-mouse, 141.

Sea-nettles, 78.

Sea-urchin, 95, 106.

Sensitive Plants, 27.

Serpents, 287.

Serpula, 136.

Sertulariadæ, 58.

Setting-sun, 240.

Shell-fishes, 239.

Shell, Formation of, 212.

Siamang, Conscience of, 358 .

Skeleton, 253.

Slow-worm, 295.

Spccies, Nature of, 252.

Spiders, 1S4-193.

Spirillum, 11.

Sponges, 25, 30-1s.

Stag-bectle, 154.

Star-fishes, 91-115.

Stentor, 22.

Stickleback, 268.

Syllis, 140.

Tadpole, 276. 
INDEX.

Tape-worm, 118.

Tarantula, 191.

Thaumantias, 80.

Thread-cells, 69

Thread-worms, 126 .

Tintinnidæ, 20.

Tortoise, 303.

Trachelocerca, 22.

Transformations ofButterfly, 161.

Dragonfly, 166.

Frogs, 275.

Star-fishes, 113.

Trepang, 112.

Tunicata, 235.

Turris, 80, 84 .
Twin-worm, 125.

Vertebrata, 252.

Vibrio, 11.

Viper, 298.

Volvox, 21.

Vorticella, 12

Wasps, 172.

Water-fleas, 216.

Water-spider, 187.

Wentletrap, 246.

Wheel-bearers, 195.

Worms, 135-144.

Worms, Intestinal, 116-129. 

$21^{3}$ 




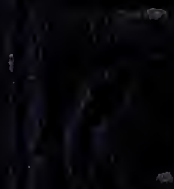

ares
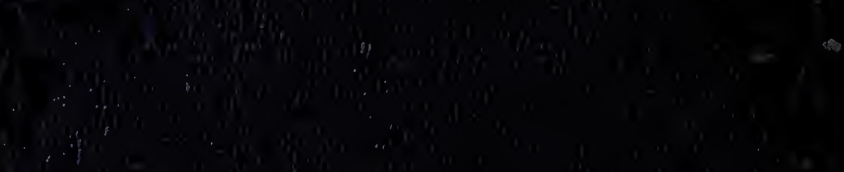

if

in

$\therefore y^{\prime}$

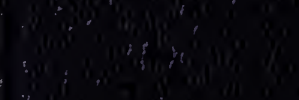

